\title{
Error Analysis and Calibration
} Uncertainty of Capacitance Standards at NIST

NIST

Special

Publication 250-52

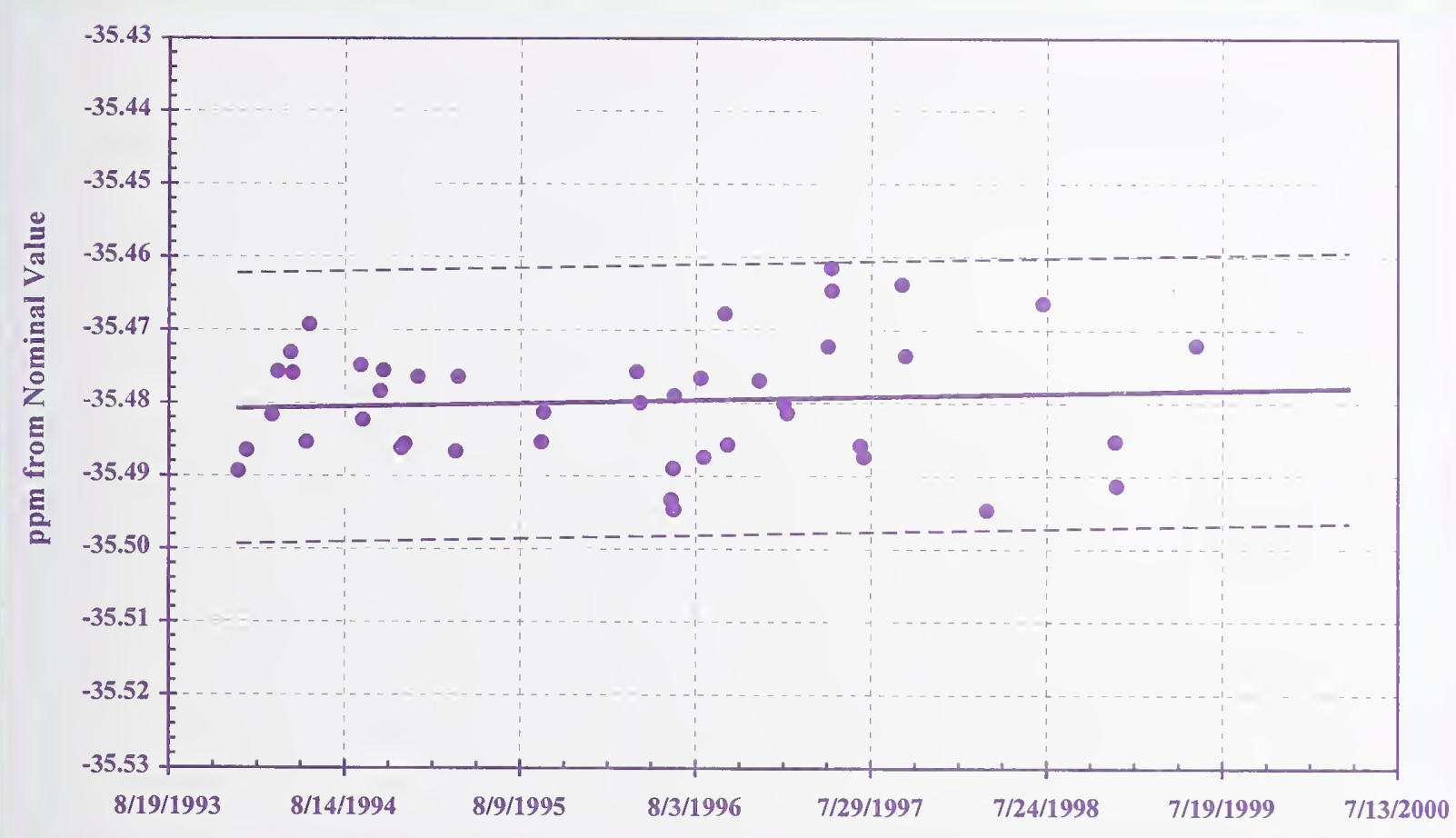

Control Chart for Reference Standards

Y. May Chang

U.S. Department of Commerce

Technology Administration

QC

National Institute of Standards and Technology

100

.457

$.250-52$ 
he National Institute of Standards and Technology was established in 1988 by Congress to "assist industry in

the development of technology ... needed to improve product quality, to modernize manufacturing processes, to ensure product reliability . . . and to facilitate rapid commercialization . . . of products based on new scientific discoveries."

NIST, originally founded as the National Bureau of Standards in 1901, works to strengthen U.S. industry's competitiveness; advance science and engineering; and improve public health, safety, and the environment. One of the agency's basic functions is to develop, maintain, and retain custody of the national standards of measurement, and provide the means and methods for comparing standards used in science, engineering, manufacturing, commerce, industry, and education with the standards adopted or recognized by the Federal Government.

As an agency of the U.S. Commerce Department's Technology Administration, NIST conducts basic and applied research in the physical sciences and engineering, and develops measurement techniques, test methods, standards, and related services. The Instifute does generic and precompetitive work on new and advanced technologies. NIST's research facilities are located at Gaithersburg, MD 20899, and at Boulder, CO 80303. Major technical operating units and their principal activities are listed below. For more information contact the Publications and Program Inquiries Desk, 301-975-3058.

\section{Office of the Director}

- National Quality Program

- International and Academic Affairs

\section{Technology Services}

- Standards Services

- Technology Partnerships

- Measurement Services

- Technology Innovation

- Information Services

\section{Advanced Technology Program}

- Economic Assessment

- Information Technology and Applications

- Chemical and Biomedical Technology

- Materials and Manufacturing Technology

- Electronics and Photonics Technology

\section{Manufacturing Extension Partnership Program \\ - Regional Programs \\ - National Programs \\ - Program Development}

\section{Electronics and Electrical Engineering} Laboratory

- Microelectronics

- Law Enforcement Standards

- Electricity

- Semiconductor Electronics

- Electromagnetic Fields ${ }^{1}$

- Electromagnetic Technology

- Optoelectronics ${ }^{1}$

\section{Chemical Science and Technology Laboratory \\ - Biotechnology \\ - Physical and Chemical Properties ${ }^{2}$ \\ - Analytical Chemistry \\ - Process Measurements \\ - Surface and Microanalysis Science}

Physics Laboratory

- Electron and Optical Physics

- Atomic Physics

- Optical Technology

- Ionizing Radiation

- Time and Frequency ${ }^{1}$

- Quantum Physics'

Materials Science and Engineering Laboratory

- Intelligent Processing of Materials

- Ceramics

- Materials Reliability ${ }^{1}$

- Polymers

- Metallurgy

- NIST Center for Neutron Research

\section{Manufacturing Engineering} Laboratory

- Precision Engineering

- Automated Production Technology

- Intelligent Systems

- Fabrication Technology

- Manufacturing Systems Integration

Building and Fire Research Laboratory

- Structures

- Building Materials

- Building Environment

- Fire Safety Engineering

- Fire Science

Information Technology Laboratory

- Mathematical and Computational Sciences ${ }^{2}$

- Advanced Network Technologies

- Computer Security

- Information Access and User Interfaces

- High Performance Systems and Services

- Distributed Computing and Information Services

- Software Diagnostics and Conformance Testing

- Statistical Engineering 


\title{
NIST MEASUREMENT SERVICES: Error Analysis and Calibration Uncertainty of Capacitance Standards at NIST
}

Y. May Chang

\author{
Electricity Division \\ Electronics and Electrical Engineering Laboratory \\ National Institute of Standards and Technology \\ Gaithersburg, MD 20899-8110
}

January 2000

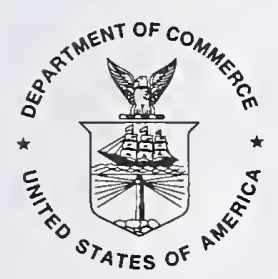

U.S. Department of Commerce

William M. Daley, Secretary

Technology Administration

Dr. Cheryl L. Shavers, Under Secretary of Commerce for Technology

National Institute of Standards and Technology

Raymond G. Kammer, Director 
National Institute of Standards and Technology Special Publication 250-52

Natl. Inst. Stand. Technol. Spec. Publ. 250-52, 109 pages (Jan. 2000) CODEN: NSPUE2 


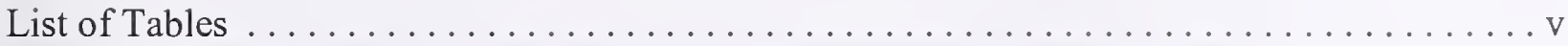

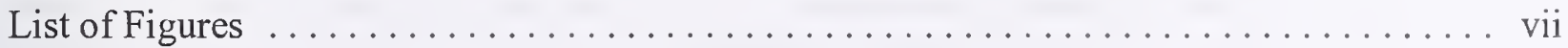

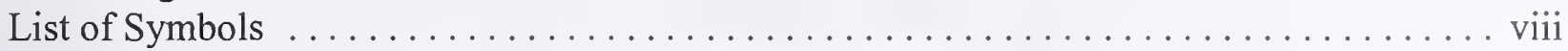

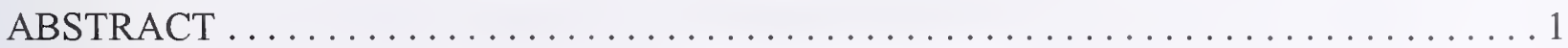

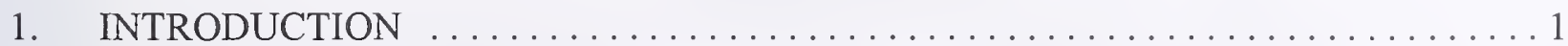

2. DESCRIPTION OF SYSTEMS AND MEASUREMENT PROCEDURES . . . . . . . . 2

2.1 Type-2 Capacitance Bridge and Standards ................... 3

2.2 Type-12 Capacitance Bridge . . . . . . . . . . . . . . . . . . . . . . 3

3. UNCERTAINTY ANALYSIS FOR THE TYPE-2 SYSTEM . . . . . . . . . . . . 4

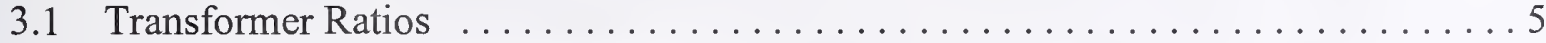

3.1.1 Corrections and Uncertainties of the $1: 1$ Ratio ............... 5

3.1.2 Calibration and Uncertainties of the $10: 1$ ( and $1: 10$ ) Ratio ........6

3.2 Dial Corrections . . . . . . . . . . . . . . . . . . . . . . . . . 7

3.2 .1 Calibration of Dial Capacitors $\ldots \ldots \ldots \ldots \ldots \ldots \ldots \ldots \ldots \ldots \ldots \ldots$

3.2 .2 Uncertainties in Dial Corrections . . . . . . . . . . . . . . . . . 8

3.2.3 Analysis of Uncertainties in Dial Corrections . . . . . . . . . . . . . . 9

3.3 Uncertainties in External Bridge Components . . . . . . . . . . . . . . . . 10

3.3 .1 Voltage Dependence of Standards . . . . . . . . . . . . . . . . 11

3.3.2 Frequency Dependence of Standards . . . . . . . . . . . . . . 11

3.3.3 Hysteresis Effects in Temperature Corrections of Standards . . . . . . . 12

3.3 .4 Lead Impedance . . . . . . . . . . . . . . . . . . . . . 12

3.3.5 Uncertainty in the Reference Standard . . . . . . . . . . . . . . . 14

3.3.6 Combined Uncertainty of the External Bridge Components . . . . . . . . . . 14

3.4 Uncertainties of Fused-Silica and Nitrogen Dielectric Capacitors at $1 \mathrm{kHz} \ldots \ldots$. . 14

3.5 Uncertainties of Fused-Silica and Nitrogen Dielectric Capacitors at $400 \mathrm{~Hz} \ldots \ldots 15$

3.6 Uncertainties of Fused-Silica and Nitrogen Dielectric Capacitors at $100 \mathrm{~Hz} \ldots \ldots 15$

3.7 Uncertainties of Air and Mica Dielectric Capacitors . . . . . . . . . . . . . . . 16

3.7.1 Three-Terminal Air Capacitance Standards . . . . . . . . . . . . . . . . 16

3.7.2 Two-Terminal HF Coaxial Capacitance Standards and Terminations . . . . 16

4. UNCERTAINTY ANALYSIS FOR THE TYPE-12 SYSTEM . . . . . . . . . . . . 17

4.1 Basic Equations of Capacitance Measurements . . . . . . . . . . . . . . . . . . 18

4.2 Type B Standard Uncertainty of Capacitance Measurements . . . . . . . . . . . . . . 19

4.2 .1 Ratio Resistors .............................. 20

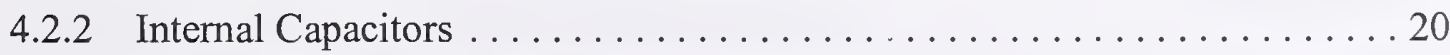

4.2 .3 External Bridge Components . . . . . . . . . . . . . . . . . 22

4.3 Type B Standard Uncertainty for Various Types of Capacitance Measurement . . . 23

4.3.1 Two-Terminal Measurements of Low-Capacitance Values . . . . . . . . . 23

4.3.1.1 Basic Equations of Balance .................. 23 
4.3.1.2 Analysis .............................. 24

4.3.2 Two-Terminal Measurements of High-Capacitance Values . . . . . . . . . 25

4.3.2.1 Basic Equations of Balance . . . . . . . . . . . . . 25

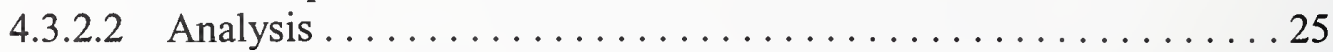

4.3.3 Three-Terminal Measurements of Low-Capacitance Values . . . . . . . 26

4.3.3.1 Basic Equations of Balance . . . . . . . . . . . . . . 26

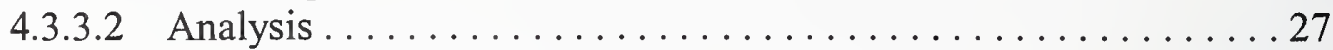

4.3.4 Three-Terminal Measurements of High-Capacitance Values

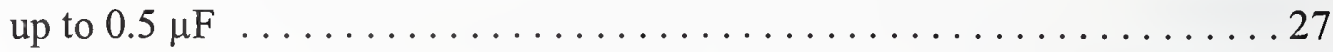

4.3.4.1 Basic Equations of Balance ...................... 27

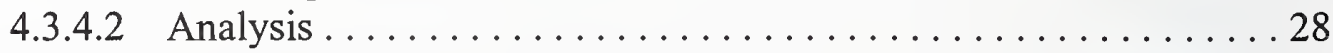

4.3.5 Three-Terminal Measurements of Capacitors Larger Than $0.5 \mu \mathrm{F} \ldots \ldots .29$

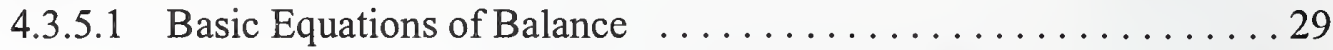

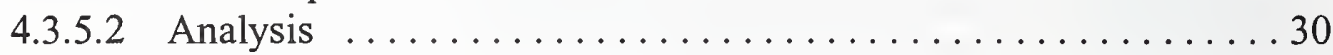

4.4 Type A Standard Uncertainty of Capacitance Measurements ............... 31

4.4.1 Repeatability of Measurements ......................... 31

4.4.2 Effect of Temperature Variations on Unknown Capacitors . . . . . . . . 31

4.4 .3 Stabilities of NIST Standards . . . . . . . . . . . . . . . . . . . 32

4.5 Expanded Uncertainty for Capacitance Measurement

Using the Type 12 System . . . . . . . . . . . . . . . . . . . . 33

4.6 Type B Standard Uncertainty of Conductance Measurements . . . . . . . . . 33

4.6 .1 Conductance Standard . . . . . . . . . . . . . . . . . . . 34

4.6.2 Contact Resistance ... . . . . . . . . . . . . . . . . . . . . . . . . 34

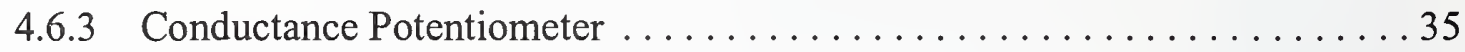

4.6.4 Residual Conductance ... . . . . . . . . . . . . . . . . . . . . . . . 36

4.6.5 Dial Corrections .................................. 36

4.7 Type A Standard Uncertainty of Conductance Measurements . . . . . . . . 36

4.7.1 Repeatability of Measurements . . . . . . . . . . . . . . . 37

4.7.2 Stabilities of NIST Standards . . . . . . . . . . . . . . . . . 37

4.8 Expanded Uncertainty for Conductance Measurement

Using the Type- 12 System . . . . . . . . . . . . . . . . . . 37

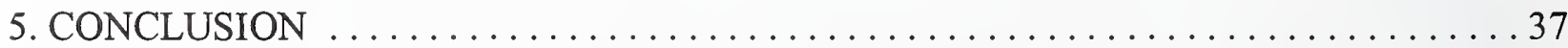

6. ACKNOWLEDGMENTS .................................. 38

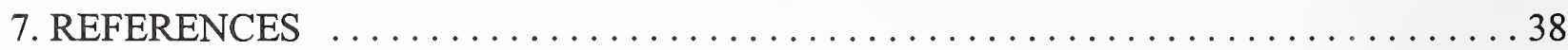

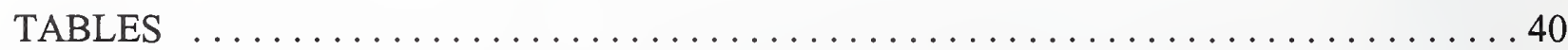

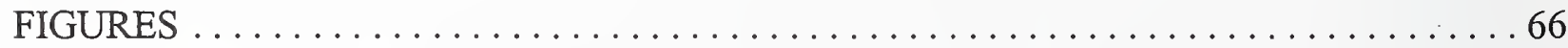

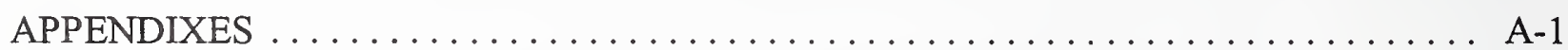

APPENDIX A. Uncertainty Analysis of the Corrections to the $1: 1$ Ratio . . . . . . . A A-1 APPENDIX B. Capacitance Dial Corrections of the Type-12 Bridge . . . . . . . . . B-1

APPENDIX C. Conductance Dial Corrections of the Type-12 Bridge . . . . . . . . . C - 1 


\section{List of Tables}

Page

Table 1. Dial Corrections of the Type-2 Bridge $\ldots \ldots \ldots \ldots \ldots \ldots \ldots \ldots \ldots$

Table 2. Standard Uncertainties in Dial Corrections of the Type-2 Bridge ........... 41

Table 3. Combined Uncertainties in Dial Corrections Using the Type-2 Bridge to

Measure Capacitors of Nominal Values of 1 pF, 10 pF, 100 pF, and 1000 pF . . . 42

Table 4. Uncertainties Due to Lead Impedance Using the Type-2 Bridge to

Measure Capacitors at Frequencies of $100 \mathrm{~Hz}, 400 \mathrm{~Hz}$, and $1 \mathrm{kHz} \ldots \ldots \ldots . .43$

Table 5. Summary of Components of Type B Standard Uncertainties Using the Type-2

Bridge to Measure Fused-Silica and Nitrogen Dielectric Capacitors at $1 \mathrm{kHz}$. . . . 44

Table 6. Expanded and Assigned Uncertainties Using the Type-2 Bridge to Measure

Fused-Silica and Nitrogen Dielectric Capacitors at $1 \mathrm{kHz} \ldots \ldots \ldots . \ldots 45$

Table 7. Expanded and Assigned Uncertainties Using the Type-2 Bridge to Measure

Fused-Silica and Nitrogen Dielectric Capacitors at $400 \mathrm{~Hz} \ldots \ldots \ldots . \ldots 46$

Table 8. Expanded and Assigned Uncertainties Using the Type-2 Bridge to Measure

Fused-Silica and Nitrogen Dielectric Capacitors at $100 \mathrm{~Hz} \ldots \ldots \ldots . \ldots 47$

Table 9. Expanded and Assigned Total Uncertainties Using the Type-2 Bridge to Measure Three-Terminal Air Capacitors at Frequencies of $400 \mathrm{~Hz}$ and $1 \mathrm{kHz} \ldots \ldots \ldots 48$

Table 10. Expanded and Assigned Total Uncertainties Using the Type-2 Bridge to Measure Three-Terminal Air Capacitors at $100 \mathrm{~Hz} \ldots \ldots \ldots \ldots \ldots \ldots \ldots . \ldots . \ldots . \ldots$

Table 11. Expanded and Assigned Total Uncertainties Using the Type-2 Bridge to Measure

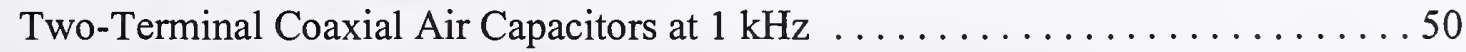

Table 12. Expanded and Assigned Total Uncertainties Using the Type-2 Bridge to Measure Two-Terminal Coaxial Mica Capacitors and

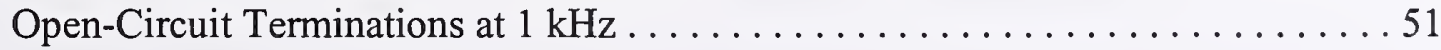

Table 13a. Summary of Components of Standard Uncertainties in Air Capacitor Dial Corrections for Two-Terminal Measurements . . . . . . . . . . . . . . . . . . 52

Table 13b. Summary of Components of Standard Uncertainties in Air Capacitor Dial Corrections for Three-Terminal Measurements 
Table 14a. Summary of Components of Standard Uncertainties in Mica Capacitor

Dial Corrections for Two-Terminal Measurements . . . . . . . . . . . . . . . . . . 54

Table 14b. Summary of Components of Standard Uncertainties in Mica Capacitor

Dial Corrections for Three-Terminal Measurements . . . . . . . . . . . . . . 55

Table 15a. Summary of Components of Type B Standard Uncertainties in Capacitance Measurements Using the Type-12 Bridge to Measure Two-Terminal Mica Capacitors at $100 \mathrm{~Hz}, 1 \mathrm{kHz}$, and $10 \mathrm{kHz} \ldots \ldots . \ldots 56$

Table 15b. Summary of Components of Type B Standard Uncertainties in Capacitance Measurements Using the Type-12 Bridge to Measure Three-Terminal Mica Capacitors at $100 \mathrm{~Hz}, 1 \mathrm{kHz}$, and $10 \mathrm{kHz}$..........5 57

Table 16a. Summary of Components of Type A Standard Uncertainties in Capacitance Measurements Using the Type-12 Bridge to Measure Two-Terminal Mica Capacitors at $100 \mathrm{~Hz}, 1 \mathrm{kHz}$, and $10 \mathrm{kHz} \ldots \ldots \ldots . \ldots 58$

Table 16b. Summary of Components of Type A Standard Uncertainties in Capacitance Measurements Using the Type-12 Bridge to Measure Three-Terminal Mica Capacitors at $100 \mathrm{~Hz}, 1 \mathrm{kHz}$, and $10 \mathrm{kHz}$......... 59

Table 17a. Summary of Expanded and Assigned Total Uncertainties in Capacitance Measurements Using the Type-12 Bridge to Measure Two-Terminal Mica Capacitors at $100 \mathrm{~Hz}, 1 \mathrm{kHz}$, and $10 \mathrm{kHz} \ldots \ldots . \ldots 60$

Table 17b. Summary of Expanded and Assigned Total Uncertainties in Capacitance Measurements Using the Type-12 Bridge to Measure Three-Terminal Mica Capacitors at $100 \mathrm{~Hz}, 1 \mathrm{kHz}$, and $10 \mathrm{kHz} \ldots \ldots \ldots 61$

Table 18a. Summary of Components of Type B Standard Uncertainties in Conductance Measurements Using the Type-12 Bridge to Measure Two-Terminal Mica Capacitors at $100 \mathrm{~Hz}, 1 \mathrm{kHz}$, and $10 \mathrm{kHz}$. . . . . . . . 62

Table 18b. Summary of Components of Type B Standard Uncertainties in Conductance Measurements Using the Type-12 Bridge to Measure Three-Terminal Mica Capacitors at $100 \mathrm{~Hz}, 1 \mathrm{kHz}$, and $10 \mathrm{kHz} \ldots \ldots . \ldots 63$

Table 19a. Summary of Components of Type A, Expanded, and Assigned Uncertainties in Conductance Measurements Using the Type-12 Bridge to Measure Two-Terminal Mica Capacitors at $100 \mathrm{~Hz}, 1 \mathrm{kHz}$, and $10 \mathrm{kHz}$. . . . . . . . 64

Table 19b. Summary of Components of Type A, Expanded, and Assigned Uncertainties in Conductance Measurements Using the Type-12 Bridge to Measure Three-Terminal Mica Capacitors at $100 \mathrm{~Hz}, 1 \mathrm{kHz}$, and $10 \mathrm{kHz} \ldots \ldots \ldots 65$ 


\section{List of Figures}

Figure 1. Block Diagram of the Farad Transfer and Calibration Process by Using the Type-2 Bridge

Figure 2a. Schematic Diagram of the NIST Type-2 Capacitance Bridge . . . . . . . . . . 67

Figure 2b. Simplified Circuit Diagram of the NIST Type-2 Capacitance Bridge . . . . . . 68

Figure 3. Internal Capacitors of the Type-2 Bridge $\ldots \ldots \ldots \ldots \ldots \ldots \ldots \ldots \ldots \ldots \ldots \ldots \ldots$

Figure 4. Lead Impedance of a capacitor connected to the Bridge $\ldots \ldots \ldots \ldots \ldots$

Figure 5a. Schematic Diagram of the Type-12 Capacitance Bridge . . . . . . . . . . . 70

Figure 5b. Simplified Circuit Diagram of the Type-12 Capacitance Bridge . . . . . . . 71

Figure 6. Components of the Type-12 Bridge for Two-Terminal

Low-Capacitance Values Measurements .................... 72

Figure 7. Components of the Type-12 Bridge for Two-Terminal

High-Capacitance Values Measurements $\ldots \ldots \ldots \ldots \ldots \ldots \ldots \ldots \ldots \ldots$

Figure 8. Components of the Type-12 Bridge for Three-Terminal Low-Capacitance Values Measurements ...................... 74

Figure 9. Components of the Type-12 Bridge for Three-Terminal Measurements

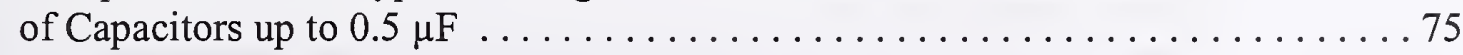

Figure 10. Components of the Type-12 Bridge for Three-Terminal Measurements

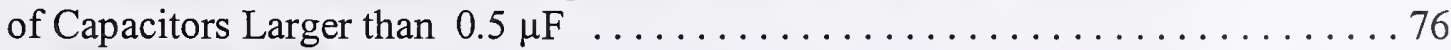

Figure 11. Simplified Circuit Diagram of the Type-12 Capacitance Bridge Including the Conductance Components 


\section{Type-2 System}

$a$ and $b \quad$ In-phase and quadrature corrections of the 1:1 ratio.

$\mathbf{C}_{1}$ to $\mathbf{C}_{8} \quad$ Dial capacitors of the Type-2 bridge.

$C_{1}$ to $C_{8} \quad$ Nominal values of capacitors $\mathrm{C}_{1}$ to $\mathrm{C}_{8}$.

$C_{1}$ to $C_{8} \quad$ Real values of capacitors $\mathbf{C}_{1}$ to $\mathbf{C}_{8}$.

$\mathrm{C}_{\mathrm{s}}, \mathbf{C}_{\mathrm{X}}, \& \mathbf{C}_{\mathrm{d}}$ Reference capacitor, unknown capacitor, and total dial capacitors.

$C_{\mathrm{s}}, C_{\mathrm{x}}, \& C_{\mathrm{d}}$ Nominal values of capacitors $\mathrm{C}_{\mathrm{s}}, \mathrm{C}_{\mathrm{x}}$, and $\mathrm{C}_{\mathrm{d}}$.

$C_{\mathrm{s}}, C_{\mathrm{x}}, \& C_{\mathrm{d}}$ Real values of capacitors $\mathbf{C}_{\mathrm{s}}, \mathbf{C}_{\mathrm{x}}$, and $\mathbf{C}_{\mathbf{d}}$.

$(\Delta C / C) \quad$ Uncertainty in the capacitance due to the lead impedance.

$d_{1}$ to $d_{8} \quad$ Dial corrections of $\mathbf{C}_{1}$ to $\mathbf{C}_{8}$.

$d_{\mathrm{s}}$

$D F_{\mathrm{c}}$

Deviation of the reference capacitor from its nominal value.

$e_{\mathrm{mb}}$

$E_{\mathrm{S}}$ and $E_{\mathrm{x}}$

Dissipation factor of the capacitor.

Maximum bound of error.

$\begin{array}{ll}G_{\mathrm{c}} \text { and } \Delta G & \text { Parallel conductance of } \mathbf{C} \text {, and the uncertainty of } G_{\mathrm{c}} . \\ \mathbf{G}_{\mathbf{r}} \text { and } g_{i} & \text { Conductance of the internal dial resistors and admittance of the } i\end{array}$ th dial.

$I_{\mathrm{s}}, I_{\mathrm{d}}, I_{\mathrm{X}}, \& I_{\mathrm{g}}$ Current through $\mathbf{C}_{\mathbf{s}}, \mathbf{C}_{\mathbf{d}}, \mathbf{C}_{\mathbf{x}}$, and $\mathbf{G}_{\mathbf{r}}$.

$k$,

$L_{1}$

M and $M$

$\mathrm{m}$

$p_{5}$

$r_{i}$

$\sum_{R_{k}} c_{k}$

$R_{1}$

$s_{\mathrm{a}}$ and $s_{\mathrm{b}}$

$s_{\mathrm{cb}}$

$s_{\mathrm{cd}}$

$s_{\mathrm{f}}$

$s_{i}$ and $s_{j}$

$s_{k}$

$s_{1}$ and $s_{11}$

$s_{\mathrm{Ra}}$ and $s_{\mathrm{Rb}}$

$s_{\mathrm{S}}$

$s_{\text {sc }}$

$s_{\text {sd }}$

$s_{\mathrm{tc}}$ and $s_{\mathrm{tcl}}$

$s_{\mathrm{va}}$ and $s_{\mathrm{vb}}$
Coverage factor for confidence level, normally equal to 2 .

Series inductance of leads.

Multiplier of the conductance and its setting.

Ratio of measurement, either 1 or 10.

A constant, either plus or minus 0.5 .

Dial reading of $\mathbf{c}_{i}$.

Sum of dial readings giving the capacitance value of $\mathbf{c}_{k}$, for $k>i+1$.

Series resistance of leads.

Standard uncertainties of the in-phase and quadrature corrections of 1:1 ratio.

Combined standard uncertainty of the external bridge components.

Combined standard uncertainty of dial corrections.

Standard uncertainty of the capacitor due to frequency dependence.

Standard deviations of the components of the Type A and Type B standard uncertainties.

Standard uncertainty of the dial correction of the $k^{\text {th }}$ dial.

Standard uncertainties of interpolations of the last dial at $1 \mathrm{kHz}$ and $100 \mathrm{kHz}$.

Standard uncertainties of the in-phase and quadrature corrections of 1:10 ratio.

Standard uncertainty of the reference standard, due to its stability.

Combined standard uncertainty of the reference standard in measurements.

Equivalent standard deviation (refer as the standard uncertainty) of a component.

Standard uncertainties in temperature corrections of fused-silica and nitrogen dielectric capacitors.

In-phase and quadrature standard uncertainties of the capacitor due to voltage dependence. 
$u_{\mathrm{c}}, u_{\mathrm{a}}, \& u_{\mathrm{b}}$

$U$ and $U_{\mathrm{t}}$

$Y_{\mathrm{s}}, Y_{\mathrm{x}}, \& y_{\mathrm{i}}$

$\mathrm{Y}$ and $\mathrm{Z}$
Combined, Type A and Type B standard uncertainties.

Expanded and total (assigned) uncertainties.

Admittance of $\mathbf{C}_{\mathbf{s}}, \mathbf{C}_{\mathbf{x}}$, and $\mathbf{c}_{i}$.

Effective admittance and impedance of the capacitor, where $Y=(1 / Z)$.

\section{The Type-12 System}

$C_{1}$ and $C_{2}$

Total capacitance of arm AD and arm CD.

$C_{\mathrm{a}}$ and $C_{\mathrm{c}}$

$C_{\mathrm{m}}$ and $C_{r}$

$\mathrm{C}_{\mathrm{x}}$ and $C_{\mathrm{x}}$

$C_{\mathbf{x}}$

Effective internal capacitors on arm $\mathrm{AD}$ and arm $\mathrm{CD}$.

Capacitance of mica capacitor dial readings and of air capacitor dial reading, $r$.

Unknown capacitor and its value.

Nominal value of capacitor $\mathbf{C}_{\mathbf{x}}$.

For two-terminal measurements:

$C_{\mathrm{a} 0}$ and $C_{\mathrm{c} 0}$ Internal capacitors on arm $\mathrm{AD}$ and $\operatorname{arm} \mathrm{CD}$ without connecting $\mathbf{C}_{\mathbf{x}}$ to arm $\mathrm{CD}$. $C_{\mathrm{a} 1}$ and $C_{\mathrm{c} 1}$ Internal capacitors on arm $\mathrm{AD}$ and arm $\mathrm{CD}$ with $\mathrm{C}_{\mathbf{x}}$ connecting to arm $\mathrm{CD}$. $C_{\mathrm{r} 0}$ and $C_{\mathrm{r} 1}$ Dial readings of air capacitors with and without connecting $\mathbf{C}_{\mathbf{x}}$ to arm CD.

For three-terminal measurements:

$C_{\mathrm{a} 1}$ and $C_{\mathrm{c} 1}$ Internal capacitors on arm $\mathrm{AD}$ and arm $\mathrm{CD}$ with $\mathbf{C}_{\mathbf{x}}$ connecting to arm $\mathrm{AD}$. $C_{\mathrm{a} 2}$ and $C_{\mathrm{c} 2}$ Internal capacitors on arm $\mathrm{AD}$ and arm $\mathrm{CD}$ with $\mathrm{C}_{\mathbf{x}}$ connecting to arm $\mathrm{CD}$. $C_{\mathrm{r} 1}$ and $C_{\mathrm{r} 2}$ Dial readings of air capacitors with $\mathbf{C}_{\mathbf{x}}$ connecting to arm $\mathrm{AD}$ and arm $\mathrm{CD}$. (For $C_{\mathbf{x}}>0.5 \mu \mathrm{F}$ )

$C_{\mathrm{a} 1}$ to $C_{\mathrm{a} 4}$ Internal capacitors on arm $\mathrm{AD}$ for the four respective measurements.

$C_{\mathrm{c} 1}$ to $C_{\mathrm{c} 4}$

$C_{\mathrm{r} 1}$ to $C_{\mathrm{r} 4}$

$C_{\mathrm{m} 2} \& C_{\mathrm{m} 3}$ Dial readings of mica capacitors for the second and third measurements.

$\mathbf{C}_{\mathbf{b}}$ and $C_{\mathrm{b}}$

$C_{\mathrm{b}}$

$C_{\text {eff }}$

$e_{\mathrm{bZ}}$

$e_{\mathrm{ds}}$

$e_{\text {gc }}$

$e_{\text {gr }}$

$e^{\text {gs }}$

$G_{\mathrm{a}}$ and $G_{\mathrm{c}}$ $G_{\mathrm{m}}$ and $G_{r}$ $\mathbf{G}_{\mathbf{s}}$ and $G_{\mathrm{S}}$ $\mathbf{G}_{\mathbf{X}}$ and $G_{\mathbf{X}}$ $\mathbf{K}_{\mathbf{g}}$ and $K_{\mathrm{g}}$ $L_{1}$ $\mathbf{R}_{\mathbf{1}}$ and $\mathbf{R}_{\mathbf{2}}$
Capacitance decade box and its value.

Nominal value of capacitance decade box $\mathbf{C}_{\mathbf{b}}$.

Effective capacitance of a capacitor $\mathbf{C}_{\mathbf{x}}$.

Maximum error caused by lead impedance.

Maximum error due to dial switching.

Maximum error due to residual conductance.

Maximum error due to contact resistance.

Maximum error due to conductance standard.

Applied frequency.

Effective internal conductance on arm $A D$ and arm $C D$.

conductance of mica capacitor dial readings and conductance dial reading, $r$.

Conductance standard and its value.

Conductance of unknown capacitor and its value.

Divider resistor and its value.

Series inductance of leads.

Ratio resistors on arm $\mathrm{AB}$ and arm $\mathrm{CB}$. 


$R_{1}$ and $R_{2}$
$R_{\mathrm{r} 1}$ and $R_{\mathrm{r} 2}$
$s_{\mathrm{bZ}}$
$\mathrm{s}_{\mathrm{bp} 2}$ and $\mathrm{s}_{\mathrm{bp} 3}$
$\mathrm{~s}_{\mathrm{br}}$
$s_{\mathrm{dr}}$
$s_{\mathrm{ds}}$
$s_{\mathrm{gc}}$
$s_{\mathrm{gm}}$
$s_{\mathrm{gp}}$
$s_{\mathrm{gpd}}$
$s_{\mathrm{gr}}$
$s_{\mathrm{grm}}$
$s_{\mathrm{gs}}$
$s_{\mathrm{m}}$
$\mathrm{s}_{\mathrm{m} 2}$ and $\mathrm{s}_{\mathrm{m} 3}$

Values of ratio resistors $\mathbf{R}_{\mathbf{1}}$ and $\mathbf{R}_{\mathbf{2}}$.

Contact resistance of the two balances.

Standard uncertainty due to lead impedance.

Standard uncertainties due to corrections of plates P2 and P3.

Standard uncertainty of external bridge components.

Standard uncertainty in the air capacitor dials due to dial corrections.

Standard uncertainty due to dial switching.

Standard uncertainty due to residual conductance.

Standard uncertainty in conductance corrections of the mica capacitor dials.

Standard uncertainty in conductance potentiometer.

Standard uncertainty of the predicted conductance value of the NIST standard.

Standard uncertainty due to contact resistance.

Standard uncertainty due to repeatability of measurements in conductance.

Standard uncertainty due to conductance standard.

Combined Standard uncertainty of the internal mica capacitor dials.

Standard uncertainties in the mica capacitor dials corresponding the readings of $C_{\mathrm{m} 2}$ and $C_{\mathrm{m} 3}$.

$s_{\mathrm{mf}}$

$s_{\mathrm{mp}}$

$s_{\mathrm{mr}}$

$s_{\mathrm{pd}}$

$s_{\mathrm{ra}}$

$s_{\mathrm{rc}}$

$\mathrm{s}_{\mathrm{rc} 0}$ to $\mathrm{s}_{\mathrm{rc} 4}$

$s_{\mathrm{rm}}$

$s_{\text {tf }}$

$s_{\mathrm{tm}}$

$s_{\text {tp }}$

$u_{\mathrm{a}}$ and $u_{\mathrm{b}}$

$u_{\text {ga }}$ and $u_{\text {gb }}$

$U$ and $U_{\mathrm{t}}$

$U_{\mathrm{g}}$ and $U_{\mathrm{gt}}$

Standard uncertainty in the mica capacitor dials due to the uncertainty of transfer standard.

Standard uncertainty in the mica capacitor dials due to temperature variations.

Standard uncertainty in the mica capacitor dials due to dial corrections.

Standard uncertainty of the predicted capacitance value of the NIST standard.

Standard uncertainty contributed by the ratio resistors.

Combined Standard uncertainty of the internal air capacitor dials.

Standard uncertainties in the air capacitor dials corresponding the readings of $C_{\mathrm{r} 0}$ to $C_{\mathrm{r} 4}$.

Standard uncertainty due to repeatability of measurements in capacitance.

Standard uncertainty in the air capacitor dials due to the uncertainty of transfer standard.

Standard uncertainty on unknown capacitor due to temperature variations.

Standard uncertainty in the air capacitor dials due to temperature variations.

Type A and Type B standard uncertainties of capacitance measurements.

Type A and Type B standard uncertainties of conductance measurements.

Expanded and total (assigned) uncertainties of capacitance measurements.

Expanded and total (assigned) uncertainties of conductance measurements. 


\title{
ERROR ANALYSIS AND CALIBRATION UNCERTAINTY \\ OF CAPACITANCE STANDARDS AT NIST
}

\author{
Y. May Chang \\ Electricity Division \\ National Institute of Standards and Technology
}

\section{ABSTRACT}

This document presents the analysis of error sources that contribute to the total uncertainty of capacitance calibrations at the National Institute of Standards and Technology (NIST). Based on considerations of the measuring systems and calibration procedures, and data taken on NIST working and check standards and customer's standards, uncertainties in the calibrations for each model and nominal value of capacitor are estimated. The results of the analysis are expressed as expanded uncertainties using the coverage factor $k=2$, in accordance with NIST Technical Note 1297. Also included are a detailed description and analysis for each component of error in the evaluation of Type A and Type B standard uncertainties.

\section{INTRODUCTION}

Since 1960, a transformer-ratio capacitance-measuring system [1], known as the " Type-2 " bridge, has been used in the National Bureau of Standards / National Institute of Standards and Technology (NBS/NIST) impedance calibration laboratory (ICL) to transfer the farad from the primary capacitance laboratory (PCL), via transfer standards, to NIST working standards and, ultimately, to customer's standards. The values of these standards are expressed in terms of measurements of the NIST calculable capacitor, used to realize the farad in SI units. During the past ten years, high quality commercial instruments, such as detectors and function generators, have become available for use in the Type- 2 system to improve its resolution. The establishment of a bank of oil-bath-type fused-silica capacitors with predicable temperature corrections for use as reference standards in the ICL has increased the stability of Type-2 system measurements. In 1993, NIST issued a new policy on the expression of uncertainty associated with measurement results, as described in NIST Technical Note (NIST TN) 1297 using the coverage factor $k=2$ [2], consistent with the international practice $[2,3]$. Therefore, based on the above modifications, uncertainties in NIST capacitance calibration have been reevaluated and reestablished for each model and type of capacitance standard measured.

In brief, the combined standard uncertainty of a measured value is the combination of estimates of two types of uncertainties. The first is the Type A standard uncertainty, defined as that which can be evaluated by statistical methods. The other is the Type B standard uncertainty, which has no root in formal statistics, but rather evaluated many times based solely on the experience of the 
metrologist.

The combined standard uncertainty, $u_{\mathrm{c}}$, is defined as the "RSS" (root-sum-of-squares) of both types, as:

$$
u_{\mathrm{c}}=\left[u_{\mathrm{a}}{ }^{2}+u_{\mathrm{b}}{ }^{2}\right]^{1 / 2}
$$

where $u_{\mathrm{c}}$ is the combined standard uncertainty, and

$u_{\mathrm{a}}$ and $u_{\mathrm{b}}$ are Type $\mathrm{A}$ and Type $\mathrm{B}$ standard uncertainties, respectively.

According to the guidelines recommended by the International Bureau of Weights and Measures [3], the overall, or expanded uncertainty, $U$, is expressed as:

$$
U=k u_{\mathrm{c}}
$$

or

$$
U=k\left[\Sigma\left(s_{i}\right)^{2}+\Sigma\left(s_{j}\right)^{2}\right]^{1 / 2},
$$

where $U$ is the expanded uncertainty, $k$ is the coverage factor to be chosen on the basis of the approximate confidence level desired, and $s_{i}$ and $s_{j}$ are the standard deviations of the components of Type A and equivalent standard deviations of the components of Type B standard uncertainties, respectively. The coverage factor used at NIST to calculate $U$ is generally $k=2$, indicating a level of confidence of approximately 95 percent.

Therefore, the total uncertainty, $U_{\mathrm{t}}$ assigned to capacitance calibration at NIST is calculated according to the following equation:

$$
U_{\mathrm{t}}=2\left[\Sigma\left(s_{i}\right)^{2}+\Sigma\left(s_{j}\right)^{2}\right]^{1 / 2} .
$$

In this document, unless otherwise stated, the uniform distribution is used to obtain the equivalent standard deviation of the components of the Type B standard uncertainties from the maximum bounds of error for each source of errors. Thus,

$$
s_{\mathrm{sd}}=\boldsymbol{e}_{\mathrm{mb}} / \sqrt{3},
$$

where $s_{\mathrm{sd}}$ is the equivalent standard deviation, as one of the $s_{j}$ in Eqs. (2b) and (3), (hereafter referred as the standard uncertainty) of a typical component of the Type B standard uncertainty, and $\pm e_{\mathrm{mb}}$ are its maximum bounds of error.

\section{DESCRIPTION OF SYSTEMS AND MEASUREMENT PROCEDURES}

There are two major capacitance measuring systems in the ICL at NIST. One is the Type- 2 bridge, which is mainly used to calibrate capacitors of nominal values up to $10000 \mathrm{pF}$ at frequencies of 
$100 \mathrm{~Hz}, 400 \mathrm{~Hz}$, and $1 \mathrm{kHz}$. The other is the Type- 12 bridge, which is a resistance ratio capacitance measuring system for calibration of capacitors of nominal values from $0.001 \mu \mathrm{F}$ to $1 \mu \mathrm{F}$ at frequencies of $66 \mathrm{~Hz}, 100 \mathrm{~Hz}, 400 \mathrm{~Hz}, 1 \mathrm{kHz}$, and $10 \mathrm{kHz}$. Since 1992, commercial impedance meters have also been used as capacitance comparators, after they have been characterized using NIST standards, in an effort to automate some of the calibration services. A detailed description of the capacitance calibration service at NIST is given in [4].

\subsection{Type-2 Capacitance Bridge and Standards}

The NIST Type-2 bridge is a transformer-ratio bridge used for comparing unknown capacitors of coaxial connectors with external reference standards whose values are well defined. A set of eight internal air capacitors with values of $100 \mathrm{pF}, 10 \mathrm{pF}, \ldots \ldots \ldots, 10^{-5} \mathrm{pF}$ are used to balance the bridge during measurements. Values of these internal capacitors are selected by means of dial settings to balance the bridge at 1:1,1:10, or 10:1 ratios. During the transfer of the farad, an NIST-made $10 \mathrm{pF}$ air-bath-type fused-silica capacitor from the PCL is used as the reference to measure a group of 10 $\mathrm{pF}$ oil-bath-type fused-silica capacitors in the ICL. These capacitors, which are also NIST-made and have known temperature coefficients, serve as the primary reference in the ICL. Changes in their temperatures are precisely monitored via internal resistive sensors of copper, and are used to adjust their assigned values of capacitance at the time of measurement. The primary reference is employed to measure two secondary reference sets, each having one $10 \mathrm{pF}$ and one $100 \mathrm{pF}$ commercial airbath-type fused-silica capacitors in a temperature-controlled oven. The secondary references are used for routine calibrations. Also, the primary reference is directly employed to calibrate customer's fused-silica capacitors.

The ICL also has a number of capacitance check standards. Among these are six commercial drynitrogen-dielectric, parallel-plate capacitors housed in the Styrofoam containers originally supplied as protectors during shipment. Their nominal values are $1 \mathrm{pF}, 10 \mathrm{pF}, 100 \mathrm{pF}(2)$, and $1000 \mathrm{pF}$ (2). There is also an NIST-made, $10000 \mathrm{pF}$ capacitor. These check standards are used to ensure that the measuring system remains under control and are used also as a part of the process of calibrating capacitors having dielectrics other than fused-silica, as shown below.

Calibration procedures for customer's capacitors having nitrogen and air dielectrics have two steps. The first step is to use the secondary reference to measure the check standards. Secondly, the check standards are used as working standards to measure the customers' capacitors. Values of all reference and check standards are kept in a database. They are used in control charts to ensure that the Type- 2 bridge is in good operational condition. Figure 1 is a block diagram illustrating the transfer of the farad and the calibration measurement process using the Type- 2 system. Prior to performing any measurements, the internal capacitors of the Type- 2 bridge are calibrated against the reference standard to obtain dial corrections used in the calculation of that day's measurement results.

\subsection{Type-12 Capacitance Bridge}

The Type- 12 bridge is a resistance ratio bridge having internal capacitors as its reference and is 
mainly used to calibrate mica-dielectric capacitors of exposed binding-post connectors in the range from $0.001 \mu \mathrm{F}$ to $1 \mu \mathrm{F}$. In general, calibration of customers' capacitors is performed using two measurements (at a 1:1 ratio of the resistance arms) to eliminate the effects of lead impedance. In the two-terminal configuration, the bridge is balanced with and without connecting the unknown capacitor to the capacitance arm. In the three-terminal configuration, the bridge is balanced by connecting the unknown capacitor to each of the capacitance arms. For each configuration, final results are calculated using dial readings from both measurements.

\section{UNCERTAINTY ANALYSIS FOR THE TYPE-2 SYSTEM}

A complete schematic diagram of the Type-2 bridge is shown in Fig. 2a. Bridge components and operational procedures of the Type- 2 system were described in detail by Cutkosky [1]. Figure $2 b$ is a simplified circuit diagram of the Type-2 bridge, where $\mathbf{C}_{\mathbf{S}}$ is the external reference capacitor, $\mathbf{C}_{\mathbf{X}}$ is the unknown capacitor to be measured, $\mathbf{C}_{\mathbf{d}}$ represents the internal dial capacitors, $\mathbf{G}_{\mathbf{r}}$ represents the conductance of the internal dial resistors, and $\mathbf{M}$ is the multiplier of the conductance settings. At balance, the detector current is equal to zero, and the detector is at virtual ground. The balance is achieved by applying voltages from the appropriate taps of the transformer to the internal capacitors and to the conductance control network. The general balance equation is:

$$
I_{\mathrm{S}}+I_{\mathrm{d}}+I_{\mathrm{g}}=I_{\mathrm{X}}
$$

where $I_{\mathrm{S}}$ is the current through the reference capacitor, $\mathbf{C}_{\mathbf{s}}$,

$I_{\mathrm{d}}$ is the current provided by the capacitance network, $\mathbf{C}_{\mathbf{d}}$, as described below,

$I_{\mathrm{g}}$ is the current supplied by the conductance balance divider and network, and

$I_{\mathrm{X}}$ is the current through the unknown capacitor, $\mathbf{C}_{\mathbf{x}}$.

The dial capacitance, $\mathbf{C}_{\mathbf{d}}$, is provided by a set of eight air capacitors whose values range from $100 \mathrm{pF}$ to $10^{-5} \mathrm{pF}$ having a total capacitance up to $111 \mathrm{pF}$ (see Fig. 3). $\mathbf{G}_{\mathbf{r}}$ is a set of four dials providing conductance from $0.001 \mu \mathrm{S}$ to $1 \mu \mathrm{S}$ with a multiplier switch to extend the total range from $10^{-8} \mu \mathrm{S}$ to $1 \mu \mathrm{S}$. The dials are switches of a four-decade transformer divider that applies selected voltages to a tuned phase shift network providing conductance balance through a number of ranges (see Fig. 2a). Another switch is included for reversing the sign of the conductance component - for allowing the unknown capacitor to have greater or lesser conductance than the internal capacitors of the Type-2 bridge. It can be seen from Fig. 2a that each capacitor-switch combination provides the equivalent of a decade of capacitance by selection of the voltage applied to the capacitor, and that if an unknown capacitor is connected to the bridge as shown in Fig. $2 \mathrm{~b}$ and the bridge balanced, the capacitance of $\mathbf{C}_{\mathbf{X}}$ is equal to the value of $\mathbf{C}_{\mathbf{S}}$ plus the sum of the dial settings. The balance equation can be written as:

$$
E_{\mathrm{S}} Y_{\mathrm{S}}+E_{\mathrm{S}}\left(\sum r_{i} y_{i}\right)+p_{5} E_{\mathrm{S}}\left(M \sum g_{i}\right)=-E_{\mathrm{X}} Y_{\mathrm{X}},
$$

where $E_{\mathrm{S}}$ and $E_{\mathrm{X}}$ are voltages produced by the transformer windings on the reference, $\mathbf{C}_{\mathbf{S}}$ and the unknown capacitor, $\mathbf{C}_{\mathbf{X}}$ sides of the bridge, respectively, 
$Y_{\mathrm{S}}$ and $Y_{\mathrm{x}}$ are admittances of $\mathbf{C}_{\mathrm{s}}$ and $\mathbf{C}_{\mathrm{x}}$, respectively,

$r_{i}$ is the dial reading of $i^{\text {th }}$ dial applying voltage to capacitor $\mathbf{c}_{\boldsymbol{i}}$, where $0 \leq r_{i} \leq 1$, in increments of 0.1 ,

$y_{i}$ is the admittance of $\mathbf{c}_{i}$,

$g_{i}$ is the effective admittance associated with the settings of the $i^{\text {th }}$ conductance dial coupled with the frequency compensation network,

$p_{5}$ is a constant whose value can be taken as either plus or minus 0.5 , and

$M$ is the multiplier of the conductance dial settings, where $10^{-5} \leq M \leq 1$.

On the secondary side of the transformer, besides the \pm 1 taps, a pair of \pm 0.1 taps are also externally available for the reference and unknown capacitors to be connected to obtain 1:1,1:10, and 10:1 ratios.

At present, this bridge is not used to measure the conductance or loss in standard capacitors.

The uncertainty associated with capacitance measurements using the Type-2 bridge is comprised of two types, as given in Eq. (3). The evaluation of the components of the Type B standard uncertainty takes into account errors in

- the transformer ratios,

- the main dial corrections (i.e., values of the $\mathbf{C}_{d}$ capacitor set),

- frequency dependence of the reference and bridge,

- similar voltage dependence,

- temperature corrections,

- lead impedance, and

- the uncertainty of the reference standards.

The evaluation of the Type A standard uncertainty is based on the variability of the measurement data. A detailed analysis for each type of uncertainty is given in the following sections.

\subsection{Transformer Ratios}

\subsubsection{Corrections and Uncertainties of the 1:1 Ratio}

Corrections for errors of the 1:1 ratio of the Type- 2 bridge can be determined with two measurements by using two capacitors of nominally equal value. One measurement is taken with $\mathbf{C}_{\mathbf{X}}$ and $\mathbf{C}_{\mathbf{s}}$ connected as shown in Fig. $2 \mathrm{~b}$. The other measurement is taken with $\mathbf{C}_{\mathbf{x}}$ and $\mathbf{C}_{\mathbf{S}}$ interchanged. The balance equation of the second measurement can be written as:

$$
E_{\mathrm{S}} Y_{\mathrm{x}}+E_{\mathrm{S}}\left(\sum r_{n} y_{n}\right)+p_{5} E_{\mathrm{S}}\left(M^{\prime} \sum g_{n}\right)=-E_{\mathrm{x}} Y_{\mathrm{S}}
$$

where parameters with subscript $n$ have the same meanings as those in Eq. (6) with subscript $i$, and $M^{\prime}$ is the multiplier of the second balance. $M^{\prime}$ is normally equal to $M$.

By combining Eqs. (6) and (7), (with $M=M^{\prime}$ ) the result becomes: 


$$
\left(E_{\mathrm{S}}+E_{\mathrm{X}}\right)\left(Y_{\mathrm{S}}+Y_{\mathrm{X}}\right)+E_{\mathrm{S}}\left(\sum r_{i} y_{i}+\sum r_{n} y_{n}\right)+p_{5} E_{\mathrm{S}} M\left(\sum g_{i}+\sum g_{n}\right)=0
$$

Assuming $E_{\mathbf{S}}=1 \mathrm{~V}$ as the reference, and by the definition of $1: 1$ ratio, $\left(E_{\mathbf{X}} / E_{\mathbf{S}}\right) \cong-1$, then:

$$
E_{\mathrm{X}}=-(1+a+\mathrm{j} b) \text {, }
$$

where $a$ is the in-phase correction to the ratio, and

$b$ is the quadrature correction to the ratio.

The errors in the in-phase and quadrature corrections to the 1:1 ratio that are incurred with the measured data, external capacitance standards, dial readings, interpolation of last dials, load admittance, and lead impedance are shown in Appendix A. The combined standard uncertainties that contribute to the 1:1 ratio correction are estimated, also given in Appendix A, as:

and

$$
s_{\mathrm{a}}<0.005 \mathrm{ppm}^{1}
$$

$$
s_{\mathrm{b}}<0.03 \mathrm{ppm} \text {, }
$$

where $s_{\mathrm{a}}$ and $s_{\mathrm{b}}$ are the standard uncertainties in the in-phase and quadrature corrections of the $1: 1$ ratio, respectively.

In routine calibrations of capacitors using the Type- 2 bridge, only capacitance values are reported even though both capacitance and conductance dials are used to obtain a balance. Therefore, only the in-phase standard uncertainties of the ratio corrections are included in the Type B standard uncertainty.

\subsubsection{Calibration and Uncertainties of the 10:1 (and 1:10) Ratio}

The calibration method and error analysis related to the 10:1 (and 1:10) ratio transformer are discussed in detail by Cutkosky and Shields [5]. Based on the numerical results contained in [5], standard uncertainties in the corrections at the 1:10 ratio are incurred with voltage variations, temperature variations, and the repeatability of measurements. By combining these components with those at 1:1 ratios, given in Eq. (10), total standard uncertainties that contribute to 10:1 (and 1:10) ratio corrections are estimated as:

and

$$
s_{\mathrm{Ra}} \leq 42.25 \times 10^{-3} \mathrm{ppm}<0.043 \mathrm{ppm}
$$

$$
s_{\mathrm{Rb}} \leq 32.49 \times 10^{-3} \mathrm{ppm}<0.033 \mathrm{ppm},
$$

where $s_{\mathrm{Ra}}$ and $s_{\mathrm{Rb}}$ are the standard uncertainties in the in-phase and quadrature corrections of the

1 The term uncertainty as used in this document refers to the relative standard uncertainty when the unit is expressed in ppm [2]. 
10:1 (and 1:10) ratio, respectively.

\subsection{Dial Corrections}

The internal capacitors of the Type- 2 bridge are a set of eight three-terminal air capacitors, $\mathbf{C}_{1}$ to $\mathbf{C}_{8}$, with adjustable dials, as shown in Fig. 3. One side of each capacitor is connected to the detector, and the other side is connected to the transformer via dial switches, which have the range from -0.1 to +1.0 of full voltage. As shown in Fig. $2 a$, when a dial is set at any value from +0.1 up to +1.0 , the capacitor is connected to the " $\mathrm{S}$ " side of the bridge. When a dial is set to -0.1 , it is connected to the "X" side of the bridge. The -0.1 positions of the dials are useful in ratio measurements, or measuring capacitors of lower than nominal values. Among these internal capacitors, which range from $100 \mathrm{pF}$ to $10^{-5} \mathrm{pF}$, only $\mathbf{C}_{3}$, the $1 \mathrm{pF}$ capacitor is purposely temperature compensated. Since air capacitors vary with the room temperature and humidity, these are calibrated prior to each measurement. All dial capacitors are calibrated at a frequency of $1 \mathrm{kHz}$, and dial corrections are applied to the measurement results.

\subsubsection{Calibration of the Dial Capacitors}

The nominal values of the internal capacitors are shown in Fig. 3 and given as:

$$
\begin{aligned}
C_{1}= & 100 \mathrm{pF}=10 C_{2}, \\
C_{2}= & 10 \mathrm{pF}=10 C_{3}, \\
C_{3}= & 1 \mathrm{pF}=10 C_{4}, \\
& \cdot \\
C_{7}= & 10^{-5} \mathrm{pF}=10 C_{8}, \text { and } \\
C_{8}= & 10^{-6} \mathrm{pF} .
\end{aligned}
$$

The first step in the calibration of capacitors $\mathbf{C}_{1}$ to $\mathbf{C}_{\mathbf{8}}$ is to calibrate $\mathbf{C}_{3}$ against a $10 \mathrm{pF}$ reference standard using a 1:10 ratio by setting $\mathbf{C}_{3}$ to the +1.0 switch position and connecting the reference capacitor to the - 0.1 tap on the " $\mathrm{X}$ " side of the transformer. Afterward, internal calibrations of dial corrections are performed by using $\mathbf{C}_{3}$ (at the +1.0 switch position) as reference to calibrate $\mathbf{C}_{2}$ (at the -0.1 switch position) and using $\mathbf{C}_{3}$ (at the -0.1 switch position) to calibrate $\mathbf{C}_{4}$ (at the +1.0 switch position). Other internal capacitors can be calibrated similarly by running up and down the range. The balance equation comparing $\mathbf{C}_{\boldsymbol{i}}$ with $\mathbf{C}_{(\boldsymbol{i}+1)}$ can be written as:

$$
C_{i}+d_{i}=\boldsymbol{m}\left(C_{(i+1)}+d_{(i+1)}+\sum r_{k} c_{k}\right)
$$

where $\boldsymbol{C}_{\boldsymbol{i}}$ and $\boldsymbol{C}_{(\boldsymbol{i}+1)}$ are nominal values of $\mathbf{C}_{\boldsymbol{i}}$ and $\mathbf{C}_{(\boldsymbol{i}+1)}$, respectively, 
$d_{i}$ and $d_{(i+1)}$ are dial corrections of $\mathbf{C}_{\boldsymbol{i}}$ and $\mathbf{C}_{(i+1)}$, respectively,

$\boldsymbol{m}=10$ is the ratio, and

$\sum r_{k} c_{k}$ is the sum of dial readings giving the capacitance value at balance, for $k>i+1$.

The balance equation for calibrating $\mathbf{C}_{\mathbf{3}}$ (where $\boldsymbol{C}_{\mathbf{3}}=1 \mathrm{pF}$ ) with the $10 \mathrm{pF}$ reference standard $\left(\mathrm{C}_{\mathrm{s}}\right.$ ), according to Eqs. (12) and (13), is:

$$
C_{\mathrm{s}}+d_{\mathrm{s}}=10\left(\boldsymbol{C}_{3}+d_{3}+\sum r_{k} c_{k}\right)
$$

where $C_{\mathrm{s}}(=10 \mathrm{pF})$ is the nominal value of the reference standard,

$d_{\mathrm{s}}$ is the deviation of the reference from its nominal value, and

$\sum r_{k} c_{k}$ is the sum of the dial readings giving the capacitance value at balance, for $k>3$.

The dial corrections are related similarly by:

$$
d_{i}=10\left(d_{(i+1)}+\sum r_{k} c_{k}\right), \quad(k>i+1),
$$

and, hence (from Eq. (14)),

$$
d_{3}=(0.1) d_{\mathrm{s}}-\sum r_{k} c_{k} . \quad(k>3) .
$$

Therefore, dial corrections for each of the internal capacitors can be determined from a known reference capacitor and dial readings. After the preliminary results of dial corrections are obtained, from Eqs. (15) and (16), the final values of the dial corrections can be determined by including the corrections of those dials used in dial correction measurements.

\subsubsection{Uncertainties in Dial Corrections}

Rewrite Eqs. (15) and (16) by including the dial corrections of the internal capacitors, $d_{k}$ as:

$$
\begin{aligned}
d_{i} & =10\left(d_{(i+1)}+\sum r_{k} c_{k}+\sum r_{k} d_{k}\right),(k>i+1), \text { and } \\
d_{3} & =(0.1) d_{\mathrm{s}}-\left(\sum r_{k} c_{k}+\sum r_{k} d_{k}\right),(k>3),
\end{aligned}
$$

where $c_{k}$ is the nominal value of the $k^{\text {th }}$ capacitor, $\mathbf{c}_{k}$, and

$d_{k}$ is the correction to the $k^{\text {th }}$ capacitor, $\mathbf{c}_{\boldsymbol{k}}$.

The standard uncertainties of each internal capacitor can be estimated from Eqs. (17) and (18).

As mentioned in the previous section, (3.2.1), the first step is to calibrate the third dial, $\mathbf{C}_{\mathbf{3}}$ by using a $10 \mathrm{pF}$ reference standard. Therefore, the standard uncertainty of the correction of the third dial, $d_{3}$ is determined first. The relationship of the variance of each term in Eq. (18) can be written as:

$$
\operatorname{Var}\left(d_{3}\right)=(0.1)^{2}\left(s_{\mathrm{Ra}}{ }^{2}+s_{\mathrm{S}}{ }^{2}\right)+\sum r_{k}^{2} \operatorname{Var}\left(d_{k}\right)+s_{1}^{2},
$$


where $\operatorname{Var}\left(d_{3}\right)$ is the variance of the dial correction of the third dial, $d_{3}$,

$s_{\mathrm{Ra}}$ is the in-phase standard uncertainty in the 1:10 ratio, as given in Eq. (11),

$s_{\mathrm{S}}$ is the standard uncertainty of the reference standard,

$r_{k}$ is the dial reading for the $k^{\text {th }}$ dial, where $k>3$,

$\operatorname{Var}\left(d_{k}\right)$ is the variance of the dial correction of the $k^{\text {th }}$ dial, where $k>3$,

$s_{1}$ is the standard uncertainty of interpolation of the least significant capacitance dial incurred during measurement, and

$\mathbf{c}_{\boldsymbol{k}}$ does not have a variance.

Then the standard uncertainty for the correction of the third dial, $s_{3}$ can be expressed as:

$$
s_{3}=\left[(0.1)^{2} s_{\mathrm{Ra}}^{2}+(0.1)^{2} s_{\mathrm{S}}^{2}+\sum\left(r_{k}^{2} s_{k}^{2}\right)+s_{1}^{2}\right]^{(1 / 2)},
$$

where $s_{k}$ is the standard deviation of the dial correction of the $k^{\text {th }}$ dial, where $k>3$.

After $s_{3}$ is determined, the standard uncertainties of other dials, $s_{i}$, can be estimated from $s_{3}$ by using the appropriate expression similar to Eq. (20).

For capacitors $\mathbf{C}_{\mathbf{4}}$ to $\mathbf{C}_{\mathbf{8}}$, the standard uncertainties for the dial corrections can be expressed, according to Eq. (17), as:

$$
s_{i}=\left[(0.1)^{2} s_{\mathrm{Ra}}{ }^{2}+(0.1)^{2} s_{(i-1)}{ }^{2}+\sum\left(r_{k}{ }^{2} s_{k}{ }^{2}\right)+s_{1}{ }^{2}\right]^{(1 / 2)},(k>i+1 \text { and } 4 \leq i \leq 8) .
$$

Similarly, standard uncertainties in dial corrections of $\mathbf{C}_{1}$ and $\mathbf{C}_{2}$ are given as:

$$
s_{i}=\left[(10)^{2} s_{\mathrm{Ra}}^{2}+(10)^{2} s_{(i+1)}{ }^{2}+(10)^{2} \sum\left(r_{k}^{2} s_{k}^{2}\right)+s_{1}^{2}\right]^{(1 / 2)},(k>\mathrm{i}+1 \text { and } i=1 \text { or } 2) .
$$

\subsubsection{Analysis of Uncertainties in Dial Corrections}

As mentioned previously, only capacitance values are reported. The component of errors from the cross product of quadrature errors in the 10:1 (or 1:10) ratio and the internal capacitors is negligible. Therefore, only the components of the in-phase standard uncertainties of the dial corrections are included in the Type B standard uncertainty. Based upon Eqs. (20), (21), and (22), the standard uncertainty, $s_{3}$, for the dial correction $d_{3}$ of $\mathbf{C}_{3}$ is determined first, and the standard uncertainties of other dials, $s_{i}$, are obtained from $s_{3}$. Estimated values of each term of Eq. (20) are given as follows:

1) According to Eq. (11) in section 3.1.2, the in-phase standard uncertainty for the 10:1 (and $1: 10$ ) ratio corrections, $s_{\mathrm{Ra}}$, is estimated to be less than $0.043 \mathrm{ppm}$. For $C_{3}=1 \mathrm{pF}$, this becomes:

$s_{\mathrm{Ra}}<0.043 \times 10^{-6} \mathrm{pF}$.

2) The combined standard uncertainty of the reference standard, $s_{\mathrm{SC}}$, is less than $0.72 \mathrm{ppm}$, which will be discussed in section 3.4, (i.e., $s_{\mathrm{sc}}<0.72 \mathrm{ppm}$ ). For $\boldsymbol{C}_{\mathrm{s}}=10 \mathrm{pF}$, then we have: 
$s_{\text {sc }}<7.2 \times 10^{-6} \mathrm{pF}$.

3) Table 1 gives a set of typical data of the average values and standard deviations of dial corrections of the Type- 2 bridge from 15 measurements taken over a period of one year. Measurement records show that only the three lowest dials are needed during dial correction measurements of $\mathbf{C}_{3}$. Looking at $r_{k}=1.0$ (which is a maximum) in Table 1 , the standard deviation of the dial corrections used during the calibration of $\mathbf{C}_{3}$ is estimated from the standard deviations of the last three dial corrections, (dials number 6,7, and 8), also given in Table 1. Thus,

$$
\left(\sum r_{k}^{2} s_{k}^{2}\right)^{(1 / 2)}<0.08 \times 10^{-6} \mathrm{pF} .
$$

4) The maximum bounds of error due to the interpolation of the last capacitance dial is equal to $\pm\left(3 \times 10^{-7}\right) \mathrm{pF}$. Therefore, the standard uncertainty of the interpolation of the last dial becomes:

$$
s_{1}<0.2 \times 10^{-6} \mathrm{pF} \text {. }
$$

According to Eq. (20), the combined standard uncertainty for the third dial can be estimated by using the RSS of the above components, which are also shown in Table 2, as:

$$
s_{3}=0.75 \times 10^{-6} \mathrm{pF}<10^{-6} \mathrm{pF} \text {. }
$$

After $s_{3}$ is determined, other $s_{i}$ can be estimated similarly from Eqs. (21) and (22). Table 2 is the summary of standard uncertainties for each dial correction, $s_{i}$, of the Type- 2 bridge.

The combined standard uncertainty in the dial corrections during measurements depends on the number of dials being used and is estimated as the RSS of standard uncertainties from those dials. In general, the order of the dial number being used starts from dial number 8 and goes incrementally to dial number 1. Table 3 gives the estimated combined standard uncertainties of dial corrections, $s_{\mathrm{cd}}$, for capacitors of various nominal values, according to the number of dials being used during measurements.

\subsection{Uncertainties in External Bridge Components}

As mentioned in sections 1 and 2, the transfer of the farad to the impedance calibration laboratory (ICL) is from a group of NIST-made $10 \mathrm{pF}$ fused-silica capacitance standards in the primary capacitance laboratory (PCL). The primary reference in the ICL is a group of the same type of capacitors. The construction and stability of these standards, including results from measurements of their performance, were discussed in detail by Cutkosky and Lee [6]. The analysis of measurement uncertainties when using fused-silica capacitance standards as the reference is mainly based upon the test results from [6]. During routine calibrations when nitrogen dielectric capacitors are used as the reference standards, the uncertainty analysis is based on the performance of such capacitors as published by the manufacturer [7]. 


\subsubsection{Voltage Dependence of Standards}

The voltage dependence of a group of ten $10 \mathrm{pF}$ capacitors was observed in [6] by measuring their capacitance and dissipation factors from $100 \mathrm{~V}$ to $200 \mathrm{~V}$. Using the average values of the measurements, as well as the systematic and standard errors, the results are:

and

$$
s_{\mathrm{va}}=3.54 \times 10^{-9}<0.004 \mathrm{ppm}
$$

$$
s_{\mathrm{vb}}=2.73 \times 10^{-9}<0.003 \mathrm{ppm} \text {, }
$$

where $s_{\mathrm{va}}$ and $s_{\mathrm{vb}}$ are the in-phase and quadrature standard uncertainties, respectively, of the fusedsilica capacitance standards due to voltage dependence. This dependency is believed not to change with time.

The uncertainty of measuring the voltage dependence of $100 \mathrm{pF}$ and $1000 \mathrm{pF}$ air capacitors is reported to be in the order of $0.001 \mathrm{ppm}$ [8].

\subsubsection{Frequency Dependence of Standards}

The results of comparing a group of ten $10 \mathrm{pF}$ fused-silica capacitors with two $10 \mathrm{pF}$ air capacitors at three frequencies $(159 \mathrm{~Hz}, 1592 \mathrm{~Hz}$, and $15920 \mathrm{~Hz})$ were presented in [6]. Since the transfer of the farad from the PCL to the ICL involves measurements of a transportable $10 \mathrm{pF}$ fused-silica dielectric capacitor at $1592 \mathrm{~Hz}$ in the PCL and measurements of that same standard in the ICL at $1 \mathrm{kHz}$, the uncertainty due to frequency dependence is first estimated between frequencies of $1592 \mathrm{~Hz}$ and $1 \mathrm{kHz}$. The uncertainties due to frequency dependence for frequencies of $400 \mathrm{~Hz}$ and $100 \mathrm{~Hz}$ are estimated between frequencies of $1 \mathrm{kHz}$ and $400 \mathrm{~Hz}$, and $1 \mathrm{kHz}$ and $100 \mathrm{~Hz}$, respectively. Recently, additional data were obtained from the PCL for three $10 \mathrm{pF}$ fused-silica capacitors (\#113, $\# 112$, and \#125) at frequencies of $1592 \mathrm{~Hz}, 1 \mathrm{kHz}, 400 \mathrm{~Hz}$, and $100 \mathrm{~Hz}$. Using a natural logarithmic fit to all the data of capacitor \#113, which has the largest frequency dependence, the maximum values of errors due to frequency dependence at frequencies of $1 \mathrm{kHz}, 400 \mathrm{~Hz}$, and $100 \mathrm{~Hz}$ are estimated to be $1.17 \mathrm{ppm}, 1.50 \mathrm{ppm}$, and $3.0 \mathrm{ppm}$, respectively [9].

According to Eq. (4),

$$
\begin{array}{lll}
s_{\mathrm{f}} \leq 0.68 \mathrm{ppm} & <0.7 \mathrm{ppm} & \text { (between frequencies of } 1592 \mathrm{~Hz} \text { and } 1 \mathrm{kHz} \text { ) } \\
s_{\mathrm{f}} \leq 0.87 \mathrm{ppm} & <0.9 \mathrm{ppm} & \text { (between frequencies of } 1 \mathrm{kHz} \text { and } 400 \mathrm{~Hz} \text { ) } \\
s_{\mathrm{f}} \leq 1.73 \mathrm{ppm} \quad<1.8 \mathrm{ppm} & \text { (between frequencies of } 1 \mathrm{kHz} \text { and } 100 \mathrm{~Hz} \text { ) }
\end{array}
$$

where $s_{\mathrm{f}}$ is the standard uncertainty of the $10 \mathrm{pF}$ fused-silica capacitors due to frequency dependence from the PCL as reference.

The reference standards in the ICL are maintained at a frequency of $1 \mathrm{kHz}$, and the majority of the calibration measurements, including the determination of dial corrections, are performed at $1 \mathrm{kHz}$. 
Therefore, no additional errors due to frequency dependence are incurred except for calibrations performed at frequencies other than $1 \mathrm{kHz}$.

\subsubsection{Hysteresis Effects in Temperature Corrections of Standards}

Each NIST-made $10 \mathrm{pF}$ fused-silica dielectric capacitor has a known temperature coefficient, which is used to obtain a temperature correction during measurements. Errors in the temperature measurements and their effects are negligible $\left(<10^{-9}\right)$. However, hysteresis effects of temperature on the capacitance of fused-silica dielectric capacitors are known to exist and will introduce errors in the corrections. As described in [6], changes of capacitance of a group of nine such capacitors were observed when measured at $25^{\circ} \mathrm{C}$ before and after being subjected to $50{ }^{\circ} \mathrm{C}$. These results are employed to estimate the uncertainty due to temperature changes in the environment. Utilizing the average change and the standard deviation of the mean, it is estimated to be:

$$
s_{\text {tc }} \leq 0.084 \mathrm{ppm}<0.1 \mathrm{ppm},
$$

where $s_{\mathrm{tc}}$ is the standard uncertainty in temperature correction of using fused-silica capacitors as reference.

In routine calibrations of nitrogen and air dielectric capacitors, no temperature corrections are applied. Standard uncertainties associated with the nitrogen dielectric working standards (used as reference standards ) due to variations of room temperature during measurements are estimated to be less than $1 \mathrm{ppm}$, assuming the temperature variation is within $\pm 0.5^{\circ} \mathrm{C}$. Thus,

$$
s_{\mathrm{tc} 1} \leq 1 \mathrm{ppm},
$$

where $s_{\mathrm{tcl}}$ is the standard uncertainty from temperature changes of nitrogen dielectric capacitors used as references.

\subsubsection{Lead Impedance}

In general, the effects of leads that are used to connect a capacitor, $\mathbf{C}$, to a bridge can be represented by the capacitor in series with a resistor and an inductor, as shown in Fig. 4. The expression for the effective impedance in Fig. 4 can be shown to be:

$$
Z=\left\{R_{1}+\left[G_{\mathrm{c}} /\left(G_{\mathrm{c}}{ }^{2}+\omega^{2} C^{2}\right)\right]\right\}+\mathrm{j} \omega\left\{L_{1}-\left[C /\left(G_{\mathrm{c}}{ }^{2}+\omega^{2} C^{2}\right)\right]\right\},
$$

where $Z$ is the effective impedance of the capacitor $\mathbf{C}$,

$R_{1}$ is the series resistance of leads,

$L_{1}$ is the series inductance of leads, and

$G_{\mathrm{c}}$ is the parallel conductance of the capacitor C.

The dissipation factors, $D F_{c}$, of the fused-silica, nitrogen, and air capacitors are all less than $10^{-5}$; therefore, the magnitude of $\left(G_{\mathrm{c}}{ }^{2}+\omega^{2} C^{2}\right)$ is approximately equal to $\omega^{2} C^{2}$, since $G_{\mathrm{c}}{ }^{2}<\left(10^{-10}\right) \omega^{2} C^{2}$. 
Therefore, Eq. (23) can be written as:

$$
Z=\left[R_{1}+\left(G_{\mathrm{c}} / \omega^{2} C^{2}\right)\right]+\mathrm{j} \omega\left[L_{1}-\left(C / \omega^{2} C^{2}\right)\right],
$$

Thus, the equivalent equation of admittance, $Y=(1 / Z)$ is expressed as:

$$
Y=\left(\omega^{2} C^{2}\right) /\left[\left(R_{1} \omega^{2} C^{2}+G_{\mathrm{c}}\right)+\mathrm{j} \omega C\left(\omega^{2} L_{1} C-1\right)\right],
$$

where $Y$ is the effective admittance of the capacitor.

The value of $L_{1}$ is less than $10^{-6} \mathrm{H}$ and $G_{\mathrm{c}}$ is less than $10^{-10} \mathrm{~S}$. By multiplying the numerator and the denominator of Eq. (25) by $\left[\left(R_{1} \omega^{2} C^{2}+G_{\mathrm{c}}\right)-\mathrm{j} \omega C\left(\omega^{2} L_{1} C-1\right)\right]$ and eliminating all second order terms of $L_{1}$ and $G_{\mathrm{c}}$, Eq. (25) becomes:

$$
Y=\left[\left(G_{\mathrm{c}}+R_{1} \omega^{2} C^{2}\right)+\mathrm{j} \omega C\left(1-\omega^{2} L_{1} C\right)\right] /\left[1+R_{1} \omega^{2} C^{2}+2 R_{1} G_{\mathrm{c}}-2 \omega^{2} L_{1} C\right],
$$

For a one meter long coaxial cable, $R_{1}$ and $L_{1}$ were measured to be approximately $0.1 \Omega$ and $0.5 \mu \mathrm{H}$, respectively. For measurements of capacitors of nominal values up to $10^{4} \mathrm{pF}$, at frequencies up to $1592 \mathrm{~Hz}$, Eq. (26) can be reduced to:

$$
Y=\left[\left(G_{\mathrm{c}}+R_{1} \omega^{2} C^{2}\right)+\mathrm{j} \omega C\left(1-\omega^{2} L_{1} C\right)\right] /\left[1-2 \omega^{2} L_{1} C\right] .
$$

By multiplying the numerator and the denominator of Eq. (27) by ( $1+2 \omega^{2} L_{1} C$ ), and eliminating the second order terms of $L_{1}$ and $G_{\mathrm{c}}$, Eq. (27) becomes:

$$
Y=\left(G_{\mathrm{c}}+R_{1} \omega^{2} C^{2}+2 R_{1} \omega^{4} L_{1} C^{3}\right)+\mathrm{j} \omega C\left(1+\omega^{2} L_{1} C\right) .
$$

Furthermore, the third term in Eq. $(28),\left(2 R_{1} \omega^{4} L_{1} C^{3}\right)$ is less than $10^{-15} \mathrm{~S}$, which is negligible as compared with $G_{\mathrm{c}}$ and $\left(R_{1} \omega^{2} C^{2}\right)$. Therefore, Eq. (28) becomes:

$$
Y=\left(G_{\mathrm{C}}+R_{1} \omega^{2} C^{2}\right)+\mathrm{j} \omega C\left(1+\omega^{2} L_{1} C\right) .
$$

The effective values of capacitance and conductance of the standard with lead impedance are:

$$
\begin{aligned}
& C_{\text {eff }}=C\left(1+\omega^{2} L_{1} C\right)=C[1+(\Delta C / C)], \text { and } \\
& G_{\text {eff }}=\left(G_{\mathrm{c}}+R_{1} \omega^{2} C^{2}\right)=\left(G_{\mathrm{c}}+\Delta G\right),
\end{aligned}
$$

where $(\Delta C / C)$ and $\Delta G$ are uncertainties in the capacitance and conductance values of a capacitor due to the lead impedance.

For measurements using the fused-silica dielectric transfer standard from PCL, $C=10 \mathrm{pF}$, estimated uncertainties in the lead impedance are calculated to be:

$$
(\Delta C / C) \quad=1.97 \times 10^{-10} \leq 0.0002 \mathrm{ppm}, \text { and }
$$




$$
\Delta G \quad=3.94 \times 10^{-16} \mathrm{~S} \leq 4 \times 10^{-7} \mathrm{nS} .
$$

Table 4 gives a summary of the uncertainties due to lead impedance for measurements of various nominal capacitance values at frequencies of $100 \mathrm{~Hz}, 400 \mathrm{~Hz}$, and $1 \mathrm{kHz}$.

\subsubsection{Uncertainty in the Reference Standard}

The relative stability of eleven fused-silica dielectric capacitors was measured over a period of five months in 1964 [6]. With the exception of one capacitor, which exhibited a fairly steady increase in capacitance over time and has a large voltage dependence of capacitance, data taken on the others indicated the maximum bounds of error are $\pm 0.076 \mathrm{ppm}$. Therefore, the uncertainty of these standards is taken to be:

$$
s_{\mathrm{S}}=0.044 \mathrm{ppm}<0.05 \mathrm{ppm},
$$

where $s_{\mathrm{S}}$ is the standard uncertainty of using the $10 \mathrm{pF}$ fused-silica dielectric capacitors from the PCL as reference.

\subsubsection{Combined Uncertainty of the External Bridge Components}

The combined uncertainty of the external bridge components is estimated as the RSS of the above five components in sections 3.3.1 to 3.3.5 as:

$$
s_{\mathrm{cb}}=\left(s_{\mathrm{va}}^{2}+{s_{\mathrm{f}}}^{2}+{s_{\mathrm{tc}}}^{2}+(\Delta C / C)^{2}+{s_{\mathrm{s}}}^{2}\right)^{1 / 2} \quad \mathrm{ppm},
$$

where $s_{\mathrm{cb}}$ is the combined standard uncertainty in the external bridge components using the Type- 2 bridge to measure fused-silica and nitrogen dielectric capacitors. Table 5 contains a summary of $s_{\mathrm{cb}}$ for various nominal values of capacitors measured at $1 \mathrm{kHz}$.

After the combined Type B standard uncertainty is estimated by using a capacitance standard from the PCL as reference to measure another capacitor, $\mathbf{C}_{\mathbf{X}}$, this value is utilized as the uncertainty $\left(s_{S}\right)$ of $\mathbf{C}_{\mathbf{S}}$ when it ( previously $\mathbf{C}_{\mathbf{X}}$ ) is used as a reference to calibrate other capacitors later on, also shown in Table 5.

\subsection{Uncertainties of Fused-Silica and Nitrogen Dielectric Capacitors at $1 \mathrm{kHz}$}

Table 5 is a summary of the calculations for the combined Type B standard uncertainties for measurements of fused-silica and nitrogen dielectric capacitors of different nominal values at a frequency of $1 \mathrm{kHz}$ in the ICL, using the Type-2 bridge. Again, since only capacitance values are reported, only the components in capacitance measurements are used for uncertainty calculations. By taking the RSS value of all the above components, the uncertainty in measurements, using a $10 \mathrm{pF}$ fused-silica capacitance standard from PCL as reference, is estimated to be $0.711 \mathrm{ppm}$. Therefore, the combined Type B standard uncertainty of measuring an oil-bath type $10 \mathrm{pF}$ fused- 
silica capacitor in ICL is assigned to be $0.72 \mathrm{ppm}$, including the components of transformer ratio, dial corrections, and external bridge components. Other calculations using the oil-bath type capacitor as the reference standard utilize $s_{\mathrm{sc}}=0.72 \mathrm{ppm}$ as the uncertainty.

The Type A standard uncertainty is estimated from the measurement data on the repeatability of measurements. A calibration of customer's fused-silica dielectric capacitor standard consists of at least five sets of measurements performed over a two-week period, and the pooled standard deviation of within and between days measurements is employed as the Type A standard uncertainty. The expanded uncertainty of such capacitors is calculated from both Type A and Type B standard uncertainties with a coverage factor of $k=2$ [3], as given in Eq. (3). For nitrogen dielectric capacitor standards, the Type A standard uncertainty is taken from results of calibrations of a large population of standards. In an individual calibration, the capacitor is measured a few times to ensure that the use of the population statistics is valid. In the case where the Type A standard uncertainty is over the limit, the total uncertainty is increased according to the data. Table 6 gives the expanded and assigned uncertainties for calibrations of fused-silica and nitrogen dielectric capacitance standards at $1 \mathrm{kHz}$, including both Type A and Type B standard uncertainties.

\subsection{Uncertainties of Fused-Silica and Nitrogen Dielectric Capacitors at $400 \mathrm{~Hz}$}

The error analysis for the calibration of fused-silica and nitrogen dielectric capacitors at a frequency of $400 \mathrm{~Hz}$ is similar to that at $1 \mathrm{kHz}$. Since the assigned value of the oil-bath-type fused-silica reference capacitor in the ICL is measured at $1 \mathrm{kHz}$, there is an uncertainty of $0.9 \mathrm{ppm}$ in frequency dependent error, when using it as a reference to calibrate other capacitors at $400 \mathrm{~Hz}$.

Table 7 is a summary of the expanded and assigned total uncertainties for calibrations of fused-silica and nitrogen dielectric capacitors at a frequency of $400 \mathrm{~Hz}$.

\subsection{Uncertainties of Fused-Silica and Nitrogen Dielectric Capacitors at $100 \mathrm{~Hz}$}

The error analysis for the calibration of fused-silica and nitrogen dielectric capacitors at a frequency of $100 \mathrm{~Hz}$ is similar to that at $1 \mathrm{kHz}$ with two exceptions:

1) At $100 \mathrm{~Hz}$, due to lower applied voltage, the resolution of the bridge is lower than at $1 \mathrm{kHz}$, such that an uncertainty exists in the $10^{-5} \mathrm{pF}$ dial, instead of the $10^{-6} \mathrm{pF}$ dial. The maximum bounds of error is estimated to be $\pm\left(3 \times 10^{-6}\right) \mathrm{pF}$. According to the nominal values of the unknown standards, the standard uncertainty to be included in the combined uncertainties at measurement, $s_{\mathrm{cb}}$ is :

$\begin{array}{lllll}s_{\mathrm{s} 1} \leq 2 & \mathrm{ppm} & \text { (for } 1 & \mathrm{pF} \text { capacitors), } \\ s_{\mathrm{s} 1} \leq 0.2 & \mathrm{ppm} & \text { (for } 10 & \mathrm{pF} \text { capacitors), } \\ s_{\mathrm{s} 1} \leq 0.02 & \mathrm{ppm} & \text { (for } 100 & \mathrm{pF} \text { capacitors), and } \\ s_{\mathrm{s} 1} \leq 0.002 & \mathrm{ppm} & \text { (for 1000 } & \mathrm{pF} \text { capacitors), }\end{array}$

where $s_{\mathrm{S} 1}$ is the standard uncertainty in the interpolation of the last dial. 
2) Since the assigned value of the oil-bath type fused-silica reference capacitor in the ICL is measured at $1 \mathrm{kHz}$, there is an uncertainty component of $1.6 \mathrm{ppm}$ from its frequency dependency, when using it as a reference to calibrate other capacitors at $100 \mathrm{~Hz}$.

With the above assumptions, the expanded and assigned total uncertainties for capacitance calibrations of fused-silica and nitrogen dielectric types of capacitors at $100 \mathrm{~Hz}$ is given in Table 8 .

\subsection{Uncertainties of Air and Mica Dielectric Capacitors}

NIST/Gaithersburg also provides calibration services at a frequency of $1 \mathrm{kHz}$ for air and mica dielectric capacitance standards in three-terminal or two-terminal high-frequency (HF) coaxial arrangements for plugging into a capacitance bridge or an impedance instrument directly. These capacitors are used mainly to calibrate the bridge or instrument at high frequencies, with its reference at $1 \mathrm{kHz}$. Stabilities of these capacitors are not as high as those with fused-silica and nitrogen dielectrics and they are affected more readily by the environment. Evaluation of the Type B standard uncertainty for these capacitors is based on the manufacturer's published information on sources of instability for these types of capacitors $[7,10]$ and on the specifications for each nominal value and type of capacitor. Evaluation of the Type A standard uncertainty is estimated from the measurement data; the capacitors are measured a few times to ensure that the standard deviation is within a given limit commensurate with the assigned total uncertainty based on population statistics. Assuming the laboratory conditions during measurements are such that the temperature change is less than $\pm 0.5^{\circ} \mathrm{C}$ and the relative humidity change is less than $\pm 8 \%$, the combined Type B standard uncertainty and the expanded uncertainties (coverage factor of $k=2$ ) for each type of capacitor are estimated. The results are shown in tables $9,10,11$, and 12 .

\subsubsection{Three-Terminal Air Capacitance Standards}

The terminals of these air dielectric capacitors are arranged to connect directly to the terminals of certain commercial capacitance bridges. Adapters also can be utilized to connect them to other impedance (LRC) meters and instruments. Table 9 gives the expanded and assigned total uncertainties (and their components) of these capacitance standards at $400 \mathrm{~Hz}$ and $1 \mathrm{kHz}$, with nominal values that range from $0.001 \mathrm{pF}$ to $10000 \mathrm{pF}$. These capacitors can be used at $100 \mathrm{~Hz}$, as well as at frequencies higher than $1 \mathrm{kHz}$. The expanded and assigned total uncertainties of threeterminal air capacitors at $100 \mathrm{~Hz}$ is shown in table 10.

\subsubsection{Two-Terminal HF Coaxial Capacitance Standards and Terminations}

The terminals of these capacitors, with the combination of certain commercial precision coaxial connectors, can be connected directly to instruments to obtain low lead inductance and high stability at high frequency (HF) $[11,12]$. Therefore, these capacitors are mainly used for measurements in the radio frequency range, with their reference values determined at $1 \mathrm{kHz}$. There are three types of HF coaxial capacitance standards available, as characterized by their nominal values and dielectric materials. 
Table 11 contains the calibration uncertainties for two types of HF coaxial air capacitors. The lowervalued type, with nominal values that range from $1 \mathrm{pF}$ to $20 \mathrm{pF}$, has a relatively flat frequency response to a few hundred megahertz (see Fig. 3 in Ref. 12). These capacitors can be employed as low-capacitance terminations for any two-port device. The mid-valued type, with nominal values that range from $50 \mathrm{pF}$ to $1000 \mathrm{pF}$, has negligible changes in effective capacitance with frequency up to the megahertz range (see Fig. 2 in Ref. 11). These capacitors are used mainly to calibrate capacitance bridges and other instruments at high frequencies from their reference values at $1 \mathrm{kHz}$.

The higher-valued coaxial capacitance standards use mica as a dielectric. The nominal values of these capacitors range from $0.001 \mu \mathrm{F}$ to $0.1 \mu \mathrm{F}$. Like the mid-valued type, these capacitors also have very low changes in effective capacitance below $100 \mathrm{kHz}$ (see Fig. 1 in Ref. 12). The main application for this type of capacitor is to calibrate instruments at higher frequencies from their reference values at $1 \mathrm{kHz}$. Table 12 gives the various calibration uncertainties for this type of capacitor.

The open-circuit terminations are useful as capacitance standards at low frequency for calibration bridges, and as shield caps for open-circuit lines in establishing initial conditions of line length and signal phase [10]. There are two types of open-circuit terminations, depending on the effective position of termination (plane position). The plane positions of these terminations are $0.26 \mathrm{~cm}$ and $4 \mathrm{~cm}$, which have capacitance values of $0.172 \mathrm{pF}$ and $2.670 \mathrm{pF}$, respectively, at low frequencies. NIST provides calibration services for these terminations at a frequency of $1 \mathrm{kHz}$ with the calibration uncertainties given in Table 12 .

\section{UNCERTAINTY ANALYSIS FOR THE TYPE-12 SYSTEM}

The original unity-ratio admittance bridge, known as the No. 12 type, was developed by Bell Laboratories in 1942 [13] for precision measurements of capacitance up to $1.11 \mu \mathrm{F}$ and conductance up to $1000 \mu \mathrm{S}$. Later on, an improved Type-12 capacitance bridge was designed, also by Bell Laboratories, with a capacitance divider to measure low capacitance values and multi-range, direct reading conductance standards. A complete schematic diagram of the Type-12 bridge is shown in Fig. 5a. Specifications of bridge components and internal standards, and operational procedures of the Type-12 bridge are described in detailed by Wilhelm [14].

There are two mica capacitance dials, three air capacitance dials, and two conductance (resistance) dials, all with ten steps in each dial, in the Type- 12 bridge. The mica dials range from $0.1 \mu \mathrm{F}$ to $1 \mu \mathrm{F}$ and from $0.01 \mu \mathrm{F}$ to $0.1 \mu \mathrm{F}$, and the air dials range from $0.001 \mu \mathrm{F}$ to $0.01 \mu \mathrm{F}, 0.0001 \mu \mathrm{F}$ to $0.001 \mu \mathrm{F}$, and $0.00001 \mu \mathrm{F}$ to $0.0001 \mu \mathrm{F}$. A $0.005 \mu \mathrm{F}$ mica capacitor, measured using the Type- 2 bridge, is used as a transfer standard to calibrate the $0.01 \mu \mathrm{F}$ steps of both the mica capacitance and the air capacitance dials of the Type-12 bridge. All other steps of mica and air capacitance dials are calibrated from the $0.01 \mu \mathrm{F}$ step, used as a reference. The conductance dials range from $10 \mu \mathrm{S}$ to $100 \mu \mathrm{S}$ and from $100 \mu \mathrm{S}$ to $1000 \mu \mathrm{S}$, and are calibrated against resistance standards. Both capacitance and conductance dials are adjusted to obtain a final balance at the time of measurement 
to provide capacitance and conductance values of the mica capacitors being calibrated by the Type12 bridge.

\subsection{Basic Equations of Capacitance Measurements}

Figure $5 \mathrm{~b}$ is a simplified schematic of the Type- 12 bridge showing the components for capacitance measurements, where $\mathbf{R}_{\mathbf{1}}$ and $\mathbf{R}_{\mathbf{2}}$ are resistors with a nominal ratio of 1:1. Using $C_{1}$ and $C_{2}$ as the total capacitance of each of the other two arms, the basic equation of balance for making capacitance measurements (when the voltage across detector D is zero) is:

$$
R_{1} C_{1}=R_{2} C_{2}
$$

where $C_{1}$ and $C_{2}$ are the total capacitances of arm $\mathrm{AD}$ and arm $\mathrm{CD}$, respectively.

As shown in Fig. $5 \mathrm{~b}, C_{1}$ and $C_{2}$ can be expressed as:

and

$$
C_{1}=C_{\mathrm{x}}+C_{\mathrm{m}}+C_{\mathrm{a}} \quad \text { (when } \mathrm{C}_{\mathrm{x}} \text { is connected to arm AD) }
$$

$$
C_{2}=C_{\mathrm{x}}+C_{\mathrm{c}} \quad \text { (when } \mathbf{C}_{\mathbf{x}} \text { is connected to arm CD), }
$$

where $\mathbf{C}_{\mathbf{x}}$ is the unknown capacitor to be measured, $C_{\mathrm{m}}$ is the reading of internal mica dial capacitors, and $C_{\mathrm{a}}$ and $C_{\mathrm{c}}$ are effective capacitances of arms $\mathrm{AD}$ and $\mathrm{CD}$, respectively, with internal air capacitors coupled so that:

$$
C_{\mathrm{a}}+C_{\mathrm{c}}=C \quad(\text { a constant }) .
$$

Each dial of the air capacitors of the Type- 12 bridge is arranged such that the dial reading indicates the difference of the effective capacitance between arm $\mathrm{AD}$ and arm $\mathrm{CD}$, plus a constant capacitance $C$, as:

$$
C_{r}=\left(C_{\mathrm{a}}-C_{\mathrm{c}}\right)+C
$$

where $C_{r}$ is the capacitance value corresponding to the dial reading, $r$.

Substituting Eq. (36) into Eq. (37) gives:

$$
C_{r}=2 C_{\mathrm{a}} .
$$

The internal air capacitors of the Type-12 bridge simulate three decade capacitors consisting of ten $0.001 \mu \mathrm{F}(1000 \mathrm{pF})$, ten $0.0001 \mu \mathrm{F}(100 \mathrm{pF})$, and ten $0.00001 \mu \mathrm{F}(10 \mathrm{pF})$ capacitors, and a continuously variable capacitor providing a capacitance range of $(11 \pm 0.5) \mathrm{pF}$.

Using the $10 \mathrm{pF} / \mathrm{step}$ dial as an example, where $C=50 \mathrm{pF}$, a set of four capacitors of $5 \mathrm{pF}, 10 \mathrm{pF}$, $15 \mathrm{pF}$, and $20 \mathrm{pF}$, are switched back and forth individually from arm CD to arm AD when the dial readings are increased from 0 to 1,1 to 2 , and 9 to 10 . The capacitance values corresponding 
to the dial readings are obtained in accordance with Eq. (36) and with the following procedure for switching the capacitors:

At dial reading $r=0$, all four capacitors are connected to arm $\mathrm{CD}$, then

$C_{\mathrm{c}}=50 \mathrm{pF}$ and $C_{\mathrm{a}}=0$; therefore, $C_{r}=0$.

At dial reading $r=1$, the $5 \mathrm{pF}$ capacitor is connected to arm $\mathrm{AD}$, the other three are connected to arm $\mathrm{CD}$, then

$$
C_{\mathrm{c}}=45 \mathrm{pF} \text { and } C_{\mathrm{a}}=5 \mathrm{pF} \text {; therefore, } C_{r}=10 \mathrm{pF} \text {. }
$$

At dial reading $r=2$, the $10 \mathrm{pF}$ capacitor is connected to arm $\mathrm{AD}$, the other three are connected to arm $\mathrm{CD}$, then

$$
C_{\mathrm{c}}=40 \mathrm{pF} \text { and } C_{\mathrm{a}}=10 \mathrm{pF} \text {; therefore, } C_{r}=20 \mathrm{pF} \text {. }
$$

At dial reading $r=10$, all four capacitors are connected to arm $\mathrm{AD}$, and then

$C_{\mathrm{c}}=0$ and $C_{\mathrm{a}}=50 \mathrm{pF}$; therefore, $C_{r}=100 \mathrm{pF}$.

Measurements of two- and three-terminal mica capacitors with nominal values up to $0.005 \mu \mathrm{F}$ are made using internal air capacitors only.

The Type-12 bridge also has a set of internal decade mica capacitors of ten $0.01 \mu \mathrm{F}$ and ten $0.1 \mu \mathrm{F}$ which are employed in the arm $\mathrm{AD}$, together with the air capacitors, to measure mica capacitors with nominal values larger than $0.005 \mu \mathrm{F}$. As mentioned previously, a $0.005 \mu \mathrm{F}$ mica capacitor is used as a transfer standard to obtain the dial corrections for the $0.01 \mu \mathrm{F}$ step of both air and mica dial capacitors from Type- 2 bridge measurements. All other steps of air and mica dial capacitors are calibrated against the $0.01 \mu \mathrm{F}$ step.

Again, the total uncertainty associated with Type- 12 bridge capacitance measurements contains both Type A and Type B standard uncertainties. An analysis of each type of uncertainty is contained in the following sections.

\subsection{Type B Standard Uncertainty of Capacitance Measurements}

The evaluation of the components of the Type B standard uncertainty for the Type-12 bridge is based on uncertainties in the ratio of resistors, $\mathbf{R}_{\mathbf{1}}$ and $\mathbf{R}_{\mathbf{2}}$, in the internal air and mica capacitors, and in the external bridge components. An analysis of each component at various frequencies is discussed in general to cover the entire range of capacitance calibrations. The Type B standard uncertainty for each type of capacitance measurement depends on the measurement procedure and internal standards used for the calibrations. 
According to the specifications for the Type-12 bridge [13], the maximum bounds of error in the 1:1 ratio are $\pm 30 \mathrm{ppm}$. Thus, according to Eq. (4), the uncertainty in the ratio of 1:1 is estimated as:

$$
s_{\mathrm{ra}}=17.3 \mathrm{ppm} \leq 18 \mathrm{ppm},
$$

where $s_{\mathrm{ra}}$ is the standard uncertainty contributed by the ratio resistors.

\subsubsection{Internal Capacitors}

The uncertainty components of both air and mica dial capacitors depend on their characteristics and errors due to their calibrations and environmental variations, which are discussed as follows:

\section{1) Dial Corrections}

Data and analyses of capacitance dial corrections for the Type- 12 bridge at various frequencies $(100 \mathrm{~Hz}, 1 \mathrm{kHz}$, and $10 \mathrm{kHz})$ are given in Appendix B. The capacitance correction of each dial setting has been evaluated by fitting a regression line to the corresponding data of 25 years to determine the predicted value. These corrections are updated once a year and are used to measure two sets of check standards of the Type-12 bridge. The data histories of these check standards are analyzed to ensure that the linear models of the dial corrections are valid. Thus, the standard deviations of the predicted values of the dial corrections for a particular date can be obtained. The standard uncertainty of the dial corrections is the RSS of the standard deviations of the predicted values for the dials which depend on the nominal value of the capacitor being measured.

For the air capacitor dials, the standard deviations of the predicted values of the dial corrections of those dials being used during measurements for the two-terminal and threeterminal configurations range between $0.018 \mathrm{pF}$ and $0.076 \mathrm{pF}$, as given in the first rows of Tables $13 \mathrm{a}$ and $13 \mathrm{~b}^{2}$. According to the nominal values of the unknown capacitors, the respective standard uncertainties (in ppm) of the dial corrections of the air capacitors, $s_{\mathrm{dr}}$, for both the two-terminal and three-terminal measurements are estimated and also given in Tables $13 \mathrm{a}$ and $13 \mathrm{~b}$ (second rows).

For the mica capacitor dials, the standard uncertainties are estimated in the same manner as in the air capacitor dials for the two-terminal and three-terminal measurements, respectively. According to the dials being used during measurements and the nominal values of the unknown capacitors, the standard uncertainty of the corrections of the mica capacitor dials, $s_{\mathrm{mr}}$, are included in Tables $14 \mathrm{a}$ and $14 \mathrm{~b}$, for the two-terminal and three-terminal

2 Starting from Table 13, the Tables are arranged that Table xxa and Table xxb are using the "a" and the "b" to refer to the components of standard uncertainties for the two-terminal and three-terminal measurements, respectively. 
measurements, respectively.

2) Temperature variations

The temperature coefficients of air and mica capacitors are $10 \mathrm{ppm} /{ }^{\circ} \mathrm{C}$ and $45 \mathrm{ppm} /{ }^{\circ} \mathrm{C}$, respectively. The temperature in the ICL is always maintained at $(23 \pm 1)^{\circ} \mathrm{C}$. Therefore, the maximum bounds of error owing to temperature effects for the readings of the air and mica capacitance dials are $\pm 10 \mathrm{ppm}$ and $\pm 45 \mathrm{ppm}$, respectively. According to Eq. (4),

$s_{\mathrm{tp}}=5.77 \mathrm{ppm} \leq 6 \mathrm{ppm}$, and $s_{\mathrm{mp}}=25.98 \mathrm{ppm} \leq 26 \mathrm{ppm}$,

where $s_{\mathrm{tp}}$ and $s_{\mathrm{mp}}$ refer to the standard uncertainties in the air and mica dial capacitors, respectively, due to temperature variations, which are included in Tables 13a to $14 \mathrm{~b}$.

3) Dial switching

The maximum bounds of error due to the switching of dials, $\pm e_{\mathrm{ds}}$ are estimated to be $\pm 0.01 \mathrm{pF}$, which will affect only the measurements of low capacitance. Accordingly,

$s_{\mathrm{ds}}=5.77 \mathrm{ppm} \leq 6 \quad \mathrm{ppm} \quad($ for $C=0.001 \mu \mathrm{F})$,

$s_{\mathrm{ds}}=0.58 \mathrm{ppm} \leq 0.6 \mathrm{ppm} \quad($ for $C=0.01 \mu \mathrm{F})$,

$s_{\mathrm{ds}}=0.06 \mathrm{ppm} \leq 0.1 \mathrm{ppm} \quad($ for $C=0.1 \mu \mathrm{F})$, and

$s_{\mathrm{ds}}=0.006 \mathrm{ppm} \leq 0.01 \mathrm{ppm} \quad($ for $C=1 \quad \mu \mathrm{F})$.

where $s_{\mathrm{ds}}$ is the standard uncertainty due to the switching of dials, also included in Tables $13 \mathrm{a}$ to $14 \mathrm{~b}$.

4) Uncertainty of transfer standard

From numerous measurements, the calibrated value of the transfer standard, a $0.005 \mu \mathrm{F}$ mica capacitor has an uncertainty of less than $0.03 \mathrm{pF}$, which will cause an uncertainty of less than $6 \mathrm{ppm}$ in the dial corrections of both air and mica dial capacitors. Thus,

$s_{\mathrm{tf}} \leq 6 \mathrm{ppm}$, and $s_{\mathrm{mf}} \leq 6 \mathrm{ppm}$,

where $s_{\mathrm{tf}}$ and $s_{\mathrm{mf}}$ are the standard uncertainties in the air and mica capacitor dial corrections, respectively, due to the uncertainty of the transfer standard, which are given in Tables 13a to $14 \mathrm{~b}$.

For measurements of capacitors with nominal values up to $0.005 \mu \mathrm{F}$, (only air-dial capacitors are needed), $s_{\mathrm{tf}}$ is used as the standard uncertainty. However, for capacitors of nominal values larger than $0.005 \mu \mathrm{F}$, the RSS of $s_{\mathrm{tf}}$ and $s_{\mathrm{mf}}$ is used to estimate the standard uncertainty from the dial corrections in measurements.

The combined uncertainty of the internal capacitors is defined as the RSS of the above components, which are estimated for each type of measurement as: 


$$
\begin{aligned}
& s_{\mathrm{rc}}=\left(s_{\mathrm{dr}}{ }^{2}+s_{\mathrm{tp}}{ }^{2}+s_{\mathrm{ds}}{ }^{2}+s_{\mathrm{tf}}{ }^{2}\right)^{(1 / 2)}, \text { and } \\
& s_{\mathrm{m}}=\left(s_{\mathrm{mr}}{ }^{2}+s_{\mathrm{mp}}{ }^{2}+s_{\mathrm{ds}}{ }^{2}+s_{\mathrm{mf}}{ }^{2}\right)^{(1 / 2)},
\end{aligned}
$$

where $s_{\mathrm{rc}}$ and $s_{\mathrm{m}}$ are the combined uncertainties in the air and mica capacitor dials, respectively, which are also included in Tables $13 \mathrm{a}$ to $14 \mathrm{~b}$.

\subsubsection{External Bridge Components}

1) Capacitance Between Connectors

Two special plates, $\mathrm{P} 2$ and $\mathrm{P} 3$, have been constructed to connect to the Type-12 bridge so that it can perform direct measurements on two-terminal and three-terminal mica capacitors, respectively, without using cables. Each plate has been evaluated to obtain its series inductance and resistance, and parallel capacitance. After these corrections are applied, the maximum bounds of error introduced by connections are found to be $\pm 0.02 \mathrm{pF}$ and $\pm 0.01 \mathrm{pF}$ for plates P2 and P3, respectively. These values imply that, according to Eq. (4), the uncertainty when using plate $\mathrm{P} 2$ is in the range from $0.012 \mathrm{ppm}$ (in measuring $1 \mu \mathrm{F}$ capacitors) to $12 \mathrm{ppm}$ (in measuring $0.001 \mu \mathrm{F}$ capacitors), and the uncertainty when using plate $\mathrm{P} 3$ is from $0.006 \mathrm{ppm}$ to $6 \mathrm{ppm}$. Hence,

$0.012 \leq s_{\mathrm{bp} 2} \leq 12 \mathrm{ppm} \quad$ and $\quad 0.006 \leq s_{\mathrm{bp} 3} \leq 6 \mathrm{ppm}$,

where $s_{\mathrm{bp} 2}$ and $s_{\mathrm{bp} 3}$ are the standard uncertainties due to the applied corrections of plates $\mathrm{P} 2$ and $\mathrm{P} 3$, respectively.

2) Series Lead Impedance

The effective capacitance of an unknown capacitor, $\boldsymbol{C}_{\mathbf{X}}$, including series lead inductance is taken to be (see derivation of Eq. (30a) in sect. 3.3.4):

$C_{\text {eff }}=C_{\mathrm{X}}\left(1+\omega^{2} L_{1} C_{\mathrm{X}}\right)$

where $C_{\text {eff }}$ is the effective capacitance, $L_{1}$ is the series lead inductance, and $\omega=2 \pi f$ in which $f$ is the applied frequency. The lead inductance of the Type- 12 bridge is estimated to be less than $0.2 \mu \mathrm{H}$, and the maximum error caused by lead impedance, $\boldsymbol{e}_{\mathbf{b Z}}$ is less than $(2 \pi f)^{2}(0.2) 10^{-6}\left(C_{\mathbf{x}}\right)$, which is $8 f^{2}\left(C_{\mathbf{x}}\right)$ ppm. Accordingly,

$s_{\mathrm{bZ}}=4.6 f^{2}\left(C_{\mathbf{x}}\right) \quad \mathrm{ppm}$,

where $s_{\mathrm{bz}}$ is the standard uncertainty due to lead impedance, $f$ is the applied frequency in kilohertz $(\mathrm{kHz})$, and $\boldsymbol{C}_{\mathbf{X}}$ is nominal value of the unknown capacitor in microfarad $(\mu \mathrm{F})$.

The combined uncertainty of the external bridge components, $s_{\mathrm{br}}$, is defined as the RSS of the above 
two components, which are estimated from each type of measurement, as:

$$
s_{\mathrm{br}}=\left(s_{\mathrm{bp}}{ }^{2}+s_{\mathrm{bZ}}{ }^{2}\right)^{(1 / 2)}
$$

where $s_{\mathrm{bp}}$ is equal to either $s_{\mathrm{bp} 2}$ or $s_{\mathrm{bp} 3}$, depending on which plate (either P2 or P3) is being used. These are given in Tables $15 \mathrm{a}$ and $15 \mathrm{~b}$.

The Type B component of standard uncertainty for capacitance measurements made with the Type-12 bridge, $\mathrm{U}_{\mathrm{b}}$, is defined as the RSS of the four components, $s_{\mathrm{ra}}, s_{\mathrm{rc}}, s_{\mathrm{m}}$, and $s_{\mathrm{br}}$ in Eqs. (39), (43), (44), and (48). This uncertainty is analyzed in detail for each type of measurement in the following section and the numerical results are given in Tables $15 \mathrm{a}$ and $15 \mathrm{~b}$ for the two-terminal and three-terminal measurements, respectively.

\subsection{Type B Standard Uncertainty for Various Types of Capacitance Measurement}

\subsubsection{Two-Terminal Measurements of Low-Capacitance Values}

$$
\left(0.001 \mu \mathrm{F} \leq C_{\mathbf{X}} \leq 0.005 \mu \mathrm{F}\right)
$$

\subsubsection{Basic Equations of Balance}

This type of measurement covers the range of capacitors with nominal values from $0.001 \mu \mathrm{F}$ to $0.005 \mu \mathrm{F}$, where only internal air-dial capacitors are used to balance the bridge. Using internal air capacitors, the bridge is balanced twice, with and without the unknown capacitor connected to the arm CD, as shown in Fig. 6. According to Eq. (33), the equations of balance are given as:

and

$$
R_{1} C_{\mathrm{a} 0}=R_{2} C_{\mathrm{c} 0}
$$

$$
R_{1} C_{\mathrm{a} 1}=R_{2}\left(C_{\mathrm{c} 1}+C_{\mathrm{X}}\right) \text {, }
$$

where $C_{\mathrm{a} 0}$ and $C_{\mathrm{c} 0}$ are capacitance values of internal air capacitors, $\mathbf{C}_{\mathrm{a}}$ and $\mathbf{C}_{\mathbf{c}}$, at balance without connecting the unknown capacitor $\mathbf{C}_{\mathrm{x}}$, and $C_{\mathrm{a} 1}$ and $C_{\mathrm{c} 1}$ are the corresponding capacitance values at balance with $\mathbf{C}_{\mathbf{X}}$ connected to arm $\mathrm{CD}$.

From Eqs. (49) and (50), the value of the unknown capacitor can be written as:

$$
C_{\mathrm{x}}=\left[1+\left(R_{1} / R_{2}\right)\right]\left(C_{\mathrm{a} 1}-C_{\mathrm{a} 0}\right),
$$

By substituting Eq. (38) into Eq. (51), $C_{\mathrm{X}}$ can be expressed in terms of dial readings as:

$$
C_{\mathrm{X}}=(1 / 2)\left[1+\left(R_{1} / R_{2}\right)\right]\left(C_{\mathrm{r} 1}-C_{\mathrm{r} 0}\right),
$$

where $C_{\mathrm{r} 1}=2 C_{\mathrm{a} 1}$ and $C_{\mathrm{r} 0}=2 C_{\mathrm{a} 0}$ are dial readings of the internal air capacitors at balance, with and without connecting $\mathbf{C}_{\mathbf{X}}$ to arm $\mathrm{CD}$, respectively. 
The ratio resistors are always set to be equal, $\left(R_{1}=R_{2}\right)$ so that Eq. (52) becomes:

$$
C_{\mathrm{X}}=\left(C_{\mathrm{r} 1}-C_{\mathrm{r} 0}\right)
$$

which is the equation used to calculate the value of the unknown capacitor.

\subsubsection{Analysis}

The relationship among the variances of the terms of Eq. (52) can be estimated by:

$$
\operatorname{Var}\left(C_{\mathrm{X}}\right)=(1 / 2)^{2}\left(C_{\mathrm{r} 1}-C_{\mathrm{r} 0}\right)^{2} s_{\mathrm{ra}}{ }^{2}+(1 / 2)^{2}\left(\left[1+\left(R_{1} / R_{2}\right)\right]^{2}\left({s_{\mathrm{rcl}}}^{2}+s_{\mathrm{rc} 0}{ }^{2}\right),\right.
$$

where $s_{\mathrm{ra}}, s_{\mathrm{rcl}}$, and $s_{\mathrm{rc} 0}$ are the standard uncertainties in the ratio (contributed by the resistors) and the air capacitor dials of both measurements, respectively.

By substituting Eq. (53) and ( $\left.R_{1}=R_{2}\right)$ into Eq. (54), it becomes:

$$
\operatorname{Var}\left(C_{\mathrm{X}}\right)=\left[(1 / 2) C_{\mathrm{X}} s_{\mathrm{ra}}\right]^{2}+s_{\mathrm{rc}}{ }^{2},
$$

where $s_{\mathrm{rc}}^{2}=s_{\mathrm{rcl} 1}{ }^{2}+s_{\mathrm{rc} 0}{ }^{2}$.

From Eq. (39), the uncertainty contributed by the ratio resistors for two-terminal low-capacitance measurements, $\left[(1 / 2) C_{\mathrm{X}} s_{\mathrm{ra}}\right]$, is $9 \mathrm{ppm}$ (see the first three columns of Table 15a). The capacitance uncertainties associated with each dial reading, $s_{\mathrm{rc} 0}$ and $s_{\mathrm{rcl}}$, can be estimated from the corresponding terms of Eq. (43), as:

$$
\begin{aligned}
& s_{\mathrm{rc} 0}=\left(s_{\mathrm{dr} 0}{ }^{2}+s_{\mathrm{tp} 0}{ }^{2}+s_{\mathrm{ds} 0}{ }^{2}+s_{\mathrm{tf} 0}{ }^{2}\right)^{(1 / 2)}, \text { and } \\
& s_{\mathrm{rcl} 1}=\left(s_{\mathrm{dr} 1}{ }^{2}+s_{\mathrm{tpl} 1}{ }^{2}+s_{\mathrm{ds} 1}{ }^{2}+s_{\mathrm{tfl}}{ }^{2}\right)^{(1 / 2)} \text {. }
\end{aligned}
$$

The combined uncertainty of the internal air dial capacitors, $s_{\mathrm{rc}}$, is estimated to be between $18 \mathrm{ppm}$ and $62 \mathrm{ppm}$. (See the first three columns of Tables 13a and 15a).

At frequencies of $100 \mathrm{~Hz}$ and $1 \mathrm{kHz}$, the uncertainties due to lead impedance are negligible for capacitor values up to $0.005 \mu \mathrm{F}$. The uncertainty of evaluating plate $\mathrm{P} 2,0.012 \mathrm{pF}$, is found to be between $3 \mathrm{ppm}$ and $12 \mathrm{ppm}$.

At a frequency of $10 \mathrm{kHz}$, the lead impedance including series inductance is calculated from Eq. (47), and the combined uncertainties in the bridge components range from $4 \mathrm{ppm}$ to $12 \mathrm{ppm}$.

The Type-B standard uncertainties for two-terminal low capacitance value measurements, as well as their individual uncertainty components, are included in the first three columns of Table 15a. 


\subsubsection{Two-Terminal Measurements of High-Capacitance Values$$
\left(0.005 \mu \mathrm{F}<C_{\mathbf{x}} \leq 1 \mu \mathrm{F}\right)
$$

\subsubsection{Basic Equations of Balance}

Measurement procedures of this type are the same as those for low-capacitance values, except that the mica dial capacitors are needed when the unknown is connected to arm $\mathrm{CD}$, as shown in Fig. 7. The equations of balance, corresponding to Eqs. (49) and (50) become:

and

$$
R_{1} C_{\mathrm{a} 0}=R_{2} C_{\mathrm{c} 0}
$$

$$
R_{1}\left(C_{\mathrm{a} 1}+C_{\mathrm{m}}\right)=R_{2}\left(C_{\mathrm{c} 1}+C_{\mathrm{X}}\right),
$$

where $C_{\mathrm{a} 0}$ and $C_{\mathrm{c} 0}$ are the values of the air capacitors at balance without connecting the unknown capacitor $\mathrm{C}_{\mathrm{x}} ; C_{\mathrm{a} 1}$ and $C_{\mathrm{c} 1}$ are the values of the air capacitors, and $C_{\mathrm{m}}$ is the value of the mica capacitors at balance with $\mathrm{C}_{\mathbf{X}}$ connected to arm $\mathrm{CD}$.

The value of the unknown capacitor can be expressed as:

$$
C_{\mathrm{X}}=\left(R_{1} / R_{2}\right) C_{\mathrm{m}}+(1 / 2)\left[1+\left(R_{1} / R_{2}\right)\right]\left(C_{\mathrm{r} 1}-C_{\mathrm{r} 0}\right),
$$

where $C_{\mathrm{m}}$ is the mica dial reading, and $C_{\mathrm{r} 1}=2 C_{\mathrm{a} 1}$ and $C_{\mathrm{r} 0}=2 C_{\mathrm{a} 0}$ are air-dial readings of internal capacitors at balance, with and without connecting $\mathbf{C}_{\mathbf{X}}$ to arm $\mathrm{CD}$, respectively.

The ratio resistors are always set to be equal, $\left(R_{1}=R_{2}\right)$ so that Eq. (59) becomes:

$$
C_{\mathrm{x}}=C_{\mathrm{m}}+\left(C_{\mathrm{r} 1}-C_{\mathrm{r} 0}\right)
$$

which is the equation used to calculate the value of the unknown capacitor.

\subsubsection{Analysis}

The relationship among the variances of the terms of Eq. (59) can be estimated by:

$$
\begin{gathered}
\operatorname{Var}\left(C_{\mathrm{X}}\right)=\left[\mathrm{C}_{\mathrm{m}}+(1 / 2)\left(C_{\mathrm{r} 1}-C_{\mathrm{r} 0}\right)\right]^{2} s_{\mathrm{ra}}{ }^{2}+\left(R_{1} / R_{2}\right)^{2} s_{\mathrm{m}}{ }^{2} \\
+(1 / 2)^{2}\left[1+\left(R_{1} / R_{2}\right)\right]^{2}\left(s_{\mathrm{rcl}}{ }^{2}+s_{\mathrm{rc} 0}{ }^{2}\right),
\end{gathered}
$$

where $s_{\mathrm{ra}}, s_{\mathrm{m}}, s_{\mathrm{rc} 1}$, and $s_{\mathrm{rc} 0}$ are the standard uncertainties in the ratio (contributed by the resistors), the mica capacitor dial, and the air capacitor dials of both measurements, respectively.

According to Eq. (60), the first term of Eq. (61) can be expressed as:

$$
\left[\mathrm{C}_{\mathrm{m}}+(1 / 2)\left(C_{\mathrm{r} 1}-C_{\mathrm{r} 0}\right)\right]^{2} s_{\mathrm{ra}}{ }^{2} \leq\left(C_{\mathrm{x}}\right)^{2} s_{\mathrm{ra}}{ }^{2},
$$


By substituting Eq. (62) and ( $\left.R_{1}=R_{2}\right)$ into Eq. (61), it becomes:

$$
\operatorname{Var}\left(C_{\mathrm{X}}\right) \leq\left(C_{\mathrm{X}} s_{\mathrm{ra}}\right)^{2}+s_{\mathrm{m}}{ }^{2}+s_{\mathrm{rc}}{ }^{2},
$$

where $s_{\mathrm{rc}}^{2}=s_{\mathrm{rcl}}^{2}+s_{\mathrm{rc} 0}^{2}$.

From Eq. (39), the uncertainty contributed by the ratio resistors, $s_{\mathrm{ra}}$, for the two-terminal highcapacitance measurements is $18 \mathrm{ppm}$. (See Table 15a).

The uncertainty of the internal mica capacitors is estimated from the dials being used. According to Eq. (60), the value of the mica-dials correspond to the nominal value of the unknown capacitor. Therefore, the combined uncertainty of the internal mica capacitors, $s_{\mathrm{m}}$, is estimated to range between $28 \mathrm{ppm}$ and $35 \mathrm{ppm}$, from Eq. (44). (See Table 14a). The combined uncertainty of the internal air-dial capacitors for the two-terminal high capacitance measurements, $s_{\text {rc }}$, is estimated to be less than 9 ppm, from Eq. (43). (See Tables 13a, columns 4 to 10 and 15a).

Uncertainties due to the capacitance of plate $\mathrm{P} 2$ are $\pm 0.02 \mathrm{pF}$ and uncertainties in lead impedance are functions of both frequency and capacitance values, as shown in Eq. (47). At frequencies of $100 \mathrm{~Hz}$ and $1 \mathrm{kHz}$, the combined uncertainties are less than $5 \mathrm{ppm}$. However, at a frequency of $10 \mathrm{kHz}$, these uncertainties increase substantially for high valued capacitors, and are calculated to be as large as $475 \mathrm{ppm}$.

The Type-B standard uncertainties for two-terminal high-capacitance value measurements, as well as their individual uncertainty components, are included in Table 15a.

\subsubsection{Three-Terminal Measurements of Low-Capacitance Values}

$$
\left(0.001 \mu \mathrm{F} \leq C_{\mathbf{X}} \leq 0.005 \mu \mathrm{F}\right)
$$

\subsubsection{Basic Equations of Balance}

This type of measurement is similar to those of two-terminal low-capacitance measurements, except that the unknown capacitor, $\mathbf{C}_{\mathbf{X}}$, is connected to arm $\mathrm{AD}$ in the first balance and to arm $\mathrm{CD}$ in the second balance, as illustrated in Fig. 8. In this case, the equations of balance are:

and

$$
R_{1}\left(C_{\mathrm{a} 1}+C_{\mathrm{X}}\right)=R_{2} C_{\mathrm{c} 1}
$$

$$
R_{1} C_{\mathrm{a} 2}=R_{2}\left(C_{\mathrm{c} 2}+C_{\mathrm{x}}\right)
$$

where $C_{\mathrm{a} 1}$ and $C_{\mathrm{c} 1}$ are the values of the selected internal capacitors at balance with $\mathbf{C}_{\mathbf{x}}$ connected to arm $\mathrm{AD}$, and $C_{\mathrm{a} 2}$ and $C_{\mathrm{c} 2}$ are the values at balance with $\mathbf{C}_{\mathbf{x}}$ connected to arm $\mathrm{CD}$.

From Eqs. (64) and (65), the value of the unknown capacitor can be expressed as:

$$
C_{\mathrm{x}}=(1 / 2)\left(C_{\mathrm{r} 2}-C_{\mathrm{r} 1}\right),
$$


where $C_{\mathrm{r} 1}=2 C_{\mathrm{a} 1}$ and $C_{\mathrm{r} 2}=2 C_{\mathrm{a} 2}$ are dial readings of internal air capacitors at balance with $\mathbf{C}_{\mathrm{x}}$ connected to arm $\mathrm{AD}$ and to arm $\mathrm{CD}$, respectively.

\subsubsection{Analysis}

The relationship among the variances of the terms of Eq. (66) can be estimated by:

$$
\operatorname{Var}\left(C_{\mathrm{X}}\right)=(1 / 2)^{2} s_{\mathrm{rc} 1}^{2}+(1 / 2)^{2} s_{\mathrm{rc} 0}^{2},
$$

where $s_{\mathrm{rc} 1}$ and $s_{\mathrm{rc} 0}$ are the standard uncertainties in the air capacitor dials of both measurements, respectively.

Eq. (67) can also be expressed as:

$$
\operatorname{Var}\left(C_{\mathrm{X}}\right)=\left[(1 / 2) s_{\mathrm{rc}}\right]^{2},
$$

where $s_{\mathrm{rc}}^{2}=s_{\mathrm{rcl}}{ }^{2}+s_{\mathrm{rc} 0}{ }^{2}$.

According to Eq. (66), $C_{\mathrm{X}}$ is independent of $R_{1}$ and $R_{2}$, so uncertainties contributed by the ratio resistors will not affect this type of measurement. The uncertainties in the air dial readings are estimated to be between $8 \mathrm{ppm}$ and $31 \mathrm{ppm}$. (See the first three columns of Table 15b).

Uncertainties due to external bridge components are similar to uncertainties of two-terminal measurements of the same nominal values, except that the capacitance of the plate, $\mathrm{P} 3$, is $0.006 \mathrm{pF}$, and these are found to be less than $6 \mathrm{ppm}$.

The Type-B standard uncertainties of three-terminal low-capacitance value measurements are included in Table 15b, as well as their individual uncertainty components for each capacitance value at $100 \mathrm{~Hz}, 1 \mathrm{kHz}$, and $10 \mathrm{kHz}$.

\subsubsection{Three-Terminal Measurements of High-Capacitance Values up to $0.5 \mu \mathrm{F}$$$
\left(0.005 \mu \mathrm{F}<C_{\mathbf{x}} \leq 0.5 \mu \mathrm{F}\right)
$$

\subsubsection{Basic Equations of Balance}

Measurement procedures for capacitors of this type are similar to those of three-terminal lowcapacitance value measurements, except that internal mica capacitors are needed for the second balance, and a dummy capacitor (a mica decade capacitance box) is connected into the arm CD for both balances, as shown in Fig. 9. The equations of balance, as in Eqs. (64) and (65), become:

and

$$
R_{1}\left(C_{\mathrm{a} 1}+C_{\mathrm{x}}\right)=R_{2}\left(C_{\mathrm{c} 1}+C_{\mathrm{b}}\right)
$$

$$
R_{1}\left(C_{\mathrm{a} 2}+C_{\mathrm{m}}\right)=R_{2}\left(C_{\mathrm{c} 2}+C_{\mathrm{x}}+C_{\mathrm{b}}\right),
$$


where $C_{\mathrm{a} 1}$ and $C_{\mathrm{cl}}$ are values of the internal air capacitors at balance with the unknown capacitor, $\mathbf{C}_{\mathbf{X}}$ connected to arm $\mathrm{AD}, C_{\mathrm{a} 2}$ and $C_{\mathrm{C} 2}$ are values of the internal air capacitors at balance with $\mathbf{C}_{\mathbf{x}}$ connected to arm $\mathrm{CD}, C_{\mathrm{m}}$ are values of the internal mica capacitors at the second balance, and $C_{\mathrm{b}}$ is the value of the dummy capacitance box.

From Eqs. (69) and (70), the value of the unknown capacitor can be expressed as:

$$
C_{\mathrm{X}}=\left[R_{1} /\left(R_{1}+R_{2}\right)\right] C_{\mathrm{m}}+(1 / 2)\left[R_{1} /\left(R_{1}+R_{2}\right)\right]\left(C_{\mathrm{r} 2}-C_{\mathrm{r} 1}\right) .
$$

The ratio resistors are always set to be equal $\left(R_{1}=R_{2}\right)$, so Eq. (71) becomes:

$$
C_{\mathrm{x}}=(1 / 2) C_{\mathrm{m}}+(1 / 4)\left(C_{\mathrm{r} 2}-C_{\mathrm{r} 1}\right)
$$

which is the equation used to calculate the unknown capacitor.

\subsubsection{Analysis}

Rewrite Eq. (71) as:

$$
C_{\mathrm{X}}=\left\{\left(R_{1} / R_{2}\right) /\left[1+\left(R_{1} / R_{2}\right)\right]\right\} C_{\mathrm{m}}+(1 / 2)\left\{\left(R_{1} / R_{2}\right) /\left[1+\left(R_{1} / R_{2}\right)\right]\right\}\left(C_{\mathrm{r} 2}-C_{\mathrm{r} 1}\right) .
$$

The relationship among the variances of the terms of Eq. (71) can be estimated by:

$$
\begin{aligned}
\operatorname{Var}\left(C_{\mathrm{X}}\right)= & {\left[1+\left(R_{1} / R_{2}\right)\right]^{-4}\left[\mathrm{C}_{\mathrm{m}}+(1 / 2)\left(C_{\mathrm{r} 1}-C_{\mathrm{r} 0}\right)\right]^{2} s_{\mathrm{ra}}{ }^{2}+\left\{\left(R_{1} / R_{2}\right) /\left[1+\left(R_{1} / R_{2}\right)\right]\right\}^{2} s_{\mathrm{m}}{ }^{2} } \\
& +(1 / 2)^{2}\left\{\left(R_{1} / R_{2}\right) /\left[1+\left(R_{1} / R_{2}\right)\right]\right\}^{2}\left(s_{\mathrm{rc} 1}{ }^{2}+s_{\mathrm{rc} 0}{ }^{2}\right),
\end{aligned}
$$

where $s_{\mathrm{ra}}, s_{\mathrm{m}}, s_{\mathrm{rcl} 1}$, and $s_{\mathrm{rc} 0}$ are the standard uncertainties in the ratio (contributed by the resistors), the mica capacitor dial, and the air capacitor dials of both measurements, respectively.

By substituting Eq. (72) and ( $\left.R_{1}=R_{2}\right)$ into Eq. (74), it becomes:

$$
\operatorname{Var}\left(C_{\mathrm{X}}\right)=\left[(1 / 2) C_{\mathrm{X}} s_{\mathrm{ra}}\right]^{2}+\left[(1 / 2) s_{\mathrm{m}}\right]^{2}+\left[(1 / 4) s_{\mathrm{rc}}\right]^{2},
$$

where $s_{\mathrm{rc}}^{2}=s_{\mathrm{rcl}}^{2}+s_{\mathrm{rc} 0}^{2}$.

As in the two-terminal high-capacitance value measurements, the uncertainty contributed by the ratio resistors in the three-terminal case, $\left[\left(\frac{1}{2}\right) C_{\mathrm{X}} s_{\text {ra }}\right]$, is also $9 \mathrm{ppm}$. (See Table 15b).

Using an analysis similar to that in the case of two-terminal high-capacitance measurements, one finds that the uncertainties in the internal mica capacitors for the three-terminal measurements, $\left[(1 / 2) s_{\mathrm{m}}\right]$, are estimated to be less than $23 \mathrm{ppm}$. The uncertainties in the air-dial capacitors, $\left[(1 / 4) s_{\mathrm{rc}}\right]$, are estimated to be less than $3 \mathrm{ppm}$. These are also given in Table $15 \mathrm{~b}$.

Uncertainties due to external bridge components are similar to those in making two-terminal 
measurements of the same nominal values, except that the capacitance of the plate, $\mathrm{P} 3$, is $0.006 \mathrm{pF}$, and these are estimated to be less than $3 \mathrm{ppm}$ at frequencies of $100 \mathrm{~Hz}$ and $1 \mathrm{kHz}$. However, at a frequency of $10 \mathrm{kHz}$, these uncertainties increase substantially for high-valued capacitors, and are calculated to be as large as $235 \mathrm{ppm}$.

The Type-B standard uncertainties of three-terminal high-capacitance value measurements are included in Table $15 \mathrm{~b}$, as well as their individual uncertainty components for each capacitance value at $100 \mathrm{~Hz}, 1 \mathrm{kHz}$, and $10 \mathrm{kHz}$.

\subsubsection{Three-Terminal Measurements of Capacitors Larger Than $0.5 \mu \mathrm{F}$}

\subsubsection{Basic Equations of Balance}

Due to range limitations of the internal mica capacitors of the Type-12 bridge, four balances are needed to measure unknown capacitors larger than $0.5 \mu \mathrm{F}$, and measurements are performed at frequencies only up to $1 \mathrm{kHz}$. The dummy capacitor box, $\mathbf{C}_{\mathbf{b}}$, is connected across the arm $\mathrm{CD}$ and its value is set to either 0 or the nominal value of the unknown capacitor, $\mathbf{C}_{\mathbf{X}}$, as shown in Fig. 10. Using $C_{\mathrm{x}}=1 \mu \mathrm{F}$ as an example, the measurement sequence and equations of balance in accordance to Fig. 10 are described as follows:

1) Connect $\mathbf{C}_{\mathbf{X}}$ across arm $\mathrm{AD}$, set the mica dials to zero, and the value of $C_{\mathbf{b}}$ to $1 \mu \mathrm{F}$. Use the air dials to obtain a balance, and record the reading as $C_{\mathrm{r} 1}$. The equation of balance is:

$R_{1}\left(C_{\mathrm{a} 1}+C_{\mathrm{x}}\right)=R_{2}\left(C_{\mathrm{c} 1}+C_{\mathrm{b}}\right)$.

2) Disconnect $\mathbf{C}_{\mathbf{x}}$, and leave $C_{\mathrm{b}}$ at $1 \mu \mathrm{F}$. Use both the air and mica dials to obtain a balance, and record the readings as $C_{\mathrm{r} 2}$ and $C_{\mathrm{m} 2}$, respectively. The equation of balance is:

$R_{1}\left(C_{\mathrm{a} 2}+C_{\mathrm{m} 2}\right)=R_{2}\left(C_{\mathrm{c} 2}+C_{\mathrm{b}}\right)$.

3) Connect $\mathbf{C}_{\mathbf{x}}$ across arm $\mathrm{CD}$, and set $C_{\mathbf{b}}$ to zero. Use both the air and mica dials to obtain a balance, and record the readings as $C_{\mathrm{r} 3}$ and $C_{\mathrm{m} 3}$, respectively. The equation of balance is:

$R_{1}\left(C_{\mathrm{a} 3}+C_{\mathrm{m} 3}\right)=R_{2}\left(C_{\mathrm{c} 3}+C_{\mathrm{x}}\right)$.

4) Disconnect $\mathbf{C}_{\mathbf{X}}$, set both mica dials and $\boldsymbol{C}_{\mathrm{b}}$ to zero. Use the air dials to obtain a balance, and record the reading as $C_{\mathrm{r} 4}$. The equation of balance is:

$R_{1} C_{\mathrm{a} 4}=R_{2} C_{\mathrm{c} 4}$

The numerical subscripts of Eqs. (76) to (79) indicate the values of mica and air capacitors in the corresponding measurements.

The value of the unknown capacitor, $\mathbf{C}_{\mathbf{X}}$ can be expressed as: 


$$
C_{\mathrm{X}}=\left[R_{1} /\left(R_{1}+R_{2}\right)\right]\left(C_{\mathrm{m} 2}+C_{\mathrm{m} 3}\right)+(1 / 2)\left[\left(C_{\mathrm{r} 2}-C_{\mathrm{r} 1}\right)+\left(C_{\mathrm{r} 3}-C_{\mathrm{r} 4}\right)\right],
$$

where $C_{\mathrm{r} 1}$ to $C_{\mathrm{r} 4}$ and $C_{\mathrm{m} 2}$ to $C_{\mathrm{m} 3}$ are air and mica dial readings, respectively, corresponding to each measurement.

The ratio resistors are always set to be equal $\left(R_{1}=R_{2}\right)$, so Eq. (80) becomes:

$$
C_{\mathrm{x}}=(1 / 2)\left(C_{\mathrm{m} 2}+C_{\mathrm{m} 3}\right)+(1 / 2)\left[\left(C_{\mathrm{r} 2}-C_{\mathrm{r} 1}\right)+\left(C_{\mathrm{r} 3}-C_{\mathrm{r} 4}\right)\right]
$$

which is the equation used to calculate the value of the unknown capacitor.

\subsubsection{Analysis}

Rewrite Eq. (80) as:

$$
C_{\mathrm{X}}=\left\{\left(R_{1} / R_{2}\right) /\left[1+\left(R_{1} / R_{2}\right)\right]\right\}\left(C_{\mathrm{m} 2}+C_{\mathrm{m} 3}\right)+(1 / 2)\left[\left(C_{\mathrm{r} 2}-C_{\mathrm{r} 1}\right)+\left(C_{\mathrm{r} 3}-C_{\mathrm{r} 4}\right)\right] .
$$

The relationship among the variances of the terms of Eq. (82) can be estimated by:

$$
\begin{aligned}
\operatorname{Var}\left(C_{\mathrm{X}}\right)=[1+ & \left.\left(R_{1} / R_{2}\right)\right]^{-4}\left(C_{\mathrm{m} 2}+C_{\mathrm{m} 3}\right)^{2} s_{\mathrm{ra}}{ }^{2} \\
& +\left\{\left(R_{1} / R_{2}\right) /\left[1+\left(R_{1} / R_{2}\right)\right]\right\}^{2}\left(s_{\mathrm{m} 2}{ }^{2}+s_{\mathrm{m} 3}{ }^{2}\right) \\
& +(1 / 2)^{2}\left(s_{\mathrm{rc} 1}{ }^{2}+s_{\mathrm{rc} 2}{ }^{2}+s_{\mathrm{rc} 3}{ }^{2}+s_{\mathrm{rc} 4}{ }^{2}\right),
\end{aligned}
$$

where $s_{\mathrm{ra}}, s_{\mathrm{m} 2}, s_{\mathrm{m} 3}, s_{\mathrm{rcl}}, s_{\mathrm{rc} 2}, s_{\mathrm{rc} 3}$ and $s_{\mathrm{rc} 4}$ are the standard uncertainties in the ratio ( contributed by the resistors), the mica capacitor dials, and the air capacitor dials of the four measurements, respectively.

According to Eq. (81), the first term of Eq. (83) can be expressed as:

$$
\left(C_{\mathrm{m} 2}+C_{\mathrm{m} 3}\right)^{2}{s_{\mathrm{ra}}}^{2} \leq\left(2 C_{\mathrm{X}}\right)^{2}{s_{\mathrm{ra}}}^{2},
$$

By substituting Eq. (84) and ( $\left.R_{1}=R_{2}\right)$ into Eq. (83), it becomes:

$$
\operatorname{Var}\left(C_{\mathrm{X}}\right) \leq\left[(1 / 2) C_{\mathrm{X}} s_{\mathrm{ra}}\right]^{2}+\left[(1 / 2) s_{\mathrm{m}}\right]^{2}+\left[(1 / 2) s_{\mathrm{rc}}\right]^{2},
$$

where $s_{\mathrm{m}}{ }^{2}=s_{\mathrm{m} 2}{ }^{2}+s_{\mathrm{m} 3}{ }^{2}$ and $s_{\mathrm{rc}}{ }^{2}=s_{\mathrm{rc} 1}{ }^{2}+s_{\mathrm{rc} 2}{ }^{2}+s_{\mathrm{rc} 3}{ }^{2}+s_{\mathrm{rc} 4}{ }^{2}$.

In Eq. (85), the first term represents uncertainties in the ratio; the second and third terms represent uncertairities in the mica and air dial readings, respectively.

As in the three-terminal high-capacitance value measurements, the uncertainty contributed by the ratio resistors, $\left[(1 / 2) C_{\mathrm{X}} s_{\mathrm{ra}}\right]$, is also $9 \mathrm{ppm}$. (See Table 15b). According to Eq. (81), two balances using the internal mica capacitors and four balances using the internal air capacitors are required to 
measure the unknown capacitor of value equal to $1 \mu \mathrm{F}$. The combined uncertainty in the mica capacitor dial readings, $\left[(1 / 2) s_{\mathrm{m}}\right]$, is estimated to be less than $16 \mathrm{ppm}$. The uncertainty in the air capacitance dial readings, $\left[(1 / 2) s_{\text {rc }}\right]$, is estimated to be $5 \mathrm{ppm}$. (See the last column of Table 15b).

For $C_{\mathbf{x}}=1 \mu \mathrm{F}$, the uncertainty due to the external bridge components is estimated to be $5 \mathrm{ppm}$ at frequencies of $100 \mathrm{~Hz}$ and $1 \mathrm{kHz}$.

The Type-B standard uncertainties for measurements of three-terminal mica capacitors of value equal to $1 \mu \mathrm{F}$, as well as their individual uncertainty components, at both $100 \mathrm{~Hz}$ and $1 \mathrm{kHz}$, are also included in Table 15b.

\subsection{Type A Standard Uncertainty of Capacitance Measurements}

The evaluation of the Type A standard uncertainty for the Type-12 system in making capacitance measurements is based on the repeatability and the effect of temperature variations on unknown capacitors during measurements. Also involved are the stabilities of the NIST standards that are used with an impedance meter as a comparator. An uncertainty analysis of each component that contributes to the Type A standard uncertainty for both two- and three-terminal measurements is given in the following sections.

\subsubsection{Repeatability of Measurements}

The procedure for using the Type- 12 bridge to calibrate mica capacitors at NIST is to perform two complete measurements on the unknown capacitor and to report the average of these two results as the calibrated value. The range of these two measured values is compared with a given "limit" to ensure that it is within this limit. In the case where the range is over the limit, additional measurements are required to observe the variability of the unknown and to obtain an estimate of the component of uncertainty due to repeatability. From NIST historical data of a large population of standards, the range is $60 \mathrm{ppm}$, except for capacitors of $0.001 \mu \mathrm{F}$, for which the range is $100 \mathrm{ppm}$. These limits correspond to the maximum bounds of error in repeatability of $\pm 30 \mathrm{ppm}$ for all capacitors except the $0.001 \mu \mathrm{F}$ capacitors where the limits are $\pm 50 \mathrm{ppm}$. According to Eq. (4),

$$
\begin{array}{ll}
s_{\mathrm{rm}}=17.3 \mathrm{ppm} \leq 20 \mathrm{ppm}, & \left(\text { for } C_{\mathbf{x}}>0.001 \mu \mathrm{F}\right), \\
s_{\mathrm{rm}}=28.9 \mathrm{ppm} \leq 30 \mathrm{ppm}, & \left(\text { for } C_{\mathbf{x}}=0.001 \mu \mathrm{F}\right),
\end{array}
$$

where $s_{\mathrm{rm}}$ is the standard uncertainty due to repeatability of results of measurements of capacitance. The values of $s_{\mathrm{rm}}$ are included in Tables 16a and $16 \mathrm{~b}$.

\subsubsection{Effect of Temperature Variations on Unknown Capacitors}

As stated previously, the temperature coefficients of air and mica dielectric capacitors are approximately $10 \mathrm{ppm} /{ }^{\circ} \mathrm{C}$ and $45 \mathrm{ppm} /{ }^{\circ} \mathrm{C}$, respectively, and the temperature of the ICL is always 
maintained at $23{ }^{\circ} \mathrm{C} \pm 1{ }^{\circ} \mathrm{C}$. Uncertainties in unknown capacitors due to temperature changes are dependent on the length of time needed to perform measurements and to connect additional components. If an external decade capacitance box is needed (such as in three-terminal calibrations of capacitors with values from $0.01 \mu \mathrm{F}$ and up), the temperature coefficient of the box will also contribute additional uncertainties in measurements. The maximum bounds of error due to temperature changes are equal to $\pm \mathrm{TC}^{*}(\Delta \mathrm{T})$. According to Eq. (4),

$$
s_{\mathrm{tm}}=\mathrm{TC}^{*}(\Delta \mathrm{T}) / \sqrt{3} \mathrm{ppm}
$$

where $s_{\mathrm{tm}}$ is the standard uncertainty component owing to the effect of temperature changes in the ICL on the values of the unknown capacitor, $\mathrm{TC}$ is the temperature coefficient (in ppm $/{ }^{\circ} \mathrm{C}$ ), and $\Delta \mathrm{T}$ is the maximum change in temperature $\left(\right.$ in $\left.{ }^{\circ} \mathrm{C}\right)$ during the measurement.

In two-terminal measurements, it takes less than $10 \mathrm{~min}$ to complete the measurement on one unknown capacitor. The maximum change in temperature during measurement is $0.15^{\circ} \mathrm{C}$, which corresponds to an uncertainty, $s_{\mathrm{tm}}$, of $4 \mathrm{ppm}$ in capacitance, as shown in Table 16a.

The time required to complete three-terminal measurements on one unknown capacitor is less than $20 \mathrm{~min}$, which corresponds to a maximum change in temperature of less than $0.3^{\circ} \mathrm{C}$, and introduces an uncertainty, $s_{\mathrm{tm}}$, of $10 \mathrm{ppm}$ in the low-value unknown capacitors $\left(C_{\mathbf{X}} \leq 0.005 \mu \mathrm{F}\right)$. For $0.005 \mu \mathrm{F}<C_{\mathrm{X}} \leq 0.5 \mu \mathrm{F}$, the values of a capacitance box are needed for balances. Although the value of the capacitance box does not enter into the calculation of unknown capacitors, the variation in its capacitance values during measurements is reflected in the balance readings and the final value of the unknown capacitor, $C_{\mathbf{X}}$, as shown in Eqs. (68) and (69). The combined uncertainty due to temperature changes that occur during measurement, $s_{\mathrm{tm}}$, is estimated to be $15 \mathrm{ppm}$, which is the RSS of uncertainties in the unknown capacitor and in the capacitance box. For $C_{\mathbf{x}}>0.5 \mu \mathrm{F}$, it may take as long as $30 \mathrm{~min}$ to complete one measurement, which corresponds to a maximum change in temperature up to $0.4{ }^{\circ} \mathrm{C}$. The combined uncertainty due to temperature changes that occur during measurement, $s_{\mathrm{tm}}$, is estimated to be $20 \mathrm{ppm}$, which is the RSS of uncertainties for the unknown capacitor and for the capacitance box. The values of $s_{\mathrm{tm}}$ are included in Table $16 \mathrm{~b}$.

\subsubsection{Stabilities of NIST Standards}

Since 1993, the calibration procedures for measuring mica capacitors at $1 \mathrm{kHz}$ at NIST have been modified by using commercial impedance meters to compare a customer's standard with a NIST standard of the same type over a short time. Then, the value for a customer's standard is calculated from the predicted value of the NIST standard by using the "substitution method". This method is similar to the procedures used for inductance standards calibration, and is described in detail in [15]. The Type-12 bridge is used to measure the NIST standards (for updating data bases from which predicted values of NIST standards are derived), and to calibrate customers' standards at frequencies other than $1 \mathrm{kHz}$. From three to five years of data on NIST standards at $1 \mathrm{kHz}$, the standard uncertainties of the predicted values of both two- and three-terminal measurements of NIST standards, $s_{\mathrm{pd}}$, are estimated to be between $10 \mathrm{ppm}$ and $25 \mathrm{ppm}$, which are included in the Tables $16 \mathrm{a}$ and $16 \mathrm{~b}$. 
Similar measurements have also been performed on four NIST standards at frequencies of $100 \mathrm{~Hz}$ and $10 \mathrm{kHz}$, and standard uncertainties of their predicted values are also given in the Tables 16a and $16 \mathrm{~b}$. The Type- 12 bridge is employed to perform measurements on mica capacitors with nominal values other than these four values at frequencies other than $1 \mathrm{kHz}$.

Tables $16 \mathrm{a}$ and $16 \mathrm{~b}$ provide summaries of the uncertainty components of Type A evaluation of standard uncertainties for the Type-12 bridge in measuring two-terminal and three-terminal mica dielectric capacitors, respectively, at frequencies of $100 \mathrm{~Hz}, 1 \mathrm{kHz}$, and $10 \mathrm{kHz}$. The Type A standard uncertainties for capacitance measurements using the Type-12 system are defined as the RSS of these components $\left(s_{\mathrm{rm}}, s_{\mathrm{tm}}\right.$, and $\left.s_{\mathrm{pd}}\right)$, and also are included in Tables 16a and 16b.

\subsection{Expanded Uncertainty for Capacitance Measurement Using the Type-12 System}

The expanded uncertainty for each nominal value of mica capacitor is calculated from both Type A and Type $\mathrm{B}$ components of uncertainty with a coverage factor of $k=2[2]$. Tables $17 \mathrm{a}$ and $17 \mathrm{~b}$ give the expanded and assigned total uncertainties for two-terminal and three-terminal capacitance measurements, respectively, using the Type- 12 system.

\subsection{Type B Standard Uncertainty of Conductance Measurements}

The Type-12 bridge, which has a conductance standard as well as mica and air capacitance standards, was designed to be direct-reading for capacitance and conductance. The analysis of the uncertainties in conductance measurements is based on considerations taken into account by the designers of the Type-12 bridge [14].

During measurements, both capacitance and conductance dials are adjusted to obtain a balance from which to determine the capacitance and conductance values of the unknown capacitor. As shown in Fig. 5a, the conductance standard, $\mathbf{G}_{\mathbf{S}}$, of the Type-12 bridge consists of two decades with ten $100 \mu \mathrm{S}$ steps, and ten $10 \mu \mathrm{S}$ steps, plus a continuously variable standard with a range of $-1 \mu \mathrm{S}$ to $11 \mu \mathrm{S}$. Similar to the internal air capacitors, $\mathbf{G}_{\mathbf{s}}$, is a differential-type standard, independently connected to arms $\mathrm{AD}$ and $\mathrm{CD}$ such that the sum of the conductance in both arms is a constant. There is a divider resistor, $\mathbf{K}_{\mathbf{g}}$, which serves as a range shifter, so that the reading of the conductance standard can be divided by $1,10,100,1000$, or 10000 . Specifications and operational procedures for the conductance standard of the Type-12 bridge are described in detail by Wilhelm [14]. Figure 11 is a simplified diagram of the Type- 12 bridge including the conductance components in each arm, where $\left(G_{\mathrm{a}} / K_{\mathrm{g}}\right)$ and $\left(G_{\mathrm{c}} / K_{\mathrm{g}}\right)$ are effective conductance adjustments to arm $\mathrm{AD}$ and arm $\mathrm{CD}$, respectively, and the quantity of $\left(G_{\mathrm{a}}+G_{\mathrm{c}}\right)$ is equal to a constant. $G_{\mathrm{S}}$ provides readings in both decades and the variable dial to cover the required range and keeps the sum of $G_{\mathrm{a}}$ and $G_{\mathrm{c}}$ a constant. Equations used to calculate the conductance of unknown capacitors are similar to those used to calculate capacitance with $C_{\mathrm{m}}, C_{\mathrm{r} 1}$, and $C_{\mathrm{r} 2}$ being replaced by $G_{\mathrm{m}},\left(G_{\mathrm{r} 1} / K_{\mathrm{g}}\right)$, and $\left(G_{\mathrm{r} 2} / K_{\mathrm{g}}\right)$, respectively. For example, in the two- terminal high-capacitance measurements, from Eq. (60), the conductance value, $G_{\mathrm{X}}$, of the unknown capacitor $\mathbf{C}_{\mathbf{X}}$, is calculated from the two balances as:

$$
G_{\mathrm{x}}=G_{\mathrm{m}}+\left(G_{\mathrm{r} 1}-G_{\mathrm{r} 2}\right) / K_{\mathrm{g}},
$$


where $G_{\mathrm{m}}$ is the conductance of the internal mica capacitors with $\mathbf{C}_{\mathbf{X}}$ connected to arm CD, $G_{\mathrm{r} 1}$ is the conductance dial readings without connecting $\mathbf{C}_{\mathbf{X}}$,

$G_{\mathrm{r} 2}$ is the conductance dial readings with $\mathrm{C}_{\mathrm{X}}$ connected to arm $\mathrm{CD}$, and $K_{\mathrm{g}}$ is the divider setting.

For the cases where mica capacitance dials are not used to perform conductance measurements, the corresponding term of $G_{\mathrm{m}}$ is equal to zero.

In general, the Type-12 bridge is used for high-Q capacitance measurements, and conductance is the minor component. Therefore, the uncertainty analysis of conductance measurement for each nominal value of mica capacitor is based on a general measurement procedure for both two- and three-terminal measurements at frequencies of $1 \mathrm{kHz}, 100 \mathrm{~Hz}$, and $10 \mathrm{kHz}$. There are five components included in the Type B evaluation of standard uncertainty of conductance measurements. These are discussed in the following sections.

\subsubsection{Conductance Standard}

According to [13], the conductance standard, which was devised by Young [16], has a deviation of $\pm 0.2 \%$ from its nominal value. Since there are two balances required for most measurements except for an unknown $C_{\mathrm{X}}=1 \mu \mathrm{F}$, which required four balances, the maximum bounds of error due to the limit of accuracy of the conductance standard are estimated to be:

$$
\begin{array}{lll} 
\pm e_{\text {gs }}= \pm 0.002(2)^{(1 / 2)} G_{\mathrm{S}} & \mu \mathrm{S} & \left(\text { for } C_{\mathrm{x}}<1 \mu \mathrm{F}\right), \text { and } \\
\pm e_{\text {gs }}= \pm 0.002(4)^{(1 / 2)} G_{\mathrm{S}} & \mu \mathrm{S} & \left(\text { for } C_{\mathbf{x}}=1 \mu \mathrm{F}\right),
\end{array}
$$

where $\pm e_{\mathrm{gs}}$ are the maximum bounds of error in conductance measurements due to the limit of accuracy in the conductance standard, $G_{\mathrm{S}}$ (in $\mu \mathrm{S}$ ). Accordingly, the uncertainties in conductance standards are expressed as:

$$
\begin{array}{lll}
s_{\text {gS }}=0.0016 G_{\mathrm{S}} & \mu \mathrm{S} & \left(\text { for } C_{\mathbf{x}}<1 \mu \mathrm{F}\right), \text { and } \\
s_{\text {gS }}=0.0023 G_{\mathrm{S}} & \mu \mathrm{S} & \left(\text { for } C_{\mathbf{x}}=1 \mu \mathrm{F}\right),
\end{array}
$$

where $s_{\mathrm{gS}}$ are the standard uncertainties due to the limit of accuracy in the conductance standard, $G_{\mathrm{S}}($ in $\mu \mathrm{S})$.

According to the conductance values of the check standards, the values of $s_{\mathrm{gs}}$ for each nominal value of capacitor at frequencies of $100 \mathrm{~Hz}, 1 \mathrm{kHz}$, and $10 \mathrm{kHz}$ in the two-terminal and three-terminal configurations are estimated and included in Tables $18 \mathrm{a}$ and $18 \mathrm{~b}$, respectively.

\subsubsection{Contact Resistance}

The contact resistance in the capacitance standard decade switches was estimated to be $0.005 \Omega$ [14]. 
This resistance is considered as being in series with the internal capacitance of the decade switches. Since there are two or more balances required for each measurement, and results are calculated from the difference of these readings, the maximum bounds of error for each nominal value of $C_{\mathbf{X}}$ are estimated from the difference of the contact resistance of each balance as:

$$
\pm e_{\mathrm{gr}}= \pm \omega^{2} C_{\mathrm{x}}^{2}\left(R_{\mathrm{r} 1}-R_{\mathrm{r} 2}\right)
$$

where $\pm e_{\mathrm{gr}}$ are the maximum bounds of error due to contact resistance, and $R_{\mathrm{r} 1}$ and $R_{\mathrm{r} 2}$ are contact resistance in the capacitance decade switches at the first and second balances, respectively.

Assuming the differences between $R_{\mathrm{r} 1}$ and $R_{\mathrm{r} 2}$ are less than $0.002 \Omega$, Eq. (89) can be expressed as:

$$
\pm e_{\mathrm{gr}}= \pm 0.08 f^{2} C_{\mathrm{x}}{ }^{2}
$$

Accordingly, the standard uncertainty in contact resistance, $s_{\mathrm{gr}}$, is estimated as:

$$
s_{\mathrm{gr}}=0.046 f^{2} C_{\mathbf{x}}{ }^{2}
$$

The values of $s_{\mathrm{gr}}$ for each nominal value of capacitor at frequencies of $100 \mathrm{~Hz}, 1 \mathrm{kHz}$, and $10 \mathrm{kHz}$ in the two-terminal and three-terminal configurations are included in Tables 18a and 18b, respectively.

\subsubsection{Conductance Potentiometer}

According to [14], the limited resolution of the conductance potentiometer has an error in reading the continuous adjusted dial of $\pm 0.1 \mathrm{uS}$, plus $\pm 0.1 \mu \mathrm{S}$ in calibration, all divided by the conductance divider $\boldsymbol{K}_{\mathbf{g}}$. Accordingly, the standard uncertainty in conductance measurements as well as in conductance calibrations due to the limited resolution of the conductance potentiometer is estimated to be $0.058 \mu \mathrm{S}$. When two (or four) balances are needed for routine measurements the combined uncertainty, defined as the RSS of the above three (or five) terms, (two (or four) in measurements and one in calibration, all are $0.058 \mu \mathrm{S}$ ), is expressed as:

$$
\begin{array}{llll}
s_{\text {gp }}=0.10 / K_{\mathrm{g}} & \mu \mathrm{S}, & & \left(\text { for } C_{\mathrm{x}}<1 \mu \mathrm{F}\right), \text { and } \\
s_{\text {gp }}=0.13 / K_{\mathrm{g}} & \mu \mathrm{S}, & & \left(\text { for } C_{\mathbf{x}}=1 \mu \mathrm{F}\right),
\end{array}
$$

where $s_{\mathrm{gp}}$ is the standard uncertainty in conductance potentiometer, due to its limited resolution, and $K_{\mathrm{g}}$ is the setting of the conductance divider.

According to the conductance divider, $\boldsymbol{K}_{\mathrm{g}}$, being used in measurements, the values of $s_{\mathrm{gp}}$ for each nominal value of capacitors at frequencies of $100 \mathrm{~Hz}, 1 \mathrm{kHz}$, and $10 \mathrm{kHz}$ in the two-terminal and three-terminal configurations are estimated and included in Tables $18 \mathrm{a}$ and $18 \mathrm{~b}$, respectively. 


\subsubsection{Residual Conductance}

According to [14], the maximum bounds of error due to the limit of resolution in residual conductance in arms $\mathrm{AD}$ and $\mathrm{CD}$ are functions of frequency and given as:

$$
\pm e_{\text {gc }}= \pm(0.02) f / K_{\mathrm{g}} \quad \mu \mathrm{S},
$$

where $\pm e_{\text {gc }}$ are the maximum bounds of error due to the residual conductance. Accordingly,

$$
s_{\mathrm{gc}}=(0.0115) f / K_{\mathrm{g}} \quad \mu \mathrm{S},
$$

where $s_{\mathrm{gc}}$ is the standard uncertainty due to the residual conductance,

$f$ is the applied frequency in $\mathrm{kHz}$, and

$K_{\mathrm{g}}$ is the setting of the conductance divider.

The values of $s_{\mathrm{gc}}$ for each nominal value of capacitor at frequencies of $100 \mathrm{~Hz}, 1 \mathrm{kHz}$, and $10 \mathrm{kHz}$ in the two-terminal and three-terminal configurations are included in Tables 18a and 18b, respectively.

\subsubsection{Dial Corrections}

Data and analyses of conductance corrections of internal mica dial capacitors for the Type-12 bridge at frequencies of $100 \mathrm{~Hz}, 1 \mathrm{kHz}$, and $10 \mathrm{kHz}$ are given in Appendix C. As discussed in section 4.2.2, the standard uncertainty of the dial corrections is estimated from the predicted values of the dials being used during measurements, depending on the nominal value of the capacitor being measured. The standard uncertainty in conductance corrections of the internal mica capacitors, $s_{\mathrm{gm}}$, for the twoterminal and three-terminal measurements of capacitors $C_{\mathbf{X}} \geq 0.01 \mu \mathrm{F}$ at frequencies of $100 \mathrm{~Hz}$, $1 \mathrm{kHz}$, and $10 \mathrm{kHz}$ are estimated and given in Table $18 \mathrm{a}$ and $18 \mathrm{~b}$, respectively.

The Type B standard uncertainties for the Type- 12 bridge measurement of conductance at frequencies of $1 \mathrm{kHz}, 100 \mathrm{~Hz}$, and $10 \mathrm{kHz}$, defined as the RSS of the above uncertainties, are also given in Tables $18 \mathrm{a}$ and $18 \mathrm{~b}$.

\subsection{Type A Standard Uncertainty of Conductance Measurements}

The evaluation of the Type A standard uncertainty for the Type-12 system in making conductance measurements is similar to that in making capacitance measurements. It is based on the repeatability in measurement results, the variation of conductance corrections of the capacitance dials during measurements, and the stability of the NIST conductance standards used with an impedance meter as a comparator. An analysis of each term is given in the following sections. 


\subsubsection{Repeatability of Measurements}

As pointed out in section 4.4.1 for repeatability of capacitance measurements, the range of a given "limit" for conductance measurements is also contained in NIST internal documents for each nominal value of capacitor at each frequency. Accordingly, the maximum bounds of error of individual capacitor are obtained, and the standard uncertainty in conductance is estimated as:

$$
s_{\text {grm }}=\text { (maximum bounds of error) } / \sqrt{3} \mu \mathrm{S},
$$

where $s_{\text {grm }}$ is the standard uncertainty due to repeatability of results of measurements of conductance and is given in Table 19a and 19b.

\subsubsection{Stabilities of NIST Standards}

Using the same method as in section 4.4.4, conductance values of unknown capacitors measured at $100 \mathrm{~Hz}, 1 \mathrm{kHz}$, and $10 \mathrm{kHz}$ can be calculated by utilizing the "substitution method" [15] from data obtained by employing an impedance meter as a comparator. The uncertainties of the predicted values of conductance in unknown capacitors at a frequency of $100 \mathrm{~Hz}, 1 \mathrm{kHz}$, and $10 \mathrm{kHz}, s_{\mathrm{gpd}}$ are given in Tables 19a and 19b as well. The "substitution method" is not used on some capacitors at frequencies other than $1 \mathrm{kHz}$; therefore, these uncertainties are not applied for those frequencies.

The Type A standard uncertainty of conductance measurements is defined as the RSS of $s_{\text {grm }}$ and $\mathrm{s}_{\mathrm{gpd}}$, and these are all summarized in Table 19a and $19 \mathrm{~b}$.

4.8 Expanded Uncertainty for Conductance Measurement Using the Type-12 System

The expanded uncertainties of conductance measurements (for each nominal value of mica capacitor) are calculated from both Type A and Type B standard uncertainties with a coverage factor of $k=2$ [2], and the results are provided in Table $19 \mathrm{a}$ and $19 \mathrm{~b}$ for the two-terminal and three-terminal configurations, respectively.

\section{CONCLUSION}

The revised uncertainties of NIST capacitance calibrations have been established, according to NIST's policy on expression of uncertainty [2] and on the modification of measurement procedures in Impedance Calibration Laboratory. Numerical results are also included in the NIST Calibration Services Users Guide (SP 250, 1998 edition) [17]. 


\section{ACKNOWLEDGMENTS}

The author would like to acknowledge the members of the MCOM Subcommittee for Capacitance Calibration Services; Carroll Croarkin (Chairman), Barry Bell, Norman Belecki, Andrew Koffman, and John Mayo-Wells for their valuable suggestions and contributions of the analysis. Special thanks to Robert Palm for his support in the graphs of the manuscript.

\section{REFERENCES}

[1] R. D. Cutkosky, "Capacitance Bridge -- NBS Type 2," National Bureau of Standards Report 7103, March, 1963.

[2] B. N. Taylor and C. E. Kuyatt, "Guidelines for Evaluating and Expressing the Uncertainty of NIST Measurement Results," Natl. Inst. Stand. Technol. Technical Note 1297, September, 1994.

[3] International Bureau of Weights and Measures (BIPM) Working Group on the Statement of Uncertainties, Metrologia, vol. 17, pp. 73-74, 1981.

[4] Y. M. Chang and S. B. Tillett, "NIST Calibration Service for Capacitance Standards at Low Frequencies," Natl. Inst. Stand. Technol. Special Publication 250 Series (NIST SP250-47), April, 1998.

[5] R. D. Cutkosky and J. Q. Shields, "The Precision Measurement of Transformer Ratios," IRE Trans. Instrum., vol. I-9, pp. 243-250, September, 1960.

[6] R. D. Cutkosky and L. H. Lee, "Improved Ten-Picofarad Fused Silica Dielectric Capacitor," J. Res. Nat. Bur. Stand., vol. 69C (Eng. and Instr.) no. 3, pp. 173-179, July-September, 1965.

[7] "A Highly Stable Reference Standard Capacitor, "The General Radio Experimenter, vol. 37, no. 8, August, 1963.

[8] J. Q. Shields, "Voltage Dependence of Precision Air Capacitors," J. Res. Nat. Bur. Stand., vol. 69C (Eng. and Instr.), no. 4, pp. 265-274, Oct.-Dec. 1965.

[9] Y. M. Chang and S. B. Tillett, "Recent Developments in the Capacitance Calibration Services at the National Institute of Standards and Technology," Proceedings of NCSL, July, 1998.

[10] "General Radio Catalog 73" General Radio Company, 1973. 
[11] "Capacitance Standards with Precision Connectors," The General Radio Experimenter, vol. 41, no. 9, September, 1967.

[12] "More Coaxial Capacitance Standards," The General Radio Experimenter, vol. 42, no. 5, May, 1968.

[13] W. D. Voelker, "An Improved Capacitance Bridge for Precision Measurements," Bell Labs Record, vol. 20, pp. 133-137, Jan., 1942.

[14] H. T. Wilhelm, "The Type-12 Capacitance Bridge," Bell Labs Memorandum, MM 70-47359, Case 70052-213, File 37954-15, May, 1970.

[15] Y. M. Chang and S. B. Tillett, "Calibration Procedures for Inductance Standards using a Commercial Impedance Meter as a Comparator," Natl. Inst. Stand. Internal Report (NISTIR) 4466, Nov., 1990.

[16] C. H. Young, Conductance Standard, U. S. Patent 2-326-274.

[17] "NIST Calibration Services Users Guide," Natl. Inst. Stand. Technol. Special Publication 250, 1998 edition, U. S. Government Printing Office, Washington, DC 20402. 
Table 1. Dial Corrections of the Type-2 Bridge

[ All values are in $\left(10^{-6} \mathrm{pF}\right)$, except nominal values of dials ]

\begin{tabular}{|c|c|c|c|c|c|c|c|c|}
\hline Dial No. & 1 & 2 & 3 & 4 & 5 & 6 & 7 & 8 \\
\hline $\begin{array}{c}\text { Nominal } \\
\text { Value }(\mathrm{pF})\end{array}$ & 100 & 10 & 1 & 0.1 & 0.01 & 0.001 & 0.0001 & 0.00001 \\
\hline $4 / 25 / 94$ & 5160.1 & -890.59 & 3.741 & -11.426 & 1.657 & 0.566 & 0.357 & 0.336 \\
\hline $5 / 27 / 94$ & 5169.1 & -870.49 & 7.951 & -11.405 & 1.560 & 0.556 & 0.356 & 0.336 \\
\hline $6 / 1 / 94$ & 5903.3 & -756.47 & 13.353 & -10.365 & 1.664 & 0.566 & 0.357 & 0.336 \\
\hline $8 / 4 / 94$ & 7587.3 & -478.27 & 34.973 & -7.803 & 1.900 & 0.592 & 0.359 & 0.436 \\
\hline $8 / 19 / 94$ & 8078.1 & -372.19 & 36.181 & -6.982 & 2.002 & 0.600 & 0.360 & 0.436 \\
\hline $9 / 16 / 94$ & 6801.0 & -634.24 & 39.876 & -8.712 & 1.829 & 0.583 & 0.358 & 0.336 \\
\hline $10 / 31 / 94$ & 7270.2 & -517.18 & 36.682 & -8.132 & 1.887 & 0.589 & 0.459 & 0.446 \\
\hline $11 / 28 / 94$ & 6932.2 & -549.18 & 22.982 & -8.702 & 1.830 & 0.583 & 0.358 & 0.336 \\
\hline $12 / 30 / 94$ & 7051.8 & -620.02 & 23.898 & -8.910 & 1.929 & 0.591 & 0.459 & 0.446 \\
\hline $1 / 17 / 95$ & 6209.7 & -733.73 & 11.127 & -10.087 & 1.691 & 0.569 & 0.457 & 0.446 \\
\hline $2 / 27 / 95$ & 6769.5 & -692.15 & 14.485 & -9.752 & 1.725 & 0.572 & 0.457 & 0.446 \\
\hline $3 / 17 / 95$ & 6174.9 & -738.51 & 7.149 & -9.985 & 1.801 & 0.680 & 0.468 & 0.447 \\
\hline $4 / 28 / 95$ & 6117.6 & -742.64 & 7.235 & -10.276 & 1.672 & 0.567 & 0.357 & 0.436 \\
\hline $5 / 19 / 95$ & 6442.8 & -680.12 & 7.688 & -9.731 & 1.727 & 0.573 & 0.357 & 0.436 \\
\hline Mean Value & 6547.7 & -662.56 & 19.094 & -9.448 & 1.777 & 0.585 & 0.394 & 0.404 \\
\hline $\begin{array}{l}\text { Standard } \\
\text { Deviation }\end{array}$ & 839.0 & 146.07 & 13.052 & 1.302 & 0.126 & 0.030 & 0.051 & 0.053 \\
\hline
\end{tabular}


Table 2. Standard Uncertainties in Dial Corrections of the Type-2 Bridge

[ All values are in $\left(10^{-6} \mathrm{pF}\right)$, except nominal values of dials ]

\begin{tabular}{|c|c|c|c|c|c|c|c|c|c|c|}
\hline Dial No. & 3 & & 4 & 5 & 6 & 7 & 8 & & 2 & 1 \\
\hline $\begin{array}{c}\text { Nominal } \\
\text { Value } C_{\mathrm{i}}(\mathrm{pF})\end{array}$ & 1 & & 0.1 & 0.01 & 0.001 & 1E-04 & $1 \mathrm{E}-05$ & & 10 & 100 \\
\hline $\begin{array}{l}\text { Mean Value } \\
\text { of Dial } \\
\text { Correction }\end{array}$ & 19.094 & & -9.448 & 1.777 & 0.585 & 0.394 & 0.404 & & -662.56 & 6547.69 \\
\hline Standard Dev. & 13.052 & & 1.302 & 0.126 & 0.030 & 0.051 & 0.053 & & 146.07 & 839.0 \\
\hline $\begin{array}{c}\text { No. of } \\
\text { Dials Used }\end{array}$ & 3 & & 3 & 3 & 1 & 1 & 1 & & 4 & 5 \\
\hline $\begin{array}{c}\text { Components of } \\
\text { Standard } \\
\text { Uncertainty }\end{array}$ & & & & & & & & & & \\
\hline $\begin{array}{c}(0.1) s_{\mathrm{Ra}} \\
2 \quad 2\end{array}$ & 0.0043 & $\begin{array}{c}(0.1) s_{\mathrm{Ra}} \\
2 \quad 2\end{array}$ & 4E-04 & $4 \mathrm{E}-05$ & $4 \mathrm{E}-06$ & $4 \mathrm{E}-07$ & $4 \mathrm{E}-08$ & $(10) s_{\mathrm{Ra}}$ & 4.3 & 43 \\
\hline$\left[\Sigma\left(r_{k}^{2} s_{k}^{2}\right)\right]^{(1 / 2)}$ & 0.08 & {$\left[\Sigma\left(r_{k}^{2} s_{k}^{2}\right)\right]^{(1 / 2)}$} & 0.08 & 0.08 & 0.05 & 0.05 & 0.05 & $10\left[\Sigma\left(r_{k}^{2} s_{k}^{2}\right)\right]^{(1 / 2)}$ & 1.48 & 13.1 \\
\hline$s_{1}$ & 0.2 & $s_{1}$ & 0.2 & 0.2 & 0.2 & 0.2 & 0.2 & $s_{1}$ & 0.2 & 0.2 \\
\hline$(0.1) s_{\mathrm{s}}$ & 0.75 & $(0.1) s_{(i-1)}$ & 0.100 & 0.025 & 0.023 & 0.022 & 0.022 & $(10) s_{(i+1)}$ & 10 & 130 \\
\hline SSQ & 0.609 & & 0.056 & 0.047 & 0.043 & 0.043 & 0.043 & & 120.72 & 18920.7 \\
\hline RSS & 0.780 & & 0.237 & 0.217 & 0.207 & 0.207 & 0.207 & & 10.99 & 137.6 \\
\hline $\begin{array}{c}\text { Assigned } \\
\text { Uncertainty }\left(s_{i}\right)\end{array}$ & 1 & & 0.25 & 0.23 & 0.22 & 0.22 & 0.22 & & 13 & 150 \\
\hline
\end{tabular}

Remarks :

$s_{\mathrm{Ra}}: \quad$ Standard uncertainty of the 1:10 ratio

$\left[\Sigma\left(r_{k}^{2} s_{k}^{2}\right)\right]^{(1 / 2)}: \quad$ Standard Deviation of the dial corrections for the $k^{\text {th }}$ dial of reading $r_{k}$

$s_{1}: \quad$ Standard uncertainty due to the interpolation in last dial

$s_{\mathrm{S}}: \quad$ Uncertainty of reference standard 
Table 3. Combined Uncertainties in Dial Corrections Using the Type-2 Bridge to Measure Capacitors of Nominal Values of $1 \mathrm{pF}, 10 \mathrm{pF}, 100 \mathrm{pF}$, and $1000 \mathrm{pF}$

\begin{tabular}{|c|cccc|}
\hline $\begin{array}{c}\text { Nominal Value } \\
\text { of Capacitor (pF) }\end{array}$ & 1 & 10 & 100 & 1000 \\
\hline $\begin{array}{c}\text { No. of Dials Used } \\
\text { Routinely }\end{array}$ & 4 & 5 & 5 & 6 \\
\hline $\begin{array}{c}\text { Assigned Combined } \\
\text { Uncertainty }\end{array}$ & 0.45 & 0.51 & 0.51 & 1.12 \\
$s_{\mathrm{cd}}\left(10^{-6} \mathrm{pF}\right) *$ \\
$s_{\mathrm{cd}}(\mathrm{ppm})$
\end{tabular}

Remark :

* From number of dials used to perform measurements, as given in the following table:

\begin{tabular}{|c|cccccccc|}
\hline No.of dials used & 1 & 2 & 3 & 4 & 5 & 6 & 7 & 8 \\
\hline Dial No. & 8 & $7 \& 8$ & 6 to 8 & 5 to 8 & 4 to 8 & 3 to 8 & 2 to 8 & 1 to 8 \\
\hline $\begin{array}{c}\text { Assigned Combined } \\
\text { Uncertainty } \\
s_{\mathrm{cd}}\left(10^{-6} \mathrm{pF}\right)\end{array}$ & 0.22 & 0.31 & 0.38 & 0.45 & 0.51 & 1.12 & 13.05 & 150.57 \\
\hline
\end{tabular}


Table 4. Uncertainties in Lead Impedance Using the Type-2 Bridge to Measure Capacitors at Frequencies of $100 \mathrm{~Hz}, 400 \mathrm{~Hz}$, and $1 \mathrm{kHz}$

\begin{tabular}{|c|ccc|}
\hline Frequency & $1 \mathrm{kHz}$ & $400 \mathrm{~Hz}$ & $100 \mathrm{~Hz}$ \\
\hline $\begin{array}{c}\text { Nominal Value } \\
\text { of Capacitor }(\mathrm{pF})\end{array}$ & $\begin{array}{c}\Delta C / C \\
(\mathrm{ppm})\end{array}$ & $\begin{array}{c}\Delta C / C \\
(\mathrm{ppm})\end{array}$ & $\begin{array}{c}\Delta C / C \\
(\mathrm{ppm})\end{array}$ \\
\hline & & & \\
1 & $<<0.0002$ & $<<0.0002$ & $<<0.0002$ \\
10 & 0.0002 & $<<0.0002$ & $<<0.0002$ \\
100 & 0.00197 & 0.00032 & $<<0.0002$ \\
1000 & 0.0197 & 0.0032 & 0.0002 \\
10000 & 0.197 & 0.032 & 0.00197 \\
\hline
\end{tabular}




\begin{tabular}{|c|c|c|c|c|c|c|c|c|c|c|c|c|}
\hline & & 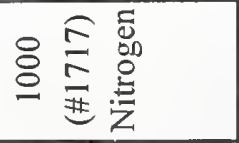 & 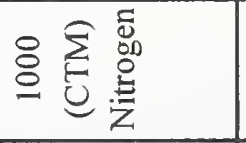 & $\stackrel{\overparen{\Xi}}{\ddot{\theta}}$ & & $\mid \begin{array}{l}n \\
8 \\
0 \\
0\end{array}$ & $\begin{array}{l}\overline{8} \\
\overline{8} \\
0\end{array}$ & & 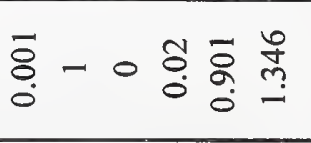 & $\stackrel{0}{m}$ & $\stackrel{n}{m}$ & \\
\hline & & 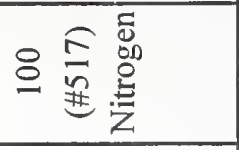 & 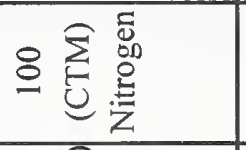 & 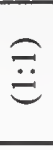 & & $\mid \begin{array}{l}n \\
0 \\
0 \\
0\end{array}$ & 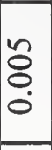 & & 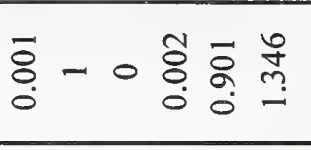 & 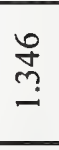 & $\dddot{n}$ & \\
\hline 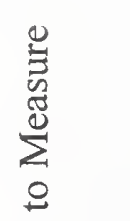 & & 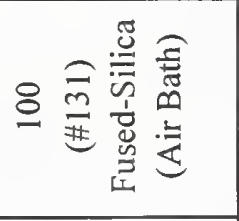 & 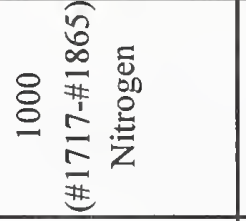 & $\stackrel{\overbrace \ddot{\theta}}{\ddot{\theta}}$ & & $\underset{\tilde{O}}{\stackrel{m}{0}}$ & ஜे & & ¿े & $\frac{n}{5}$ & $\stackrel{n}{\circ}$ & 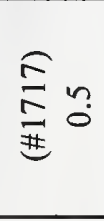 \\
\hline 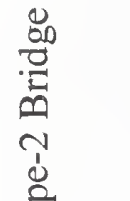 & 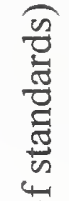 & 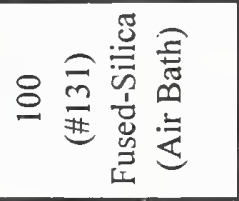 & 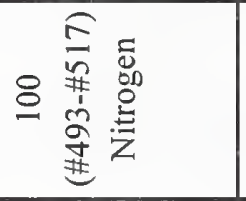 & $\stackrel{\overbrace{}}{\rightleftharpoons}$ & & $\mid \begin{array}{l}n \\
0 \\
0 \\
0\end{array}$ & $\begin{array}{l}n \\
0 \\
0 \\
0\end{array}$ & & 兽 & $\frac{⿱}{*}$ & $\stackrel{n}{0}$ & 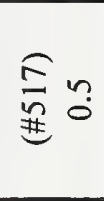 \\
\hline 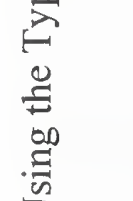 & 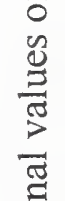 & 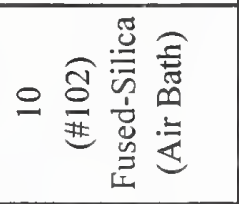 & 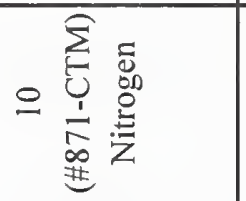 & $\stackrel{\overparen{\nexists}}{\ddot{\theta}}$ & & $\mid \begin{array}{l}n \\
0 \\
0 \\
0\end{array}$ & $\begin{array}{l}\bar{n} \\
0 \\
0\end{array}$ & & 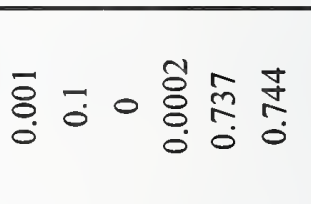 & $\frac{\mathfrak{n}}{i}$ & $\stackrel{n}{0}$ & \\
\hline 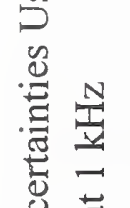 & 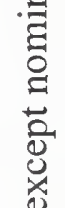 & 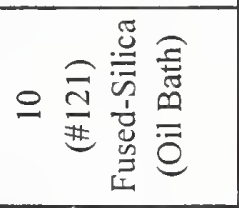 & 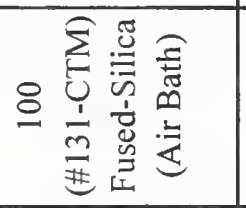 & $\stackrel{\overbrace{}}{\ddot{\theta}}$ & & 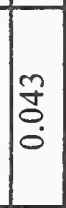 & $\ddot{n}$ & & 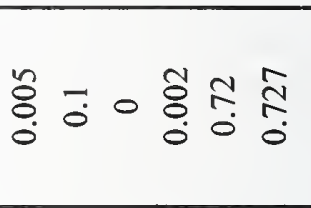 & 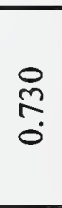 & $\stackrel{m}{0}$ & $\stackrel{\vec{m}}{\#}$ \\
\hline 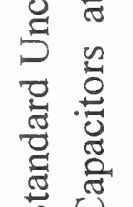 & हू & 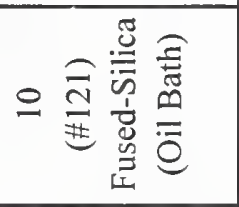 & 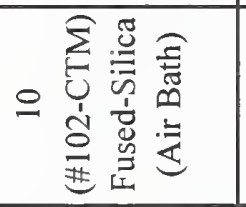 & $\stackrel{\overparen{\nexists}}{\ddot{\Xi}}$ & & $\mid \begin{array}{l}n \\
8 \\
8 \\
0\end{array}$ & 点 & & 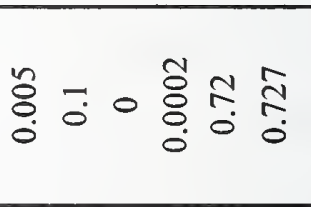 & $\stackrel{\grave{1}}{0}$ & $\stackrel{m}{0}$ & Ð \\
\hline $\begin{array}{ll}\infty & 0 \\
0 & 0 \\
0 & \frac{0}{0} \\
0 & \frac{0}{0} \\
0 & 0 \\
0 & 0 \\
0 & 0\end{array}$ & $\frac{0}{\frac{2}{3}}$ & 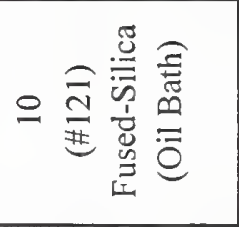 & 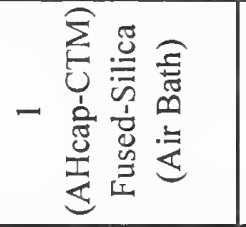 & $\stackrel{0}{\stackrel{0}{\Xi}}$ & & 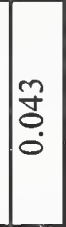 & 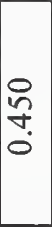 & & 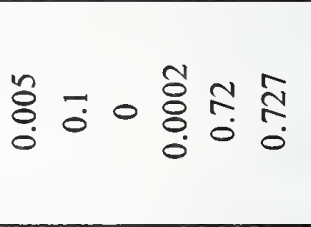 & $\begin{array}{l}\infty \\
\infty \\
\infty\end{array}$ & $\grave{0}$ & \\
\hline 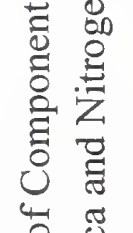 & & 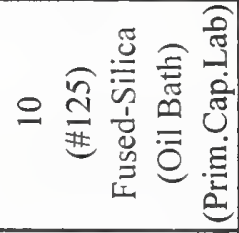 & 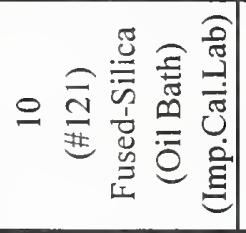 & $\stackrel{\overparen{\Xi}}{\Xi}$ & & $\mid \begin{array}{l}n \\
\delta \\
0 \\
0 \\
0\end{array}$ & $\begin{array}{l}\bar{n} \\
0 \\
0\end{array}$ & & 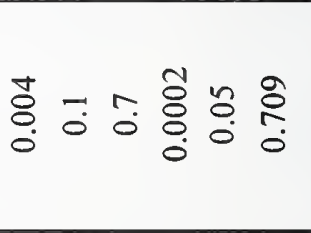 & $\bar{\nabla}$ & $\stackrel{N}{\mathfrak{0}}$ & \\
\hline 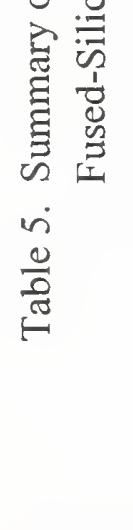 & & 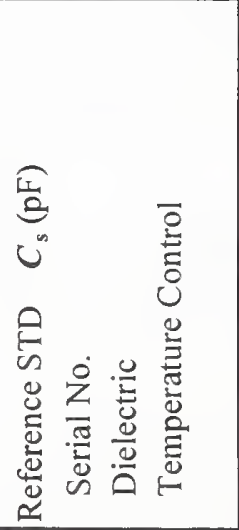 & 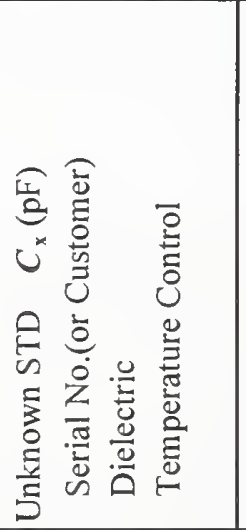 & $\underbrace{\tilde{u}^{\infty}}$ & 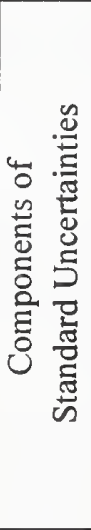 & 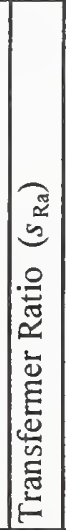 & 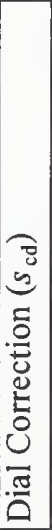 & 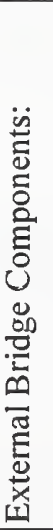 & 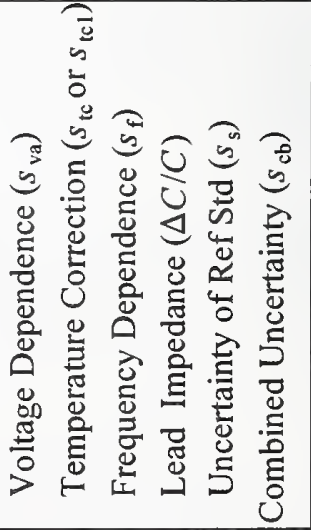 & 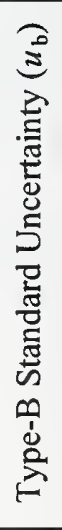 & 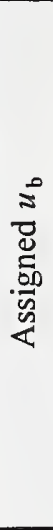 & 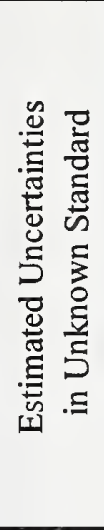 \\
\hline
\end{tabular}




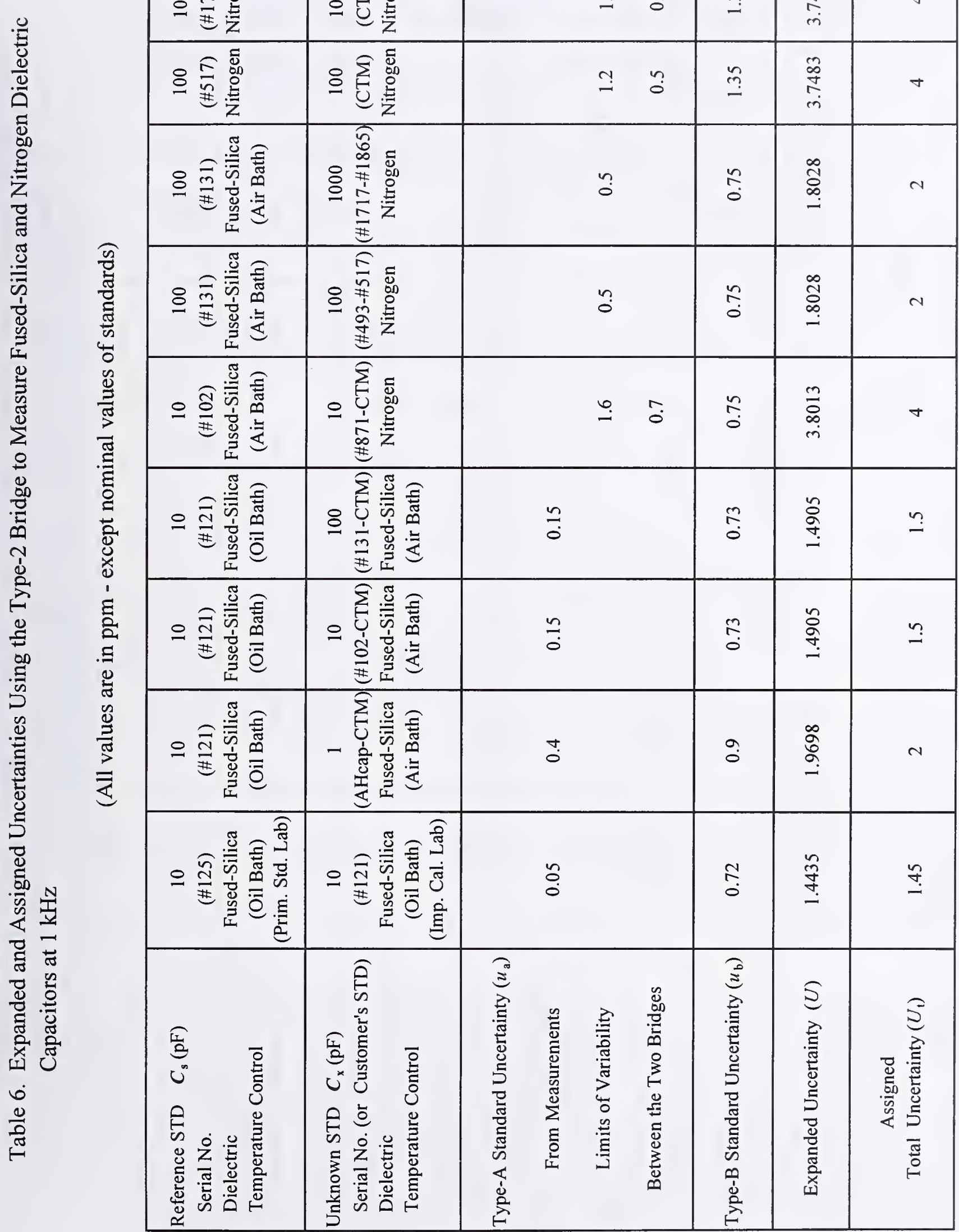




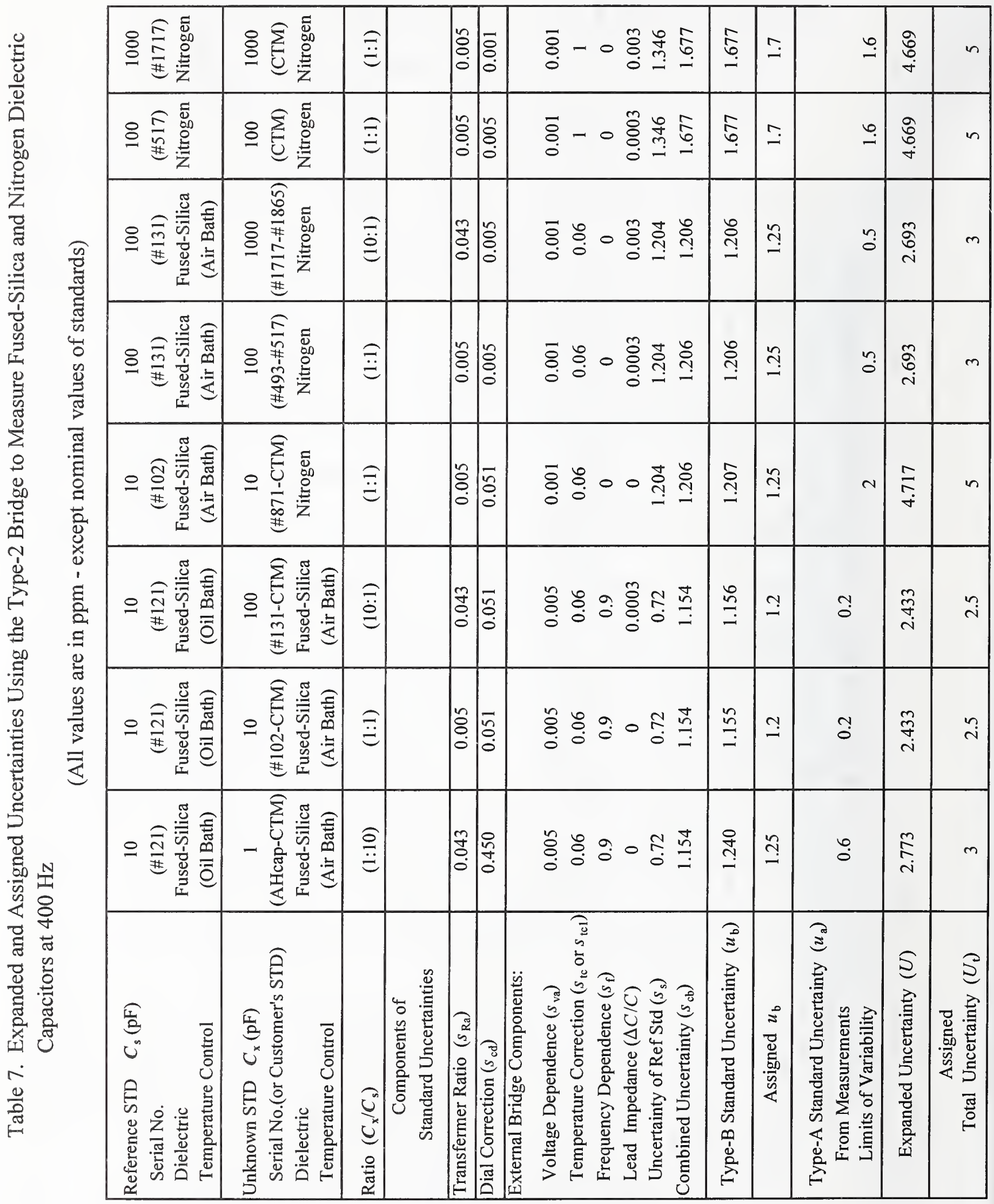


Table 9. Expanded and Assigned Total Uncertainties Using the Type-2 Bridge to Measure Three-Terminal Air Capacitors at Frequencies of $400 \mathrm{~Hz}$ and $1 \mathrm{kHz}$

(All values are in ppm, except nominal values of capacitors)

\begin{tabular}{|c|c|c|c|c|c|}
\hline $\begin{array}{l}\text { Nominal Value of } \\
\text { Capacitors }(\mathrm{pF})\end{array}$ & 0.001 & 0.01 & 0.1 & 1 to 1000 & 10000 \\
\hline \multicolumn{6}{|l|}{$\begin{array}{c}\text { Components of } \\
\text { Standard Uncertainties }\end{array}$} \\
\hline Temperature & 20 & 20 & 15 & 10 & 10 \\
\hline Relative Humidity & 16 & 16 & 16 & 16 & 16 \\
\hline Hysterises & 20 & 20 & 20 & 20 & 20 \\
\hline Voltage & 5 & 5 & 5 & 5 & 5 \\
\hline $\begin{array}{l}\text { Interpolation of Last Dial } \\
\qquad\left(2 \times 10^{-7} \mathrm{pF}\right)\end{array}$ & 200 & 20 & 2 & 0.2 to 0.0002 & 0.00002 \\
\hline Type B Standard Uncertainty $\left(u_{\mathrm{b}}\right)$ & 202.68 & 38.48 & 30.17 & 27.95 & 27.95 \\
\hline Assigned $u_{\mathrm{b}}$ & 210 & 40 & 32 & 30 & 30 \\
\hline Type A Standard Uncertainty $\left(u_{\mathrm{a}}\right)$ & 950 & 90 & 30 & 30 & 60 \\
\hline Expanded Uncertainty $(U)$ & 1945.87 & 196.98 & 87.73 & 84.85 & 134.16 \\
\hline $\begin{array}{c}\text { Assigned } \\
\text { Total Uncertainty }\left(U_{t}\right)\end{array}$ & 2000 & 200 & 100 & 100 & 150 \\
\hline
\end{tabular}


Table 10. Expanded and Assigned Total Uncertainties Using the Type-2 Bridge to Measure Three-Terminal Air Capacitors at $100 \mathrm{~Hz}$

(All values are in ppm, except nominal values of capacitors)

\begin{tabular}{|c|c|c|c|c|}
\hline $\begin{array}{c}\text { Nominal Value of } \\
\text { Capacitors }(\mathrm{pF})\end{array}$ & 0.01 & 0.1 & 1 & 10 to 1000 \\
\hline $\begin{array}{c}\text { Components of } \\
\text { Standard Uncertainties }\end{array}$ & 20 & 15 & 10 & 10 \\
\hline $\begin{array}{c}\text { Temperature } \\
\text { Relative Humidity } \\
\text { Hysterises }\end{array}$ & 16 & 16 & 16 & 16 \\
Voltage & 20 & 20 & 20 & 20 \\
Frequency \\
Interpolation of Last Dial \\
$\left(2 \times 10^{-6} \mathrm{pF}\right)$
\end{tabular}


Table 11. Expanded and Assigned Total Uncertainties Using the Type-2 Bridge to Measure Two-Terminal Coaxial Air Capacitors at $1 \mathrm{kHz}$

(All values are in ppm, except nominal values of capacitors)

\begin{tabular}{|c|c|c|c|c|c|c|}
\hline \multirow{2}{*}{$\begin{array}{c}\text { Nominal Value of } \\
\text { Capacitors }(\mathrm{pF})\end{array}$} & \multicolumn{5}{|c|}{ (Lower-Valued ) } & (Mid-Valued ) \\
\cline { 2 - 7 } $\begin{array}{c}\text { Components of } \\
\text { Standard Uncertainties }\end{array}$ & 1 & 2 & 5 & 10 & 20 & 50 to 1000 \\
\hline $\begin{array}{c}\text { Temperature } \\
\text { Relative Humidity }\end{array}$ & 100 & 40 & 20 & 40 & 20 & 10 \\
Hysterises & 400 & 200 & 80 & 0 & 0 & 16 \\
Voltage & 20 & 20 & 20 & 20 & 20 & 20 \\
\hline Type B Standard Uncertainty $\left(u_{\mathrm{b}}\right)$ & 412.83 & 205 & 85 & 45 & 28.72 & 27.95 \\
\hline Assigned $u_{\mathrm{b}}$ & 5 & 5 & 5 & 5 & 5 & 5 \\
\hline Assigned & 415 & 205 & 85 & 45 & 30 & 28 \\
\hline Type A Standard Uncertainty $\left(u_{\mathrm{a}}\right)$ & 35 & 35 & 35 & 20 & 20 & 10 \\
\hline Expanded Uncertainty $(U)$ & 832.95 & 415.93 & 183.85 & 98.49 & 72.11 & 59.46 \\
\hline
\end{tabular}


Table 12. Expanded and Assigned Total Uncertainties of Using the Type-2 Bridge to Measure Two-Terminal Coaxial Mica Capacitors and Open-Circuit Terminations at $1 \mathrm{kHz}$

(All values are in ppm, except nominal values of capacitors)

\begin{tabular}{|c|c|c|c|c|}
\hline & \multicolumn{2}{|c|}{ Coaxial Mica Capacitors } & \multicolumn{2}{c|}{ Open-Circuit Terminations } \\
\cline { 2 - 5 } Nominal Value of Capacitors $(\mathrm{pF})$ & 1000 & 5000 to 100000 & 0.172 & 2.67 \\
\hline $\begin{array}{c}\text { Components of } \\
\text { Standard Uncertainties }\end{array}$ & & & & \\
\hline Temperature & 5 & 15 & 150 & 150 \\
Relative Humidity & 16 & 16 & 400 & 100 \\
Hysteresis & 20 & 20 & 20 & 20 \\
Voltage & 2 & 2 & 5 & 5 \\
\hline Type B Standard Uncertainty $\left(u_{\mathrm{b}}\right)$ & 26.17 & 29.75 & 427.70 & 181.45 \\
\hline Assigned $u_{\mathrm{b}}$ & 27 & 30 & 450 & 200 \\
\hline Type A Standard Uncertainty $\left(u_{\mathrm{a}}\right)$ & 10 & 10 & 200 & 60 \\
\hline Expanded Uncertainty $(U)$ & 57.58 & 63.25 & 984.89 & 417.61 \\
\hline Assigned & 60 & 65 & 1000 & 450 \\
\hline Total Uncertainty $\left(U_{\mathrm{t}}\right)$ & & & & \\
\hline
\end{tabular}


Table 13a. Summary of Components of Standard Uncertainties in Air Capacitor Dial Corrections for Two-Terminal Measurements

\begin{tabular}{|c|c|c|c|c|c|c|c|c|c|c|}
\hline Unknown Standard $C_{\mathrm{x}}(\mu \mathrm{F})$ & 0.001 & 0.002 & 0.005 & 0.01 & 0.02 & 0.05 & 0.1 & 0.2 & 0.5 & 1.0 \\
\hline $\begin{array}{l}\text { Std Dev.of Pred.Values of } \\
\text { Dial Correction (pF) } \\
\text { Std Dev.of Pred.Values of } \\
\text { Dial Correction (ppm) }\end{array}$ & $\begin{array}{l}0.0601 \\
60.136\end{array}$ & $\begin{array}{l}0.0672 \\
33.584\end{array}$ & $\begin{array}{l}0.0759 \\
15.184\end{array}$ & $\begin{array}{l}0.0208 \\
2.085\end{array}$ & $\begin{array}{r}0.0208 \\
1.042\end{array}$ & $\begin{array}{l}0.0208 \\
0.417\end{array}$ & $\begin{array}{r}0.0208 \\
0.208\end{array}$ & $\begin{array}{l}0.0208 \\
0.104\end{array}$ & $\begin{array}{l}0.0276 \\
0.055\end{array}$ & $\begin{array}{r}0.0213 \\
0.021\end{array}$ \\
\hline $\begin{array}{c}\text { Components of } \\
\text { Standard Uncertainties (ppm) }\end{array}$ & & & & & & & & & & \\
\hline Pred.Values of Dial Corr't $\left(s_{\mathrm{dr}}\right)$ & 60.136 & 33.584 & 15.184 & 2.085 & 1.042 & 0.417 & 0.208 & 0.104 & 0.055 & 0.021 \\
\hline Temperature Variation $\left(s_{\mathrm{tp}}\right)$ & 6 & 6 & 6 & 6 & 6 & 6 & 6 & 6 & 6 & 6 \\
\hline Dial Switching $\left(s_{\mathrm{ds}}\right)$ & 6 & 3 & 1.5 & 0.6 & 0.3 & 0.15 & 0.1 & 0.05 & 0.02 & 0.01 \\
\hline Transfer Standard $\left(s_{\mathrm{tf}}\right)$ & 6 & 6 & 6 & 6 & 6 & 6 & 6 & 6 & 6 & 6 \\
\hline RSS & 61.027 & 34.769 & 17.459 & 8.758 & 8.554 & 8.497 & 8.488 & 8.486 & 8.485 & 8.485 \\
\hline $\begin{array}{l}\text { Assigned Standard Uncertainties } \\
\text { in Air Cap. Dial Corrections }\left(s_{\mathrm{rc}}\right)\end{array}$ & 62 & 35 & 18 & 9 & 9 & 9 & 9 & 9 & 9 & 9 \\
\hline
\end{tabular}


Table 13b. Summary of Components of Standard Uncertainties in Air Capacitor Dial Corrections for Three-Terminal Measurements

\begin{tabular}{|c|c|c|c|c|c|c|c|c|c|c|}
\hline Unknown Standard $C_{\mathrm{x}}(\mu \mathrm{F})$ & 0.001 & 0.002 & 0.005 & 0.01 & 0.02 & 0.05 & 0.1 & 0.2 & 0.5 & 1.0 \\
\hline $\begin{array}{l}\text { Std Dev.of Pred.Values of } \\
\text { Dial Correction (pF) } \\
\text { Std Dev.of Pred.Values of } \\
\text { Dial Correction (ppm) }\end{array}$ & $\begin{array}{l}0.0607 \\
60.744\end{array}$ & $\begin{array}{l}0.0749 \\
37.448\end{array}$ & $\begin{array}{l}0.0636 \\
12.723\end{array}$ & $\begin{array}{l}0.0224 \\
2.238\end{array}$ & $\begin{array}{l}0.0241 \\
1.205\end{array}$ & $\begin{array}{l}0.0183 \\
0.365\end{array}$ & $\begin{array}{r}0.0266 \\
0.266\end{array}$ & $\begin{array}{c}0.0191 \\
0.095\end{array}$ & $\begin{array}{r}0.0264 \\
0.053\end{array}$ & $\begin{array}{r}0.0324 \\
0.032\end{array}$ \\
\hline $\begin{array}{c}\text { Components of } \\
\text { Standard Uncertainties (ppm) }\end{array}$ & & & & & & & & & & \\
\hline Pred.Values of Dial Corr't $\left(s_{\mathrm{dr}}\right)$ & 60.744 & 37.448 & 12.723 & 2.238 & 1.205 & 0.365 & 0.266 & 0.095 & 0.053 & 0.032 \\
\hline Temperature Variation $\left(s_{\mathrm{tp}}\right)$ & 6 & 6 & 6 & 6 & 6 & 6 & 6 & 6 & 6 & 6 \\
\hline Dial Switching $\left(s_{\mathrm{ds}}\right)$ & 6 & 3 & 1.5 & 0.6 & 0.3 & 0.15 & 0.1 & 0.05 & 0.02 & 0.01 \\
\hline Transfer Standard $\left(s_{\mathrm{tf}}\right)$ & 6 & 6 & 6 & 6 & 6 & 6 & 6 & 6 & 6 & 6 \\
\hline RSS & 61.627 & 38.515 & 15.366 & 8.796 & 8.576 & 8.494 & 8.490 & 8.486 & 8.485 & 8.485 \\
\hline $\begin{array}{l}\text { Assigned Standard Uncertainties } \\
\text { in Air Cap. Dial Corrections }\left(s_{\text {rc }}\right)\end{array}$ & 62 & 39 & 16 & 9 & 9 & 9 & 9 & 9 & 9 & 9 \\
\hline
\end{tabular}


Table 14a. Summary of Components of Standard Uncertainties in Mica Capacitor Dial Corrections for Two-Terminal Measurements

\begin{tabular}{|c|c|c|c|c|c|c|c|}
\hline Unknown Standard $C_{\mathrm{x}}(\mu \mathrm{F})$ & 0.01 & 0.02 & 0.05 & 0.1 & 0.2 & 0.5 & 1.0 \\
\hline \multicolumn{8}{|l|}{$\begin{array}{c}\text { Components of } \\
\text { Standard Uncertainties (ppm) }\end{array}$} \\
\hline \multicolumn{8}{|l|}{ (At all Frequencies) } \\
\hline Temperature Variation $\left(s_{\mathrm{mp}}\right)$ & 26 & 26 & 26 & 26 & 26 & 26 & 26 \\
\hline Dial Switching $\left(s_{\mathrm{ds}}\right)$ & 0.6 & 0.3 & 0.15 & 0.1 & 0.05 & 0.02 & 0.01 \\
\hline Transfer Standard $\left(s_{\mathrm{mf}}\right)$ & 6 & 6 & 6 & 6 & 6 & 6 & 6 \\
\hline \multicolumn{8}{|l|}{$($ At Frequency $=100 \mathrm{~Hz})$} \\
\hline $\begin{array}{l}\text { Std Dev.of Pred.Values of } \\
\text { Dial Correction }(\mathrm{pF})\end{array}$ & .1585 & .2331 & .4412 & 1.0096 & 2.5727 & 7.7378 & 11.8816 \\
\hline Std Dev.of Pred.Values of & 15850 & 11655 & 8824 & 10096 & 12864 & 15.476 & 11887 \\
\hline RSS & 31.042 & 29.119 & 28.105 & 28.530 & 29.622 & 30.846 & 29.209 \\
\hline $\begin{array}{l}\text { Assigned Standard Uncertainties } \\
\text { in Mica Cap. Dial Corrections }\left(s_{\mathrm{m}}\right)\end{array}$ & 32 & 30 & 29 & 29 & 30 & 31 & 30 \\
\hline \multicolumn{8}{|l|}{ (At Frequency $=1 \mathrm{kHz}$ ) } \\
\hline $\begin{array}{l}\text { Std Dev.of Pred.Values of } \\
\text { Dial Correction }(\mathrm{pF})\end{array}$ & 0.0702 & 0.1208 & 0.3019 & 0.6075 & 1.413 & 4.4166 & 6.5888 \\
\hline $\begin{array}{l}\text { Std Dev.of Pred.Values of } \\
\text { Dial Correction }(\mathrm{ppm})\left(s_{\mathrm{mr}}\right)\end{array}$ & 7.020 & 6.040 & 6.038 & 6.075 & 7.065 & 8.833 & 6.589 \\
\hline RSS & 27.598 & 27.360 & 27.358 & 27.366 & 27.603 & 28.107 & 27.485 \\
\hline $\begin{array}{l}\text { Assigned Standard Uncertainties } \\
\text { in Mica Cap. Dial Corrections }\left(s_{\mathrm{m}}\right)\end{array}$ & 28 & 28 & 28 & 28 & 28 & 29 & 28 \\
\hline \multicolumn{8}{|l|}{$($ At Frequency $=10 \mathrm{kHz})$} \\
\hline $\begin{array}{l}\text { Std Dev.of Pred.Values of } \\
\text { Dial Correction }(\mathrm{pF})\end{array}$ & 0.0627 & 0.1087 & 0.275 & 0.4965 & 1.288 & 3.991 & 21.8635 \\
\hline $\begin{array}{l}\text { Std Dev.of Pred.Values of } \\
\text { Dial Correction }(\mathrm{ppm})\left(s_{\mathrm{mr}}\right)\end{array}$ & 6.270 & 5.435 & 5.500 & 4.965 & 6.440 & 7.982 & 21.864 \\
\hline RSS & 27.417 & 27.233 & 27.245 & 27.142 & 27.450 & 27.852 & 34.497 \\
\hline $\begin{array}{l}\text { Assigned Standard Uncertainties } \\
\text { in Mica Cap. Dial Corrections }\left(s_{\mathrm{m}}\right)\end{array}$ & 28 & 28 & 28 & 28 & 28 & 28 & 35 \\
\hline
\end{tabular}


Table 14b. Summary of Components of Standard Uncertainties in Mica Capacitor Dial Corrections for Three-Terminal Measurements

\begin{tabular}{|c|c|c|c|c|c|c|c|}
\hline Unknown Standard $C_{\mathrm{x}}(\mu \mathrm{F})$ & 0.01 & 0.02 & 0.05 & 0.1 & 0.2 & 0.5 & 1.0 \\
\hline \multicolumn{8}{|l|}{$\begin{array}{c}\text { Components of } \\
\text { Standard Uncertainties (ppm) }\end{array}$} \\
\hline \multicolumn{8}{|l|}{ (At all Frequencies) } \\
\hline Temperature Variation $\left(s_{\mathrm{mp}}\right)$ & 26 & 26 & 26 & 26 & 26 & 26 & 26 \\
\hline Dial Switching $\left(s_{\mathrm{ds}}\right)$ & 0.6 & 0.3 & 0.15 & 0.1 & 0.05 & 0.02 & 0.01 \\
\hline Transfer Standard $\left(s_{\mathrm{mf}}\right)$ & 6 & 6 & 6 & 6 & 6 & 6 & 6 \\
\hline \multicolumn{8}{|l|}{ (At Frequency $=100 \mathrm{~Hz}$ ) } \\
\hline \multicolumn{8}{|l|}{ Std Dev.of Pred.Values of } \\
\hline \multicolumn{8}{|l|}{ Std Dev.of Pred.Values of } \\
\hline Dial Correction $(\mathrm{ppm})\left(s_{\mathrm{mr}}\right)$ & 23.310 & 18.085 & 20.192 & 25.727 & 35.999 & 23.763 & 16.803 \\
\hline RSS & 35.436 & 32.236 & 33.463 & 37.066 & 44.810 & 35.731 & 31.533 \\
\hline $\begin{array}{l}\text { Assigned Standard Uncertainties } \\
\text { in Mica Cap. Dial Corrections }\left(s_{\mathrm{m}}\right)\end{array}$ & 36 & 33 & 34 & 38 & 45 & 36 & 32 \\
\hline \multicolumn{8}{|l|}{ (At Frequency $=1 \mathrm{kHz}$ ) } \\
\hline \multicolumn{7}{|l|}{ Std Dev.of Pred.Values of } & 9.3179 \\
\hline $\begin{array}{l}\text { Std Dev.of Pred.Values of } \\
\text { Dial Correction }(\mathrm{ppm})\left(s_{\mathrm{m}}\right)\end{array}$ & 12.080 & 12.070 & 12.150 & 14.130 & 20.771 & 13.178 & 9.318 \\
\hline RSS & 29.297 & 29.288 & 29.320 & 30.194 & 33.814 & 29.760 & 28.263 \\
\hline & \multicolumn{3}{|c|}{ Assigned Standard Uncertainties } & 31 & 34 & 30 & 29 \\
\hline \multicolumn{8}{|l|}{$($ At Frequency $=10 \mathrm{kHz}$ ) } \\
\hline $\begin{array}{l}\text { Std Dev.of Pred.Values of } \\
\text { Dial Correction }(\mathrm{pF})\end{array}$ & 0.1087 & 0.2229 & 0.4965 & 1.2880 & 3.2637 & 21.8635 & NA \\
\hline $\begin{array}{l}\text { Std Dev.of Pred.Values of } \\
\text { Dial Correction }(\mathrm{ppm})\left(s_{\mathrm{mr}}\right)\end{array}$ & 10.870 & 11.145 & 9.930 & 12.880 & 16.319 & 43.727 & NA \\
\hline RSS & 28.819 & 28.919 & 28.472 & 29.629 & 31.278 & 51.225 & NA \\
\hline $\begin{array}{l}\text { Assigned Standard Uncertainties } \\
\text { in Mica Cap. Dial Corrections }\left(s_{\mathrm{m}}\right)\end{array}$ & 29 & 29 & 29 & 30 & 32 & 52 & NA \\
\hline
\end{tabular}


Table 15a. Summary of Components of Type B Standard Uncertainties in Capacitance Measurements Using the Type-12 Bridge to Measure Two-Terminal Mica Capacitors at $100 \mathrm{~Hz}, 1 \mathrm{kHz}$, and $10 \mathrm{kHz}$

(All values are in ppm - except nominal values of the unknown capacitance standards)

\begin{tabular}{|c|c|c|c|c|c|c|c|c|c|c|}
\hline Unknown Standard $C_{\mathrm{x}}(\mu \mathrm{F})$ & 0.001 & 0.002 & 0.005 & 0.01 & 0.02 & 0.05 & 0.1 & 0.2 & 0.5 & 1.0 \\
\hline \multicolumn{11}{|l|}{ Components of Standard Uncertainties } \\
\hline \multicolumn{11}{|l|}{ (At all Frequencies) } \\
\hline Ratio Resistor Arms $\left(s_{\mathrm{ra}}\right)$ & 9 & 9 & 9 & 18 & 18 & 18 & 18 & 18 & 18 & 18 \\
\hline Air Capacitor Dials $\quad\left(s_{\mathrm{rc}}\right)$ & 62 & 35 & 18 & 9 & 9 & 9 & 9 & 9 & 9 & 9 \\
\hline \multicolumn{11}{|l|}{$($ Frequency $=100 \mathrm{~Hz})$} \\
\hline Mica Capacitor Dials $\quad\left(s_{\mathrm{m}}\right)$ & - & - & - & 32 & 30 & 29 & 29 & 30 & 31 & 30 \\
\hline External Bridge Component $\left(s_{\mathrm{br}}\right)$ & 12 & 6 & 3 & 2 & 1 & 1 & 1 & 1 & 3 & 5 \\
\hline Type-B Standard Uncertainty $\left(\mathrm{U}_{\mathrm{b}}\right)$ & 63.79 & 36.63 & 20.35 & 37.85 & 36.14 & 35.31 & 35.31 & 36.14 & 37.08 & 36.47 \\
\hline Assigned $\mathrm{U}_{\mathrm{b}}$ & 65 & 40 & 25 & 40 & 40 & 40 & 40 & 40 & 40 & 40 \\
\hline \multicolumn{11}{|l|}{$($ Frequency $=1 \mathrm{kHz})$} \\
\hline Mica Capacitor Dials $\quad\left(s_{\mathrm{m}}\right)$ & - & - & - & 28 & 28 & 28 & 28 & 28 & 29 & 28 \\
\hline External Bridge Component $\left(s_{\mathrm{br}}\right)$ & 12 & 6 & 3 & 2 & 1 & 1 & 1 & 1 & 3 & 5 \\
\hline Type-B Standard Uncertainty $\left(\mathrm{U}_{\mathrm{b}}\right)$ & 63.79 & 36.63 & 20.35 & 34.54 & 34.50 & 34.50 & 34.50 & 34.50 & 35.43 & 34.84 \\
\hline Assigned $\mathrm{U}_{\mathrm{b}}$ & 65 & 40 & 25 & 40 & 40 & 40 & 40 & 40 & 40 & 40 \\
\hline \multicolumn{11}{|l|}{$($ Frequency $=10 \mathrm{kHz}$ ) } \\
\hline Mica Capacitor Dials $\quad\left(s_{\mathrm{m}}\right)$ & - & - & - & 28 & 28 & 28 & 28 & 28 & 28 & 35 \\
\hline External Bridge Component $\left(s_{\mathrm{br}}\right)$ & 12 & 7 & 4 & 5 & 10 & 25 & 48 & 95 & 235 & 470 \\
\hline Type-B Standard Uncertainty $\left(\mathrm{U}_{\mathrm{b}}\right)$ & 63.79 & 36.81 & 20.52 & 34.84 & 35.90 & 42.59 & 59.10 & 101.06 & 237.52 & 471.73 \\
\hline Assigned $U_{b}$ & 65 & 40 & 25 & 40 & 40 & 45 & 65 & 105 & 240 & 475 \\
\hline
\end{tabular}


Table 15b. Summary of Components of Type B Standard Uncertainties in Capacitance Measurements Using the Type-12 Bridge to Measure Three-Terminal Mica Capacitors at $100 \mathrm{~Hz}, 1 \mathrm{kHz}$, and $10 \mathrm{kHz}$

(All values are in ppm - except nominal values of the unknown capacitance standards)

\begin{tabular}{|c|c|c|c|c|c|c|c|c|c|c|}
\hline Unknown Standard $C_{\mathrm{x}}(\mu \mathrm{F})$ & 0.001 & 0.002 & 0.005 & 0.01 & 0.02 & 0.05 & 0.1 & 0.2 & 0.5 & 1.0 \\
\hline \multicolumn{11}{|l|}{ Components of Standard Uncertainties } \\
\hline (At all Frequencies) & \multirow[b]{2}{*}{-} & \multirow[b]{2}{*}{ - } & \multirow[b]{2}{*}{ - } & \multirow[b]{2}{*}{9} & \multirow[b]{2}{*}{9} & \multirow[b]{2}{*}{9} & \multirow[b]{2}{*}{9} & \multirow[b]{2}{*}{9} & \multirow[b]{2}{*}{9} & \multirow[b]{2}{*}{9} \\
\hline Ratio Resistor Arms $\left(s_{\text {ra }}\right)$ & & & & & & & & & & \\
\hline Air Capacitor Dials $\quad\left(s_{\text {rc }}\right)$ & 31 & 20 & 8 & 3 & 3 & 3 & 3 & 3 & 3 & 5 \\
\hline \multicolumn{11}{|l|}{$($ Frequency $=100 \mathrm{~Hz})$} \\
\hline Mica Capacitor Dials $\left(s_{\mathrm{m}}\right)$ & - & - & - & 18 & 17 & 17 & 19 & 23 & 18 & 16 \\
\hline External Bridge Component $\left(s_{\mathrm{br}}\right)$ & 6 & 3 & 2 & 1 & 1 & 1 & 1 & 1 & 3 & 5 \\
\hline Type-B Standard Uncertainty $\left(\mathrm{U}_{\mathrm{b}}\right)$ & 31.58 & 20.22 & 8.25 & 20.37 & 19.49 & 19.49 & 21.26 & 24.90 & 20.57 & 19.67 \\
\hline Assigned $U_{b}$ & 35 & 25 & 15 & 25 & 25 & 25 & 25 & 25 & 25 & 25 \\
\hline \multicolumn{11}{|l|}{ ( Frequency $=1 \mathrm{kHz}$ ) } \\
\hline Mica Capacitor Dials $\quad\left(s_{\mathrm{m}}\right)$ & \multirow[b]{2}{*}{6} & \multirow[b]{2}{*}{3} & \multirow[b]{2}{*}{2} & 15 & 15 & 15 & 16 & 17 & 15 & 15 \\
\hline External Bridge Component $\left(s_{\mathrm{tr}}\right)$ & & & & 1 & 1 & 1 & 1 & 1 & 3 & 5 \\
\hline Type-B Standard Uncertainty $\left(\mathrm{U}_{\mathrm{b}}\right)$ & 31.58 & 20.22 & 8.25 & 17.78 & 17.78 & 17.78 & 18.63 & 19.49 & 18.00 & 18.87 \\
\hline Assigned $\mathrm{U}_{\mathrm{b}}$ & 35 & 25 & 15 & 20 & 20 & 20 & 20 & 20 & 20 & 20 \\
\hline ( Frequency $=10 \mathrm{kHz}$ ) & & & & & & & & & & \\
\hline Mica Capacitor Dials $\quad\left(s_{\mathrm{m}}\right)$ & - & - & - & 15 & 15 & 15 & 15 & 16 & 26 & NA \\
\hline External Bridge Component $\left(s_{k x}\right)$ & 6 & 4 & 3 & 5 & 10 & 25 & 48 & 95 & 235 & NA \\
\hline Type-B Standard Uncertainty $\left(\mathrm{U}_{\mathrm{b}}\right)$ & 31.58 & 20.40 & 8.54 & 18.44 & 20.37 & 30.66 & 51.18 & 96.80 & 236.62 & NA \\
\hline Assigned $U_{b}$ & 35 & 25 & 15 & 20 & 25 & 35 & 55 & 100 & 240 & NA \\
\hline
\end{tabular}


Table 16a. Summary of Components of Type A Standard Uncertainties in Capacitance Measurements Using the Type-12 Bridge to Measure Two-Terminal Mica Capacitors at $100 \mathrm{~Hz}, 1 \mathrm{kHz}$, and $10 \mathrm{kHz}$

(All values are in ppm - except nominal values of unknown capacitance standards)

\begin{tabular}{|c|c|c|c|c|c|c|c|c|c|c|}
\hline Unknown Standard $C_{\mathrm{x}}(\mu \mathrm{F})$ & 0.001 & 0.002 & 0.005 & 0.01 & 0.02 & 0.05 & 0.1 & 0.2 & 0.5 & 1.0 \\
\hline \multicolumn{11}{|l|}{ Components of Standard Uncertainties } \\
\hline \multicolumn{11}{|l|}{$($ Frequency $=100 \mathrm{~Hz})$} \\
\hline Repeatability $\left(s_{\mathrm{rm}}\right)$ & 30 & 20 & 20 & 20 & 20 & 20 & 20 & 20 & 20 & 20 \\
\hline Temperature Variation $\left(s_{\mathrm{tm}}\right)$ & 4 & 4 & 4 & 4 & 4 & 4 & 4 & 4 & 4 & 4 \\
\hline Predicted Values $\left(s_{\mathrm{pd}}\right)$ & 34 & - & - & 32 & - & - & 10 & - & - & 10 \\
\hline Type-A Standard Uncertainty $\left(u_{\mathrm{a}}\right)$ & 45.52 & 20.40 & 20.40 & 37.95 & 20.40 & 20.40 & 22.72 & 20.40 & 20.40 & 22.72 \\
\hline Assigned $u_{\mathrm{a}}$ & 46 & 25 & 25 & 38 & 25 & 25 & 25 & 25 & 25 & 25 \\
\hline \multicolumn{11}{|l|}{ (Frequency $=1 \mathrm{kHz}$ ) } \\
\hline Repeatability $\left(s_{\mathrm{rm}}\right)$ & 30 & 20 & 20 & 20 & 20 & 20 & 20 & 20 & 20 & 20 \\
\hline Temperature Variation $\left(s_{\mathrm{tm}}\right)$ & 4 & 4 & 4 & 4 & 4 & 4 & 4 & 4 & 4 & 4 \\
\hline Predicted Values $\left(s_{\mathrm{pd}}\right)$ & 25 & 25 & 20 & 15 & 20 & 15 & 10 & 10 & 10 & 10 \\
\hline Type-A Standard Uncertainty $\left(u_{\mathrm{a}}\right)$ & 39.26 & 32.26 & 28.57 & 25.32 & 28.57 & 25.32 & 22.72 & 22.72 & 22.72 & 22.72 \\
\hline Assigned $u_{\mathrm{a}}$ & 40 & 35 & 30 & 30 & 30 & 30 & 25 & 25 & 25 & 25 \\
\hline \multicolumn{11}{|l|}{ (Frequency $=10 \mathrm{kHz}$ ) } \\
\hline Repeatability $\left(s_{\mathrm{rm}}\right)$ & 30 & 20 & 20 & 20 & 20 & 20 & 20 & 20 & 20 & 20 \\
\hline Temperature Variation $\left(s_{\mathrm{tm}}\right)$ & 4 & 4 & 4 & 4 & 4 & 4 & 4 & 4 & 4 & 4 \\
\hline Predicted Values $\left(s_{\mathrm{pd}}\right)$ & 15 & - & - & 10 & - & - & 15 & - & - & 15 \\
\hline Type-A Standard Uncertainty $\left(u_{\mathrm{a}}\right)$ & 33.78 & 20.40 & 20.40 & 22.72 & 20.40 & 20.40 & 25.32 & 20.40 & 20.40 & 25.32 \\
\hline Assigned $u_{\mathrm{a}}$ & 35 & 25 & 25 & 25 & 25 & 25 & 28 & 25 & 25 & 28 \\
\hline
\end{tabular}


Table 16b. Summary of Components of Type A Standard Uncertainties in Capacitance Measurements Using the Type-12 Bridge to Measure Three-Terminal Mica Capacitors at $100 \mathrm{~Hz}, 1 \mathrm{kHz}$, and $10 \mathrm{kHz}$

(All values are in ppm - except nominal values of unknown capacitance standards)

\begin{tabular}{|c|c|c|c|c|c|c|c|c|c|c|}
\hline Unknown Standard $C_{\mathrm{x}}(\mu \mathrm{F})$ & 0.001 & 0.002 & 0.005 & 0.01 & 0.02 & 0.05 & 0.1 & 0.2 & 0.5 & 1.0 \\
\hline \multicolumn{11}{|l|}{ Components of Standard Uncertainties } \\
\hline \multicolumn{11}{|l|}{$($ Frequency $=100 \mathrm{~Hz}$ ) } \\
\hline Repeatability $\left(s_{\mathrm{rm}}\right)$ & 30 & 20 & 20 & 20 & 20 & 20 & 20 & 20 & 20 & 20 \\
\hline Temperature Variation $\left(s_{\mathrm{tm}}\right)$ & 10 & 10 & 10 & 15 & 15 & 15 & 15 & 15 & 15 & 20 \\
\hline Predicted Values $\left(s_{\mathrm{pd}}\right)$ & 35 & - & - & 15 & - & - & 15 & - & - & 10 \\
\hline Type-A Standard Uncertainty $\left(u_{\mathrm{a}}\right)$ & 47.17 & 22.36 & 22.36 & 29.15 & 25.00 & 25.00 & 29.15 & 25.00 & 25.00 & 30.00 \\
\hline Assigned $u_{\mathrm{a}}$ & 48 & 25 & 25 & 30 & 25 & 25 & 30 & 25 & 25 & 30 \\
\hline \multicolumn{11}{|l|}{ ( Frequency $=1 \mathrm{kHz}$ ) } \\
\hline Repeatability $\left(s_{\mathrm{rm}}\right)$ & 30 & 20 & 20 & 20 & 20 & 20 & 20 & 20 & 20 & 20 \\
\hline Temperature Variation $\left(s_{\mathrm{tm}}\right)$ & 10 & 10 & 10 & 15 & 15 & 15 & 15 & 15 & 15 & 20 \\
\hline Predicted Values $\left(s_{\mathrm{pd}}\right)$ & 25 & 20 & 25 & 15 & 15 & 15 & 10 & 10 & 10 & 10 \\
\hline Type-A Standard Uncertainty $\left(u_{\mathrm{a}}\right)$ & 40.31 & 30.00 & 33.54 & 29.15 & 29.15 & 29.15 & 26.93 & 26.93 & 26.93 & 30.00 \\
\hline Assigned $u_{\mathrm{a}}$ & 45 & 30 & 45 & 30 & 30 & 30 & 30 & 30 & 30 & 30 \\
\hline \multicolumn{11}{|l|}{ ( Frequency $=10 \mathrm{kHz}$ ) } \\
\hline Repeatability $\left(s_{\mathrm{rm}}\right)$ & 30 & 20 & 20 & 20 & 20 & 20 & 20 & 20 & 20 & NA \\
\hline Temperature Variation $\left(s_{\mathrm{tm}}\right)$ & 10 & 10 & 10 & 15 & 15 & 15 & 15 & 15 & 15 & NA \\
\hline Predicted Values $\left(s_{\mathrm{pd}}\right)$ & 35 & - & - & 5 & - & - & 35 & - & - & \\
\hline Type-A Standard Uncertainty $\left(u_{\mathrm{a}}\right)$ & 47.17 & 22.36 & 22.36 & 25.50 & 25.00 & 25.00 & 43.01 & 25.00 & 25.00 & NA \\
\hline Assigned $u_{\mathrm{a}}$ & 48 & 25 & 25 & 30 & 25 & 25 & 45 & 25 & 25 & NA \\
\hline
\end{tabular}


Table 17a. Summary of Expanded and Assigned Total Uncertainties in Capacitance Measurements Using the Type-12 Bridge to Measure Two-Terminal Mica Capacitors at $100 \mathrm{~Hz}, 1 \mathrm{kHz}$, and $10 \mathrm{kHz}$

(All values are in ppm - except nominal values of the unknown capacitance standards)

\begin{tabular}{|c|c|c|c|c|c|c|c|c|c|c|}
\hline Unknown Standard $C_{\mathrm{x}}(\mu \mathrm{F})$ & 0.001 & 0.002 & 0.005 & 0.01 & 0.02 & 0.05 & 0.1 & 0.2 & 0.5 & 1.0 \\
\hline \multicolumn{11}{|l|}{$($ Frequency $=100 \mathrm{~Hz})$} \\
\hline Type-A Standard Uncertainty $\left(u_{\mathrm{a}}\right)$ & 46 & 25 & 25 & 38 & 25 & 25 & 25 & 25 & 25 & 25 \\
\hline Type-B Standard Uncertainty $\left(u_{\mathrm{b}}\right)$ & 65 & 40 & 25 & 40 & 40 & 40 & 40 & 40 & 40 & 40 \\
\hline Expanded Uncertainty $(U)$ & 159.26 & 94.34 & 70.71 & 110.34 & 94.34 & 94.34 & 94.34 & 94.34 & 94.34 & 94.34 \\
\hline Assigned Total Uncertainty $\left(U_{\mathfrak{t}}\right)$ & 160 & 120 & 100 & 120 & 120 & 120 & 120 & 120 & 120 & 120 \\
\hline \multicolumn{11}{|l|}{ (Frequency $=1 \mathrm{kHz}$ ) } \\
\hline Type-A Standard Uncertainty $\left(u_{\mathrm{a}}\right)$ & 40 & 35 & 30 & 30 & 30 & 30 & 25 & 25 & 25 & 25 \\
\hline Type-B Standard Uncertainty $\left(u_{\mathrm{b}}\right)$ & 65 & 40 & 25 & 40 & 40 & 40 & 40 & 40 & 40 & 40 \\
\hline Expanded Uncertainty $(U)$ & 152.64 & 106.30 & 78.10 & 100.00 & 100.00 & 100.00 & 94.34 & 94.34 & 94.34 & 94.34 \\
\hline Assigned Total Uncertainty $\left(U_{\mathrm{t}}\right)$ & 160 & 120 & 100 & 120 & 120 & 120 & 120 & 120 & 120 & 120 \\
\hline \multicolumn{11}{|l|}{ (Frequency $=10 \mathrm{kHz}$ ) } \\
\hline Type-A Standard Uncertainty $\left(u_{\mathrm{a}}\right)$ & 35 & 25 & 25 & 25 & 25 & 25 & 28 & 25 & 25 & 28 \\
\hline Type-B Standard Uncertainty $\left(u_{\mathrm{b}}\right)$ & 65 & 40 & 25 & 40 & 40 & 45 & 65 & 105 & 240 & 475 \\
\hline Expanded Uncertainty $(U)$ & 147.65 & 94.34 & 70.71 & 94.34 & 94.34 & 102.96 & 141.55 & 215.87 & 482.60 & 951.65 \\
\hline Assigned Total Uncertainty $\left(U_{\mathrm{t}}\right)$ & 160 & 120 & 100 & 120 & 120 & 120 & 150 & 250 & 500 & 1000 \\
\hline
\end{tabular}


Table 17b. Summary of Expanded and Assigned Total Uncertainties in Capacitance Measurements Using the Type-12 Bridge to Measure Three-Terminal Mica Capacitors at $100 \mathrm{~Hz}, 1 \mathrm{kHz}$, and $10 \mathrm{kHz}$

(All values are in ppm - except nominal values of the unknown capacitance standards)

\begin{tabular}{|c|c|c|c|c|c|c|c|c|c|c|}
\hline Unknown Standard $C_{\mathrm{x}}(\mu \mathrm{F})$ & 0.001 & 0.002 & 0.005 & 0.01 & 0.02 & 0.05 & 0.1 & 0.2 & 0.5 & 1.0 \\
\hline \multicolumn{11}{|l|}{ ( Frequency $=100 \mathrm{~Hz}$ ) } \\
\hline Type-A Standard Uncertainty $\left(u_{\mathrm{a}}\right)$ & 48 & 25 & 25 & 30 & 25 & 25 & 30 & 25 & 25 & 30 \\
\hline Type-B Standard Uncertainty $\left(u_{\mathrm{b}}\right)$ & 35 & 25 & 15 & 25 & 25 & 25 & 25 & 25 & 25 & 25 \\
\hline Expanded Uncertainty $(U)$ & 118.81 & 70.71 & 58.31 & 78.10 & 70.71 & 70.71 & 78.10 & 70.71 & 70.71 & 78.10 \\
\hline Assigned Total Uncertainty $\left(U_{t}\right)$ & 120 & 100 & 100 & 100 & 100 & 100 & 100 & 100 & 100 & 100 \\
\hline \multicolumn{11}{|l|}{ ( Frequency $=1 \mathrm{kHz}$ ) } \\
\hline Type-A Standard Uncertainty $\left(u_{\mathrm{a}}\right)$ & 45 & 30 & 35 & 30 & 30 & 30 & 30 & 30 & 30 & 30 \\
\hline Type-B Standard Uncertainty $\left(u_{\mathrm{b}}\right)$ & 35 & 25 & 15 & 20 & 20 & 20 & 20 & 20 & 20 & 20 \\
\hline Expanded Uncertainty $(U)$ & 114.02 & 78.10 & 76.16 & 72.11 & 72.11 & 72.11 & 72.11 & 72.11 & 72.11 & 72.11 \\
\hline Assigned Total Uncertainty $\left(U_{\mathfrak{t}}\right)$ & 120 & 100 & 100 & 100 & 100 & 100 & 100 & 100 & 100 & 100 \\
\hline \multicolumn{11}{|l|}{$($ Frequency $=10 \mathrm{kHz})$} \\
\hline Type-A Standard Uncertainty $\left(u_{\mathrm{a}}\right)$ & 48 & 25 & 25 & 30 & 25 & 25 & 45 & 25 & 25 & NA \\
\hline Type-B Standard Uncertainty $\left(u_{\mathrm{b}}\right)$ & 35 & 25 & 15 & 20 & 25 & 35 & 55 & 100 & 240 & NA \\
\hline Expanded Uncertainty $(U)$ & 118.81 & 70.71 & 58.31 & 72.11 & 70.71 & 86.02 & 142.13 & 206.16 & 482.60 & NA \\
\hline Assigned Total Uncertainty $\left(U_{\mathrm{t}}\right)$ & 120 & 100 & 100 & 100 & 100 & 100 & 150 & 250 & 500 & NA \\
\hline
\end{tabular}


Table 18a. Summary of Components of Type B Standard Uncertainties in Conductance Measurements Using the Type-12 Bridge to Measure Two-Terminal Mica Capacitors at $100 \mathrm{~Hz}, 1 \mathrm{kHz}$, and $10 \mathrm{kHz}$

(All values are in $\mu \mathrm{S}$ - except nominal values of the unknown capacitance standards)

\begin{tabular}{|c|c|c|c|c|c|c|c|c|c|c|}
\hline Unknown Standard $C_{\mathrm{x}}(\mu \mathrm{F})$ & 0.001 & 0.002 & 0.005 & 0.01 & 0.02 & 0.05 & 0.1 & 0.2 & 0.5 & 1.0 \\
\hline \multicolumn{11}{|l|}{$\begin{array}{c}\text { Components of } \\
\text { Standard Uncertainties }\end{array}$} \\
\hline \multicolumn{11}{|l|}{ (Frequency $=100 \mathrm{~Hz}$ ) } \\
\hline Accuracy of $\mathrm{G}_{\mathrm{s}}\left(s_{\mathrm{gs}}\right)$ & $4.8 \mathrm{E}-07$ & $6.4 \mathrm{E}-07$ & $1.3 \mathrm{E}-06$ & $1.6 \mathrm{E}-06$ & $3.2 \mathrm{E}-06$ & 3.2E-06 & 2.4E-05 & $3.2 \mathrm{E}-05$ & $1.6 \mathrm{E}-04$ & $2.8 \mathrm{E}-04$ \\
\hline Contact Resistance $\left(s_{\mathrm{gr}}\right)$ & $4.6 \mathrm{E}-10$ & $1.8 \mathrm{E}-09$ & $1.2 \mathrm{E}-08$ & $4.6 \mathrm{E}-08$ & $1.8 \mathrm{E}-07$ & $1.2 \mathrm{E}-06$ & $4.6 \mathrm{E}-06$ & $1.8 \mathrm{E}-05$ & $1.2 \mathrm{E}-04$ & $4.6 \mathrm{E}-04$ \\
\hline Conductance Pot. $\left(s_{\mathrm{gp}}\right)$ & $1.0 \mathrm{E}-04$ & $1.0 \mathrm{E}-04$ & $1.0 \mathrm{E}-04$ & $1.0 \mathrm{E}-04$ & $1.0 \mathrm{E}-04$ & $1.0 \mathrm{E}-04$ & $1.0 \mathrm{E}-04$ & $1.0 \mathrm{E}-04$ & $1.0 \mathrm{E}-04$ & $1.3 \mathrm{E}-04$ \\
\hline Residu. Conduct. $\left(s_{\mathrm{gc}}\right)$ & $1.2 \mathrm{E}-06$ & $1.2 \mathrm{E}-06$ & $1.2 \mathrm{E}-06$ & $1.2 \mathrm{E}-06$ & $1.2 \mathrm{E}-06$ & $1.2 \mathrm{E}-06$ & $1.2 \mathrm{E}-06$ & $1.2 \mathrm{E}-06$ & $1.2 \mathrm{E}-06$ & $1.2 \mathrm{E}-04$ \\
\hline Mica Capacitor Dials $\left(s_{\mathrm{gm}}\right)$ & - & - & - & $1.2 \mathrm{E}-04$ & $1.4 \mathrm{E}-04$ & $1.5 \mathrm{E}-04$ & 3.9E-04 & 7.6E-04 & $2.9 \mathrm{E}-03$ & 4.7E-03 \\
\hline Type-B Std. Uncertainty $\left(u_{\mathrm{gb}}\right)$ & $1.0 \mathrm{E}-04$ & $1.0 \mathrm{E}-04$ & $1.0 \mathrm{E}-04$ & $1.6 \mathrm{E}-04$ & $1.7 \mathrm{E}-04$ & $1.8 \mathrm{E}-04$ & 4.1E-04 & 7.7E-04 & $2.9 \mathrm{E}-03$ & $4.8 \mathrm{E}-03$ \\
\hline \multicolumn{11}{|l|}{$($ Frequency $=1 \mathrm{kHz})$} \\
\hline Accuracy of $\mathrm{G}_{\mathrm{s}}\left(s_{\mathrm{gs}}\right)$ & $2.4 \mathrm{E}-06$ & $3.2 \mathrm{E}-06$ & $9.6 \mathrm{E}-06$ & $1.6 \mathrm{E}-05$ & $3.2 \mathrm{E}-05$ & $3.2 \mathrm{E}-05$ & $9.6 \mathrm{E}-05$ & $1.6 \mathrm{E}-04$ & $5.6 \mathrm{E}-04$ & $2.3 E-03$ \\
\hline Contact Resistance $\left(s_{\mathrm{gr}}\right)$ & $4.6 \mathrm{E}-08$ & $1.8 \mathrm{E}-07$ & $1.2 \mathrm{E}-06$ & $4.6 \mathrm{E}-06$ & $1.8 \mathrm{E}-05$ & $1.2 \mathrm{E}-04$ & 4.6E-04 & $1.8 \mathrm{E}-03$ & $1.2 \mathrm{E}-02$ & $4.6 \mathrm{E}-02$ \\
\hline Conductance Pot. $\left(s_{\mathrm{gp}}\right)$ & $1.0 \mathrm{E}-04$ & $1.0 \mathrm{E}-04$ & $1.0 \mathrm{E}-04$ & $1.0 \mathrm{E}-04$ & $1.0 \mathrm{E}-04$ & $1.0 \mathrm{E}-04$ & $1.0 \mathrm{E}-04$ & $1.0 \mathrm{E}-04$ & $1.0 \mathrm{E}-04$ & $1.3 \mathrm{E}-04$ \\
\hline Residu. Conduct. $\left(s_{\mathrm{gc}}\right)$ & $1.2 \mathrm{E}-05$ & $1.2 \mathrm{E}-05$ & $1.2 \mathrm{E}-05$ & $1.2 \mathrm{E}-05$ & $1.2 \mathrm{E}-05$ & $1.2 \mathrm{E}-05$ & $1.2 \mathrm{E}-05$ & $1.2 \mathrm{E}-05$ & $1.2 \mathrm{E}-05$ & $1.2 \mathrm{E}-05$ \\
\hline Mica Capacitor Dials $\left(s_{\mathrm{gm}}\right)$ & - & - & - & $9.0 \mathrm{E}-05$ & $1.7 \mathrm{E}-04$ & 2.6E-04 & 8.0E-04 & $2.9 \mathrm{E}-03$ & 8.7E-03 & $1.5 \mathrm{E}-02$ \\
\hline Type-B Std. Uncertainty $\left(u_{\mathrm{gb}}\right)$ & $1.0 \mathrm{E}-04$ & $1.0 \mathrm{E}-04$ & $1.0 \mathrm{E}-04$ & $1.4 \mathrm{E}-04$ & $2.0 \mathrm{E}-04$ & $3.0 \mathrm{E}-04$ & $9.3 \mathrm{E}-04$ & $3.4 \mathrm{E}-03$ & $1.4 \mathrm{E}-02$ & $4.8 \mathrm{E}-02$ \\
\hline \multicolumn{11}{|l|}{ (Frequency $=10 \mathrm{kHz}$ ) } \\
\hline Accuracy of $\mathrm{G}_{\mathrm{s}}\left(s_{\mathrm{gs}}\right)$ & $1.6 \mathrm{E}-05$ & $1.9 \mathrm{E}-05$ & $3.2 \mathrm{E}-05$ & $4.8 \mathrm{E}-05$ & $9.6 \mathrm{E}-05$ & $9.6 \mathrm{E}-05$ & $1.6 \mathrm{E}-03$ & $3.2 \mathrm{E}-03$ & $1.6 \mathrm{E}-02$ & $1.4 \mathrm{E}-01$ \\
\hline Contact Resistance $\left(s_{\mathrm{gr}}\right)$ & $4.6 \mathrm{E}-06$ & $1.8 \mathrm{E}-05$ & $1.2 \mathrm{E}-04$ & $4.6 \mathrm{E}-04$ & $1.8 \mathrm{E}-03$ & $1.2 \mathrm{E}-02$ & $4.6 \mathrm{E}-02$ & $1.8 \mathrm{E}-01$ & $1.2 \mathrm{E}+00$ & $4.6 \mathrm{E}+00$ \\
\hline Conductance Pot. $\left(s_{\mathrm{gp}}\right)$ & $1.0 \mathrm{E}-04$ & $1.0 \mathrm{E}-04$ & $1.0 \mathrm{E}-04$ & $1.0 \mathrm{E}-04$ & $1.0 \mathrm{E}-04$ & $1.0 \mathrm{E}-04$ & $1.0 \mathrm{E}-04$ & $1.0 \mathrm{E}-03$ & $1.0 \mathrm{E}-03$ & $1.3 \mathrm{E}-01$ \\
\hline Residu. Conduct. $\left(s_{\mathrm{gc}}\right)$ & $1.2 \mathrm{E}-04$ & $1.2 \mathrm{E}-04$ & $1.2 \mathrm{E}-04$ & $1.2 \mathrm{E}-04$ & $1.2 \mathrm{E}-04$ & $1.2 \mathrm{E}-04$ & $1.2 \mathrm{E}-03$ & $1.2 \mathrm{E}-03$ & $1.2 \mathrm{E}-03$ & $1.2 \mathrm{E}-02$ \\
\hline Mica Capacitor Dials $\left(s_{\mathrm{gm}}\right)$ & - & - & - & $1.4 \mathrm{E}-03$ & $3.1 \mathrm{E}-03$ & $6.9 \mathrm{E}-03$ & $2.7 \mathrm{E}-02$ & $6.5 \mathrm{E}-02$ & $2.6 \mathrm{E}-01$ & $1.2 \mathrm{E}+00$ \\
\hline Type-B Std. Uncertainty $\left(u_{\mathrm{gb}}\right)$ & $1.5 \mathrm{E}-04$ & $1.6 \mathrm{E}-04$ & $1.9 \mathrm{E}-04$ & $1.5 \mathrm{E}-03$ & $3.6 \mathrm{E}-03$ & $1.3 \mathrm{E}-02$ & 5.3E-02 & $2.0 \mathrm{E}-01$ & $1.2 \mathrm{E}+00$ & $4.8 \mathrm{E}+00$ \\
\hline
\end{tabular}


Table 18b. Summary of Components of Type B Standard Uncertainties in Conductance Measurements Using the Type-12 Bridge to Measure Three-Terminal Mica Capacitors at $100 \mathrm{~Hz}, 1 \mathrm{kHz}$, and $10 \mathrm{kHz}$

(All values are in $\mu \mathrm{S}$ - except nominal values of the unknown capacitance standards)

\begin{tabular}{|c|c|c|c|c|c|c|c|c|c|c|}
\hline Unknown Standard $C_{x}(\mu F)$ & 0.001 & 0.002 & 0.005 & 0.01 & 0.02 & 0.05 & 0.1 & 0.2 & 0.5 & 1.0 \\
\hline $\begin{array}{l}\text { Comp } \\
\text { Standard } 1 \\
\end{array}$ & & & & & & & & & & \\
\hline (Frequency $=100 \mathrm{~Hz}$ ) & & & & & & & & & & \\
\hline Accuracy of $\mathrm{G}_{\mathrm{s}}\left(s_{\mathrm{gs}}\right)$ & $3.2 \mathrm{E}-07$ & $3.2 \mathrm{E}-07$ & $8.0 \mathrm{E}-07$ & $1.3 \mathrm{E}-06$ & $3.2 \mathrm{E}-06$ & $3.2 \mathrm{E}-06$ & $3.2 \mathrm{E}-05$ & $8.0 \mathrm{E}-05$ & $1.9 \mathrm{E}-04$ & $3.5 \mathrm{E}-04$ \\
\hline Contact Resistance $\left(s_{\mathrm{gr}}\right)$ & $4.6 \mathrm{E}-10$ & $1.8 \mathrm{E}-09$ & $1 \mathrm{E}-08$ & $4.6 \mathrm{E}-08$ & $1.8 \mathrm{E}-07$ & $1.2 \mathrm{E}-06$ & $4.6 \mathrm{E}-06$ & $1.8 \mathrm{E}-05$ & $1.2 \mathrm{E}-04$ & $4.6 \mathrm{E}-0$ \\
\hline Conductance Pot. $\left(s_{\mathrm{gp}}\right)$ & $1.0 \mathrm{E}-04$ & $1.0 \mathrm{E}-04$ & $1.0 \mathrm{E}-04$ & $1.0 \mathrm{E}-04$ & $1.0 \mathrm{E}-04$ & $1.0 \mathrm{E}-04$ & $1.0 \mathrm{E}-04$ & $1.0 \mathrm{E}-04$ & $1.0 \mathrm{E}-04$ & $1.3 \mathrm{E}-04$ \\
\hline Residu. Conduct. $\left(s_{\mathrm{gc}}\right)$ & $1.2 \mathrm{E}-06$ & $1.2 \mathrm{E}-06$ & $1 \mathrm{E}-06$ & $1.2 \mathrm{E}-06$ & $1.2 \mathrm{E}-06$ & $1.2 \mathrm{E}-06$ & $1.2 \mathrm{E}-06$ & $1.2 \mathrm{E}-06$ & $1.2 \mathrm{E}-06$ & $1.2 \mathrm{E}-04$ \\
\hline Mica Capacitor Dials $\left(s_{\mathrm{gm}}\right)$ & - & - & - & $1.4 \mathrm{E}-04$ & $1.5 \mathrm{E}-04$ & $3.9 \mathrm{E}-04$ & 7.6E-04 & $2.6 \mathrm{E}-03$ & $4.7 \mathrm{E}-03$ & $6.7 \mathrm{E}-03$ \\
\hline Type-B Std. Uncertainty $\left(u_{\mathrm{gb}}\right)$ & $1.0 \mathrm{E}-04$ & $1.0 \mathrm{E}-04$ & $1.0 \mathrm{E}-04$ & $1.7 \mathrm{E}-04$ & $1.8 \mathrm{E}-04$ & $4.1 \mathrm{E}-04$ & 7.7E-04 & $2.6 \mathrm{E}-03$ & $4.7 \mathrm{E}-03$ & $6.7 \mathrm{E}-03$ \\
\hline (Freque & & & & & & & & & & \\
\hline Accuracy of $\mathrm{G}_{\mathrm{s}}\left(s_{\mathrm{gs}}\right)$ & $1.6 \mathrm{E}-06$ & $1.6 \mathrm{E}-06$ & $8.0 \mathrm{E}-06$ & $1.3 \mathrm{E}-05$ & $3.2 \mathrm{E}-05$ & $3.2 \mathrm{E}-05$ & $1.1 \mathrm{E}-04$ & $1.6 \mathrm{E}-04$ & $5.6 \mathrm{E}-04$ & $3.5 \mathrm{E}-03$ \\
\hline Contact Resistance $\left(s_{\mathrm{gr}}\right)$ & $4.6 \mathrm{E}-08$ & $1.8 \mathrm{E}-07$ & $1 \mathrm{E}-06$ & $4.6 \mathrm{E}-06$ & $1.8 \mathrm{E}-05$ & $1.2 \mathrm{E}-04$ & $4.6 \mathrm{E}-04$ & $1.8 \mathrm{E}-03$ & $1.2 \mathrm{E}-02$ & $4.6 \mathrm{E}-02$ \\
\hline Conductance Pot. $\left(s_{\mathrm{gp}}\right)$ & $1.0 \mathrm{E}-04$ & $1.0 \mathrm{E}-04$ & $1.0 \mathrm{E}-04$ & $1.0 \mathrm{E}-04$ & $1.0 \mathrm{E}-04$ & $1.0 \mathrm{E}-04$ & $1.0 \mathrm{E}-04$ & $1.0 \mathrm{E}-04$ & $1.0 \mathrm{E}-04$ & $1.3 \mathrm{E}-04$ \\
\hline Residu. Conduct. $\left(s_{\mathrm{gc}}\right)$ & $1.2 \mathrm{E}-05$ & $1.2 \mathrm{E}-05$ & $1 \mathrm{E}-05$ & $1.2 \mathrm{E}-05$ & $1.2 \mathrm{E}-05$ & $1.2 \mathrm{E}-05$ & $1.2 \mathrm{E}-05$ & $1.2 \mathrm{E}-05$ & $1.2 \mathrm{E}-05$ & $1.2 \mathrm{E}-05$ \\
\hline Mica Capacitor Dials $\left(s_{\mathrm{gm}}\right)$ & - & - & - & $1.7 \mathrm{E}-04$ & $2.4 \mathrm{E}-04$ & $8.0 \mathrm{E}-04$ & $2.9 \mathrm{E}-03$ & $8.4 \mathrm{E}-03$ & $1.4 \mathrm{E}-02$ & $2.0 \mathrm{E}-02$ \\
\hline Type-B Std. Uncertainty $\left(u_{\mathrm{gb}}\right)$ & $1.0 \mathrm{E}-04$ & $1.0 \mathrm{E}-04$ & $1.0 \mathrm{E}-04$ & $2.0 \mathrm{E}-04$ & $2.7 \mathrm{E}-04$ & $8.2 \mathrm{E}-04$ & $2.9 \mathrm{E}-03$ & $8.6 \mathrm{E}-03$ & $1.8 \mathrm{E}-02$ & $5.1 \mathrm{E}-02$ \\
\hline (Fre & & & & & & & & & & \\
\hline Accuracy of $\mathrm{G}_{\mathrm{s}}\left(s_{\mathrm{gs}}\right)$ & $4.8 \mathrm{E}-06$ & $8.0 \mathrm{E}-06$ & $1.6 \mathrm{E}-05$ & $3.2 \mathrm{E}-05$ & $8.0 \mathrm{E}-05$ & $8.0 \mathrm{E}-05$ & $1.6 \mathrm{E}-03$ & $3.2 \mathrm{E}-03$ & $1.6 \mathrm{E}-02$ & NA \\
\hline Contact Resistance $\left(s_{\mathrm{gr}}\right)$ & $4.6 \mathrm{E}-06$ & $1.8 \mathrm{E}-05$ & $1.2 \mathrm{E}-04$ & 4.6E-04 & $1.8 \mathrm{E}-03$ & $1.2 \mathrm{E}-02$ & $4.6 \mathrm{E}-02$ & $1.8 \mathrm{E}-01$ & $1.2 \mathrm{E}+00$ & NA \\
\hline Conductance Pot. $\left(s_{\mathrm{gp}}\right)$ & $1.0 \mathrm{E}-04$ & $1.0 \mathrm{E}-04$ & $1.0 \mathrm{E}-04$ & $1.0 \mathrm{E}-04$ & $1.0 \mathrm{E}-04$ & $1.0 \mathrm{E}-04$ & $1.0 \mathrm{E}-04$ & $1.0 \mathrm{E}-03$ & $1.0 \mathrm{E}-03$ & NA \\
\hline Residu. Conduct. $\left(s_{\mathrm{gc}}\right)$ & $1.2 \mathrm{E}-04$ & $1.2 \mathrm{E}-04$ & $1.2 \mathrm{E}-04$ & $1.2 \mathrm{E}-04$ & $1.2 \mathrm{E}-04$ & $1.2 \mathrm{E}-04$ & $1.2 \mathrm{E}-03$ & $1.2 \mathrm{E}-03$ & $1.2 \mathrm{E}-03$ & NA \\
\hline Mica Capacitor Dials $\left(s_{\mathrm{gm}}\right)$ & - & - & - & $3.1 \mathrm{E}-03$ & $4.9 \mathrm{E}-03$ & $2.4 \mathrm{E}-02$ & $6.5 \mathrm{E}-02$ & $1.6 \mathrm{E}-01$ & $1.2 \mathrm{E}+00$ & NA \\
\hline Type-B Std. Uncertainty $\left(u_{\mathrm{gb}}\right)$ & $1.5 \mathrm{E}-04$ & $1.5 \mathrm{E}-04$ & $1.9 \mathrm{E}-04$ & $3.1 \mathrm{E}-03$ & $5.3 \mathrm{E}-03$ & $2.6 \mathrm{E}-02$ & $7.9 \mathrm{E}-02$ & $2.4 \mathrm{E}-01$ & $1.7 \mathrm{E}+00$ & NA \\
\hline
\end{tabular}


Table 19a. Summary of Components of Type A, Expanded, and Assigned Uncertainties in Conductance Measurements Using the Type-12 Bridge to Measure Two-Terminal Mica Capacitors at $100 \mathrm{~Hz}, 1 \mathrm{kHz}$, and $10 \mathrm{kHz}$

(All values are in $\mu \mathrm{S}$ - except nominal values of the unknown capacitance standards)

\begin{tabular}{|c|c|c|c|c|c|c|c|c|c|c|}
\hline Unknown Standard $C_{\mathrm{x}}(\mu \mathrm{F})$ & 0.001 & 0.002 & 0.005 & 0.01 & 0.02 & 0.05 & 0.1 & 0.2 & 0.5 & 1.0 \\
\hline \multicolumn{11}{|l|}{ Components } \\
\hline \multicolumn{11}{|l|}{ (Frequency $=100 \mathrm{~Hz}$ ) } \\
\hline Repeatability $\left(s_{\mathrm{grm}}\right)$ & $2.3 \mathrm{E}-05$ & $2.3 \mathrm{E}-05$ & $2.3 \mathrm{E}-05$ & 2.9E-05 & $4.0 \mathrm{E}-05$ & 7.2E-05 & $1.2 \mathrm{E}-04$ & $1.8 \mathrm{E}-04$ & $4.6 \mathrm{E}-04$ & $1.2 \mathrm{E}-03$ \\
\hline Predicted Values $\left(s_{\mathrm{gpd}}\right)$ & $1.0 \mathrm{E}-04$ & - & - & $1.2 \mathrm{E}-04$ & - & - & 2.1E-04 & - & - & $5.0 \mathrm{E}-03$ \\
\hline Type-A Std. Uncertainty $\left(u_{\text {ga }}\right)$ & $1.0 \mathrm{E}-04$ & $2.3 \mathrm{E}-05$ & $2.3 \mathrm{E}-05$ & $1.2 \mathrm{E}-04$ & $4.0 \mathrm{E}-05$ & 7.2E-05 & $2.4 \mathrm{E}-04$ & $1.8 \mathrm{E}-04$ & $4.6 \mathrm{E}-04$ & $5.1 \mathrm{E}-03$ \\
\hline Type-B Std. Uncertainty $\left(u_{\mathrm{gb}}\right)$ & $1.0 \mathrm{E}-04$ & $1.0 \mathrm{E}-04$ & $1.0 \mathrm{E}-04$ & $1.6 \mathrm{E}-04$ & $1.7 \mathrm{E}-04$ & $1.8 \mathrm{E}-04$ & 4.1E-04 & 7.7E-04 & $2.9 \mathrm{E}-03$ & $4.8 \mathrm{E}-03$ \\
\hline Expanded Uncertainty $\left(U_{\mathrm{g}}\right)$ & 0.00029 & 0.00021 & 0.00021 & 0.00040 & 0.00035 & 0.00039 & 0.00094 & 0.00158 & 0.00590 & 0.01399 \\
\hline $\begin{array}{c}\text { Assigned } \\
\text { Total Uncertainty }\left(U_{\mathrm{gg}}\right)\end{array}$ & 0.0003 & 0.0002 & 0.0002 & 0.0004 & 0.0004 & 0.0004 & 0.001 & 0.002 & 0.006 & 0.02 \\
\hline \multicolumn{11}{|l|}{$($ Frequency $=1 \mathrm{kHz})$} \\
\hline Repeatability $\left(s_{\mathrm{gmm}}\right)$ & $4.0 \mathrm{E}-05$ & $4.6 \mathrm{E}-05$ & $7.5 \mathrm{E}-05$ & $1.2 \mathrm{E}-04$ & 2.3E-04 & 5.2E-04 & $1.2 \mathrm{E}-03$ & 2.3E-03 & $7.5 \mathrm{E}-03$ & 2.3E-02 \\
\hline Predicted Values $\left(s_{\text {gpd }}\right)$ & $1.0 \mathrm{E}-04$ & $2.0 \mathrm{E}-04$ & $2.0 \mathrm{E}-04$ & $3.0 \mathrm{E}-04$ & $1.0 \mathrm{E}-03$ & $2.0 \mathrm{E}-03$ & $6.0 \mathrm{E}-03$ & $1.5 \mathrm{E}-02$ & $5.5 \mathrm{E}-02$ & $9.5 \mathrm{E}-02$ \\
\hline Type-A Std. Uncertainty $\left(u_{\mathrm{ga}}\right)$ & $1.1 \mathrm{E}-04$ & $2.1 \mathrm{E}-04$ & $2.1 \mathrm{E}-04$ & $3.2 \mathrm{E}-04$ & $1.0 \mathrm{E}-03$ & $2.1 \mathrm{E}-03$ & $6.1 \mathrm{E}-03$ & $1.5 \mathrm{E}-02$ & $5.6 \mathrm{E}-02$ & $9.8 \mathrm{E}-02$ \\
\hline Type-B Std. Uncertainty $\left(u_{\mathrm{gb}}\right)$ & $1.0 \mathrm{E}-04$ & $1.0 \mathrm{E}-04$ & $1.0 \mathrm{E}-04$ & $1.4 \mathrm{E}-04$ & $2.0 \mathrm{E}-04$ & $3.0 \mathrm{E}-04$ & 9.3E-04 & $3.4 \mathrm{E}-03$ & $1.4 \mathrm{E}-02$ & $4.8 \mathrm{E}-02$ \\
\hline Expanded Uncertainty $\left(U_{\mathrm{g}}\right)$ & 0.00030 & 0.00046 & 0.00047 & 0.00070 & 0.00209 & 0.00418 & 0.01236 & 0.03112 & 0.11473 & 0.21824 \\
\hline $\begin{array}{c}\text { Assigned } \\
\text { Total Uncertainty }\left(U_{\mathrm{gg}}\right)\end{array}$ & 0.0003 & 0.0005 & 0.0005 & 0.001 & 0.003 & 0.005 & 0.02 & 0.04 & 0.12 & 0.3 \\
\hline \multicolumn{11}{|l|}{$($ Frequency $=10 \mathrm{kHz})$} \\
\hline Repeatability $\left(s_{\mathrm{grm}}\right)$ & $1.8 \mathrm{E}-04$ & $2.3 \mathrm{E}-04$ & $5.8 \mathrm{E}-04$ & $1.2 \mathrm{E}-03$ & $2.3 \mathrm{E}-03$ & $8.1 \mathrm{E}-03$ & $2.3 \mathrm{E}-02$ & $6.4 \mathrm{E}-02$ & $3.5 \mathrm{E}-01$ & $1.2 \mathrm{E}+00$ \\
\hline Predicted Values $\left(s_{\mathrm{gpd}}\right)$ & $1.0 \mathrm{E}-04$ & - & - & $3.3 \mathrm{E}-03$ & - & - & $3.5 \mathrm{E}-02$ & - & - & $1.0 \mathrm{E}+00$ \\
\hline Type-A Std. Uncertainty $\left(u_{\mathrm{ga}}\right)$ & $2.0 \mathrm{E}-04$ & $2.3 \mathrm{E}-04$ & $5.8 \mathrm{E}-04$ & $3.5 \mathrm{E}-03$ & 2.3E-03 & $8.1 \mathrm{E}-03$ & $4.2 \mathrm{E}-02$ & $6.4 \mathrm{E}-02$ & $3.5 \mathrm{E}-01$ & $1.5 \mathrm{E}+00$ \\
\hline Type-B Std. Uncertainty $\left(u_{\mathrm{gb}}\right)$ & $1.5 \mathrm{E}-04$ & $1.6 \mathrm{E}-04$ & $1.9 \mathrm{E}-04$ & $1.5 \mathrm{E}-03$ & $3.6 \mathrm{E}-03$ & $1.3 \mathrm{E}-02$ & $5.3 \mathrm{E}-02$ & $2.0 \mathrm{E}-01$ & $1.2 \mathrm{E}+00$ & $4.8 \mathrm{E}+00$ \\
\hline Expanded Uncertainty $\left(U_{\mathrm{g}}\right)$ & 0.0005 & 0.0006 & 0.0012 & 0.0076 & 0.0085 & 0.0314 & 0.1356 & 0.4116 & 2.4667 & 10.0424 \\
\hline $\begin{array}{c}\text { Assigned } \\
\text { Total Uncertainty }\left(U_{\mathrm{gg}}\right)\end{array}$ & 0.001 & 0.001 & 0.005 & 0.01 & 0.02 & 0.05 & 0.2 & 0.5 & 3.0 & 10.0 \\
\hline
\end{tabular}


Table 19b. Summary of Components of Type A, Expanded, and Assigned Uncertainties in Conductance Measurements Using the Type-12 Bridge to Measure Three-Terminal Mica Capacitors at $100 \mathrm{~Hz}, 1 \mathrm{kHz}$, and $10 \mathrm{kHz}$

(All values are in $\mu \mathrm{S}$ - except nominal values of the unknown capacitance standards)

\begin{tabular}{|c|c|c|c|c|c|c|c|c|c|c|}
\hline Unknown Standard $C_{\mathrm{x}}(\mu \mathrm{F})$ & 0.001 & 0.002 & 0.005 & 0.01 & 0.02 & 0.05 & 0.1 & 0.2 & 0.5 & 1.0 \\
\hline \multicolumn{11}{|l|}{ Components } \\
\hline \multicolumn{11}{|l|}{$($ Frequency $=100 \mathrm{~Hz}$ ) } \\
\hline Repeatability $\left(s_{\mathrm{gmm}}\right)$ & $2.3 \mathrm{E}-05$ & 2.3E-05 & $2.3 \mathrm{E}-05$ & 2.9E-05 & $4.0 \mathrm{E}-05$ & 7.2E-05 & $1.2 \mathrm{E}-04$ & $1.8 \mathrm{E}-04$ & $4.6 \mathrm{E}-04$ & $1.2 \mathrm{E}-03$ \\
\hline Predicted Values $\left(s_{\mathrm{gpd}}\right)$ & $1.5 \mathrm{E}-05$ & - & - & 7.4E-05 & - & - & $1.9 \mathrm{E}-04$ & - & - & $4.6 \mathrm{E}-03$ \\
\hline Type-A Std. Uncertainty $\left(u_{\mathrm{ga}}\right)$ & 2.7E-05 & 2.3E-05 & $2.3 \mathrm{E}-05$ & 7.9E-05 & $4.0 \mathrm{E}-05$ & 7.2E-05 & $2.2 \mathrm{E}-04$ & $1.8 \mathrm{E}-04$ & $4.6 \mathrm{E}-04$ & $1.2 \mathrm{E}-03$ \\
\hline Type-B Std. Uncertainty $\left(u_{\mathrm{gb}}\right)$ & $1.0 \mathrm{E}-04$ & $1.0 \mathrm{E}-04$ & $1.0 \mathrm{E}-04$ & 1.7E-04 & $1.8 \mathrm{E}-04$ & 4.1E-04 & 7.7E-04 & $2.6 \mathrm{E}-03$ & $4.7 \mathrm{E}-03$ & $6.7 \mathrm{E}-03$ \\
\hline Expanded Uncertainty $\left(U_{\mathrm{g}}\right)$ & 0.00021 & 0.00021 & 0.00021 & 0.00037 & 0.00037 & 0.00083 & 0.00161 & 0.00528 & 0.00950 & 0.01359 \\
\hline $\begin{array}{c}\text { Assigned } \\
\text { Total Uncertainty }\left(U_{\mathrm{g}}\right)\end{array}$ & 0.0002 & 0.0002 & 0.0002 & 0.0004 & 0.0004 & 0.0009 & 0.002 & 0.006 & 0.010 & 0.02 \\
\hline \multicolumn{11}{|l|}{$($ Frequency $=1 \mathrm{kHz})$} \\
\hline Repeatability $\left(s_{\mathrm{grm}}\right)$ & $4.0 \mathrm{E}-05$ & $4.6 \mathrm{E}-05$ & $7.5 \mathrm{E}-05$ & $1.2 \mathrm{E}-04$ & $2.3 \mathrm{E}-04$ & $5.2 \mathrm{E}-04$ & $1.2 \mathrm{E}-03$ & $2.3 \mathrm{E}-03$ & $7.5 \mathrm{E}-03$ & $2.3 \mathrm{E}-02$ \\
\hline Predicted Values $\left(s_{\mathrm{gpd}}\right)$ & $1.0 \mathrm{E}-04$ & 2.0E-04 & $2.0 \mathrm{E}-04$ & $3.0 \mathrm{E}-04$ & $1.0 \mathrm{E}-03$ & $2.0 \mathrm{E}-03$ & $6.0 \mathrm{E}-03$ & $1.5 \mathrm{E}-02$ & $5.5 \mathrm{E}-02$ & $9.5 \mathrm{E}-02$ \\
\hline Type-A Std. Uncertainty $\left(u_{\text {ga }}\right)$ & $1.1 \mathrm{E}-04$ & 2.1E-04 & 2.1E-04 & 3.2E-04 & $1.0 \mathrm{E}-03$ & 2.1E-03 & $6.1 \mathrm{E}-03$ & $1.5 \mathrm{E}-02$ & $5.6 \mathrm{E}-02$ & 9.8E-02 \\
\hline Type-B Std. Uncertainty $\left(u_{\mathrm{gb}}\right)$ & $1.0 \mathrm{E}-04$ & $1.0 \mathrm{E}-04$ & $1.0 \mathrm{E}-04$ & 2.0E-04 & 2.7E-04 & 8.2E-04 & $2.9 \mathrm{E}-03$ & $8.6 \mathrm{E}-03$ & $1.8 \mathrm{E}-02$ & 5.1E-02 \\
\hline Expanded Uncertainty $\left(U_{\mathrm{g}}\right)$ & 0.00030 & 0.00046 & 0.00047 & 0.00076 & 0.00212 & 0.00444 & 0.01354 & 0.03487 & 0.11700 & 0.22018 \\
\hline $\begin{array}{c}\text { Assigned } \\
\text { Total Uncertainty }\left(U_{\mathrm{gt}}\right)\end{array}$ & 0.0003 & 0.0005 & 0.0005 & 0.001 & 0.003 & 0.005 & 0.02 & 0.04 & 0.12 & 0.3 \\
\hline \multicolumn{11}{|l|}{ (Frequency $=10 \mathrm{kHz}$ ) } \\
\hline Repeatability $\left(s_{\mathrm{grm}}\right)$ & $1.8 \mathrm{E}-04$ & 2.3E-04 & $5.8 \mathrm{E}-04$ & 1.2E-03 & $2.3 \mathrm{E}-03$ & 8.1E-03 & $2.3 \mathrm{E}-02$ & $6.4 \mathrm{E}-02$ & $3.5 \mathrm{E}-01$ & NA \\
\hline Predicted Values $\left(s_{\mathrm{gpd}}\right)$ & $3.5 \mathrm{E}-05$ & - & - & 2.3E-03 & - & - & $3.2 \mathrm{E}-02$ & - & - & NA \\
\hline Type-A Std. Uncertainty $\left(u_{\mathrm{ga}}\right)$ & $1.8 \mathrm{E}-04$ & 2.3E-04 & $5.8 \mathrm{E}-04$ & $2.6 \mathrm{E}-03$ & $2.3 \mathrm{E}-03$ & 8.1E-03 & $3.9 \mathrm{E}-02$ & $6.4 \mathrm{E}-02$ & $3.5 \mathrm{E}-01$ & NA \\
\hline Type-B Std. Uncertainty $\left(u_{\mathrm{gb}}\right)$ & $1.5 \mathrm{E}-04$ & $1.5 \mathrm{E}-04$ & $1.9 \mathrm{E}-04$ & $3.1 \mathrm{E}-03$ & $5.3 \mathrm{E}-03$ & $2.6 \mathrm{E}-02$ & $7.9 \mathrm{E}-02$ & $2.4 \mathrm{E}-01$ & $1.7 \mathrm{E}+00$ & NA \\
\hline Expanded Uncertainty $\left(U_{\mathrm{g}}\right)$ & 0.0005 & 0.0006 & 0.0012 & 0.0081 & 0.0115 & 0.0548 & 0.1773 & 0.5001 & 3.4532 & NA \\
\hline $\begin{array}{c}\text { Assigned } \\
\text { Total Uncertainty }\left(U_{\mathrm{gt}}\right)\end{array}$ & 0.001 & 0.001 & 0.005 & 0.01 & 0.02 & 0.06 & 0.2 & 0.5 & 4.0 & NA \\
\hline
\end{tabular}




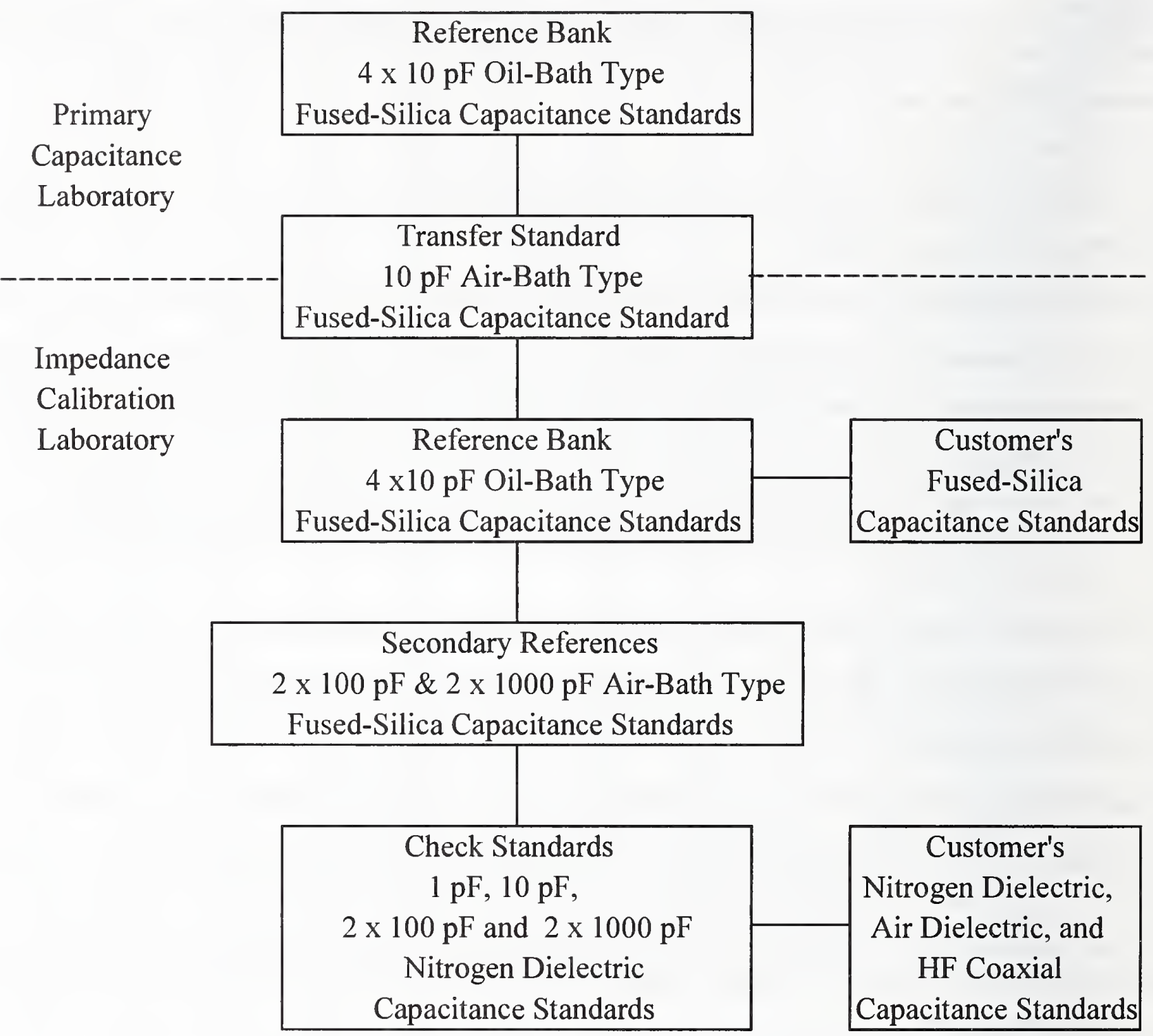

Figure 1. Block Diagram of the Farad Transfer and Calibration Process Using the Type-2 Bridge. 


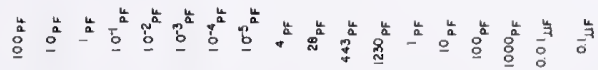

$$
\begin{aligned}
& \text { o }
\end{aligned}
$$
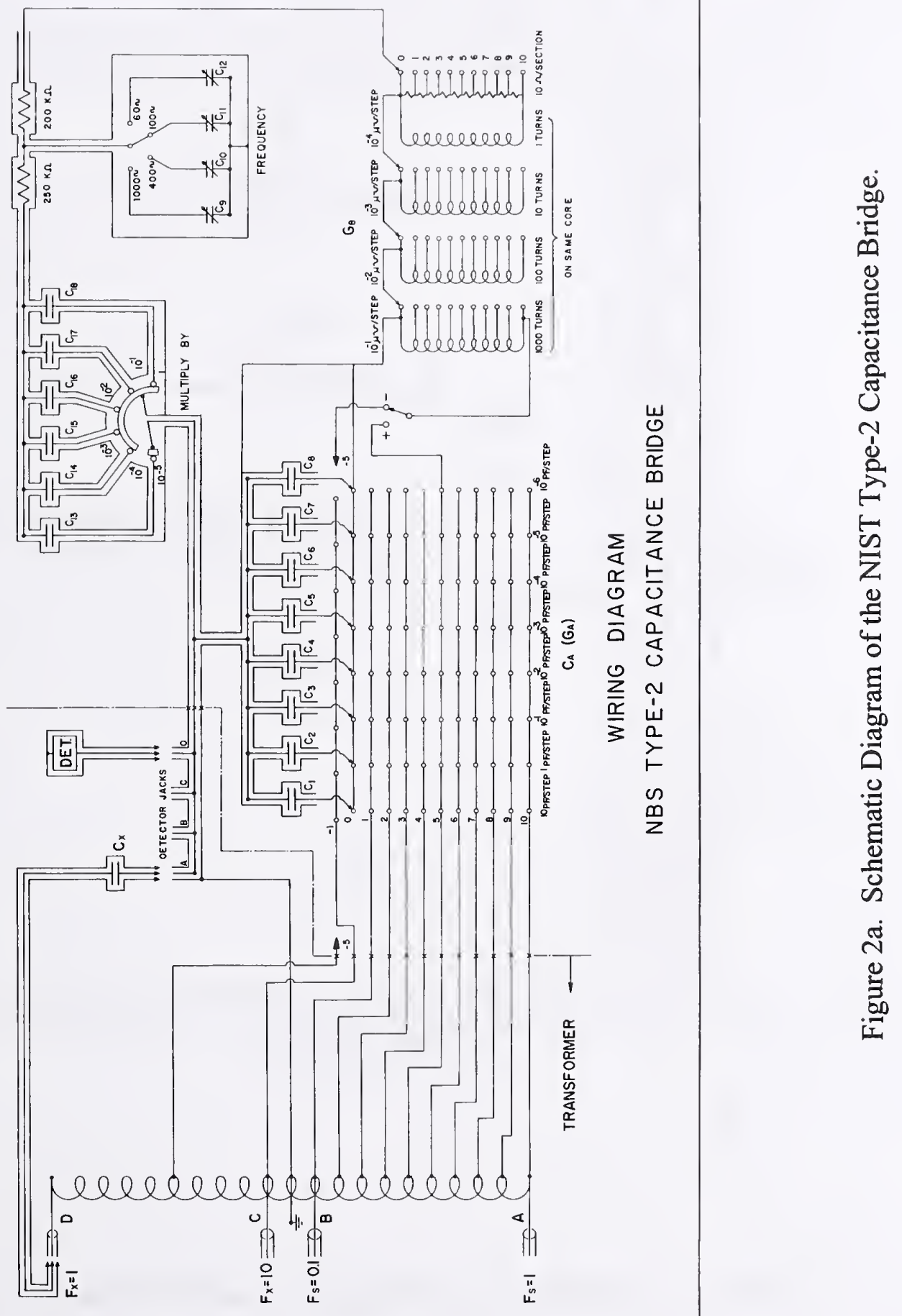


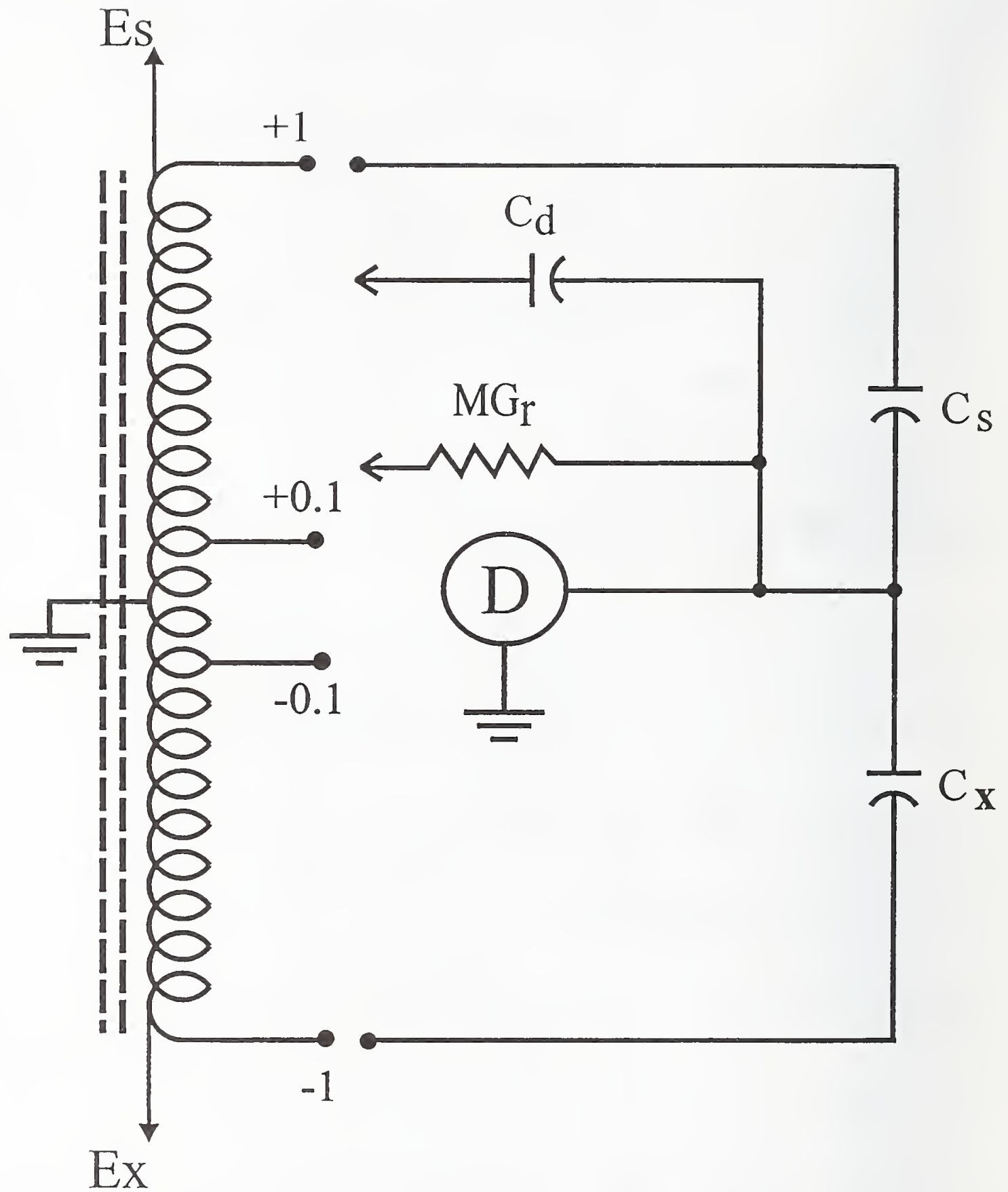

Figure 2b. Simplified Circuit Diagram of the NIST Type-2 Capacitance Bridge. 


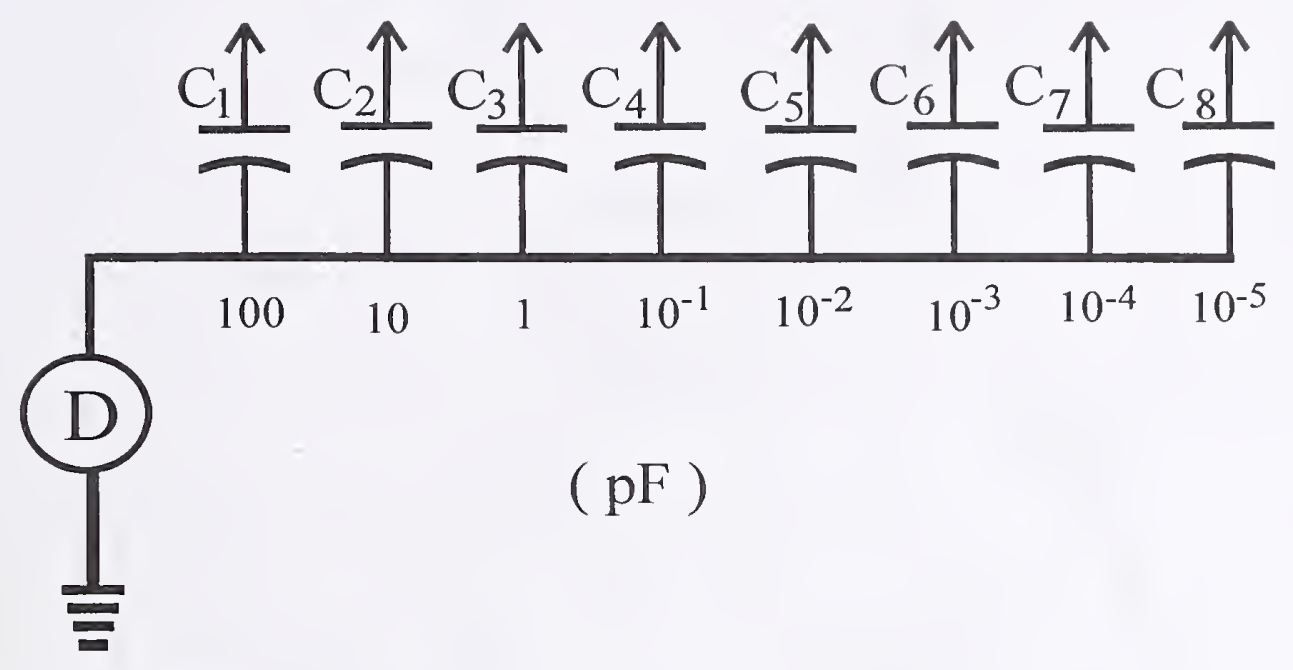

Figure 3. Internal Capacitors of the Type-2 Bridge.

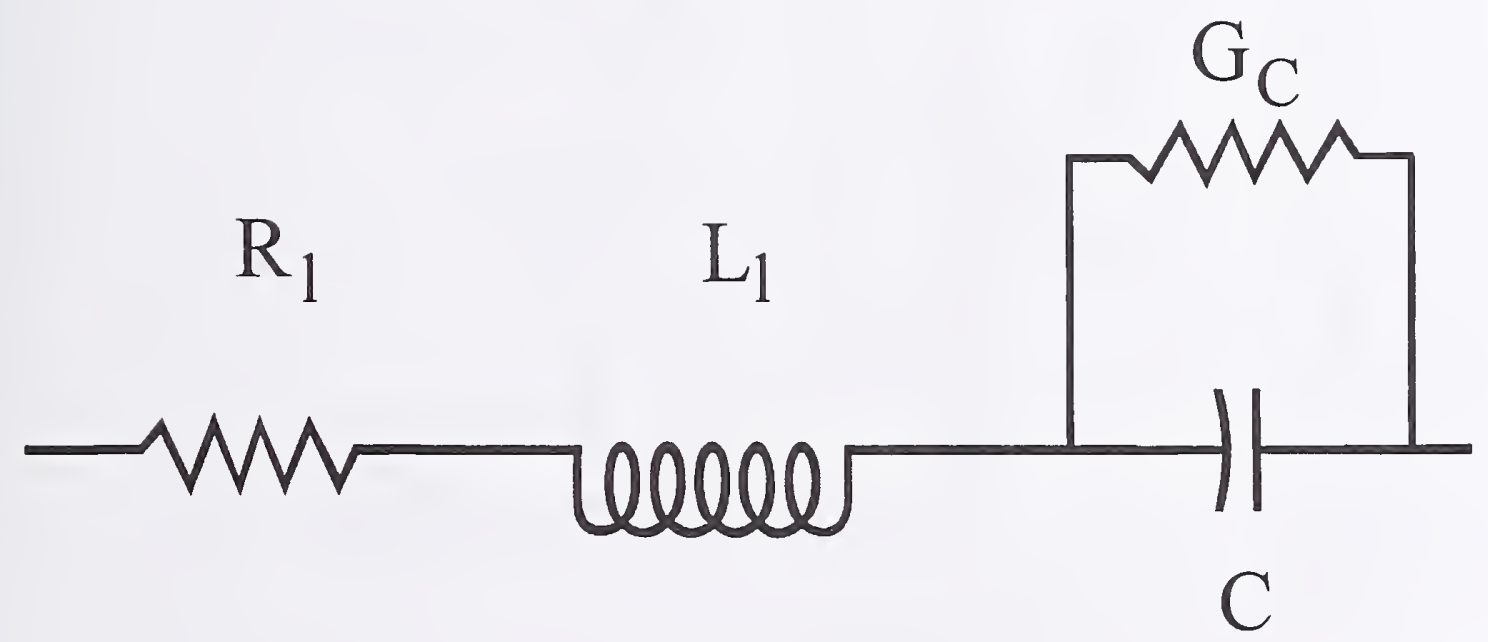

Figure 4. Lead Impedance of a Capacitor Connected to the Bridge. 


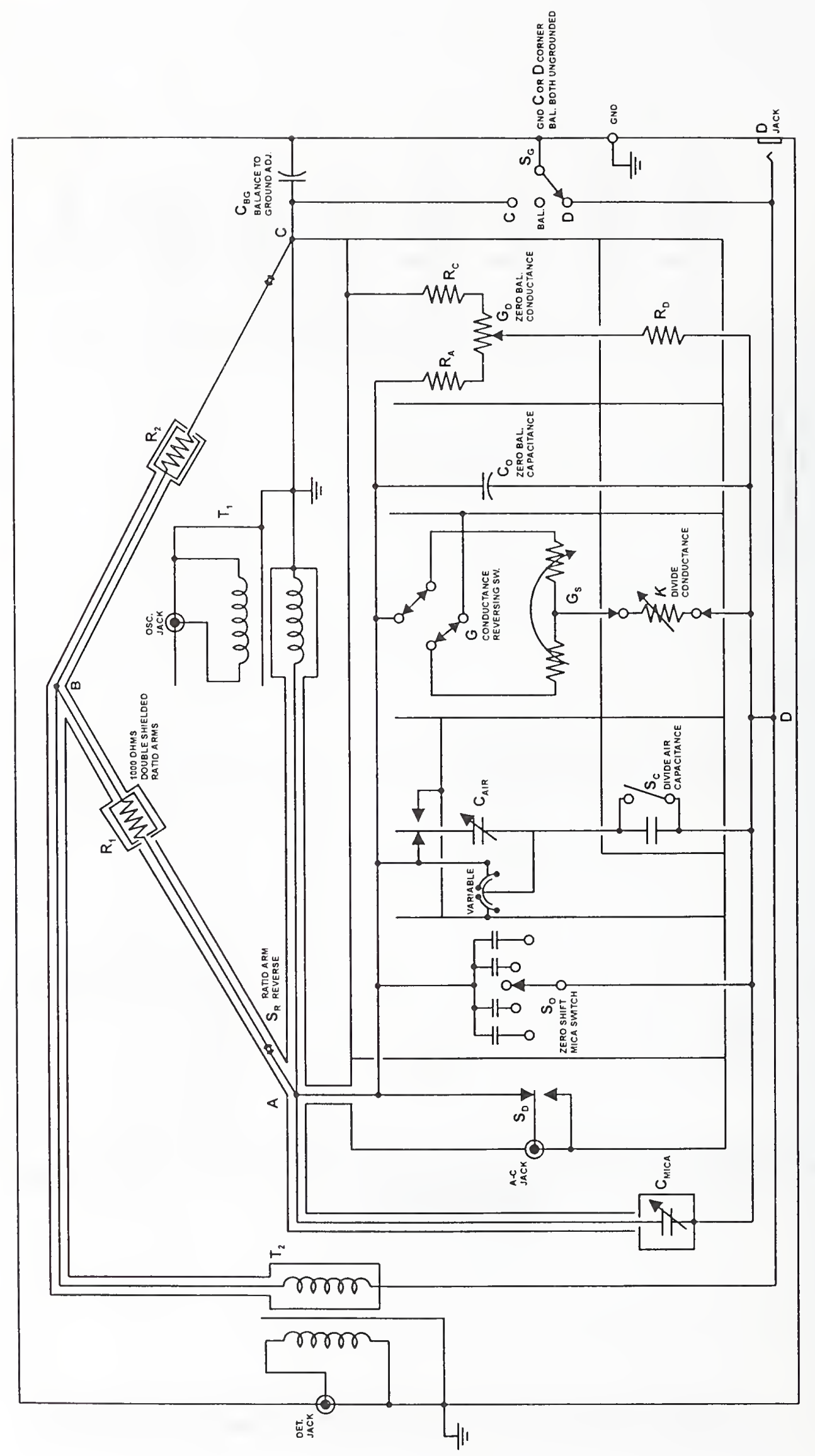

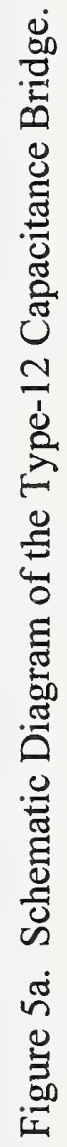




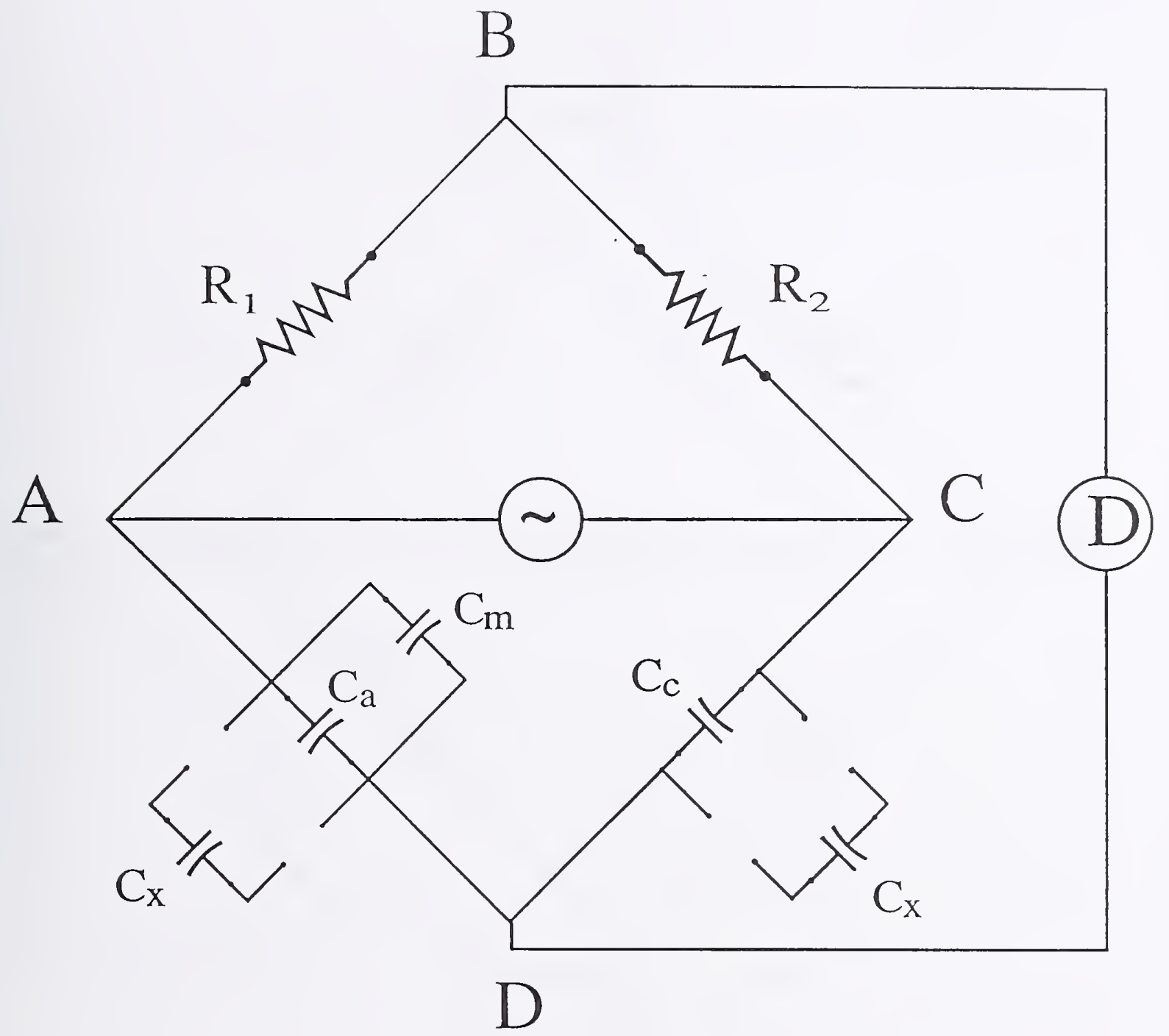

Figure 5b. Simplified Circuit Diagram of the Type-12 Capacitance Bridge. 


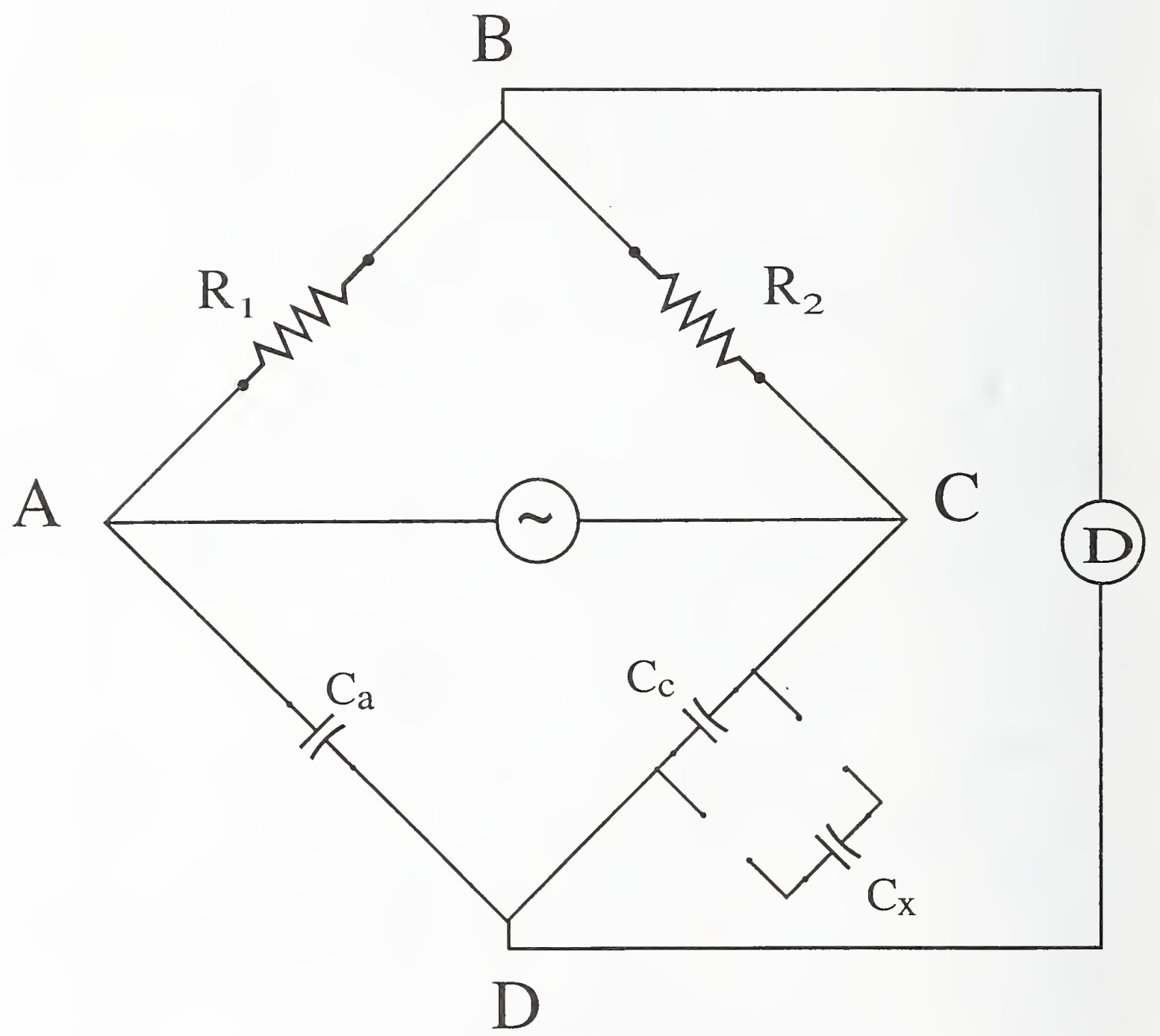

Figure 6. Components of the Type-12 Bridge for Two-Terminal Low-Capacitance Values Measurements. 


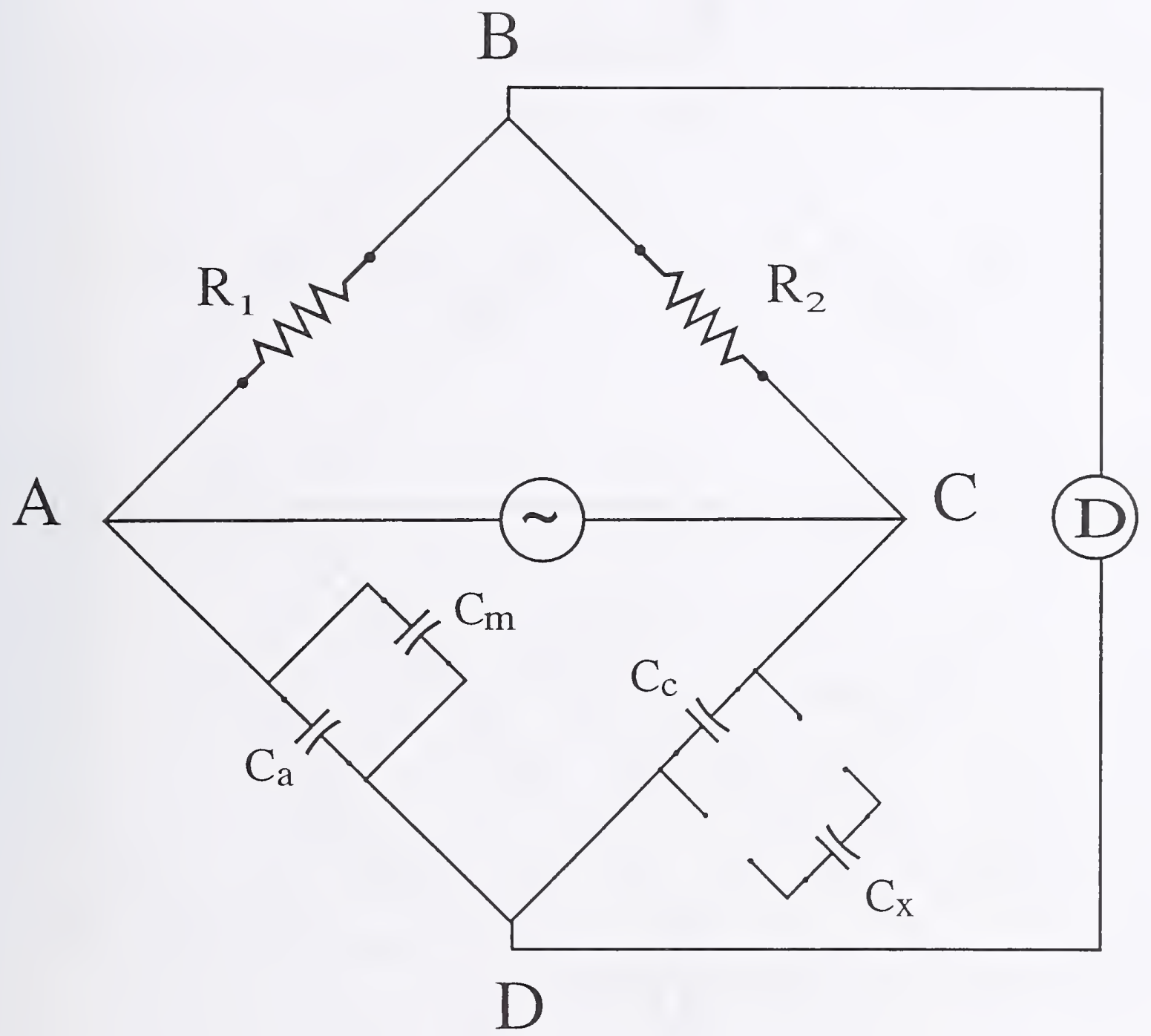

Figure 7. Components of the Type-12 Bridge for Two-Terminal High-Capacitance Values Measurements. 


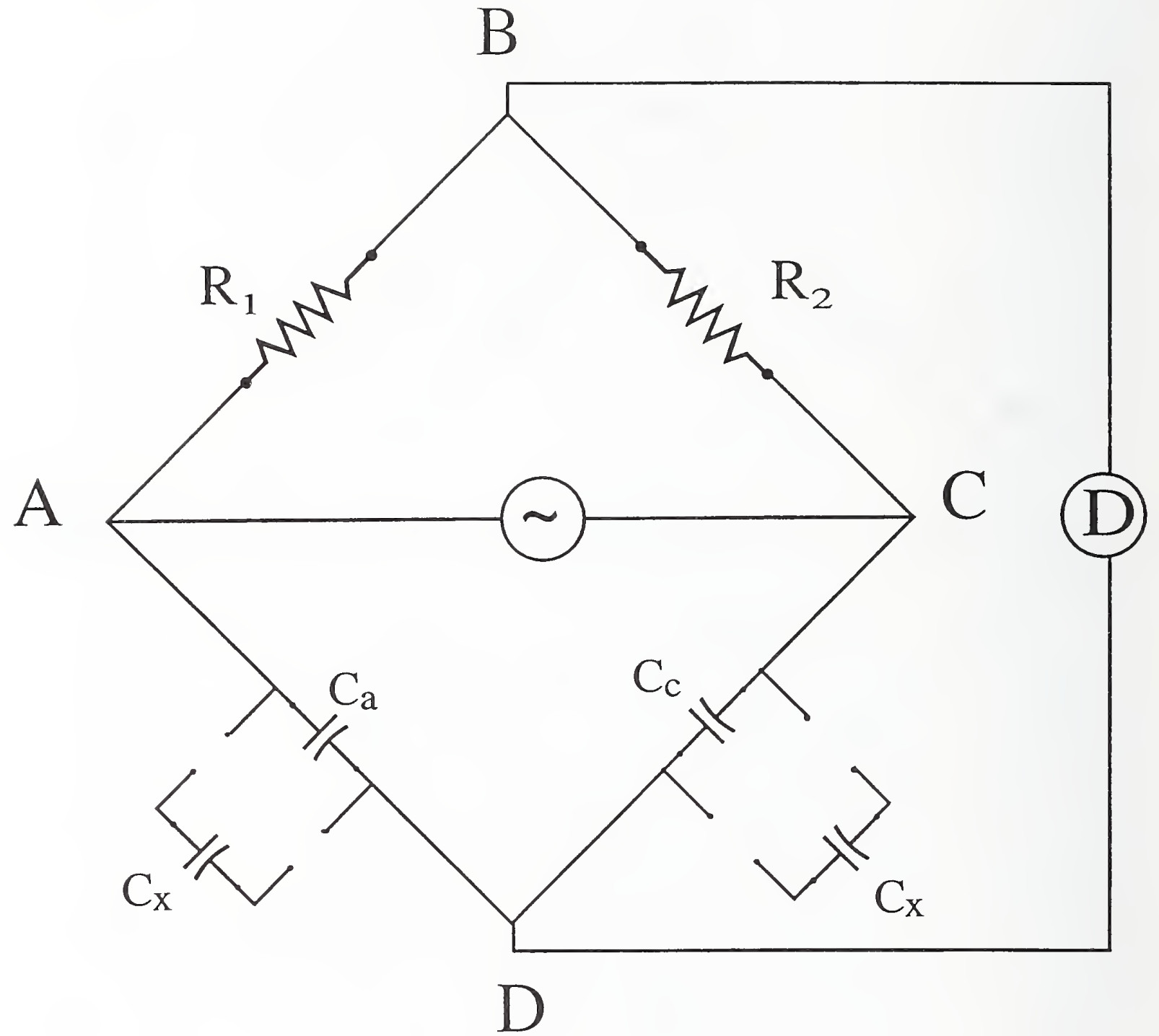

Figure 8. Components of the Type-12 Bridge for Three-Terminal Low-Capacitance Values Measurements. 


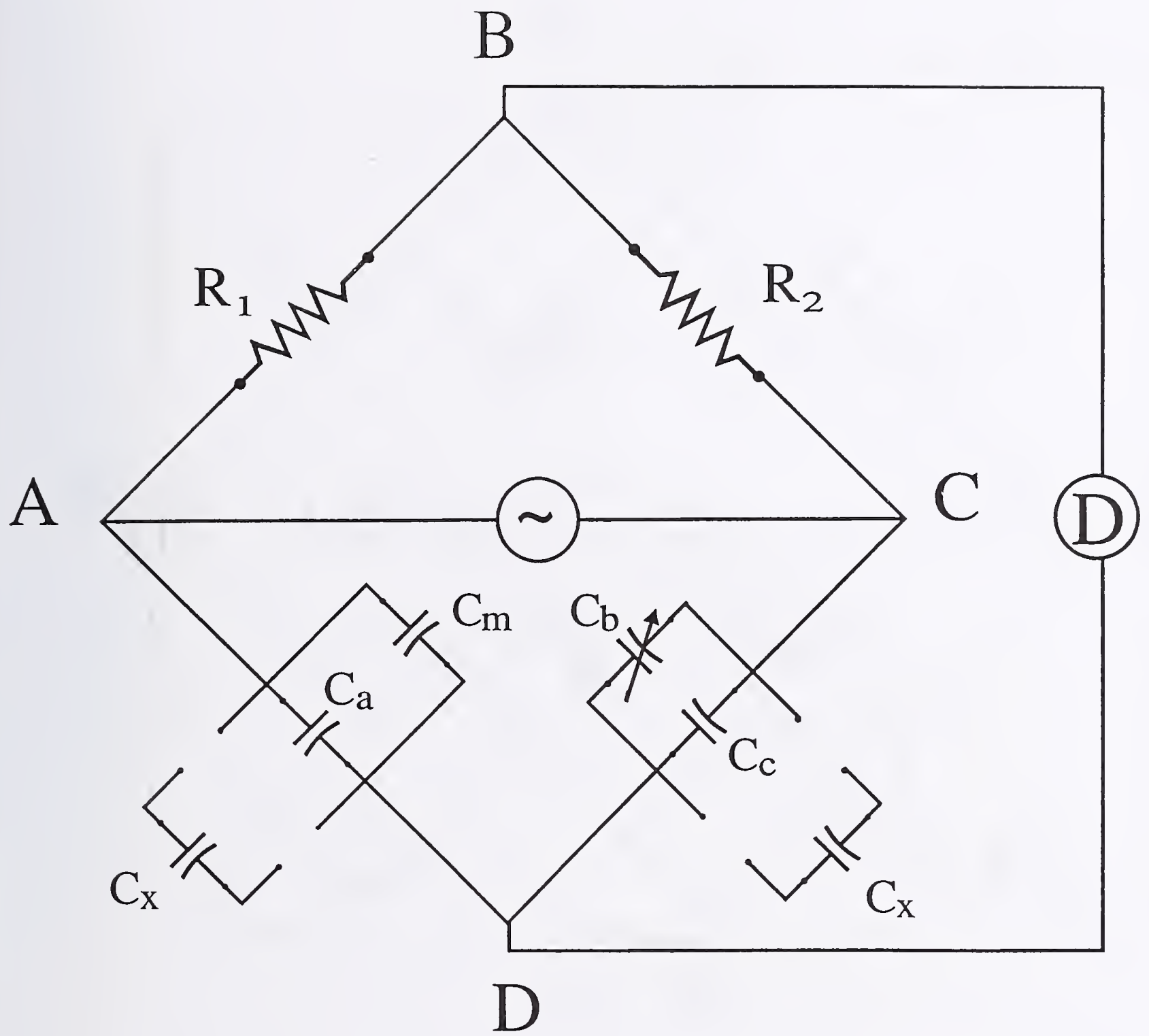

Figure 9. Components of the Type-12 Bridge for Three-Terminal Measurements of Capacitors up to $0.5 \mu \mathrm{F}$. 


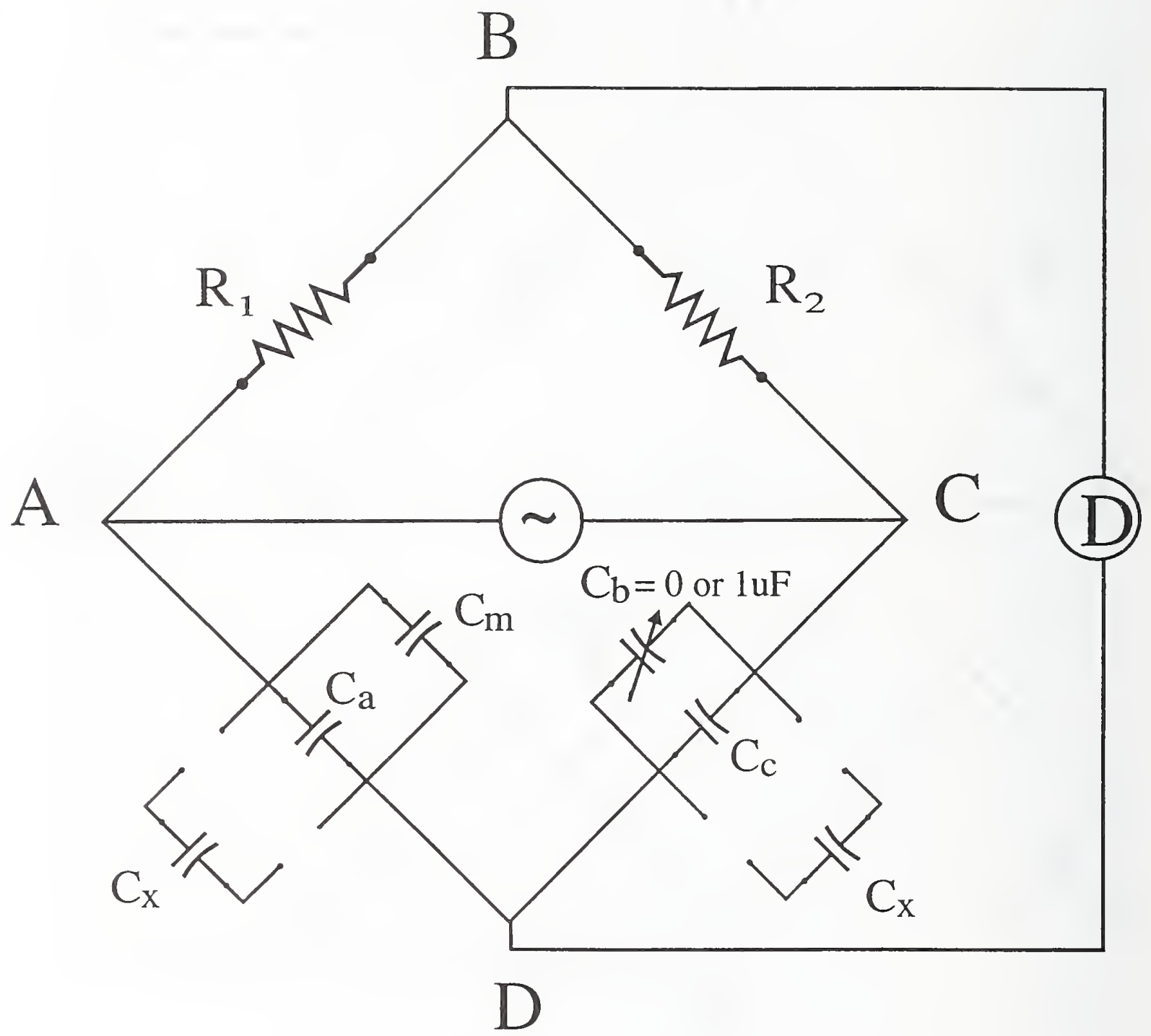

Figure 10. Components of the Type-12 Bridge for Three-Terminal Measurements of Capacitors Larger Than $0.5 \mu \mathrm{F}$. 


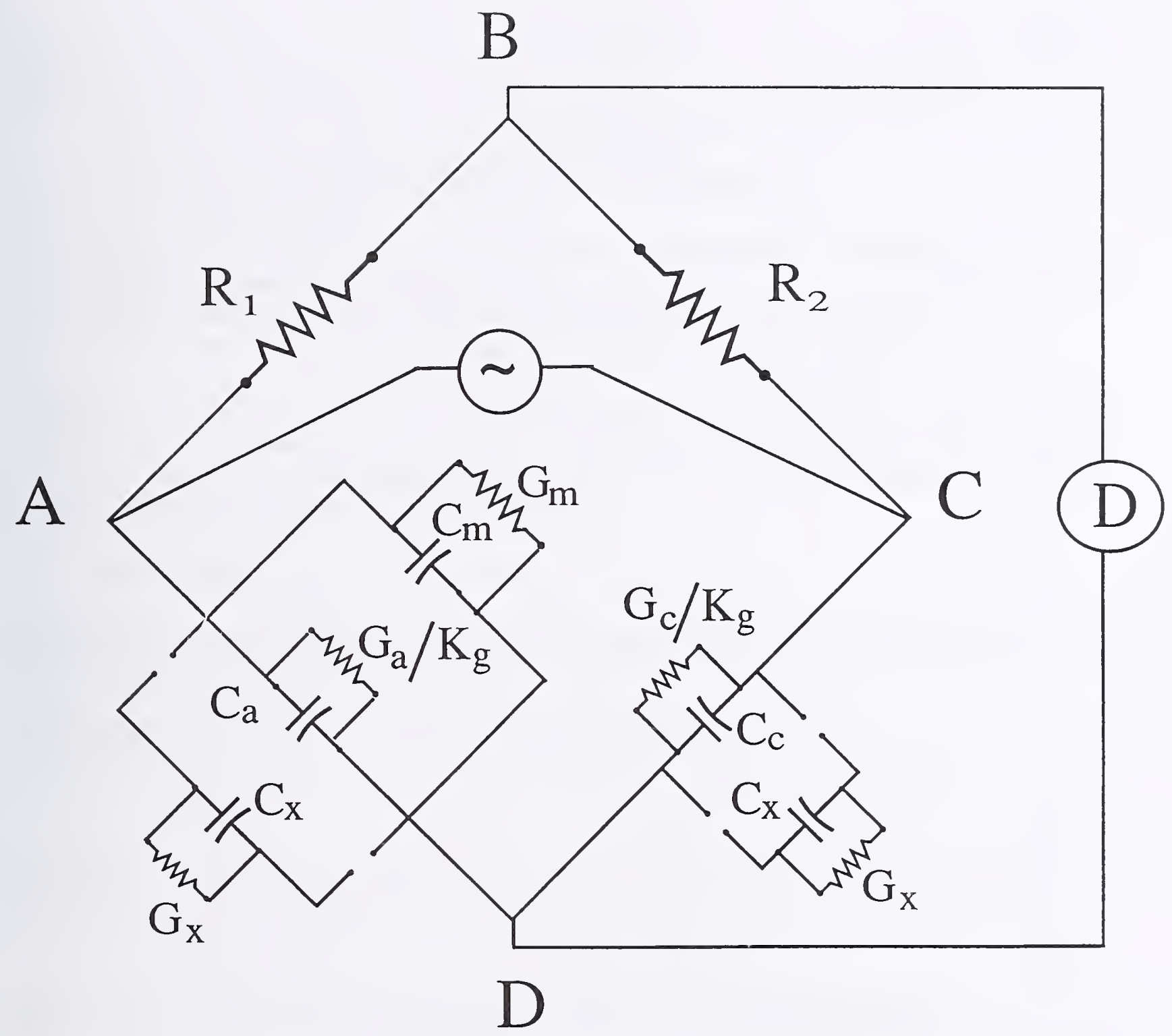

Figure 11. Simplified Circuit Diagram of the Type-12 Capacitance Bridge Including the Conductance Components. 

Rewrite the balance equation and the corrections to the $1: 1$ ratio of the Type- 2 bridge as shown in Eqs. (6) to (9) of the text as Eqs. (A1) to (A4) as:

$$
E_{\mathrm{S}} Y_{\mathrm{S}}+E_{\mathrm{S}}\left(\sum r_{i} y_{i}\right)+p_{5} E_{\mathrm{S}}\left(M \sum g_{i}\right)=-E_{\mathrm{x}} Y_{\mathrm{x}}
$$

where $E_{\mathrm{S}}$ and $E_{\mathrm{x}}$ are voltages produced by the transformer windings on the reference, $\mathbf{C}_{\mathrm{s}}$ and the unknown capacitor, $\mathbf{C}_{\mathrm{x}}$ sides of the bridge, respectively,

$Y_{\mathrm{s}}$ and $Y_{\mathrm{x}}$ are admittances of $\mathbf{C}_{\mathbf{s}}$ and $\mathbf{C}_{\mathbf{X}}$, respectively,

$r_{i}$ is the dial reading of $i$ dial applying voltage to capacitor $\mathbf{c}_{i}$,

$y_{i}$ is the admittance of $\mathbf{c}_{\boldsymbol{i}}$,

$g_{i}$ is the effective admittance associated with the settings of the $i^{\text {th }}$ conductance dial coupled with the frequency compensation network,

$p_{5}$ is a constant whose value can be taken as either plus or minus 0.5 , and

$M$ is the multiplier of the conductance dial settings, where $10^{-5} \leq M \leq 1$.

Corrections for errors of 1:1 ratio of the Type- 2 bridge can be determined in two measurements by using two capacitors of nominally equal value. One measurement is taken with $\mathbf{C}_{\mathbf{x}}$ and $\mathbf{C}_{\mathbf{S}}$ connected as shown in Fig. 2 b. The other measurement is taken with $\mathbf{C}_{\mathbf{X}}$ and $\mathbf{C}_{\mathbf{S}}$ interchanged. The balance equation of the second measurement can be written as:

$$
E_{\mathrm{S}} Y_{\mathrm{x}}+E_{\mathrm{S}}\left(\sum r_{n} y_{n}\right)+p_{5} E_{\mathrm{s}}\left(M^{\prime} \sum g_{n}\right)=-E_{\mathrm{x}} Y_{\mathrm{S}}
$$

where parameters with subscript $n$ have the same meanings as those in Eq. (A1) with subscript $i$, and $M^{\prime}$ is the multiplier of the second balance. $M^{\prime}$ is normally equal to $M$.

By combining Eqs. (A1) and (A2), (with $M=M^{\prime}$ ) the result becomes:

$$
\left(E_{\mathrm{S}}+E_{\mathrm{x}}\right)\left(Y_{\mathrm{s}}+Y_{\mathrm{x}}\right)+E_{\mathrm{s}}\left(\sum r_{i} y_{i}+\sum r_{n}+y_{n}\right)+p_{5} E_{\mathrm{s}} M\left(\sum g_{i}+\sum g_{n}\right)=0 \text {. }
$$

Assuming $E_{s}=1 \mathrm{~V}$ as the reference, and by the definition of 1:1 ratio, $\left(E_{x} / E_{s}\right) \cong-1$, then:

$$
E_{\mathrm{X}}=-(1+a+\mathrm{j} b)
$$

where $a$ and $b$ are the in-phase and quadrature corrections to the ratio, respectively.

Substitution of Eq. (A4) into Eq. (A3) gives:

$$
(a+\mathrm{j} b)=\left\{\left[\left(\sum r_{i} y_{i}+\sum r_{n} y_{n}\right)+p_{5} M\left(\sum g_{i}+\sum g_{n}\right)\right] /\left(Y_{\mathrm{s}}+Y_{\mathrm{x}}\right)\right\} .
$$

Let $Y_{\mathrm{k}}=\mathrm{j} \omega C_{\mathrm{k}}\left(1-\mathrm{j} D F_{\mathrm{k}}\right), y_{\mathrm{k}}=\mathrm{j} \omega c_{\mathrm{k}}\left(1-\mathrm{j} d f_{\mathrm{k}}\right)$, and $g_{\mathrm{k}}=g_{\mathrm{k}}\left(1+\mathrm{j} x_{\mathrm{k}}\right)$, where $D F_{\mathrm{k}}$ and $d f_{\mathrm{k}}$ are the dissipation factors of the respective capacitors $\mathbf{C}_{\mathbf{k}}$ and $\mathbf{c}_{\mathbf{k}}$, and $x_{\mathrm{k}}$ is the phase correction of the resistor network used in the conductance dials. The magnitudes of $D F_{\mathrm{k}}, d f_{\mathrm{k}}$, and $x_{\mathrm{k}}$ are all less than 
$10^{-5}$. Therefore, by eliminating these terms, the approximate equation for the ratio corrections is:

$$
a_{1}+\mathrm{j} b_{1}=\left[\left(\sum r_{i} c_{i}+\sum r_{n} c_{n}\right)+\mathrm{j}(-1 / \omega) p_{5} M\left(\sum g_{i}+\sum g_{n}\right)\right] /\left(C_{\mathrm{S}}+C_{\mathrm{x}}\right),
$$

where $a_{1}$ and $b_{1}$ are in-phase and quadrature corrections applied to the 1:1 ratio.

The design of performing the above two measurements to obtain ratio corrections is an attempt to eliminate errors in non-unity ratios. However, the error sources which occurred during both measurements are similar and affect the extent to which the offset cannot be eliminated. Therefore, the exact values of ratio corrections in Eq. (A5) can be expressed as:

$$
(a+\mathrm{j} b)=a_{1}+e_{\mathrm{a}}+\mathrm{j} b_{1}+\mathrm{j} e_{\mathrm{b}}
$$

where $e_{\mathrm{a}}$ and $e_{\mathrm{b}}$ are the errors in the in-phase and quadrature corrections, respectively, of the 1:1 ratio, and these can be derived by combining Eqs. (A5), (A6), and (A7) as follows.

By including the in-phase and quadrature components, the first term in the numerator of the right hand side of the Eq. (A5) can be written as:

$$
\begin{aligned}
\left(\sum r_{i} y_{i}+\sum r_{n} y_{n}\right) & =\sum r_{i}\left(\mathrm{j} \omega c_{i}\right)\left(1-\mathrm{j} d f_{i}\right)+\sum r_{n}\left(\mathrm{j} \omega c_{n}\right)\left(1-\mathrm{j} d f_{n}\right) \\
& =\omega\left[\left(\sum r_{i} c_{i} d f_{i}+\sum r_{n} c_{n} d f_{n}\right)+\mathrm{j}\left(\sum r_{i} c_{i}+\sum r_{n} c_{n}\right)\right] .
\end{aligned}
$$

The second term in the numerator of the right hand side of the Eq. (A5) can be written as:

$$
\begin{aligned}
p_{5} M\left(\sum g_{i}+\sum g_{n}\right) & =p_{5} M\left[\sum g_{i}\left(1+\mathrm{j} x_{i}\right)+\sum g_{n}\left(1+\mathrm{j} x_{n}\right)\right] \\
& =p_{5} M\left[\left(\sum g_{i}+\sum g_{n}\right)+\mathrm{j}\left(\sum g_{i} x_{i}+\sum g_{n} x_{n}\right)\right] .
\end{aligned}
$$

The numerator of the right hand side of the Eq. (A5) is the summation of Eqs. (A8) and (A9), which is:

$$
\begin{aligned}
& \left(\sum r_{i} y_{i}+\sum r_{n} y_{n}\right)+p_{5} M\left(\sum g_{i}+\sum g_{n}\right)= \\
& \begin{array}{l}
\omega\left[\left(\sum r_{i} c_{i} d f_{i}+\sum r_{n} c_{n} d f_{n}\right)+\left(p_{5} M / \omega\right)\left(\sum g_{i}+\sum g_{n}\right)\right] \\
\quad+j \omega\left[\left(\sum r_{i} c_{i}+\sum r_{n} c_{n}\right)+\left(p_{5} M / \omega\right)\left(\sum g_{i} x_{i}+\sum g_{n} x_{n}\right)\right] .
\end{array}
\end{aligned}
$$

The denominator of the right hand side of the Eq. (A5) can be written as:

$$
\left(Y_{\mathrm{s}}+Y_{\mathrm{x}}\right)=\mathrm{j} \omega C \mathrm{~s}\left(1-\mathrm{j} D F_{\mathrm{s}}\right)+\mathrm{j} \omega C \mathrm{x}\left(1-\mathrm{j} D F_{\mathrm{x}}\right)=\omega\left[\left(C \mathrm{~s} D F_{\mathrm{s}}+C \mathrm{x} D F_{\mathrm{x}}\right)+\mathrm{j}(C \mathrm{~s}+C \mathrm{x})\right] .
$$

Thus,

$$
\left[1 /\left(Y_{\mathrm{s}}+Y_{\mathrm{x}}\right)\right]=(1 / \omega)\left\{1 /\left[\left(C_{\mathrm{s}} D F_{\mathrm{s}}+C_{\mathrm{x}} D F_{\mathrm{x}}\right)+\mathrm{j}\left(C_{\mathrm{s}}+C_{\mathrm{X}}\right)\right]\right\}
$$


Multiply both the numerator and the denominator of the right hand side of Eq. (A11) by $\left[\left(C_{\mathrm{S}} D f_{\mathrm{S}}+C_{\mathrm{X}} D F_{\mathrm{X}}\right)-\mathrm{j}\left(C_{\mathrm{S}}+C_{\mathrm{x}}\right)\right]$ and eliminate the second order terms of $D F_{\mathrm{S}}$ and $D f_{\mathrm{X}}$. Eq. (A11) becomes:

$$
\left[1 /\left(Y_{\mathrm{s}}+Y_{\mathrm{X}}\right)\right]=(1 / \omega)\left\{\left[\left(C_{\mathrm{S}} D F_{\mathrm{S}}+C_{\mathrm{X}} D F_{\mathrm{X}}\right) /\left(C_{\mathrm{S}}+C_{\mathrm{X}}\right)^{2}\right]-\mathrm{j}\left[1 /\left(C_{\mathrm{S}}+C_{\mathrm{X}}\right)\right]\right\}
$$

In measurements using the $1: 1$ ratio, $C_{\mathrm{S}} \cong C_{\mathrm{X}}$, and

$$
\begin{aligned}
& {\left[\left(C_{\mathrm{s}} D F_{\mathrm{s}}+C_{\mathrm{x}} \mathrm{DF} F_{\mathrm{x}}\right) /\left(C_{\mathrm{s}}+C_{\mathrm{x}}\right)\right] \cong\left[\left(D F_{\mathrm{s}}+D F_{\mathrm{X}}\right) / 2\right] . \text { Then, }} \\
& {\left[1 /\left(Y_{\mathrm{s}}+Y_{\mathrm{x}}\right)\right]=(1 / \omega)\left\{\left(D F_{\mathrm{s}}+D F_{\mathrm{x}}\right) /\left[2\left(C_{\mathrm{s}}+C_{\mathrm{x}}\right)\right]\right\}-\mathrm{j}\left\{1 /\left[\omega\left(C_{\mathrm{s}}+C_{\mathrm{x}}\right)\right]\right\} .}
\end{aligned}
$$

The expression of Eq. (A5) can be obtained by the multiplication of Eq. (A10) and (A12). After the separation of the real and imaginary parts, and the elimination of the second order terms of $D F_{S}$, $D F_{\mathrm{x}}, d f_{i}, d f_{n}, x_{i}$, and $x_{n}$, the in-phase correction, $a$, and the quadrature correction, $b$ of the 1:1 ratio can be expressed as:

$$
\begin{aligned}
a=\{ & \left(p_{5} M / \omega\right)\left[(1 / 2)\left(\sum g_{i}+\sum g_{n}\right)\left(D F_{\mathrm{S}}+D F_{\mathrm{x}}\right)+\left(\sum g_{i} x_{i}+\sum g_{n} x_{n}\right)\right] \\
& \left.+\left(\sum r_{i} c_{i}+\sum r_{n} c_{n}\right)\right\} /\left(C_{\mathrm{S}}+C_{\mathrm{x}}\right),
\end{aligned}
$$

and

$$
\begin{aligned}
b=\{ & {\left[(1 / 2)\left(\sum r_{i} c_{i}+\sum r_{n} c_{n}\right)\left(D F_{\mathrm{S}}+D F_{\mathrm{x}}\right)-\left(\sum r_{i} c_{i} d f_{i}+\sum r_{n} c_{n} d f_{n}\right)\right] } \\
& \left.-\left(p_{5} M / \omega\right)\left(\sum g_{i}+\sum g_{n}\right)\right\} /\left(C_{\mathrm{S}}+C_{\mathrm{X}}\right) .
\end{aligned}
$$

According to Eq. (A7),

and

$$
e_{\mathrm{a}}=a-a_{1}
$$

$$
e_{\mathrm{b}}=b-b 1 \text {. }
$$

By substituting $a_{1}$ and $b_{1}$ from Eq. (A6) and $a$ and $b$ from Eq. (A13) into Eq. (A14), the errors in the in-phase and quadrature corrections of the 1:1 ratio become:

and

$$
e_{\mathrm{a}}=\left(p_{5} M / \omega\right)\left[(1 / 2)\left(\sum g_{i}+\sum g_{n}\right)\left(D F_{\mathrm{S}}+D F_{\mathrm{x}}\right)+\left(\sum g_{i} x_{i}+\sum g_{n} x_{n}\right)\right] /\left(C_{\mathrm{S}}+C_{\mathrm{x}}\right),
$$

$$
e_{\mathrm{b}}=\left[(1 / 2)\left(\sum r_{i} c_{i}+\sum r_{n} c_{n}\right)\left(D F_{\mathrm{S}}+D F_{\mathrm{x}}\right)-\left(\sum r_{i} c_{i} d f_{i}+\sum r_{n} c_{n} d f_{n}\right)\right] /\left(C_{\mathrm{S}}+C_{\mathrm{x}}\right) \text {. }
$$

In general, the capacitance and conductance dial readings of the two measurements when $\mathbf{C}_{\mathbf{X}}$ and $\mathrm{C}_{\mathrm{s}}$ are interchanged are in opposite signs, i.e., one is positive and the other is negative. Therefore, the magnitude of summations of the dial readings of the two measurements ( $i$ and $n)$ in Eqs. (A15) and (A16) is usually less than each individual reading, and these can be estimated from the measured data. 
In order to estimate the standard uncertainties in the ratio corrections, a few assumptions and approximations are needed to apply to Eqs. (A15) and (A16). In general, all values of $D F_{\mathrm{S}}, D F_{\mathrm{X}}$, $d f_{i}, d f_{n}, x_{i}$, and $x_{n}$ are less than $10^{-5}$, and ratios of $\left[x_{i} /\left(D F_{\mathrm{s}}+D F_{\mathrm{x}}\right)\right]$ and $\left[x_{n} /\left(D F_{\mathrm{S}}+D F_{\mathrm{x}}\right)\right]$ are less than 1. Maximum bounds of errors $\pm e_{\mathrm{a}}$ and $\pm e_{\mathrm{b}}$, in ratio corrections are estimated from the following sources and related assumptions; and the standard uncertainties, $s_{\mathrm{a}}$ and $s_{\mathrm{b}}$, are obtained in accordance to Eq. (4) of the text.

\section{1) Uncertainties estimated from the measured data}

According to the data from measurements performed on capacitors of various nominal values, it was found that:

$\left|\left(\sum g_{i}+\sum g_{n}\right)\right| \leq 10^{-8} \mathrm{~S}$ and $\left|\left(\sum r_{i} c_{i}+\sum r_{n} c_{n}\right)\right| \leq 10^{-5} \mathrm{pF}\left(\right.$ for $\left.C_{\mathbf{s}}=C_{\mathbf{x}}=10 \mathrm{pF}\right)$, $\left|\left(\sum g_{i}+\sum g_{n}\right)\right| \leq 10^{-7} \mathrm{~S}$ and $\left|\left(\sum r_{i} c_{i}+\sum r_{n} c_{n}\right)\right| \leq 10^{-4} \mathrm{pF}\left(\right.$ for $\left.C_{\mathbf{s}}=C_{\mathbf{x}}=100 \mathrm{pF}\right)$, $\left|\left(\sum g_{i}+\sum g_{n}\right)\right| \leq 10^{-6} \mathrm{~S}$ and $\left|\left(\sum r_{i} c_{i}+\sum r_{n} c_{n}\right)\right| \leq 10^{-3} \mathrm{pF}\left(\right.$ for $\left.C_{\mathbf{s}}=C_{\mathbf{x}}=1000 \mathrm{pF}\right)$, and $M \leq 10^{-3}$.

By appropriate multiplication in Eqs. (A15) and (A16), the maximum bounds of errors are estimated, and the standard uncertainties are found to be:

$s_{\mathrm{a} 1} \leq 0.001 \mathrm{ppm}$ and $s_{\mathrm{b} 1} \ll 0.001 \mathrm{ppm}$,

where $s_{\mathrm{a} 1}$ and $s_{\mathrm{b} 1}$ are the standard uncertainties from measured data in the in-phase and quadrature corrections of the 1:1 ratio, respectively.

2) Uncertainties due to the inaccuracies of the external capacitance standards

Assume the external capacitors, $\mathbf{C}_{\mathbf{S}}$ and $\mathbf{C}_{\mathbf{x}}$, are inaccurate by $\pm 0.01 \%$, the maximum bounds of errors are estimated by substituting $C_{S}=C_{S}\left(1 \pm 10^{-4}\right)$ and $C_{\mathrm{x}}=C_{\mathrm{x}}\left(1 \pm 10^{-4}\right)$ into Eqs. (A15) and (A16). Accordingly,

$s_{\mathrm{a} 2}<0.001 \mathrm{ppm}$ and $s_{\mathrm{b} 2} \ll 0.001 \mathrm{ppm}$,

where $s_{\mathrm{a} 2}$ and $s_{\mathrm{b} 2}$ are the standard uncertainties of the external capacitance standards, in the in-phase and quadrature corrections of the 1:1 ratio, respectively.

3) Uncertainties due to the dial readings

Assume the capacitance and conductance dials are inaccurate by $\pm 1 \%$, the maximum bounds of errors are estimated by substituting $c_{i}=c_{i}(1 \pm 0.01), c_{n}=c_{n}(1 \pm 0.01), g_{i}=g_{i}(1 \pm 0.01)$, and $g_{n}=g_{n}(1 \pm 0.01)$ into Eqs. (A15) and (A16). Accordingly,

$s_{\mathrm{a} 3} \ll 0.001 \mathrm{ppm}$ and $s_{\mathrm{b} 3} \ll 0.001 \mathrm{ppm}$,

where $s_{\mathrm{a} 3}$ and $s_{\mathrm{b} 3}$ are the standard uncertainties of the dial readings, in the in-phase and quadrature corrections of the 1:1 ratio, respectively. 
The sensitivity of the conductance dials is such that changes of the \pm 1 step on the fourth dial do not affect the balance. This introduces a standard uncertainty to the in-phase correction of:

$s_{\mathrm{a} 4} \leq 0.002 \mathrm{ppm}$,

where $s_{\mathrm{a} 4}$ is the standard uncertainty in the in-phase correction of the 1:1 ratio from the interpolation of the last dial.

The sensitivity of the capacitance dials is such that the difference between two steps of the last dial can be estimated to gain another digit of accuracy. Such interpolation introduces the maximum bounds of error of $\pm\left(3 \times 10^{-7}\right) \mathrm{pF}$ to the dial readings, which affects the quadrature correction according to the nominal values of test capacitors:

$\begin{aligned} s_{\mathrm{b} 4} \leq 0.02 \mathrm{ppm} & & \left(\text { for } C_{\mathrm{s}}=C_{\mathbf{X}}=10 \mathrm{pF}\right), \\ s_{\mathrm{b} 4} \leq 0.002 \mathrm{ppm} & & \left(\text { for } C_{\mathrm{s}}=C_{\mathbf{X}}=100 \mathrm{pF}\right), \text { and } \\ s_{\mathrm{b} 4} \leq 0.0002 \mathrm{ppm} & & \left(\text { for } C_{\mathbf{s}}=C_{\mathbf{x}}=1000 \mathrm{pF}\right),\end{aligned}$

where $s_{\mathrm{b} 4}$ is the standard uncertainty in the quadrature correction of the 1:1 ratio from the interpolation of the last dial.

3) Uncertainties due to load admittance and lead impedance

An accurate method to analyze and measure the components of loading errors and lead impedance was discussed and calculated in [5]. The maximum bounds of errors in ratio corrections owing to loading effect and lead impedance are estimated. Accordingly,

$s_{\mathrm{a} 5} \leq 0.004 \mathrm{ppm}$ and $s_{\mathrm{b} 5} \leq 0.019 \mathrm{ppm}$,

where $s_{\mathrm{a} 5}$ and $s_{\mathrm{b} 5}$ are the standard uncertainties due to load admittance and lead impedance, in the in-phase and quadrature corrections of the 1:1 ratio, respectively.

In routine calibration of capacitors using the Type- 2 bridge, only capacitance values are reported, even though both capacitance and conductance dials are used to obtain a balance. Therefore, only the in-phase standard uncertainties of the ratio corrections are to be included in the Type B standard uncertainty. The combined standard uncertainties that contribute to $1: 1$ ratio corrections, $s_{\mathrm{a}}$ and $s_{\mathrm{b}}$, are defined as the square root of the sum-of-squares (RSS) of each component, which are estimated to be:

and

$$
s_{\mathrm{a}}=\left(s_{\mathrm{a} 1}^{2}+s_{\mathrm{a} 2}{ }^{2}+s_{\mathrm{a} 3}{ }^{2}+s_{\mathrm{a} 4}{ }^{2}+s_{\mathrm{a} 5}{ }^{2}\right)^{(1 / 2)}<0.005 \mathrm{ppm},
$$

$$
s_{\mathrm{b}}=\left(s \mathrm{~b}_{1}{ }^{2}+s \mathrm{~b}_{2}{ }^{2}+s \mathrm{~b}_{3}{ }^{2}+s \mathrm{~b}_{4}{ }^{2}+s \mathrm{~b}_{5}{ }^{2}\right)^{(1 / 2)}<0.03 \mathrm{ppm} \text {. }
$$



APPENDIX B. CAPACITANCE DIAL CORRECTIONS OF THE TYPE-12 BRIDGE

Data and analyses of capacitance corrections for each capacitor dial of the Type- 12 bridge are included in the following tables:

Table B-1. Data and Analysis of the $(0.1 \mu \mathrm{F} / \mathrm{step})$ Mica Capacitor Dial Corrections of the Type- 12 Bridge at $100 \mathrm{~Hz}$

[All values are in $\mathrm{pF}$ except the dials which are in $(\mu \mathrm{F} / \mathrm{step})]$

\begin{tabular}{|c|c|c|c|c|c|c|c|c|c|c|}
\hline Date Dial & 0.1 & 0.2 & 0.3 & 0.4 & 0.5 & 0.6 & 0.7 & 0.8 & 0.9 & $0 . \mathrm{X}$ \\
\hline $6 / 67$ & 19.701 & 41.053 & 97.318 & 88.878 & 108.694 & 129.700 & 183.656 & 204.267 & 225.604 & 242.514 \\
\hline $11 / 67$ & 20.437 & 44.477 & 98.434 & 95.788 & 116.348 & 140.055 & 191.927 & 213.334 & 237.464 & 255.166 \\
\hline $5 / 68$ & 21.847 & 45.248 & 101.395 & 96.267 & 118.168 & 141.237 & 195.189 & 217.845 & 241.382 & 260.284 \\
\hline $9 / 69$ & 20.758 & 44.866 & \begin{tabular}{|l|}
99.509 \\
\end{tabular} & 100.527 & 121.418 & 145.294 & 197.802 & 219.432 & 243.710 & 261.716 \\
\hline $12 / 70$ & 20.664 & 45.464 & 100.178 & 98.560 & 119.320 & 143.764 & 196.294 & 217.848 & 242.717 & 260.552 \\
\hline $9 / 72$ & 20.817 & 45.897 & 96.451 & 106.001 & 127.050 & 151.815 & 199.822 & 221.694 & 246.911 & 265.385 \\
\hline $6 / 74$ & 21.012 & 44.577 & 96.139 & 99.552 & 120.756 & 143.991 & 193.474 & 215.618 & 239.273 & 257.560 \\
\hline $11 / 75$ & 21.435 & 46.830 & 103.188 & 105.313 & 126.560 & 151.373 & 205.533 & 227.700 & 253.190 & 271.885 \\
\hline $1 / 77$ & 21.693 & 45.409 & 104.405 & 100.598 & 122.436 & 145.847 & 202.762 & 225.370 & 249.734 & 268.604 \\
\hline $4 / 78$ & 19.716 & 41.565 & 99.931 & 93.988 & 113.837 & 135.478 & 191.719 & 212.355 & 234.427 & 251.531 \\
\hline $11 / 80$ & 19.338 & 42.613 & 99.161 & 98.911 & 118.419 & 141.564 & 195.577 & 215.905 & 239.642 & 255.905 \\
\hline $8 / 82$ & 20.726 & 45.563 & 104.109 & 109.993 & 130.962 & 155.511 & 211.717 & 233.171 & 257.810 & 275.475 \\
\hline $9 / 83$ & 20.642 & 46.292 & \begin{tabular}{|l|}
98.191 \\
\end{tabular} & 111.796 & 132.763 & 158.175 & 208.107 & 229.569 & 255.559 & 273.476 \\
\hline $1 / 85$ & 20.874 & 48.402 & 104.174 & 117.362 & 138.158 & 164.957 & 218.316 & 240.047 & 267.163 & 284.982 \\
\hline $3 / 85$ & 21.416 & 46.567 & 103.820 & 107.933 & 129.529 & 154.597 & 209.513 & 231.897 & 257.120 & 275.731 \\
\hline $2 / 91^{*}$ & 20.367 & 43.857 & 99.149 & 106.297 & 126.824 & 150.029 & 201.141 & 222.516 & 246.128 & 263.833 \\
\hline N. Val. (pF) & $1.0 \mathrm{E}+05$ & $2.0 \mathrm{E}+05$ & $3.0 \mathrm{E}+05$ & $4.0 \mathrm{E}+05$ & $5.0 \mathrm{E}+05$ & $6.0 \mathrm{E}+05$ & $7.0 \mathrm{E}+05$ & $8.0 \mathrm{E}+05$ & $9.0 \mathrm{E}+05$ & $1.0 \mathrm{E}+06$ \\
\hline Mean $(p F)$ & 20.7152 & 44.9175 & 100.347 & 102.360 & 123.203 & 147.087 & 200.159 & 221.786 & 246.115 & 264.037 \\
\hline $\mathrm{SD}(\mathrm{pF})$ & 0.7072 & 1.9211 & 2.836 & 7.365 & 7.628 & 8.928 & 8.843 & 9.131 & 10.375 & 10.701 \\
\hline Slope (pF/day) & $-1.5 \mathrm{E}-05$ & $1.9 \mathrm{E}-04$ & $3.9 \mathrm{E}-04$ & $2.0 \mathrm{E}-03$ & $2.0 \mathrm{E}-03$ & $2.2 \mathrm{E}-03$ & 2.3E-03 & $2.3 \mathrm{E}-03$ & $2.5 \mathrm{E}-03$ & $2.4 \mathrm{E}-03$ \\
\hline ( $\mathrm{pF} /$ year) & -0.006 & 0.071 & 0.143 & 0.721 & 0.718 & 0.796 & 0.829 & 0.823 & 0.897 & 0.886 \\
\hline SDfit $(\mathrm{pF})$ & 0.731 & 1.916 & 2.732 & 5.363 & 5.763 & 7.045 & 6.706 & 7.147 & 8.361 & 8.850 \\
\hline $\mathrm{SD}(2 / 01)(\mathrm{pF})$ & 0.981 & 2.573 & 3.668 & 7.200 & 7.738 & 9.459 & 9.004 & 9.595 & 11.225 & 11.882 \\
\hline
\end{tabular}

* See Section 4.2.2 
Table B-2. Data and Analysis of the ( $0.1 \mu \mathrm{F} / \mathrm{step})$ Mica Capacitor Dial Corrections of the Type-12 Bridge at $1 \mathrm{kHz}$

[All values are in $\mathrm{pF}$ except the dials which are in $(\mu \mathrm{F} / \mathrm{step})$ ]

\begin{tabular}{|c|c|c|c|c|c|c|c|c|c|c|}
\hline Date Dial & 0.1 & 0.2 & 0.3 & 0.4 & 0.5 & 0.6 & 0.7 & 0.8 & 0.9 & $0 . X$ \\
\hline $6 / 67$ & 9.522 & 20.953 & 34.653 & 43.932 & 53.654 & 64.848 & 76.408 & 87.139 & 98.631 & 106.029 \\
\hline $11 / 67$ & 9.705 & 22.182 & 34.121 & 46.703 & 56.383 & 68.800 & 78.367 & 89.047 & 101.917 & 109.401 \\
\hline $5 / 68$ & 10.244 & 22.408 & 35.507 & 46.347 & 56.786 & 68.780 & 79.704 & 91.092 & 103.511 & 111.678 \\
\hline $10 / 69$ & 9.533 & 22.286 & 34.772 & 49.342 & 59.030 & 71.561 & 81.847 & 92.502 & 105.488 & 112.861 \\
\hline $12 / 70$ & 9.542 & 22.709 & 35.576 & 48.770 & 58.502 & 71.422 & 82.079 & 92.883 & 106.127 & 113.514 \\
\hline 9/72 & 9.897 & 23.147 & 31.106 & 53.148 & 63.368 & 76.185 & 82.202 & 92.999 & 106.621 & 114.550 \\
\hline $6 / 74$ & 10.752 & 23.997 & 33.094 & 52.792 & 63.621 & 76.659 & 83.574 & 95.366 & 108.613 & 116.993 \\
\hline $11 / 75$ & 10.588 & 24.618 & 39.073 & 55.295 & 66.103 & 79.755 & 92.148 & 103.905 & 118.263 & 126.865 \\
\hline $1 / 77$ & 10.213 & 22.744 & 37.782 & 50.548 & 60.833 & 73.164 & 86.462 & 92.568 & 110.491 & 118.474 \\
\hline $4 / 78$ & 9.394 & 21.063 & 36.221 & 48.260 & 57.992 & 69.640 & 83.019 & 93.405 & 105.327 & 112.628 \\
\hline $11 / 80$ & 9.435 & 22.353 & 36.393 & 52.559 & 62.166 & 75.404 & 88.194 & 98.502 & 111.187 & 118.503 \\
\hline $8 / 82$ & 9.446 & 22.688 & 37.819 & 56.923 & 66.559 & 79.701 & 93.087 & 103.668 & 117.187 & 124.176 \\
\hline $9 / 83$ & 9.592 & 23.459 & 33.441 & 58.878 & 68.678 & 82.418 & 90.272 & 101.104 & 115.226 & 122.771 \\
\hline $1 / 85$ & 9.724 & 24.240 & 38.454 & 61.502 & 71.393 & 85.677 & 97.786 & 108.552 & 123.278 & 130.692 \\
\hline $3 / 85$ & 9.171 & 21.622 & 34.525 & 52.493 & 61.847 & 74.082 & 87.226 & \begin{tabular}{|l|}
97.457 \\
\end{tabular} & 110.102 & 116.931 \\
\hline $2 / 91$ & 9.857 & 22.480 & 33.344 & 56.339 & 66.521 & 79.029 & 88.098 & 98.671 & 111.643 & 118.968 \\
\hline N. Val. (pF) & $1.0 \mathrm{E}+05$ & $2.0 \mathrm{E}+05$ & $3.0 \mathrm{E}+05$ & $4.0 \mathrm{E}+05$ & $5.0 \mathrm{E}+05$ & $6.0 \mathrm{E}+05$ & $7.0 \mathrm{E}+05$ & $8.0 \mathrm{E}+05$ & $9.0 \mathrm{E}+05$ & $1.0 \mathrm{E}+06$ \\
\hline Mean $(p F)$ & 9.7884 & 22.6843 & 35.3676 & 52.1144 & 62.0898 & 74.8203 & 85.6546 & 96.1788 & 109.601 & 117.190 \\
\hline $\mathrm{SD}(\mathrm{pF})$ & 0.4470 & 1.0358 & 2.1787 & 4.8477 & 4.9138 & 5.6067 & 5.8077 & 5.8919 & 6.494 & 6.523 \\
\hline Slope (pF/day) & $-3.8 \mathrm{E}-05$ & 7.5E-05 & $1.2 \mathrm{E}-04$ & $1.4 \mathrm{E}-03$ & $1.4 \mathrm{E}-03$ & $1.5 \mathrm{E}-03$ & $1.7 \mathrm{E}-03$ & $1.6 \mathrm{E}-03$ & $1.8 \mathrm{E}-03$ & $1.7 \mathrm{E}-03$ \\
\hline ( $\mathrm{pF} /$ year) & -0.014 & 0.027 & 0.045 & 0.526 & 0.517 & 0.564 & 0.624 & 0.601 & 0.643 & 0.617 \\
\hline SDfit (pF) & 0.451 & 1.053 & 2.230 & 3.094 & 3.286 & 3.970 & 3.767 & 4.100 & 4.674 & 4.908 \\
\hline $\mathrm{SD}(2 / 01)(\mathrm{pF})$ & 0.606 & 1.413 & 2.994 & 4.154 & 4.412 & 5.330 & 5.058 & 5.505 & 6.275 & 6.589 \\
\hline
\end{tabular}


Table B-3. Data and Analysis of the ( $0.1 \mu \mathrm{F} / \mathrm{step})$ Mica Capacitor Dial Corrections of the Type- 12 Bridge at $10 \mathrm{kHz}$

[All values are in $\mathrm{pF}$ except the dials which are in $(\mu \mathrm{F} / \mathrm{step})$ ]

\begin{tabular}{|c|c|c|c|c|c|c|c|c|c|c|}
\hline Date Dial & 0.1 & 0.2 & 0.3 & 0.4 & 0.5 & 0.6 & 0.7 & 0.8 & 0.9 & $0 . \mathrm{X}$ \\
\hline $6 / 67$ & 16.633 & 40.841 & 49.829 & 109.127 & 133.238 & 173.159 & 197.804 & 234.249 & 267.953 & 334.641 \\
\hline $11 / 67$ & 17.537 & 43.049 & 51.619 & 113.617 & $\mid 138.727$ & 180.194 & 193.636 & 232.127 & 265.649 & 333.446 \\
\hline $5 / 68$ & 17.580 & 42.757 & 51.198 & 112.780 & 137.699 & 178.588 & 192.175 & 229.817 & 263.211 & 331.357 \\
\hline $9 / 69$ & 17.023 & 42.341 & 51.152 & 113.782 & 137.885 & 179.716 & 195.162 & 230.105 & 263.758 & 330.093 \\
\hline $12 / 70$ & 17.577 & 43.579 & 53.528 & 116.540 & 141.480 & 183.752 & 198.649 & 236.748 & 271.662 & 338.677 \\
\hline $7 / 72$ & 17.200 & 43.264 & 47.719 & 116.766 & 140.603 & 183.300 & 192.219 & 233.629 & 268.911 & 338.315 \\
\hline $6 / 74$ & 17.242 & 42.382 & 46.622 & 113.742 & 137.876 & 179.084 & 190.984 & 214.931 & 247.191 & 316.558 \\
\hline $11 / 75$ & 17.373 & 43.618 & 53.638 & 117.938 & 143.700 & 185.088 & 200.033 & 234.903 & 264.293 & 333.768 \\
\hline $1 / 77$ & 17.433 & 43.129 & 53.667 & 117.288 & 141.523 & 182.779 & 197.197 & 234.093 & 268.804 & 336.119 \\
\hline $4 / 78$ & 16.649 & 41.610 & 52.254 & 114.918 & 138.599 & 180.768 & 194.839 & 224.878 & 252.769 & 321.523 \\
\hline $11 / 80$ & 15.938 & 42.038 & 52.608 & 116.776 & 140.616 & 180.812 & 213.659 & 251.150 & 290.010 & 352.910 \\
\hline $8 / 82$ & 16.626 & 42.233 & 52.724 & 120.318 & 145.889 & 187.436 & 200.815 & 239.526 & 264.850 & 328.029 \\
\hline $9 / 83$ & 16.262 & 42.149 & 47.889 & 118.916 & 143.913 & 186.143 & 202.890 & 238.802 & 281.866 & 349.791 \\
\hline $1 / 85$ & 16.406 & 39.757 & 49.519 & 114.702 & 139.098 & 178.572 & $\mid 195.466$ & 225.324 & 251.888 & 306.074 \\
\hline $3 / 85$ & 16.218 & 41.479 & 52.377 & 115.708 & 138.774 & 178.980 & 195.691 & 231.559 & 265.150 & 330.821 \\
\hline $2 / 91$ & 16.440 & 41.815 & 50.474 & 114.584 & 137.736 & 178.309 & 197.036 & 232.733 & 265.200 & 381.138 \\
\hline N. Val. (pF) & $1.0 \mathrm{E}+05$ & $2.0 \mathrm{E}+05$ & $3.0 \mathrm{E}+05$ & $4.0 \mathrm{E}+05$ & $5.0 \mathrm{E}+05$ & $6.0 \mathrm{E}+05$ & $7.0 \mathrm{E}+05$ & $8.0 \mathrm{E}+05$ & $9.0 \mathrm{E}+05$ & $1.0 \mathrm{E}+06$ \\
\hline Mean $(\mathrm{pF})$ & 16.8836 & 42.2526 & 51.0511 & 115.469 & 139.835 & 181.043 & 197.391 & 232.786 & 265.823 & 335.204 \\
\hline $\mathrm{SD}(\mathrm{pF})$ & 0.5486 & 1.0266 & 2.2112 & 2.681 & 3.050 & 3.570 & 5.433 & 7.740 & 10.413 & 16.652 \\
\hline Slope (pF/day) & $-1.5 \mathrm{E}-04$ & $-1.7 \mathrm{E}-04$ & $-3.4 \mathrm{E}-06$ & $4.9 \mathrm{E}-04$ & $3.9 \mathrm{E}-04$ & $2.8 \mathrm{E}-04$ & 7.0E-04 & $4.2 \mathrm{E}-04$ & $2.5 \mathrm{E}-04$ & 2.1E-03 \\
\hline ( $\mathrm{pF} /$ year) & -0.054 & -0.061 & -0.001 & 0.177 & 0.141 & 0.103 & 0.255 & 0.153 & 0.091 & 0.749 \\
\hline SDfit $(\mathrm{pF})$ & 0.397 & 0.959 & 2.289 & 2.431 & 2.973 & 3.612 & 5.288 & 7.928 & 10.756 & 16.285 \\
\hline $\mathrm{SD}(2 / 01)(\mathrm{pF})$ & 0.532 & 1.288 & 3.073 & 3.264 & 3.991 & 4.850 & 7.100 & 10.644 & 14.441 & 21.863 \\
\hline
\end{tabular}


Table B-4. Data and Analysis of the ( $0.01 \mu \mathrm{F} / \mathrm{step})$ Mica Capacitor Dial Corrections of the Type-12 Bridge at $100 \mathrm{~Hz}$

[All values are in $\mathrm{pF}$ except the dials which are in $(\mu \mathrm{F} / \mathrm{step})$ ]

\begin{tabular}{|c|c|c|c|c|c|c|c|c|c|c|}
\hline Date Dial & 0.01 & 0.02 & 0.03 & 0.04 & 0.05 & 0.06 & 0.07 & 0.08 & 0.09 & $0.0 \mathrm{X}$ \\
\hline $6 / 67$ & 2.558 & 4.926 & 7.174 & 9.840 & 12.623 & 14.896 & 14.297 & 17.852 & 20.346 & 20.623 \\
\hline $11 / 67$ & 2.625 & 5.143 & 7.624 & 10.009 & 12.915 & 15.365 & 14.988 & 18.629 & 21.272 & 21.610 \\
\hline $5 / 68$ & 2.869 & 5.312 & 7.746 & 10.342 & 13.396 & 15.802 & 15.491 & 19.284 & 21.900 & 22.447 \\
\hline $9 / 69$ & 2.748 & 5.161 & 7.616 & 10.066 & 12.994 & 15.354 & 14.925 & 18.615 & 21.250 & 21.668 \\
\hline $12 / 70$ & 2.613 & 5.186 & 7.619 & 9.907 & 12.835 & 15.398 & 15.018 & 18.656 & 21.449 & 21.824 \\
\hline $9 / 72$ & 2.531 & 4.978 & 7.249 & 9.696 & 12.602 & 15.066 & 14.710 & 18.554 & 21.358 & 21.820 \\
\hline $6 / 74$ & 2.700 & 5.340 & 7.391 & 9.638 & 12.584 & 15.011 & 14.454 & 18.104 & 20.857 & 21.272 \\
\hline $11 / 75$ & 2.733 & 5.162 & 7.615 & 9.838 & 12.801 & 15.117 & 14.655 & 18.411 & 21.117 & 21.615 \\
\hline $1 / 77$ & 2.694 & 5.178 & 7.534 & 9.940 & 12.989 & 15.458 & 14.922 & 18.643 & 21.339 & 21.753 \\
\hline $4 / 78$ & 2.373 & 4.774 & 6.707 & 8.948 & 11.758 & 14.134 & 13.794 & 16.750 & 19.338 & 19.506 \\
\hline $11 / 80$ & 2.462 & 4.778 & 6.880 & 8.789 & 11.673 & 14.044 & 12.596 & 16.207 & 18.829 & 19.183 \\
\hline $8 / 82$ & 2.573 & 5.109 & 7.083 & 9.094 & 12.029 & 14.328 & 13.611 & 17.282 & 19.888 & 20.209 \\
\hline $9 / 83$ & 2.560 & 5.155 & 7.132 & 9.092 & 11.990 & 14.445 & 13.767 & 17.450 & 20.127 & 20.537 \\
\hline $1 / 85$ & 2.667 & 5.210 & 7.462 & 9.317 & 12.252 & 14.854 & 14.049 & 17.711 & 20.489 & 20.781 \\
\hline $3 / 85$ & 2.671 & 5.264 & 7.200 & 9.133 & 11.992 & 14.577 & 13.778 & 17.519 & 20.262 & 20.551 \\
\hline $2 / 91$ & 2.589 & 5.152 & 6.584 & 8.570 & 11.486 & 14.342 & 13.384 & 16.967 & 19.256 & 18.972 \\
\hline N. Val. (pF) & $1.0 \mathrm{E}+05$ & $2.0 \mathrm{E}+05$ & $3.0 \mathrm{E}+05$ & $4.0 \mathrm{E}+05$ & $5.0 \mathrm{E}+05$ & $6.0 \mathrm{E}+05$ & $7.0 \mathrm{E}+05$ & $8.0 \mathrm{E}+05$ & $9.0 \mathrm{E}+05$ & $1.0 \mathrm{E}+06$ \\
\hline Mean $(\mathrm{pF})$ & 2.6229 & 5.1143 & 7.2885 & 9.5137 & 12.4324 & 14.8869 & 14.2774 & 17.9146 & 20.5673 & 20.8982 \\
\hline $\mathrm{SD}(\mathrm{pF})$ & 0.1190 & 0.1678 & 0.3499 & 0.5232 & 0.5589 & 0.5261 & 0.7566 & 0.8420 & 0.9011 & 1.0326 \\
\hline Slope (pF/day) & $-1.3 \mathrm{E}-05$ & $1.6 \mathrm{E}-07$ & $-8.5 \mathrm{E}-05$ & $-1.7 \mathrm{E}-04$ & $-1.7 \mathrm{E}-04$ & $-1.4 \mathrm{E}-04$ & $-2.1 \mathrm{E}-04$ & $-2.2 \mathrm{E}-04$ & $-2.3 \mathrm{E}-04$ & $-2.8 \mathrm{E}-04$ \\
\hline ( $\mathrm{pF} /$ year) & -0.005 & 0.000 & -0.031 & -0.063 & -0.063 & -0.052 & -0.078 & -0.081 & -0.086 & -0.101 \\
\hline SDfit $(p F)$ & 0.118 & 0.174 & 0.277 & 0.269 & 0.329 & 0.380 & 0.516 & 0.622 & 0.676 & 0.752 \\
\hline $\mathrm{SD}(2 / 01)(\mathrm{pF})$ & 0.159 & 0.233 & 0.371 & 0.362 & 0.441 & 0.510 & 0.693 & 0.836 & 0.907 & 1.010 \\
\hline
\end{tabular}


Table B-5. Data and Analysis of the ( $0.01 \mu \mathrm{F} / \mathrm{step})$ Mica Capacitor Dial Corrections of the Type-12 Bridge at $1 \mathrm{kHz}$

[All values are in $\mathrm{pF}$ except the dials which are in $(\mu \mathrm{F} / \mathrm{step})$ ]

\begin{tabular}{|c|c|c|c|c|c|c|c|c|c|c|}
\hline Date Dial & 0.01 & 0.02 & 0.03 & 0.04 & 0.05 & 0.06 & 0.07 & 0.08 & 0.09 & $0.0 \mathrm{X}$ \\
\hline $6 / 67$ & 1.165 & 2.741 & 3.516 & 4.629 & 6.035 & 7.545 & 5.495 & 7.686 & 9.454 & 8.387 \\
\hline $11 / 67$ & 1.185 & 2.851 & 3.739 & 4.507 & 5.937 & 7.535 & 5.583 & 7.754 & 9.534 & 8.500 \\
\hline $5 / 68$ & 1.244 & 2.875 & 3.726 & 4.625 & 6.098 & 7.662 & 5.693 & 7.922 & 9.720 & 8.719 \\
\hline $10 / 69$ & 1.218 & 2.808 & 3.583 & 4.466 & 5.914 & 7.429 & 5.315 & 7.550 & 9.295 & 8.261 \\
\hline $12 / 70$ & 1.178 & 2.888 & 3.664 & 4.449 & 5.870 & 7.553 & 5.513 & 7.704 & 9.584 & 8.522 \\
\hline 9/72 & 1.234 & 2.895 & 3.524 & 4.283 & 5.730 & 7.354 & 5.238 & 7.454 & 9.338 & 8.300 \\
\hline $6 / 74$ & 1.278 & 2.905 & 3.696 & 4.466 & 5.981 & 7.546 & 5.482 & 7.754 & 9.557 & 8.587 \\
\hline $11 / 75$ & 1.251 & 2.957 & 3.760 & 4.493 & 5.999 & 7.652 & 5.648 & 7.921 & 9.774 & 8.805 \\
\hline $1 / 77$ & 1.184 & 2.818 & 3.416 & 4.205 & 5.654 & 7.228 & 5.032 & 7.256 & 9.097 & 8.093 \\
\hline $4 / 78$ & 1.093 & 2.646 & 3.084 & 3.855 & 5.193 & 6.704 & 4.337 & 6.450 & 8.216 & 7.066 \\
\hline $11 / 80$ & 1.099 & 2.706 & 3.205 & 3.801 & 5.138 & 6.687 & 4.348 & 6.460 & 8.181 & 7.128 \\
\hline $8 / 82$ & 1.086 & 2.674 & 3.068 & 3.659 & 4.999 & 6.570 & 4.159 & 6.302 & 8.055 & 6.906 \\
\hline $9 / 83$ & 1.125 & 2.850 & 3.245 & 3.872 & 5.237 & 6.877 & 4.507 & 6.657 & 8.492 & 7.375 \\
\hline $1 / 85$ & 1.137 & 2.835 & 3.332 & 3.682 & 5.134 & 6.792 & 4.494 & 6.666 & 8.501 & 7.429 \\
\hline $3 / 85$ & 1.028 & 2.652 & 2.860 & 3.233 & 4.534 & 6.110 & 3.503 & 5.562 & 7.375 & 6.188 \\
\hline $2 / 91$ & 1.054 & 2.715 & 2.881 & 3.465 & 4.801 & 6.407 & 3.621 & 5.685 & 7.494 & 6.362 \\
\hline N. Val. (pF) & $1.0 \mathrm{E}+05$ & $2.0 \mathrm{E}+05$ & $3.0 \mathrm{E}+05$ & $4.0 \mathrm{E}+05$ & $5.0 \mathrm{E}+05$ & $6.0 \mathrm{E}+05$ & $7.0 \mathrm{E}+05$ & $8.0 \mathrm{E}+05$ & $9.0 \mathrm{E}+05$ & $1.0 \mathrm{E}+06$ \\
\hline Mean $(\mathrm{pF})$ & 1.1599 & 2.8010 & 3.3937 & 4.1056 & 5.5159 & 7.1032 & 4.8730 & 7.0489 & 8.8542 & 7.7893 \\
\hline $\mathrm{SD}(\mathrm{pF})$ & 0.0747 & 0.0986 & 0.3064 & 0.4498 & 0.5031 & 0.5043 & 0.7345 & 0.7935 & 0.8052 & 0.8622 \\
\hline Slope (pF/day) & $-2.1 \mathrm{E}-05$ & $-1.8 \mathrm{E}-05$ & $-9.7 \mathrm{E}-05$ & $-1.6 \mathrm{E}-04$ & $-1.7 \mathrm{E}-04$ & $-1.7 \mathrm{E}-04$ & $-2.5 \mathrm{E}-04$ & $-2.7 \mathrm{E}-04$ & $-2.7 \mathrm{E}-04$ & $-2.8 \mathrm{E}-04$ \\
\hline ( $\mathrm{pF} /$ year) & -0.008 & -0.006 & -0.035 & -0.057 & -0.063 & -0.061 & -0.091 & -0.097 & -0.097 & -0.102 \\
\hline SDfit $(p F)$ & 0.052 & 0.090 & 0.172 & 0.180 & 0.225 & 0.253 & 0.335 & 0.379 & 0.407 & 0.453 \\
\hline $\mathrm{SD}(2 / 01)(\mathrm{pF})$ & 0.070 & 0.121 & 0.231 & 0.241 & 0.302 & 0.339 & 0.450 & 0.509 & 0.547 & 0.608 \\
\hline
\end{tabular}


Table B-6. Data and Analysis of the ( $0.01 \mu \mathrm{F} / \mathrm{step})$ Mica Capacitor Dial Corrections of the Type-12 Bridge at $10 \mathrm{kHz}$

[All values are in $\mathrm{pF}$ except the dials which are in $(\mu \mathrm{F} / \mathrm{step})$ ]

\begin{tabular}{|c|c|c|c|c|c|c|c|c|c|c|}
\hline Date Dial & 0.01 & 0.02 & 0.03 & 0.04 & 0.05 & 0.06 & 0.07 & 0.08 & 0.09 & $0.0 \mathrm{X}$ \\
\hline & & & & & & & & & & \\
$6 / 67$ & 0.269 & 1.491 & 1.829 & 2.800 & 4.312 & 6.523 & 5.180 & 8.255 & 11.291 & 11.987 \\
$11 / 67$ & 0.354 & 1.670 & 2.239 & 2.971 & 4.562 & 6.850 & 5.692 & 8.821 & 11.925 & 12.710 \\
$5 / 68$ & 0.321 & 1.610 & 2.148 & 2.905 & 4.511 & 6.784 & 5.583 & 8.742 & 11.855 & 12.634 \\
$9 / 69$ & 0.325 & 1.568 & 1.946 & 2.729 & 4.289 & 6.519 & 5.175 & 8.282 & 11.338 & 12.113 \\
$12 / 90$ & 0.353 & 1.701 & 2.211 & 2.942 & 4.530 & 6.833 & 5.616 & 8.754 & 11.908 & 12.699 \\
$9 / 72$ & 0.339 & 1.623 & 1.994 & 2.631 & 4.182 & 6.451 & 5.130 & 8.254 & 11.316 & 12.092 \\
$6 / 74$ & 0.360 & 1.613 & 1.998 & 2.716 & 4.319 & 6.509 & 5.092 & 8.164 & 11.097 & 11.857 \\
$11 / 75$ & 0.352 & 1.692 & 2.082 & 2.686 & 4.229 & 6.510 & 5.135 & 8.271 & 11.389 & 12.153 \\
$1 / 77$ & 0.306 & 1.608 & 1.916 & 2.585 & 4.164 & 6.428 & 5.024 & 8.081 & 11.224 & 12.018 \\
$4 / 78$ & 0.223 & 1.421 & 1.559 & 2.215 & 3.693 & 5.876 & 4.327 & 7.313 & 10.383 & 11.121 \\
$11 / 80$ & 0.167 & 1.386 & 1.420 & 1.749 & 3.128 & 5.337 & 3.741 & 6.542 & 9.719 & 10.403 \\
$8 / 82$ & 0.211 & 1.432 & 1.530 & 2.054 & 3.519 & 5.703 & 4.101 & 7.140 & 10.170 & 10.871 \\
$9 / 83$ & 0.240 & 1.425 & 1.485 & 1.860 & 3.362 & 5.592 & 3.935 & 6.997 & 9.975 & 10.657 \\
$1 / 85$ & 0.220 & 1.480 & 1.475 & 1.902 & 3.382 & 5.627 & 3.907 & 7.016 & 10.054 & 10.676 \\
$3 / 85$ & 0.158 & 1.452 & 1.302 & 1.713 & 3.242 & 5.427 & 3.568 & 6.527 & 9.552 & 10.156 \\
$2 / 91$ & 0.179 & 1.380 & 1.089 & 1.412 & 2.876 & 5.095 & 3.141 & 6.192 & 9.239 & 9.917 \\
& & & & & & & & & & \\
\hline & & & & & & & & & & \\
SDfit (pF) & 0.047 & 0.081 & 0.162 & 0.166 & 0.205 & 0.224 & 0.274 & 0.335 & 0.341 & 0.370 \\
N. Val. (pF) & $1.0 \mathrm{E}+05$ & $2.0 \mathrm{E}+05$ & $3.0 \mathrm{E}+05$ & $4.0 \mathrm{E}+05$ & $5.0 \mathrm{E}+05$ & $6.0 \mathrm{E}+05$ & $7.0 \mathrm{E}+05$ & $8.0 \mathrm{E}+05$ & $9.0 \mathrm{E}+05$ & $1.0 \mathrm{E}+06$ \\
Mean (pF) & 0.2736 & 1.5345 & 1.7639 & 2.3669 & 3.8938 & 6.1290 & 4.6467 & 7.7094 & 10.7772 & 11.5040 \\
SD (pF) & 0.0734 & 0.1126 & 0.3547 & 0.5138 & 0.5648 & 0.5893 & 0.8161 & 0.8759 & 0.8937 & 0.9458 \\
Slope (pF/day) & $-1.4 \mathrm{E}-05$ & $-1.6 \mathrm{E}-05$ & $-7.6 \mathrm{E}-05$ & $-1.2 \mathrm{E}-04$ & $-1.3 \mathrm{E}-04$ & $-1.3 \mathrm{E}-04$ & $-1.9 \mathrm{E}-04$ & $-2.0 \mathrm{E}-04$ & $-2.0 \mathrm{E}-04$ & $-2.1 \mathrm{E}-04$ \\
( pF/year) & -0.005 & -0.006 & -0.028 & -0.045 & -0.048 & -0.049 & -0.070 & -0.073 & -0.073 & -0.077 \\
DfF & 0.062 & 0.109 & 0.217 & 0.223 & 0.275 & 0.301 & 0.368 & 0.449 & 0.458 & 0.496 \\
\hline
\end{tabular}


Table B-7. Data and Analysis of the (1000 pF/step) Air Capacitor Dial Corrections of the Type-12 Bridge

(All values are in $\mathrm{pF}$ )

\begin{tabular}{|c|c|c|c|c|c|c|c|c|c|c|}
\hline Date Dial & 1000 & 2000 & 3000 & 4000 & 5000 & 6000 & 7000 & 8000 & 9000 & 10000 \\
\hline & & & & & & & & & & \\
$6 / 67$ & 0.060 & 0.010 & 0.189 & 0.109 & 0.189 & 0.154 & 0.334 & 0.403 & 0.353 & 0.403 \\
$11 / 67$ & 0.075 & 0.017 & 0.253 & 0.118 & 0.204 & 0.156 & 0.388 & 0.463 & 0.392 & 0.460 \\
$5 / 68$ & 0.055 & 0.009 & 0.184 & 0.113 & 0.185 & 0.145 & 0.317 & 0.379 & 0.336 & 0.391 \\
$9 / 69$ & 0.069 & 0.021 & 0.232 & 0.136 & 0.214 & 0.172 & 0.381 & 0.454 & 0.400 & 0.463 \\
$12 / 70$ & 0.074 & 0.025 & 0.244 & 0.150 & 0.241 & 0.196 & 0.406 & 0.487 & 0.431 & 0.503 \\
$9 / 72$ & 0.072 & 0.040 & 0.208 & 0.146 & 0.231 & 0.211 & 0.394 & 0.473 & 0.434 & 0.499 \\
$6 / 74$ & 0.069 & 0.040 & 0.198 & 0.183 & 0.259 & 0.239 & 0.396 & 0.465 & 0.428 & 0.485 \\
$11 / 75$ & 0.081 & 0.050 & 0.244 & 0.213 & 0.305 & 0.279 & 0.461 & 0.545 & 0.509 & 0.588 \\
$1 / 77$ & 0.071 & 0.049 & 0.184 & 0.219 & 0.298 & 0.286 & 0.425 & 0.491 & 0.466 & 0.531 \\
$4 / 78$ & 0.070 & 0.064 & 0.192 & 0.235 & 0.313 & 0.307 & 0.432 & 0.502 & 0.481 & 0.543 \\
$11 / 80$ & 0.071 & 0.062 & 0.242 & 0.233 & 0.330 & 0.318 & 0.509 & 0.591 & 0.563 & 0.642 \\
$8 / 82$ & 0.086 & 0.071 & 0.241 & 0.248 & 0.336 & 0.338 & 0.510 & 0.593 & 0.580 & 0.653 \\
$9 / 83$ & 0.090 & 0.070 & 0.259 & 0.256 & 0.357 & 0.347 & 0.535 & 0.629 & 0.607 & 0.695 \\
$1 / 85$ & 0.087 & 0.071 & 0.244 & 0.261 & 0.366 & 0.361 & 0.529 & 0.624 & 0.605 & 0.690 \\
$3 / 85$ & 0.094 & 0.080 & 0.231 & 0.277 & 0.380 & 0.375 & 0.523 & 0.613 & 0.587 & 0.671 \\
$2 / 91$ & 0.109 & 0.098 & 0.226 & 0.255 & 0.352 & 0.366 & 0.523 & 0.629 & 0.631 & 0.724 \\
& & & & & & & & & & \\
\hline & & & & & & & & & & \\
N. Val. (pF) & 1000 & 2000 & 3000 & 4000 & 5000 & 6000 & 7000 & 8000 & 9000 & 10000 \\
Mean (pF) & 0.0771 & 0.0486 & 0.2232 & 0.1970 & 0.2850 & 0.2656 & 0.4414 & 0.5213 & 0.4877 & 0.5588 \\
SD (pF) & 0.0135 & 0.0269 & 0.0263 & 0.0595 & 0.0671 & 0.0834 & 0.0725 & 0.0828 & 0.0970 & 0.1086 \\
Slope (pF/day) & $4.4 \mathrm{E}-06$ & $1.0 \mathrm{E}-05$ & $3.3 \mathrm{E}-06$ & $2.1 \mathrm{E}-05$ & $2.4 \mathrm{E}-05$ & $3.0 \mathrm{E}-05$ & $2.5 \mathrm{E}-05$ & $2.9 \mathrm{E}-05$ & $3.5 \mathrm{E}-05$ & $3.9 \mathrm{E}-05$ \\
( $\mathrm{pF} / \mathrm{year})$ & 0.002 & 0.004 & 0.001 & 0.008 & 0.009 & 0.011 & 0.009 & 0.011 & 0.013 & 0.014 \\
$\mathrm{SD}(2 / 01)(\mathrm{pF})$ & 0.010 & 0.007 & 0.034 & 0.027 & 0.029 & 0.029 & 0.037 & 0.042 & 0.035 & 0.042 \\
& & & & & & & & & & \\
\hline
\end{tabular}


Table B-8. Data and Analysis of the (100 pF/step) Air Capacitor Dial Corrections of the Type-12 Bridge

(All values are in $\mathrm{pF}$ )

\begin{tabular}{|c|c|c|c|c|c|c|c|c|c|c|}
\hline Date Dial & 100 & 200 & 300 & 400 & 500 & 600 & 700 & 800 & 900 & 1000 \\
\hline $6 / 67$ & -0.003 & 0.125 & 0.092 & 0.075 & 0.067 & 0.200 & 0.167 & 0.165 & 0.302 & 0.300 \\
\hline $11 / 67$ & -0.001 & 0.130 & 0.096 & 0.077 & 0.076 & 0.211 & 0.176 & 0.125 & 0.307 & 0.309 \\
\hline $5 / 68$ & -0.002 & 0.127 & 0.096 & 0.083 & 0.071 & 0.204 & 0.166 & 0.165 & 0.298 & 0.297 \\
\hline $9 / 69$ & 0.000 & 0.132 & 0.098 & 0.082 & 0.076 & 0.209 & 0.173 & 0.175 & 0.309 & 0.308 \\
\hline $12 / 70$ & -0.004 & 0.129 & 0.095 & 0.077 & 0.075 & 0.204 & 0.174 & 0.174 & 0.310 & 0.311 \\
\hline $9 / 72$ & -0.004 & 0.131 & 0.097 & 0.083 & 0.078 & 0.211 & 0.180 & 0.172 & 0.312 & 0.314 \\
\hline $6 / 74$ & 0.000 & 0.133 & 0.096 & 0.089 & 0.086 & 0.215 & 0.179 & 0.179 & 0.308 & 0.305 \\
\hline $11 / 75$ & -0.002 & 0.130 & 0.097 & 0.083 & 0.084 & 0.217 & 0.185 & 0.184 & 0.316 & 0.315 \\
\hline $1 / 77$ & -0.002 & 0.130 & 0.093 & 0.085 & 0.079 & 0.211 & 0.184 & 0.176 & 0.313 & 0.308 \\
\hline $4 / 78$ & -0.003 & 0.126 & 0.096 & 0.088 & 0.087 & 0.213 & 0.180 & 0.180 & 0.311 & 0.309 \\
\hline $11 / 80$ & 0.000 & 0.136 & 0.103 & 0.092 & 0.091 & 0.228 & 0.199 & 0.206 & 0.321 & 0.320 \\
\hline $8 / 82$ & 0.014 & 0.143 & 0.108 & 0.094 & 0.093 & 0.224 & 0.189 & 0.188 & 0.326 & 0.322 \\
\hline $9 / 83$ & 0.001 & 0.134 & 0.103 & 0.093 & 0.091 & 0.223 & 0.192 & 0.190 & 0.329 & 0.327 \\
\hline $1 / 85$ & -0.001 & 0.131 & 0.107 & 0.102 & 0.101 & 0.221 & 0.189 & 0.188 & 0.322 & 0.325 \\
\hline $3 / 85$ & 0.001 & 0.129 & 0.101 & 0.092 & 0.093 & 0.226 & 0.192 & 0.193 & 0.318 & 0.321 \\
\hline $2 / 91$ & 0.013 & 0.138 & 0.097 & 0.093 & 0.081 & 0.223 & 0.210 & 0.208 & 0.318 & 0.339 \\
\hline N. Val. (pF) & 100 & 200 & 300 & 400 & 500 & 600 & 700 & 800 & 900 & 1000 \\
\hline Mean $(\mathrm{pF})$ & 0.0004 & 0.1315 & 0.0984 & 0.0868 & 0.0831 & 0.2150 & 0.1834 & 0.1793 & 0.3138 & 0.3144 \\
\hline $\mathrm{SD}(\mathrm{pF})$ & 0.0053 & 0.0046 & 0.0047 & 0.0074 & 0.0093 & 0.0085 & 0.0116 & 0.0191 & 0.0084 & 0.0108 \\
\hline Slope ( $\mathrm{pF} /$ day) & $1.3 \mathrm{E}-06$ & $9.9 \mathrm{E}-07$ & $1.1 \mathrm{E}-06$ & $2.4 \mathrm{E}-06$ & $2.7 \mathrm{E}-06$ & $2.8 \mathrm{E}-06$ & $4.0 \mathrm{E}-06$ & $5.8 \mathrm{E}-06$ & $2.6 \mathrm{E}-06$ & $3.7 \mathrm{E}-06$ \\
\hline ( $\mathrm{pF} /$ year) & 0.000 & 0.000 & 0.000 & 0.001 & 0.001 & 0.001 & 0.001 & 0.002 & 0.001 & 0.001 \\
\hline SDfit (pF) & 0.004 & 0.004 & 0.004 & 0.004 & 0.006 & 0.004 & 0.005 & 0.012 & 0.005 & 0.005 \\
\hline $\mathrm{SD}(2 / 01)(\mathrm{pF})$ & 0.006 & 0.005 & 0.005 & 0.005 & 0.008 & 0.006 & 0.006 & 0.016 & 0.007 & 0.007 \\
\hline
\end{tabular}


Table B-9. Data and Analysis of the (10 pF/step) Air Capacitor Dial Corrections of the Type-12 Bridge

(All values are in $\mathrm{pF}$ )

\begin{tabular}{|c|c|c|c|c|c|c|c|c|c|c|}
\hline Date Dial & 10 & 20 & 30 & 40 & 50 & 60 & 70 & 80 & 90 & 100 \\
\hline $6 / 67$ & 0.007 & -0.057 & 0.005 & 0.047 & 0.059 & -0.015 & 0.047 & 0.059 & -0.004 & 0.007 \\
\hline $11 / 67$ & 0.007 & -0.060 & 0.006 & 0.051 & 0.059 & -0.006 & 0.060 & 0.068 & 0.003 & 0.012 \\
\hline $5 / 68$ & 0.006 & -0.056 & 0.009 & 0.055 & 0.065 & -0.001 & 0.060 & 0.067 & 0.000 & 0.009 \\
\hline 9/69 & 0.006 & -0.061 & -0.001 & 0.054 & 0.061 & -0.003 & 0.062 & 0.069 & 0.003 & 0.014 \\
\hline $12 / 70$ & 0.006 & -0.059 & 0.004 & 0.050 & 0.062 & -0.005 & 0.059 & 0.072 & 0.005 & 0.011 \\
\hline $9 / 72$ & 0.004 & -0.062 & 0.001 & 0.047 & 0.060 & -0.005 & 0.056 & 0.069 & 0.004 & 0.013 \\
\hline $6 / 74$ & 0.006 & -0.058 & 0.007 & 0.056 & 0.067 & 0.003 & 0.069 & 0.072 & 0.005 & 0.011 \\
\hline $11 / 75$ & 0.005 & -0.059 & 0.006 & 0.053 & 0.058 & -0.006 & 0.059 & 0.063 & -0.001 & 0.011 \\
\hline $1 / 77$ & 0.006 & -0.057 & 0.009 & 0.048 & 0.053 & -0.008 & 0.054 & 0.071 & 0.007 & 0.013 \\
\hline $4 / 78$ & 0.009 & -0.053 & 0.004 & 0.048 & 0.054 & -0.008 & 0.056 & 0.072 & 0.010 & 0.017 \\
\hline $11 / 80$ & 0.006 & -0.061 & -0.001 & 0.051 & 0.057 & -0.008 & 0.055 & 0.066 & 0.014 & 0.018 \\
\hline $8 / 82$ & 0.011 & -0.053 & 0.010 & 0.061 & 0.061 & -0.005 & 0.070 & 0.081 & 0.016 & 0.019 \\
\hline $9 / 83$ & 0.009 & -0.052 & 0.007 & 0.056 & 0.064 & 0.006 & 0.073 & 0.079 & 0.010 & 0.018 \\
\hline $1 / 85$ & 0.010 & -0.053 & 0.004 & 0.046 & 0.057 & 0.000 & 0.064 & 0.070 & 0.008 & 0.019 \\
\hline $3 / 85$ & 0.015 & -0.052 & 0.008 & 0.050 & 0.069 & 0.005 & 0.064 & 0.068 & 0.009 & 0.016 \\
\hline $2 / 91$ & 0.013 & -0.037 & 0.041 & 0.079 & 0.092 & 0.041 & 0.106 & 0.101 & 0.031 & 0.015 \\
\hline N. Val. (pF) & 10 & 20 & 30 & 40 & 50 & 60 & 70 & 80 & 90 & 100 \\
\hline Mean $(\mathrm{pF})$ & 0.0079 & -0.0556 & 0.0074 & 0.0533 & 0.0624 & -0.0009 & 0.0634 & 0.0717 & 0.0075 & 0.0139 \\
\hline $\mathrm{SD}(\mathrm{pF})$ & 0.0031 & 0.0060 & 0.0095 & 0.0080 & 0.0090 & 0.0124 & 0.0131 & 0.0094 & 0.0082 & 0.0037 \\
\hline Slope (pF/day) & $8.6 \mathrm{E}-07$ & $1.7 \mathrm{E}-06$ & $1.9 \mathrm{E}-06$ & $1.5 \mathrm{E}-06$ & $1.6 \mathrm{E}-06$ & $3.0 \mathrm{E}-06$ & $3.3 \mathrm{E}-06$ & $2.4 \mathrm{E}-06$ & $2.6 \mathrm{E}-06$ & $1.1 \mathrm{E}-06$ \\
\hline ( $\mathrm{pF} /$ year) & 0.000 & 0.001 & 0.001 & 0.001 & 0.001 & 0.001 & 0.001 & 0.001 & 0.001 & 0.000 \\
\hline SDfit $(p F)$ & 0.002 & 0.004 & 0.008 & 0.007 & 0.008 & 0.010 & 0.010 & 0.007 & 0.005 & 0.002 \\
\hline $\mathrm{SD}(2 / 01)(\mathrm{pF})$ & 0.003 & 0.006 & 0.011 & 0.010 & 0.011 & 0.013 & 0.014 & 0.010 & 0.006 & 0.003 \\
\hline
\end{tabular}



APPENDIX C. CONDUCTANCE DIAL CORRECTIONS OF THE TYPE-12 BRIDGE

Data and analyses of conductance corrections for each mica capacitance dial of the Type-12 bridge are included in the following tables:

Table C-1. Data and Analysis of Conductance Corrections of ( $0.1 \mu \mathrm{F} / \mathrm{step})$ Mica Capacitance Dial of the Type- 12 Bridge at $100 \mathrm{~Hz}$

(All values are in $0.001 \mu \mathrm{S}$, except the dial which is $0.1 \mu \mathrm{F} / \mathrm{step}$ )

\begin{tabular}{|c|c|c|c|c|c|c|c|c|c|c|}
\hline DIAL & 0.1 & 0.2 & 0.3 & 0.4 & 0.5 & 0.6 & 0.7 & 0.8 & 0.9 & $0 . \mathrm{X}$ \\
\hline $6 / 67$ & 15.422 & 29.480 & 50.507 & 51.425 & 66.792 & 80.853 & 101.950 & 117.432 & 131.360 & 147.055 \\
\hline $11 / 67$ & 15.573 & 30.235 & 50.848 & 52.920 & 68.485 & 83.173 & 103.873 & 119.520 & 134.050 & 149.875 \\
\hline $5 / 68$ & 15.743 & 30.173 & 51.198 & 52.458 & 68.240 & 82.723 & 103.808 & 119.660 & 134.058 & 150.110 \\
\hline $9 / 69$ & 15.693 & 30.395 & 51.225 & 54.055 & 69.765 & 84.570 & 105.435 & 121.320 & 136.035 & 152.025 \\
\hline $12 / 70$ & 15.715 & 30.563 & 51.328 & 53.610 & 69.340 & 84.240 & 105.033 & 120.908 & 135.635 & 151.625 \\
\hline $9 / 72$ & 15.915 & 30.885 & 51.800 & 55.570 & 71.485 & 86.500 & 107.485 & 123.513 & 138.455 & 154.538 \\
\hline $6 / 74$ & 15.965 & 30.625 & 51.873 & 54.035 & 70.050 & 84.778 & 106.178 & 122.265 & 136.845 & 153.253 \\
\hline $11 / 75$ & 15.710 & 30.388 & 51.223 & 53.695 & 69.333 & 84.185 & 105.025 & 120.893 & 135.780 & 151.678 \\
\hline $1 / 77$ & 15.858 & 30.230 & 51.670 & 52.705 & 68.508 & 82.953 & 104.418 & 120.410 & 134.738 & 151.003 \\
\hline $4 / 78$ & 15.490 & 29.505 & 50.995 & 51.713 & 67.243 & 81.280 & 102.760 & 118.395 & 132.310 & 148.010 \\
\hline $11 / 80$ & 15.250 & 29.470 & 50.200 & 51.913 & 67.203 & 81.570 & 102.523 & 117.965 & 132.483 & 148.273 \\
\hline $8 / 82$ & 15.398 & 29.625 & 50.568 & 48.255 & 63.630 & 77.965 & 99.140 & 114.585 & 128.813 & 144.710 \\
\hline $9 / 83$ & 15.485 & 30.228 & 50.773 & 54.513 & 70.013 & 84.783 & 105.533 & 121.128 & 135.940 & 151.943 \\
\hline $1 / 85$ & 15.400 & 30.315 & 50.933 & 55.215 & 70.668 & 85.605 & 106.255 & 121.870 & 136.780 & 152.570 \\
\hline $3 / 85$ & 15.518 & 29.993 & 51.063 & 53.140 & 68.680 & 83.713 & 104.778 & 120.455 & 134.840 & 150.700 \\
\hline $2 / 91^{*}$ & 14.625 & 28.197 & 48.720 & 49.175 & 63.505 & 76.885 & 97.022 & 111.475 & 124.565 & 139.132 \\
\hline Mean $(\mathrm{nS})$ & 15.5475 & 30.0192 & 50.9328 & 52.7748 & 68.3088 & 82.8610 & 103.826 & 119.487 & 133.918 & 149.781 \\
\hline $\mathrm{SD}(\mathrm{nS})$ & 0.3191 & 0.6465 & 0.7473 & 1.9816 & 2.2459 & 2.6261 & 2.697 & 3.027 & 3.451 & 3.773 \\
\hline Slope(nS/day) & $-7.8 \mathrm{E}-05$ & $-1.3 \mathrm{E}-04$ & $-1.5 \mathrm{E}-04$ & $-2.2 \mathrm{E}-04$ & $-3.1 \mathrm{E}-04$ & $-3.5 \mathrm{E}-04$ & $-4.0 \mathrm{E}-04$ & $-4.9 \mathrm{E}-04$ & $-5.4 \mathrm{E}-04$ & $-6.2 \mathrm{E}-04$ \\
\hline Slope(nS/year) & -0.0285 & -0.0469 & -0.0563 & -0.0798 & -0.1126 & -0.1295 & -0.1449 & -0.1772 & -0.1989 & -0.2267 \\
\hline SDfit & 0.2512 & 0.5690 & 0.6478 & 1.9616 & 2.1653 & 2.5382 & 2.5701 & 2.8362 & 3.2443 & 3.5147 \\
\hline $\mathrm{SD}(2 / 01)(\mathrm{nS})$ & 0.3373 & 0.7639 & 0.8697 & 2.6335 & 2.9070 & 3.4077 & 3.4506 & 3.8078 & 4.3556 & 4.7188 \\
\hline
\end{tabular}

* See Section 4.6.5 
Table C-2. Data and Analysis of Conductance Corrections of ( $0.1 \mu \mathrm{F} / \mathrm{step})$ Mica Capacitance Dial of the Type-12 Bridge at $1 \mathrm{kHz}$

(All values are in $0.001 \mu \mathrm{S}$, except the dial which is $0.1 \mu \mathrm{F} /$ step)

\begin{tabular}{|c|c|c|c|c|c|c|c|c|c|c|}
\hline$\overline{\text { DIAL }}$ & 0.1 & 0.2 & 0.3 & 0.4 & 0.5 & 0.6 & 0.7 & 0.8 & 0.9 & $0 . \mathrm{X}$ \\
\hline $6 / 67$ & 47.305 & 98.877 & 264.330 & 224.372 & 271.098 & 326.986 & 500.838 & 558.528 & 600.240 & 676.897 \\
\hline $11 / 67$ & 46.940 & 100.430 & 263.095 & 229.102 & 276.858 & 335.962 & 506.872 & 563.892 & 607.910 & 685.677 \\
\hline $5 / 68$ & 47.805 & 99.947 & 266.455 & 226.535 & 274.364 & 330.679 & 505.564 & 563.470 & 606.765 & 684.400 \\
\hline $9 / 69$ & 47.680 & 101.745 & 265.495 & 235.212 & 282.337 & 341.020 & 513.247 & 571.053 & 615.033 & 693.146 \\
\hline $12 / 70$ & 48.053 & 103.612 & 266.732 & 233.383 & 280.935 & 340.675 & 513.425 & 573.657 & 619.455 & 696.497 \\
\hline 9/72 & 48.202 & 102.982 & 266.970 & 241.348 & 288.850 & 347.110 & 521.205 & 580.365 & 622.810 & 702.902 \\
\hline $6 / 74$ & 48.520 & 101.800 & 268.048 & 233.778 & 282.025 & 339.182 & 514.950 & 575.485 & 616.887 & 695.442 \\
\hline $11 / 75$ & 48.898 & 103.762 & 270.010 & 237.880 & 286.902 & 345.262 & 520.682 & 581.692 & 635.092 & 705.292 \\
\hline $1 / 77$ & 49.190 & 102.397 & 270.695 & 231.745 & 281.047 & 338.747 & 516.430 & 577.637 & 622.715 & 702.235 \\
\hline $4 / 78$ & 47.653 & 98.143 & 266.622 & 225.987 & 274.072 & 328.845 & 504.327 & 562.692 & 602.840 & 680.885 \\
\hline $11 / 80$ & 49.485 & 104.973 & 272.487 & 241.390 & 290.853 & 349.962 & 525.185 & 583.917 & 631.317 & 711.745 \\
\hline $8 / 82$ & 49.868 & 105.278 & 272.753 & 243.995 & 294.873 & 352.798 & 530.568 & 588.847 & 637.482 & 715.372 \\
\hline $9 / 83$ & 50.190 & 107.250 & 272.320 & 249.523 & 299.703 & 360.835 & 535.808 & 593.048 & 645.178 & 727.558 \\
\hline $1 / 85$ & 49.015 & 108.588 & 271.920 & 251.525 & 302.480 & 363.743 & 536.508 & 598.165 & 647.708 & 728.600 \\
\hline $3 / 85$ & 49.383 & 104.635 & 271.035 & 237.648 & 288.115 & 348.248 & 522.268 & 582.600 & 629.233 & 708.830 \\
\hline $2 / 91$ & 49.877 & 104.365 & 272.027 & 238.170 & 288.995 & 347.640 & 521.587 & 581.903 & 624.710 & 705.013 \\
\hline Mean $(\mathrm{nS})$ & 48.629 & 103.049 & 268.812 & 236.35 & 285.219 & 343.606 & 518.092 & 577.309 & 622.836 & 701.281 \\
\hline $\mathrm{SD}(\mathrm{nS})$ & 1.0010 & 2.8719 & 3.2009 & 7.9901 & 9.0811 & 10.5141 & 10.7 & 11.3 & 14.3714 & 15.2700 \\
\hline Slope(nS/day) & 3.3E-04 & $7.5 \mathrm{E}-04$ & $1.1 \mathrm{E}-03$ & $2.0 \mathrm{E}-03$ & $2.5 \mathrm{E}-03$ & $2.8 \mathrm{E}-03$ & $3.0 \mathrm{E}-03$ & $3.2 \mathrm{E}-03$ & $3.8 \mathrm{~F}$ & 4.2E-03 \\
\hline Slope (nS/year) & 0.1187 & 0.2750 & 0.3878 & 0.7221 & 0.9075 & 1.0133 & 1.0896 & 1.1755 & 1.3767 & 1.5399 \\
\hline SDfit & 0.5267 & 2.1373 & 1.5763 & 6.2415 & 6.4693 & 7.7757 & 7.5324 & 7.7394 & 10.6895 & 10.7667 \\
\hline $\mathrm{SD}(2 / 01)(\mathrm{nS})$ & 0.70714 & 2.86942 & 2.11632 & 8.37964 & 8.68548 & 10.4394 & 10.1127 & 10.3907 & 14.3514 & 14.4551 \\
\hline
\end{tabular}


Table C-3. Data and Analysis of Conductance Corrections of ( $0.1 \mu \mathrm{F} / \mathrm{step}$ ) Mica Capacitance Dial of the Type-12 Bridge at $10 \mathrm{kHz}$

(All values are in $0.001 \mu \mathrm{S}$, except the dial which is $0.1 \mu \mathrm{F} / \mathrm{step}$ )

\begin{tabular}{|c|c|c|c|c|c|c|c|c|c|c|}
\hline DIAL & 0.1 & 0.2 & 0.3 & 0.4 & 0.5 & 0.6 & 0.7 & 0.8 & 0.9 & $0 . X$ \\
\hline $6 / 67$ & 492.308 & 1332.120 & 3119.400 & 4189.440 & 4649.620 & 5955.480 & 8594.100 & 10269.700 & 9946.360 & 13599.400 \\
\hline $11 / 67$ & 494.150 & 1350.415 & 3135.955 & 4212.320 & 4746.648 & 6035.588 & 8716.003 & 10398.200 & 10250.800 & 13701.600 \\
\hline $5 / 68$ & 494.148 & 1332.136 & 3127.273 & 4148.161 & 4627.199 & 5926.961 & 8596.424 & 10266.500 & 10104.200 & 13631.000 \\
\hline $9 / 69$ & 486.015 & 1327.123 & 3093.330 & 4176.263 & 4637.970 & 5938.353 & 8662.910 & 10264.940 & 10127.130 & 13492.130 \\
\hline $12 / 70$ & 503.190 & 1387.243 & 3148.095 & 4202.098 & 4643.225 & 5896.328 & 8723.505 & 10416.780 & 10026.540 & 13419.540 \\
\hline $9 / 72$ & 488.310 & 1347.368 & 3120.208 & 4302.298 & 4807.788 & 6188.928 & 9006.043 & 10757.383 & 10395.990 & 13851.110 \\
\hline $6 / 74$ & 441.985 & 1194.242 & 2898.130 & 3874.418 & 4197.330 & 5365.218 & 7934.030 & 9787.693 & 9423.110 & 13694.270 \\
\hline $11 / 75$ & 509.012 & 1361.352 & 3197.980 & 4337.532 & 4874.010 & 6246.212 & 9003.290 & 10564.867 & 10717.750 & 15029.550 \\
\hline $1 / 77$ & 498.798 & 1333.823 & 3044.683 & 4012.843 & 4292.203 & 5370.488 & 7791.873 & 9196.882 & 8557.492 & 11750.903 \\
\hline $4 / 78$ & 487.290 & 1322.732 & 3090.928 & 4127.648 & 4585.618 & 5815.363 & 8360.133 & 9562.302 & 9014.248 & 11810.493 \\
\hline $11 / 80$ & 518.512 & 1381.355 & 3205.027 & 4311.050 & 4810.923 & 5885.795 & 8535.668 & 9385.540 & 9035.413 & 12330.785 \\
\hline $8 / 82$ & 509.590 & 1353.365 & 3176.718 & 4185.795 & 4634.123 & 5873.650 & 8586.728 & 9899.805 & 9608.808 & 13451.135 \\
\hline $9 / 83$ & 498.020 & 1373.128 & 3057.235 & 4127.068 & 4719.675 & 6011.483 & 8954.090 & 11046.698 & 11089.305 & 14631.913 \\
\hline $1 / 85$ & 488.340 & 1319.033 & 3133.200 & 4134.693 & 4883.835 & 6264.903 & 9145.970 & 10427.038 & 10508.105 & 14019.673 \\
\hline $3 / 85$ & 523.880 & 1418.883 & 3164.990 & 4217.098 & 4887.130 & 6133.763 & 8723.120 & 10486.753 & 10250.585 & 13853.518 \\
\hline $2 / 91$ & 514.700 & 1352.630 & 3168.623 & 4187.365 & 4862.783 & 6208.600 & 8941.918 & 10604.585 & 10574.028 & 14193.370 \\
\hline Mean $(\mathrm{nS})$ & 496.766 & 1342.93 & 3117.61 & 4171.63 & 4678.76 & 5944.82 & 8642.24 & 10208.48 & 9976.867 & 13528.77 \\
\hline $\mathrm{SD}(\mathrm{nS})$ & 18.750 & 47.883 & 74.158 & 112.207 & 199.359 & 266.430 & 369.292 & 509.454 & 686.186 & 894.493 \\
\hline Slope(nS/day) & $3.0 \mathrm{E}-03$ & $4.4 \mathrm{E}-03$ & $5.7 \mathrm{E}-03$ & $2.7 \mathrm{E}-05$ & $2.6 \mathrm{E}-02$ & 2.5E-02 & $3.2 \mathrm{E}-02$ & $1.1 \mathrm{E}-02$ & $3.3 \mathrm{E}-02$ & $3.6 \mathrm{E}-02$ \\
\hline Slope $(\mathrm{nS} /$ year) & 1.077 & 1.602 & 2.082 & 0.010 & 9.398 & 9.024 & 11.757 & 4.157 & 11.984 & 13.074 \\
\hline SDfit & 17.639 & 48.080 & 75.149 & 116.146 & 193.896 & 267.313 & 371.903 & 526.409 & 704.537 & 920.661 \\
\hline $\mathrm{SD}(2 / 01)(\mathrm{nS})$ & 23.6814 & 64.5503 & 100.892 & 155.934 & 260.319 & 358.886 & 499.305 & 706.7409 & 945.8904 & 1236.052 \\
\hline
\end{tabular}


Table C-4. Data and Analysis of Conductance Corrections of ( $0.01 \mathrm{uF} / \mathrm{step}$ ) Mica Capacitance Dial of the Type-12 Bridge at $100 \mathrm{~Hz}$

(All values are in $0.001 \mu \mathrm{S}$, except the dial which is $0.01 \mu \mathrm{F} / \mathrm{step}$ )

\begin{tabular}{|c|c|c|c|c|c|c|c|c|c|c|}
\hline DIAL & 0.01 & 0.02 & 0.03 & 0.04 & 0.05 & 0.06 & 0.07 & 0.08 & 0.09 & $0.0 \mathrm{X}$ \\
\hline $6 / 67$ & 1.507 & 2.643 & 5.015 & 6.565 & 8.083 & 9.217 & 11.580 & 13.102 & 14.257 & 15.782 \\
$11 / 67$ & 1.520 & 2.680 & 5.098 & 6.655 & 8.165 & 9.320 & 11.723 & 13.273 & 14.450 & 16.035 \\
$5 / 68$ & 1.543 & 2.710 & 5.138 & 6.698 & 8.285 & 9.465 & 11.898 & 13.465 & 14.628 & 16.193 \\
$9 / 69$ & 1.603 & 2.765 & 5.165 & 6.760 & 8.315 & 9.463 & 11.888 & 13.448 & 14.590 & 16.160 \\
$12 / 70$ & 1.575 & 2.743 & 5.193 & 6.720 & 8.280 & 9.465 & 11.885 & 13.460 & 14.658 & 16.205 \\
$9 / 72$ & 1.478 & 2.660 & 5.143 & 6.700 & 8.255 & 9.450 & 11.973 & 13.573 & 14.785 & 16.365 \\
$6 / 74$ & 1.588 & 2.725 & 5.248 & 6.830 & 8.360 & 9.560 & 11.993 & 13.585 & 14.798 & 16.320 \\
$11 / 75$ & 1.518 & 2.683 & 5.218 & 6.750 & 8.245 & 9.503 & 11.850 & 13.440 & 14.570 & 16.088 \\
$1 / 77$ & 1.430 & 2.555 & 5.048 & 6.598 & 8.228 & 9.430 & 11.855 & 13.440 & 14.590 & 16.115 \\
$4 / 78$ & 1.490 & 2.628 & 4.980 & 6.478 & 7.950 & 9.103 & 11.465 & 13.023 & 14.185 & 15.728 \\
$11 / 80$ & 1.465 & 2.635 & 4.993 & 6.490 & 8.065 & 9.130 & 11.440 & 12.985 & 14.130 & 15.593 \\
$8 / 82$ & 1.478 & 2.563 & 4.895 & 6.410 & 7.923 & 9.118 & 11.438 & 13.038 & 14.180 & 15.648 \\
$9 / 83$ & 1.583 & 2.855 & 5.125 & 6.513 & 8.060 & 9.178 & 11.705 & 13.228 & 14.263 & 15.790 \\
$1 / 85$ & 1.613 & 2.730 & 5.145 & 6.523 & 8.070 & 9.195 & 11.603 & 13.125 & 14.293 & 15.825 \\
$3 / 85$ & 1.520 & 2.728 & 5.128 & 6.563 & 8.080 & 9.220 & 11.613 & 13.158 & 14.313 & 15.838 \\
$2 / 91$ & 1.857 & 2.987 & 5.337 & 6.717 & 8.070 & 8.880 & 11.190 & 12.730 & 13.397 & 14.665 \\
& & & & & & & & & & \\
\hline & & & & & & & & & & \\
Mean (nS) & 1.5480 & 2.7056 & 5.1168 & 6.6231 & 8.1521 & 9.2936 & 11.6937 & 13.2546 & 14.3804 & 15.8969 \\
SD (nS) & 0.0981 & 0.1062 & 0.1110 & 0.1217 & 0.1321 & 0.1907 & 0.2307 & 0.2452 & 0.3420 & 0.4072 \\
Slope(nS/day) & $1.5 \mathrm{E}-05$ & $1.6 \mathrm{E}-05$ & $4.0 \mathrm{E}-06$ & $-1.9 \mathrm{E}-05$ & $-3.0 \mathrm{E}-05$ & $-5.1 \mathrm{E}-05$ & $-5.8 \mathrm{E}-05$ & $-6.1 \mathrm{E}-05$ & $-9.0 \mathrm{E}-05$ & $-1.1 \mathrm{E}-04$ \\
Slope(nS/year) & 0.0056 & 0.0057 & 0.0015 & -0.0071 & -0.0108 & -0.0186 & -0.0213 & -0.0222 & -0.0330 & -0.0402 \\
SDfit & 0.0923 & 0.1013 & 0.1144 & 0.1143 & 0.1099 & 0.1391 & 0.1775 & 0.1910 & 0.2525 & 0.2938 \\
SD(2/01) (nS) & 0.12393 & 0.13601 & 0.15356 & 0.15347 & 0.14756 & 0.18677 & 0.23836 & 0.25649 & 0.33897 & 0.39448 \\
\hline
\end{tabular}


Table C-5. Data and Analysis of Conductance Corrections of ( $0.01 \mathrm{uF} / \mathrm{step}$ ) Mica Capacitance Dial of the Type-12 Bridge at $1 \mathrm{kHz}$

(All values are in $0.001 \mu \mathrm{S}$, except the dial which is $0.01 \mu \mathrm{F} / \mathrm{step}$ )

\begin{tabular}{|c|c|c|c|c|c|c|c|c|c|c|}
\hline DIAL & 0.01 & 0.02 & 0.03 & 0.04 & 0.05 & 0.06 & 0.07 & 0.08 & 0.09 & $0.0 \mathrm{X}$ \\
\hline $6 / 67$ & 5.743 & 9.678 & 16.308 & 22.865 & 28.638 & 32.697 & 39.490 & 45.435 & 49.357 & 55.620 \\
$11 / 67$ & 5.747 & 9.888 & 16.678 & 23.072 & 28.872 & 33.133 & 40.125 & 45.860 & 49.870 & 55.987 \\
$5 / 68$ & 5.778 & 9.775 & 16.505 & 23.045 & 28.835 & 32.940 & 39.813 & 45.813 & 49.832 & 56.142 \\
$9 / 69$ & 5.798 & 9.818 & 16.533 & 23.013 & 28.865 & 33.032 & 39.927 & 45.962 & 50.045 & 56.322 \\
$12 / 70$ & 5.785 & 9.995 & 16.883 & 23.275 & 29.055 & 33.432 & 40.415 & 46.432 & 50.720 & 56.987 \\
$9 / 72$ & 5.840 & 10.003 & 16.707 & 23.185 & 28.975 & 33.157 & 40.120 & 46.087 & 50.302 & 56.652 \\
$6 / 74$ & 5.808 & 9.813 & 16.593 & 23.195 & 29.058 & 33.179 & 40.043 & 46.030 & 50.045 & 56.470 \\
$11 / 75$ & 5.658 & 9.728 & 16.508 & 22.978 & 28.873 & 33.115 & 40.135 & 46.252 & 50.412 & 56.935 \\
$1 / 77$ & 5.700 & 9.758 & 16.370 & 22.943 & 28.693 & 33.050 & 39.928 & 46.060 & 50.310 & 56.882 \\
$4 / 78$ & 5.638 & 9.615 & 16.178 & 22.620 & 28.350 & 32.490 & 39.077 & 44.880 & 48.905 & 55.043 \\
$11 / 80$ & 5.765 & 10.050 & 16.935 & 23.273 & 29.130 & 33.418 & 40.260 & 46.403 & 50.460 & 56.905 \\
$8 / 82$ & 5.760 & 9.863 & 16.560 & 22.878 & 28.853 & 33.140 & 40.085 & 46.375 & 50.520 & 57.110 \\
$9 / 83$ & 5.758 & 10.023 & 16.825 & 23.138 & 28.860 & 33.345 & 40.420 & 46.643 & 51.475 & 57.865 \\
$1 / 85$ & 5.578 & 9.870 & 16.720 & 22.760 & 28.635 & 33.143 & 40.200 & 46.363 & 50.548 & 56.990 \\
$3 / 85$ & 5.743 & 9.990 & 16.765 & 22.905 & 28.693 & 33.098 & 40.068 & 46.043 & 50.440 & 56.763 \\
$2 / 91$ & 5.780 & 9.920 & 16.473 & 22.868 & 28.738 & 33.160 & 39.875 & 45.707 & 49.972 & 56.815 \\
& & & & & & & & & & \\
\hline & & & & & & & & & & \\
Mean (nS) & 5.7424 & 9.8617 & 16.5963 & 23.0008 & 28.8202 & 33.0956 & 39.9988 & 46.0216 & 50.2008 & 56.5930 \\
SD (nS) & 0.0680 & 0.1303 & 0.2094 & 0.1851 & 0.1949 & 0.2389 & 0.3358 & 0.4336 & 0.5799 & 0.6626 \\
Slope(nS/day) & $-7.4 \mathrm{E}-06$ & $1.7 \mathrm{E}-05$ & $1.3 \mathrm{E}-05$ & $-2.3 \mathrm{E}-05$ & $-1.6 \mathrm{E}-05$ & $2.2 \mathrm{E}-05$ & $2.1 \mathrm{E}-05$ & $3.8 \mathrm{E}-05$ & $8.0 \mathrm{E}-05$ & $1.3 \mathrm{E}-04$ \\
Slope(nS/year) & -0.0027 & 0.0062 & 0.0049 & -0.0083 & -0.0058 & 0.0082 & 0.0077 & 0.0138 & 0.0293 & 0.0460 \\
SDfit & 0.0674 & 0.1267 & 0.2136 & 0.1812 & 0.1969 & 0.2396 & 0.3427 & 0.4367 & 0.5583 & 0.5923 \\
SD(2/01) (nS) & 0.09046 & 0.17008 & 0.28677 & 0.24331 & 0.26441 & 0.32166 & 0.46009 & 0.58627 & 0.74954 & 0.79517 \\
\hline
\end{tabular}


Table C-6. Data and Analysis of Conductance Corrections of ( $0.01 \mathrm{uF} / \mathrm{step})$ Mica Capacitance Dial of the Type-12 Bridge at $10 \mathrm{kHz}$

(All values are in $0.001 \mu \mathrm{S}$, except the dial which is $0.01 \mu \mathrm{F} /$ step)

\begin{tabular}{|c|c|c|c|c|c|c|c|c|c|c|}
\hline DIAL & 0.01 & 0.02 & 0.03 & 0.04 & 0.05 & 0.06 & 0.07 & 0.08 & 0.09 & $0.0 \mathrm{X}$ \\
\hline $6 / 67$ & 36.761 & 73.168 & 128.885 & 183.211 & 227.610 & 275.876 & 352.813 & 414.849 & 453.899 & 552.168 \\
\hline $11 / 67$ & 36.918 & 74.121 & 130.590 & 183.374 & 227.313 & 276.509 & 355.158 & 417.483 & 457.254 & 556.228 \\
\hline $5 / 68$ & 37.018 & 73.790 & 129.590 & 183.465 & 227.440 & 275.523 & 353.373 & 414.815 & 455.213 & 551.212 \\
\hline $9 / 69$ & 37.225 & 68.573 & 124.640 & 179.008 & 222.140 & 272.695 & 350.403 & 412.085 & 445.650 & 544.008 \\
\hline $12 / 70$ & 37.393 & 75.473 & 132.605 & 186.113 & 230.045 & 280.003 & 357.448 & 419.518 & 460.445 & 559.753 \\
\hline 9/72 & 35.573 & 72.020 & 125.523 & 178.633 & 220.370 & 267.068 & 341.600 & 401.893 & 442.503 & 538.615 \\
\hline $6 / 74$ & 35.543 & 70.820 & 125.855 & 175.913 & 215.863 & 263.580 & 334.605 & 392.242 & 428.757 & 496.662 \\
\hline $11 / 75$ & 37.330 & 74.835 & 131.513 & 187.008 & 230.460 & 280.780 & 358.585 & 424.585 & 464.905 & 563.802 \\
\hline $1 / 77$ & 35.370 & 71.388 & 125.915 & 179.930 & 221.373 & 269.292 & 341.165 & 404.885 & 444.090 & 548.910 \\
\hline $4 / 78$ & 35.638 & 71.273 & 125.816 & 179.858 & 222.605 & 269.015 & 342.115 & 400.530 & 441.767 & 542.245 \\
\hline $11 / 80$ & 37.193 & 77.985 & 132.345 & 186.200 & 230.512 & 282.745 & 358.795 & 417.550 & 468.235 & 574.872 \\
\hline $8 / 82$ & 37.413 & 75.218 & 133.318 & 187.315 & 231.468 & 280.923 & 361.620 & 423.888 & 466.238 & 563.078 \\
\hline $9 / 83$ & 35.608 & 72.873 & 129.023 & 177.423 & 217.978 & 270.463 & 349.908 & 406.953 & 440.248 & 542.608 \\
\hline $1 / 85$ & 39.015 & 76.540 & 133.590 & 184.778 & 231.168 & 283.430 & 360.645 & 415.523 & 463.850 & 556.068 \\
\hline $3 / 85$ & 35.303 & 73.620 & 129.383 & 181.688 & 223.143 & 273.448 & 351.205 & 413.033 & 455.255 & 563.633 \\
\hline $2 / 91$ & 36.652 & 73.875 & 128.665 & 181.350 & 223.655 & 273.513 & 348.088 & 410.108 & 450.418 & 551.593 \\
\hline Mean $(n S)$ & 36.6221 & 73.4733 & 129.204 & 182.204 & 225.196 & 274.679 & 351.095 & 411.871 & 452.42 & 550.341 \\
\hline $\mathrm{SD}(\mathrm{nS})$ & 1.0318 & 2.3405 & 2.9816 & 3.5414 & 4.9637 & 5.8793 & 7.8936 & 8.7564 & 11.173 & 17.2627 \\
\hline Slope(nS/day) & $-9.2 \mathrm{E}-06$ & $2.8 \mathrm{E}-04$ & $2.8 \mathrm{E}-04$ & 2.7E-05 & $-5.8 \mathrm{E}-05$ & $2.6 \mathrm{E}-04$ & $2.5 \mathrm{E}-04$ & $-6.5 \mathrm{E}-05$ & $4.8 \mathrm{E}-04$ & 3 \\
\hline Slope(nS/year) & -0.0034 & 0.1029 & 0.1015 & 0.0100 & -0.0213 & 0.0953 & 0.0912 & -0.0237 & 0.1739 & 0.4550 \\
\hline SDfit & 1.0678 & 2.2960 & 2.9904 & 3.6649 & 5.1355 & 6.0434 & 8.1419 & 9.0620 & 11.4910 & 17.5384 \\
\hline $\mathrm{SD}(2 / 01)(\mathrm{nS})$ & 1.43354 & 3.08257 & 4.01479 & 4.92038 & 6.89472 & 8.11363 & 10.931 & 12.1664 & 15.4275 & 23.546 \\
\hline
\end{tabular}





\section{THE SP 250 SERIES ON NIST MEASUREMENT SERVICES*}

SP 250-1 Spectral Radiance Calibrations PB87179883

SP 250-2 Far Ultraviolet Detector Standards PB87227609

SP 250-3 Radiometric Standards in the Vacuum Ultraviolet PB87227625

SP 250-4 Fricke Dosimetry in High-Energy Electron Beams PB88110374

SP 250-5 Alpha-Particle Calibrations PB88168620

SP 250-6 Regular Spectral Transmittance PB88108550

SP 250-7 Radiance Temperature Calibrations PB88123674

SP 250-8 Spectral Reflectance PB88109905

SP 250-9 Calibration of Beta-Particle-Emitting Ophthalmic Applicators PB88108535

SP 250-10 Radioactivity Calibrations with the " $4 \pi$ " Gamma Ionization Chamber and Other Radioactivity Calibration Capabilities PB88123708

SP 250-11 Dosimetry for High Dose Applications PB88201587

SP 250-12 Neutron Personnel Dosimetry PB87227617

SP 250-13 Activation Foil Irradiation with Californium Fission Sources PB88217443

SP 250-14 Activation Foil Irradiation by Reactor Cavity Fission Sources PB88217435

SP 250-15 Photometric Calibrations PB88153747

SP 250-16 Calibration of X-Ray and Gamma-Ray Measuring Instruments PB88211826

SP 250-17 The NBS Photodetector Spectral Response Calibration Transfer Program PB88201595

SP 250-18 Neutron Source Strength Calibrations PB88211818

SP 250-19 Calibration of Gamma-Ray-Emitting Brachytherapy Sources PB89193858

SP 250-20 Spectral Irradiance Calibrations PB88123781

SP 250-21 Calibration of Beta-Particle Radiation Instrumentation PB88201579

SP 250-22 Platinum Resistance Thermometer Calibrations PB88138367

SP 250-23 Liquid-in-Glass Thermometer Calibration Service PB89128888
SP 250-24 Standard Cell Calibrations PB88123690

SP 250-25 Calibration Service for Inductive Voltage Dividers

SP 250-26 NBS Phase Angle Calibration Services PB88225636

SP 250-27 AC-DC Difference Calibrations PB892222616

SP 250-28 Solid-State DC Voltage Standard Calibrations PB88168703

SP 250-29 Traceable Frequency Calibrations PB88168364

SP 250-30 GOES Satellite Time Code Dissemination: Description and Operation PB88168760

SP 250-31 Mass Calibrations PB89153894

SP 250-32 A Calibration Service for $30 \mathrm{MHz}$ Attenuation and Phase Shift PB88238324

SP 250-33 A Calibration Service for Voltage Transformers and High-Voltage Capacitors PB882252903

SP 250-34 High Vacuum Standard and Its Use PB89193841

SP 250-35 The Calibration of Thermocouples and Thermocouple Materials PB89209340

SP 250-36 A Calibration Service for Current Transfcrmers PB91216770

SP 250-37 Photometric Calibrations PB97148472

SP 250-38 NIST Leak Calibration Service PB92149772

SP 250-39 NIST Pressure Calibration Service PB94164043

SP 250-40 Absorbed-Dose Calibration of Ionization Chambers in a ${ }^{60} \mathrm{Co}$ Gamma-Ray Beam SN003-003-03034-1 \$2.00

SP 250-41 Spectroradiometric Detector Measurements: Part I - Ultraviolet Detectors and Part II - Visible to Near-Infrared Detectors SN003-003-03550-5 \$9.50

SP 250-42 Sprectroradiometric Detector Measurements: Part III-Infrared Detectors SN003-003-03582-3 \$5.25

SP 250-43 Radiance Temperature Calibrations SN003-003-03511-4 \$10.00

SP 250-44 Radiation Processing Dosimetry Calibration Services and Measurement Assurance Program SN003-003-03513-1

"Entries containing a stock number (SN003-003-) and price can be purchased from the Superintendent of Documents, U.S. Government
Printing Office, Washington, DC 20402-9325. GPO will accept checks, money orders, VISA, and MasterCard. For more infomation, or to place
an order, call (202) 512-1800. Be sure to cite the stock number on all orders.
Entries containing PB numbers can be purchased from the National Technical Information Service, Springfield, VA 22161. NTIS will accept
American Express in addition to the payment methods listed for GPO. For more information call (703)487-4650; to place an order call American Express in addition to the payment methods listed for GPO. For more
(800) 553-6487. Fax: (703) 321-8547. Be sure to cite the PB number on all orders.

Entries without stock or PB numbers are in preparation. 
SP 250-45 Radiation Processing Dosimetry Calibration Services: Manual of Calibration Procedures SN003-003-03514-9 \$4.00

SP 250-46 NIST Multifunction Calibration System SN003-003-03515-7 \$2.75

SP 250-47 NIST Calibration Service for Capacitance Standards at Low Frequencies SN003-003-03549-1 $\$ 7.00$

SP 250-48 Spectral Reflectance SN003-003-03545-9 \$14.00

SP 250-49 NIST Calibration Services for Gas Flow Meters: Piston Prover and Bell Prover Gas Flow Facilities SN003-003-03560-2 $\$ 6.00$

SP 250-51 Calibration Service of Optoelectronic Frequency Response at $1319 \mathrm{~nm}$ for Combined Photodiode/rf Power Sensor Transfer Standards SN003-003-03623-4

SP 250-52 Error Analysis and Calibration Uncertainty of Capacitance Standards at NIST

SP 250-53 Calibration Service for Spectral Responsivity of Laser and Optical-Fiber Power Meters at Wavelengths Between $0.4 \mu \mathrm{m}$ and $1.8 \mu \mathrm{m}$ SN003-003-03624-2

* Entries containing a stock number (SN003-003-) and price can be purchased from the Superintendent of Documents, U.S. Government Printing Office, Washington, DC 20402-9325. GPO will accept checks, money orders, VISA, and MasterCard. For more infomation, or to place an order, call (202) 512-1800. Be sure to cite the stock number on all orders.

Entries containing PB numbers can be purchased from the National Technical Information Service, Springfield, VA 22161. NTIS will accept American Express in addition to the payment methods listed for GPO. For more information call (703) 487-4650; to place an order call (800) 553-6487. Fax: (703) 321-8547. Be sure to cite the PB number on all orders.

Entries without stock or PB numbers are in preparation. 


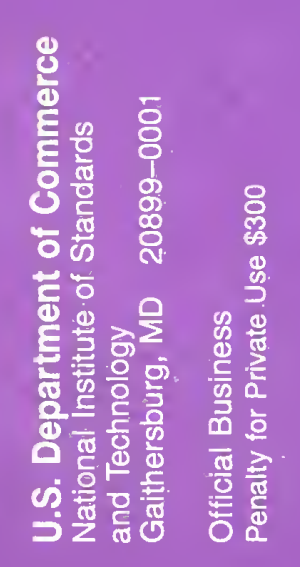

